\title{
WestVirginiaUniversity
}

THE RESEARCH REPOSITORY @ WVU

Graduate Theses, Dissertations, and Problem Reports

2015

\section{The Keyboard Works of Alex Shapiro}

\author{
Elizabeth Mary Etnoyer
}

Follow this and additional works at: https://researchrepository.wvu.edu/etd

\section{Recommended Citation}

Etnoyer, Elizabeth Mary, "The Keyboard Works of Alex Shapiro" (2015). Graduate Theses, Dissertations, and Problem Reports. 5556.

https://researchrepository.wvu.edu/etd/5556

This Dissertation is protected by copyright and/or related rights. It has been brought to you by the The Research Repository @ WVU with permission from the rights-holder(s). You are free to use this Dissertation in any way that is permitted by the copyright and related rights legislation that applies to your use. For other uses you must obtain permission from the rights-holder(s) directly, unless additional rights are indicated by a Creative Commons license in the record and/ or on the work itself. This Dissertation has been accepted for inclusion in WVU Graduate Theses, Dissertations, and Problem Reports collection by an authorized administrator of The Research Repository @ WVU.

For more information, please contact researchrepository@mail.wvu.edu. 


\title{
The Keyboard Works of Alex Shapiro
}

\section{Elizabeth Mary Etnoyer}

\author{
A research project submitted to the \\ College of Creative Arts at West Virginia University \\ in partial fulfillment of the requirements \\ for the degree of \\ Doctor of Musical Arts in \\ Piano Performance
}

Peter Amstutz, D.M.A., Committee Chair and Research Advisor James Miltenberger, D.M.A., Professor of Piano William Skidmore, M.M., Professor of Cello Mary T. Ferer, Ph.D., Professor Emerita Kristina Olson, M.A., Associate Professor, School of Art and Design

School of Music

Morgantown, West Virginia

2015

Keywords: Alex Shapiro, Arcana, Chord History, For My Father, Luvina, Notes from the Kelp, Slowly, Searching, Spark, The Resonance of Childhood, Vendaval de Luvina

Copyright (C) 2015 Elizabeth Mary Etnoyer 


\section{Abstract \\ The Keyboard Works of Alex Shapiro}

\section{Elizabeth Mary Etnoyer}

This project serves as a broad introduction to the keyboard works of American composer Alex Shapiro (1962-present), with primary focus on her works for solo piano. Ms. Shapiro has developed a well-established reputation as a serious and innovative composer, writing both acoustic and electroacoustic music for a variety of musical genres including instrumental solo and chamber music, as well as music for large ensembles. Shapiro's writing is often influenced by extramusical ideas, such as her solo piano piece Luvina (2007), a work based on the short story with that name by Mexican author Juan Rulfo. With scores that often include the composer's own program notes to guide the performer and listener, Shapiro's music carries listeners on a journey that is often unexpected, highly symbolic, and inspired by a synthesis of nature, musical influences, and life itself.

This project is organized in such a way that one can easily reference Shapiro's keyboard works as sets or individual pieces and quickly generate an idea of each piece's musical elements, unique qualities, and aspects of technical and musical difficulty. Following an introductory biographical sketch and compositional background of Shapiro's works, each chapter discussing the pieces is introduced with the composer's own program notes and sources for scores and recordings. In addition, a chapter is devoted to Shapiro's most recent piano compositions: Chord History (2014) and her new eight-movement piano suite entitled Arcana (2014), a musical exploration of the fragile relationship between humans, plants and the planet on which they coexist. The project concludes with references to Shapiro's numerous chamber works that include piano or harpsichord, as well one solo piece for organ entitled Transplant (1999).

The purpose of this project is to introduce these beautiful pieces to a diverse audience and to encourage their being performed more frequently. These works serve as excellent examples of creative writing and modern compositional technique. In addition, they give the listener a taste of the many styles and techniques Shapiro employs in her large and diverse body of compositions. 


\section{Dedication}

This project is dedicated to my family: Mom and Dad and my two older brothers Nick and Dan Etnoyer. Without your unconditional love, support, and encouragement, this project would never have seen completion. Thank you for teaching me the important life lessons of perseverance, commitment and belief in myself. 


\section{Acknowledgements}

First and foremost, I want to thank my piano instructor, committee chair, and project advisor, Dr. Peter Amstutz. Words truly cannot express my gratitude for your devoting countless hours to my development as a musician, artist, and human being. Thank you for showing me the doors of opportunity but never pushing me through them. Thank you for inspiring me, teaching me patience, giving me reassurance, and helping me build a firm musical foundation. You have prepared me for a lifetime of music making and learning. My hope is that my students will gain the same love for learning and making new discoveries that you have instilled in me.

Secondly, I wish to thank Alex Shapiro for your encouragement and support throughout this project. My initial motivation for this project came from hearing your beautiful music and knowing that it needed to be more widely shared. However, the process of getting to know about you and your life experiences are what confirmed the importance of this project to me. I hope that the results of this endeavor include a wider and deeper appreciation for your music as well as more performances and recordings. Thank you for playing a vital role in my development as a musician. I hope that I may continue learning from you and I am eager to see what you come up with next!

Thirdly, I would like to thank my entire doctoral committee: Dr. Peter Amstutz, Dr. James Miltenberger, Dr. Mary Ferer, Prof. William Skidmore, and Prof. Kristina Olson, as well as my former committee member and mentor, Dr. Kathleen Shannon. Thank you for equipping me with the skills and knowledge necessary to succeed in life beyond this degree program. Your support, occasional loving pushes towards completion, and your standards for excellence have helped me become the musician I am now. In addition, you have motivated me to challenge myself in new ways, extending this journey of learning and self-discovery beyond my formal education.

Fourthly, my deepest gratitude goes to my family, friends, and mentors near and far. I am especially grateful to my parents and two older brothers, to whom this project is dedicated, as well as to my close friends, Sarah, Malorie, Jaime, and several others not mentioned here. You have each encouraged me with your prayers, presence, cards and kind words.

Fifthly, I am especially thankful to my first three piano instructors: my own mother, Sharon Etnoyer; Dr. Virginia Raad; and Prof. Marija Sommers. Each of you played a vital role in my success. In addition, I am grateful to the music faculty at Alderson Broaddus College who stood by my side and encouraged me well beyond my years as a student there.

A special thanks to Adam Gillespie and Kathy Fletcher for the hours you both devoted to helping me with my musical excerpts and the submission process. I could not have made it to the finish line without your help! 


\section{Table of Contents}

List of Musical Excerpts ............................................................................................... vi

Preface, Part I - Statement of Topic ..............................................................................

Preface, Part II - Existing Literature and Research Methodology .......................................6

Chapter 1 - A Biographical Sketch and Compositional Overview of American

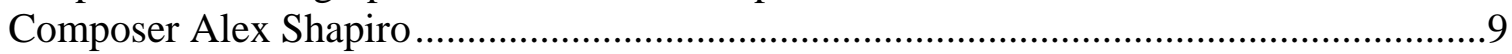

The Complete Solo Piano Works of Alex Shapiro

Chapter 2 - Single-Movement Works for Piano...............................................................21

Chapter 3 - Luvina and Vendaval de Luvina ....................................................................43

Chapter 4 - Piano Suite No. 1: The Resonance of Childhood .............................................60

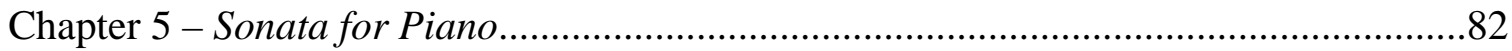

Chapter 6 - Recent Compositions: Chord History and Arcana........................................100

Chapter 7 - Chamber Works with Piano or Harpsichord; and Solo Repertoire for other

Keyboard Instruments ................................................................................................151

Chapter 8 - Conclusion of Research...............................................................................180

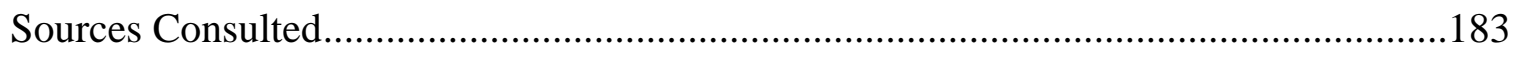

Discography of Solo Piano Works..............................................................................188

Discography of Chamber Works with Piano or Harpsichord ..........................................189

Discography of Related Works without Keyboard...........................................................190 


\section{List of Musical Excerpts}

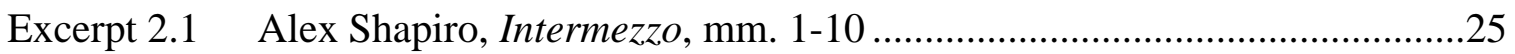

Excerpt 2.2 Alex Shapiro, Intermezzo, mm. 24-28 ………………………............26

Excerpt 2.3 Alex Shapiro, Intermezzo, mm. 46-50 ....................................................26

Excerpt 2.4 Robert Schumann, Kreisleriana Op. 16, no. 4 "Sehr langsam," mm. 1-3 ……......................................................................................

Excerpt 2.5 Alex Shapiro, Slowly, Searching, mm. 1-10..............................................30

Excerpt 2.6 Robert Schumann, Kreisleriana Op. 16, no. 4 "Sehr langsam,” mm. 11-13 .......................................................................................

Excerpt 2.7 Alex Shapiro, Slowly, Searching, mm. 103-105 ........................................31

Excerpt 2.8 Alex Shapiro, Slowly, Searching, mm. 29-40_...........................................33

Excerpt 2.9 Alex Shapiro, Slowly, Searching, mm. 52-56...........................................34

Excerpt 2.10 Alex Shapiro, Slowly, Searching, mm. 89-97 ............................................35

Excerpt 2.11 Alex Shapiro, Spark, mm. 20-25 ................................................................39

Excerpt 2.12 Alex Shapiro, Spark, mm. 76-85 ……………......................................40

Excerpt 3.1 Alex Shapiro, Luvina, mm. 1-13..............................................................47

Excerpt 3.2 Alex Shapiro, Luvina, mm. 14-16..........................................................48

Excerpt 3.3 Alex Shapiro, Luvina, mm. 30-34...........................................................48

Excerpt 3.4 Alex Shapiro, Luvina, mm. 35-38.............................................................49

Excerpt 3.5 Alex Shapiro, Luvina, mm. 24, 29, and 45-46 ..........................................49

Excerpt $3.6 \quad$ Alex Shapiro, Luvina, mm. 52-57............................................................50

Excerpt 3.7 Alex Shapiro, Luvina, mm. 60-63............................................................51

Excerpt 3.8 Alex Shapiro, Luvina, mm. 64-68...........................................................52 
Excerpt 3.9 Alex Shapiro, Luvina, mm. 90-91...........................................................53

Excerpt 3.10 Alex Shapiro, Luvina, mm. 100-102_................................................54

Excerpt 3.11 Alex Shapiro, Vendaval de Luvina, mm. 39-49..........................................57

Excerpt 3.12 Alex Shapiro, Vendaval de Luvina, mm. 74-78 _.......................................58

Excerpt 4.1 Alex Shapiro, Piano Suite No. 1: The Resonance of Childhood, I. "Variations on a Memory," mm. 1-5

Excerpt 4.2 Alex Shapiro, Piano Suite No. 1: The Resonance of Childhood, I. ““'Variations on a Memory,” mm. 10-11, 22-23, 29-31, 54-56

Excerpt 4.3 Alex Shapiro, Piano Suite No. 1: The Resonance of Childhood, I. "Variations on a Memory," mm. 44-45.

Excerpt 4.4 Alex Shapiro, Piano Suite No. 1: The Resonance of Childhood, II. “On My Mother,” mm. 1-8.

Excerpt 4.5 Alex Shapiro, Piano Suite No. 1: The Resonance of Childhood, II. “On My Mother,” mm. 46-49.

Excerpt 4.6 Alex Shapiro, Piano Suite No. 1: The Resonance of Childhood, II. “On My Mother,” mm. 56-61

Excerpt 4.7 Alex Shapiro, Piano Suite No. 1: The Resonance of Childhood, III. “Quiet Child,” mm. 1-14.

Excerpt 4.8 Alex Shapiro, Piano Suite No. 1: The Resonance of Childhood, III. “Quiet Child,” mm. 44-47. .73

Excerpt 4.9 Alex Shapiro, Piano Suite No. 1: The Resonance of Childhood, IV. "For My Father," mm. 1-9

Excerpt 4.10 Alex Shapiro, Piano Suite No. 1: The Resonance of Childhood, IV. "For My Father," mm. 34-40 . .76

Excerpt 4.11 Alex Shapiro, Piano Suite No. 1: The Resonance of Childhood, IV. "For My Father," mm. 54-63. .77

Excerpt 4.12 Alex Shapiro, Piano Suite No. 1: The Resonance of Childhood, V. “Older,” mm. 1-8

Excerpt 4.13 Alex Shapiro, Piano Suite No. 1: The Resonance of Childhood, V. “Older," mm. 17, 22-23. .79 
Excerpt 4.14 Alex Shapiro, Piano Suite No. 1: The Resonance of Childhood, V. "Older," mm. 61-67

Excerpt 5.1 Alex Shapiro, Sonata for Piano, I. “Moderato,” mm. 1-7 ……...................86

Excerpt 5.2 Alex Shapiro, Sonata for Piano, I. “Moderato,” mm. 43-46 ……...............87

Excerpt 5.3 Alex Shapiro, Sonata for Piano, I. “Moderato,” mm. 59-62 ……...............87

Excerpt 5.4 Alex Shapiro, Sonata for Piano, I. “Moderato,” mm. 80-88 ……...............88

Excerpt 5.5 Alex Shapiro, Sonata for Piano, II. “Lento; Andante,” mm. 1-15 .............90

Excerpt 5.6 Alex Shapiro, Sonata for Piano, II. “Lento; Andante,” mm. 14-16, 27-28, 36-40.

Excerpt 5.7 Alex Shapiro, Sonata for Piano, II. “Lento; Andante,” mm. 82, 90, 98-99

Excerpt 5.8 Alex Shapiro, Sonata for Piano, II. “Lento; Andante,” mm. 113-123

Excerpt 5.9 Alex Shapiro, Sonata for Piano, II. "Lento; Andante," mm. 132-135

Excerpt 5.10 Alex Shapiro, Sonata for Piano, III. “Scherzo,” mm. 3-9 ……...................95

Excerpt 5.11 Alex Shapiro, Sonata for Piano, III. “Scherzo,” mm. 18-24 …...................96

Excerpt 5.12 Alex Shapiro, Sonata for Piano, III. “Scherzo,” mm. 35-36, 42-43..........97

Excerpt 5.13 Alex Shapiro, Sonata for Piano, III. “Scherzo,” mm. 46-49................98

Excerpt 6.1 Alex Shapiro, Chord History …………….............................................105

Excerpt 6.2 Alex Shapiro, Chord History, reference of Beethoven's chords ..............106

Excerpt 6.3 Alex Shapiro, Arcana, 1. "Cradle These Roots," mm. 1-13 .....................110

Excerpt 6.4 Alex Shapiro, Arcana, 1. "Cradle These Roots,” mm. 27-34....................111

Excerpt 6.5 Alex Shapiro, Arcana, 1. "Cradle These Roots,” mm. 36-40 ...................113

Excerpt 6.6 Alex Shapiro, Arcana. 2. "Unfurl,” mm. 1-8 ...........................................114 
Excerpt 6.7 Alex Shapiro, Arcana, 2. “Unfurl,” mm. 16-22.........................................115

Excerpt 6.8 Alex Shapiro, Arcana, 2. "Unfurl,” mm. 31-35.........................................116

Excerpt 6.9 Alex Shapiro, Arcana, 2. "Unfurl,” mm. 46-48.......................................117

Excerpt 6.10 Alex Shapiro, Arcana, 3. "Heal from Within,” mm. 1-4 …......................119

Excerpt 6.11 Alex Shapiro, Arcana, 3. "Heal from Within,” mm. 9-12 …………........119

Excerpt 6.12 Alex Shapiro, Arcana, 3. "Heal from Within,” mm. 15-16 ......................120

Excerpt 6.13 Alex Shapiro, Arcana, 3. "Heal from Within," mm. 35-38 ......................120

Excerpt 6.14 Alex Shapiro, Arcana, 3. "Heal from Within,” mm. 44-48 …..................121

Excerpt 6.15 Alex Shapiro, Arcana, 4. “Reach to Light,” mm. 1-11.............................123

Excerpt 6.16 Alex Shapiro, Arcana, 4. "Reach to Light,” mm. 62-64...........................124

Excerpt 6.17 Alex Shapiro, Arcana, 4. "Reach to Light,” mm. 40-56............................125

Excerpt 6.18 Alex Shapiro, Arcana, 4. "Reach to Light,” mm. 69-74............................125

Excerpt 6.19 Alex Shapiro, Arcana, 5. "Branches and Vines,” mm. 1-8 ……..............127

Excerpt 6.20 Alex Shapiro, Arcana, 5. "Branches and Vines,” mm. 18-24 ..................128

Excerpt 6.21 Alex Shapiro, Arcana, 5. "Branches and Vines,” mm. 26-28 …..............129

Excerpt 6.22 Alex Shapiro, Arcana, 5. "Branches and Vines,” mm. 34-40 ..................130

Excerpt 6.23 Alex Shapiro, Arana, 5. “Branches and Vines,” mm. 44-46 .....................131

Excerpt 6.24 Alex Shapiro, Arcana, 6. “Touch It,” mm. 1-4 ..........................................133

Excerpt 6.25 Alex Shapiro, Arcana, 6. “Touch It,” mm. 5-8........................................133

Excerpt 6.26 Alex Shapiro, Arcana, 6. “Touch It,” mm. 23-28....................................135

Excerpt 6.27 Alex Shapiro, Arcana, 6. “Touch It,” mm. 36-37 .....................................136

Excerpt 6.28 Alex Shapiro, Arcana, 7. "Search,” mm. 1-7............................................138

Excerpt 6.29 Alex Shapiro, Arcana, 7. "Search,” mm. 8-12...........................................139 
Excerpt 6.30 Alex Shapiro, Arcana, 7. “Search,” mm. 14-15.....................................140

Excerpt 6.31 Alex Shapiro, Arcana, 7. “Search,” mm. 26-27....................................141

Excerpt 6.32 Alex Shapiro, Arcana, 7. “Search,” mm. 52-54.....................................142

Excerpt 6.33 Alex Shapiro, Arcana, 7. “Search,” mm. 57-62.....................................143

Excerpt 6.34 Alex Shapiro, Arcana, 8. “From Earth To Sky,” mm. 12-17 .................145

Excerpt 6.35 Alex Shapiro, Arcana, 8. “From Earth To Sky,” mm. 38-41 .................146

Excerpt 6.36 Alex Shapiro, Arcana, 8. "From Earth To Sky,” mm. 42-45 ..................147

Excerpt 6.37 Alex Shapiro, Arcana, 8. “From Earth To Sky,” mm. 46-50 .................148 


\section{Preface, Part I}

\section{Statement of Topic}

This project discusses the keyboard music of American composer Alex Shapiro (1962-present), with primary focus on her works for solo piano. In order to present a well-rounded understanding of this successful and influential modern-day composer, the project begins with a biographical sketch of Ms. Shapiro and a compositional overview of her works. Following the biographical introduction, five chapters discuss her solo keyboard works and include: musical characteristics with emphasis on unique qualities, aspects of technical and musical difficulty, program notes provided by the composer, and references for locating each music score and available recordings. The last chapter devoted to her solo keyboard works is dedicated to her two most recent piano compositions: Chord History, a one-page homage to Ludwig van Beethoven, and Arcana, an eight-movement piano suite that musically explores the delicate relationship between humans and plants. The final chapter discussing her keyboard works serves as a reference for her numerous collaborative pieces with piano or harpsichord, as well as her one composition for solo organ. These pieces are discussed in less detail but also give insight into Shapiro's interest in writing highly programmatic music, as individual and entire collections of works.

The first chapter of solo keyboard works looks at three independent pieces entitled: Intermezzo (1998), Slowly, Searching (2009), and Spark (2011). These works can each be considered character pieces in that each of them was born from an extramusical idea that inspired their formation, as described in the accompanying 
program notes. Intermezzo is a piece that was inspired by the ocean, Slowly, Searching serves as homage to composer Robert Schumann, and Spark reflects on the life of musician Dale Mara Bershad.

The second chapter on Shapiro's solo keyboard works focuses on Luvina, a piano piece based on the short story of the same name by Latin-American author Juan Rulfo. The original 2007 composition of Luvina is scored for piano only, with abbreviated text not to be spoken. However, the 2010 version entitled Vendaval de Luvina has almost identical musical material but with the addition of a dual-layered prerecorded digital audio track. Juan Rulfo is heard reading excerpts from his short story in the Spanish vernacular while electroacoustic sounds assist in creating the feeling of the fictitious desert land of Luvina.

The third chapter of solo keyboard works explores Shapiro's Piano Suite No. 1: The Resonance of Childhood from 1996. This intentionally short and simple work lasts about twelve minutes and includes five short pieces: "Variations on a Memory"; "On My Mother"; "Quiet Child”; "For My Father” and “Older.” Whereas many of Shapiro’s keyboard works are inspired by nature or the lives of others, this is perhaps her most intimate work in that it appears to reflect personal experiences and memories from her own childhood. As is typical in many of her compositions, each piece is filled with vivid musical descriptors such as "with growing intensity," "with rage," or "floating; otherworldly" to guide the performer's interpretation of the music.

The fourth chapter about Shapiro's solo keyboard works focuses on her 1999 composition Sonata for Piano, her only solo-piano sonata to date. This work has a total duration of sixteen minutes and consists of three movements marked "Moderato," 
"Lento; Andante," and "Scherzo." In addition to the 1999 recording of the entire sonata by pianist Teresa McCollough, the final movement, "Scherzo," was also performed and recorded at the 2006 William Garrison Piano Competition by pianist Beatrix Klein. ${ }^{1}$ According to Shapiro,

\begin{abstract}
"Sonata for Piano" is loosely written in the structural tradition of many classical sonatas. The first movement, Moderato, explores two themes that are first developed independently and ultimately are interwoven as two parts of a whole. A set of jazz harmonies are implied against more angular melodic lines. The second movement, Lento; Andante, takes the listener on an emotional, dreamlike journey leading to a passionate outburst, and the final movement, Scherzo, is just that- an impish romp that ends with a laugh. ${ }^{2}$
\end{abstract}

The fifth and final chapter on Shapiro's solo keyboard works examines her two most recent solo piano compositions: Chord History and Arcana, both completed in 2014. Chord History is a one-page homage to Ludwig van Beethoven, and consists of seven of German pianist Susanne Kessel's favorite Beethoven chords, ${ }^{3}$ as well as reference to each chord's corresponding sonata, movement, and specific measure where it occurs in Beethoven's original scores. The result is a short composition whose harmony consists of a series of the seven aforementioned chords and a simple right hand melody to link them together. The composition was written as part of a large project in the making, envisioned and created by Bonn pianist Susanne Kessel: a compilation of 250

\footnotetext{
1 "Sonata for Piano," Alex Shapiro; Composer, accessed February 1, 2015, http://www.alexshapiro.org/Sonatapg1s.html.

${ }^{2}$ Alex Shapiro, Sonata for Piano (Activist Music (ASCAP), 1999) Program Note.

3 "Chord History," Alex Shapiro; Composer, accessed February 1, 2015, http://www.alexshapiro.org/ChordHistorypg1.html.
} 
compositions by various composers from around the globe, to be completed and presented by the year 2020, in honor of the $250^{\text {th }}$ anniversary of Beethoven's birth. ${ }^{4}$

Shapiro's other recent work, Arcana, is a piano suite in eight parts. The titles to each movement are as follows: "Cradle These Roots," "Unfurl," "Heal From Within," "Reach To Light," "Branches and Vines," "Touch It," "Search," and "From Earth To Sky." This suite is a symbolic representation of the relationships between humans, plants, and the planet on which they coexist. It is Shapiro's second suite for piano and among her largest and most significant piano works to date. In addition to performance notes and symbolic titles, Shapiro uses unique compositional techniques. For example, the beginning of the first movement and conclusion of the final movement both consist of chords and pitches at the top and bottom registers of the piano. Below is a program note at the beginning of the suite, explaining how the music symbolizes the ideas of the work:

Pianist begins by slowly lowering head to keys and grasping both ends of piano with hands, to lovingly embrace the meaning of healing plants, as these ledger lines and ties are purposely drawn to surround and hug the meaning of the notes. The piano, perhaps glowing with a colored light placed inside, embodies the earth we love. ${ }^{5}$

The last subject chapter of this project discusses Shapiro's numerous chamber works including piano or harpsichord, as well as her one solo work for organ; these works exemplify her fascination with exploring unconventional instrumental combinations, sometimes including electroacoustics. An excellent example is her collection of solo and ensemble pieces based on the theme of desert land. This

\footnotetext{
${ }^{4}$ Ibid.

${ }^{5}$ Alex Shapiro, Arcana (Activist Music (ASCAP), 2014) Program Note.
} 
compilation includes five desert-themed trios with piano: Desert Notes, Desert Passage (one for violin, cello and piano and another for violin, tenor saxophone and piano), Desert Run, and Desert Thoughts, each combining wind or string (or both) instrumental families with piano. This theme also includes: Desert Waves, which was composed for five-string electric violin or viola and audio track, as well as a separate version for solo viola, and another for solo violin; and Desert Tide, composed for soprano saxophone with audio track. While these works are studied in less detail, they represent Shapiro's creative use of timbres, even including occasional use of electroacoustic sounds. 


\section{Preface, Part II \\ Existing Literature and Research Methodology}

To date there is virtually no existing scholarly research on the piano compositions of Alex Shapiro. However, her compositional approaches, styles, and contributions to the music world have sparked much attention. Two scholarly publications worthy of mention include: Twenty-First Century Music, which featured an interview with Shapiro by Tom Moore, ${ }^{6}$ and Chamber Music, which published an article entitled "American Composer: Alex Shapiro" by Kyle Gann. ${ }^{7}$ The latter eloquently addresses Shapiro’s connection with nature, her background outside classical music, and her unique approach to using all of these experiences in forming an individual and constantly evolving compositional style. Shapiro is also mentioned in the IAWM (International Alliance for Women in Music) Journal, where a notable article entitled "The 2011 Athena Festival: Embracing Diversity-Expanding Horizons" discusses Shapiro’s active presence at the 2011 Athena Festival. "Shapiro presented master classes for Murray State student composers and performers, and she gave an eye-opening chat about success in the music industry as a classical composer." Resonance of Childhood" (from Piano Suite No. 1), which was performed at the festival along with other works of hers.

\footnotetext{
${ }^{6}$ Tom Moore, “An Interview with Alex Shapiro," $21^{\text {st }}$ Century Music 17, no. 10 (2010): $1-7$.

${ }^{7}$ Kyle Gann, “American Composer: Alex Shapiro,” Chamber Music 25, no. 3: 22-23. ${ }^{8}$ Sabrina Peña Young, "The 2011 Athena Festival: Embracing Diversity-Expanding Horizons," IAWM Journal 17, no. 1 (2011), 41.
} 
There are several dissertations that make brief mention of Shapiro but say virtually nothing about her solo-piano works. The most relevant example is a dissertation by Alicia Joyelle Kosack entitled, “American women composers: Selected published works for flute and piano and for unaccompanied flute composed between 1930 and 2008." Shapiro is only one of several women composers in this study. According to an email to the author, Shapiro also mentions the existence of another dissertation:

... in 2003 or 2004, my bassoon and piano sonata "Of Breath and Touch" was among the pieces written about in a DMA dissertation called, "A Study of Six Works for Bassoon and Piano by Living Women Composers" by Kimberly Dawn Buchar Kelley at University of Illinois, Urbana-Champaign[.] ${ }^{10}$

By far the best resource for learning about Shapiro and her works is her own website, www.alexshapiro.org. This website provides a treasure of resources for the current study, including: audio clips; date and duration of compositions; publication information; names and dates of commissioned works; pages, sizes and previews of music scores; premier dates and performers; biographical and press kit information; and links for purchasing all her scores. While program notes for each of her piano compositions are supplied on the website, the identical material is also contained within the bound scores. My enjoyment of her music and the fact that research regarding this successful modern-day American composer is practically nonexistent has led me to believe that Alex Shapiro's piano music deserves further study and attention.

\footnotetext{
${ }^{9}$ Alicia Joyelle Kosack. "American women composers: Selected published works for flute and piano and for unaccompanied flute composed between 1930 and 2008." DMA diss., University of Maryland, College Park, 2010. ProQuest, UMI Dissertations Publishing, 2010. 3534282.

${ }^{10}$ Alex Shapiro, email message to author, June 15, 2015.
} 
Styles of formatting and citation within this document follow the Chicago Manual of Style, $16^{\text {th }}$ edition. The Chicago "Notes and Bibliography" system was used in citing references and compiling the bibliography. The research methods that I employed for this study primarily included individual score study (both analysis and hands-on practice), use of the composer's website and blog page, and personal contact with the composer, who was very generous throughout the project in responding to emails. Through studying her musical background, influences and total compositional output, I was able to draw comparisons and contrasts within and among her solo and ensemble keyboard works. The goal of this project was to appreciate and understand Shapiro's music more deeply, without resorting to labels that may or may not accurately depict her music. 


\section{Chapter One}

\section{A Biographical Sketch and Compositional Overview of American Composer Alex Shapiro}

Alex Shapiro is an eclectic composer whose admiration for a variety of musical genres became evident at an early age. Born in New York City in 1962 to a musical family, and raised in Manhattan, she was exposed to many different art forms and specifically developed, early on, a love for opera, choral music, jazz and rock. The following is a personal account of her childhood immersion in the arts:

I think it was an enormous stroke of luck to be born into a family that adored the arts - not only music, but visual arts and ballet and literature. Because I was an only child, born and raised in Manhattan, one of the greatest places for the arts in the world, I was able - as though it was naturally part of everybody's normal life, which only much later did I realize was not the case - to avail myself of all possible forms of art, and often the most exquisite representations of them. And theater as well, of course. There was nothing I didn't do, there was nothing my parents were not interested in... ${ }^{11}$ Even though I am a working composer, the message that I try to get out to everybody is that all of us are artists, and the art is viable and important, whether you are making it public or not. It's self-expression. ${ }^{12}$

This account of Shapiro's adolescence proved to be significant throughout her

life. When listening to her music, an element of ease in communicating universal messages seems to pervade her works. In addition, she naturally synthesizes multiple

\footnotetext{
${ }^{11}$ Alex Shapiro, in an email message to the author, June 15, 2015 suggests for accuracy that this should have read "there was nothing related to the classical (non-pop) arts that my parents were not interested in."

12 Moore, "An Interview with Alex Shapiro," 1.
} 
musical elements to form pieces that are unique and effective. In an email to the author, Shapiro adds more insight as to how she immersed herself in so many different musical genres: “... throughout my teenage years in the 1970 s, in addition to my immersion in classical music, I also spent a lot of time in jazz clubs like the Village Vanguard, punk clubs like CBGBs, discos like Studio 54, and attending Broadway musicals, equally loving and being influenced by all the different genres."13

Whether it's the "set of jazz harmonies [that] are implied against more angular melodic lines" 14 in her Sonata for Piano, her composition entitled Paper Cut for wind band, electronics and printer paper, or her 2008 work Below for contrabass flute, and electronic soundscape that includes a recording of a Pacific humpback whale, Shapiro is constantly doing the unexpected and unthinkable, but always with the intention of connecting with her listeners.

When asked in a 2010 interview about the style of her recent pieces, Shapiro described her music as "pan-genre" music and "one of emotion." 15 She cares deeply about the emotional content of her music. In fact, Shapiro is so passionate about the emotional purpose behind her music that she frequently speaks out online and in person to young developing composers and musicians. In 2009 she co-founded the ASCAP Composer Career Workshop, through which she presents four-hour seminars throughout the United States, educating composers across the U.S. about the necessary skills for developing their careers while sharing her personal motivation for creating music. ${ }^{16}$

13 Alex Shapiro, email message to author, June 15, 2015.

${ }^{14}$ Alex Shapiro, Sonata for Piano (Activist Music (ASCAP), 1999) Program Note.

${ }^{15}$ Moore, "An Interview with Alex Shapiro," 6.

${ }^{16}$ Moore, "An Interview with Alex Shapiro," 7. 
Of course not many notable composers achieve success without the help of accomplished mentors. While Shapiro's natural affinity for composing appeared at age nine, she received her first composition lesson with Leo Edwards at age fifteen, while studying at Mannes College of Music's summer program. ${ }^{17}$ According to her website, it was here that "she also had her first experience building a synthesizer and writing remarkably dreadful electronic music." ${ }^{, 18}$ Below is an excerpt from her biography detailing the rest of her compositional training:

Alex continued to explore acoustic and synthesized pieces the following two summers with Michael Czajkowski and George Tsontakis, as the youngest composer at the Aspen Music School. Subsequently, Alex was educated at The Juilliard School and Manhattan School of Music, where she pursued electronic music with Elias Tanenbaum, and was a composition student of Ursula Mamlok and John Corigliano. ${ }^{19}$

In addition, Shapiro is an accomplished pianist, having studied with New York recitalist Marshall Kreisler; ${ }^{20}$ this gives her an obvious advantage when composing successfully idiomatic keyboard compositions. She is also "an active guitarist" plays, in her own words, "very bad flute, an instrument found in the woodwind section wedged between the alto flute and the bass flute." ${ }^{22}$ Shapiro's sense of humor and her creativity are very present in her website, as well as in my personal encounters with her. However, from interviews and listening to her music, it is even clearer that the impetus

17 "Biography," Alex Shapiro; Composer, accessed February 3, 2015, http://www.alexshapiro.org/ASBio.html - BE.

${ }^{18}$ Ibid.

${ }^{19}$ Ibid.

${ }^{20}$ Ibid.

${ }^{21}$ Ibid.

${ }^{22}$ Ibid. 
behind her compositions is always to convey deep emotion. In a 2010 interview, Shapiro clearly explains her perspective on composing:

I lecture to a lot of university classes, and I can tell that they are amazed to hear me talking in emotional terms about music that they are studying in an intellectual way. Ultimately, when it comes to the listener, music is not intellectual; it's heart, and hopefully body - the whole thing. My music, stylistically, is whatever it takes to elicit emotion. ${ }^{23}$

She later goes on to say: "My mantra is 'make it matter emotionally to others' that is what is guiding me as I write these pieces." ${ }^{24}$ This seems to be true no matter what style or genre Shapiro chooses. In fact, during the time between her prestigious education and her current success in the world of concert music, Shapiro went through a significant period of composing in the world of commercial music, while living in Malibu, California. Her website contains a "Commercial Scoring" link with a complete history of her engagements in this capacity. A few noteworthy examples include: music in jazz/blues style for the 1994 film The Last Job and the score for the 1995 film Horses and Champions; numerous full length jazz tunes such as Without You, Waltzfor Parker Wilson, and Point Lobos; many TV show themes such as the main titles for Most Wanted, The Medicine Show, and Courthouse; and a variety of pop tunes which she composed and recorded herself. Mp3s can be found of Shapiro singing her own lyrics, accompanying herself on keyboard or guitar. A few examples found on her webpage include: Falling in

\footnotetext{
${ }^{23}$ Moore, "An Interview with Alex Shapiro," 6.

${ }^{24}$ Ibid.
} 
You, Found Out Hard, Time, and On Thanksgiving. ${ }^{25}$ Shapiro serves as a good example of a pan-genre composer in that stylistic idioms provide endless pathways for her to explore, rather than restricting her. She has some important words to say on this matter and is not afraid to educate others in their way of perceiving composers:

There are many composers who work fluently - and, most happily — with a wide variety of musical styles, and I'm definitely one of them. Just as we don't necessarily eat the same type of food each evening, there are some days in which we're driven to complete our five movement "Concerto Suite for Violin, De-Tuned Ocarina and Three Euphoniums," and then there are days when we're compelled to write a rock ballad or a screaming blues tune, followed by a little musical theater number that just came to mind after we finished up a jazz chart that had been rattling around in our head.... Or something like that. ${ }^{26}$

She then goes on to say:

Stylistic diversity shouldn't cause a composer to be taken less seriously in his or her primary field of pursuit. Rather, it points to broad interests that are positive influences on a musician's sensibilities. Even within individual pieces of music, as the distance between countries appears to shrink with new technology, voices and inspirations from other nations filter seamlessly into one's own work. The $21^{\text {st }}$ century has brought with it a global melting pot of sound, with endless choices for composers and players. It's about time! ${ }^{27}$

And, finally, in regard to the tempting practice of labeling musicians, she continues:

25 "Commercial Scoring," Alex Shapiro; Composer, accessed February 4, 2015, http://www.alexshapiro.org/ASJazzFilmTV.html.

26 "Commercial Scoring," Alex Shapiro; Composer, accessed February 3, 2015, http://www.alexshapiro.org/ASJazzFilmTV.html - jazz.

${ }^{27}$ Ibid. 
There's a tendency to pigeonhole composers into easy-to-digest categories: "film composer" or "concert composer" or "world music," etc. Sometimes there's not much overlap between the different musical worlds; the people pursuing pop songwriting or jazz don't usually attend the same events as the folks in what some people call "serious" or "legit" music (a term that's an unintentional insult to those who write "popular" music, and a hilarious misnomer of a lot of the concert music I know, much of which is anything but serious).... But all music shares a common history and language, regardless of genre. In fact, when asked about the nature of my concert music, I refer to myself as a "pangenre composer." 28

Still, one may wonder how a well-trained composer of concert music from New York, steeped in European music traditions, ended up in Hollywood—and, subsequently, what led her back to where her journey began. Shapiro credits one of her composition teachers, John Corigliano, with opening her eyes to the differences and advantages of film scoring over concert scoring. She remembers looking together, upon his return from a scoring session in Hollywood, at his score for Altered States and she recalls,

A light bulb went on when I realized at that moment that film was the perfect way to get audiences to hear sophisticated music that they might not be as eager to hear in a concert hall. When you put music with pictures the heart and brain perceive it differently. ${ }^{29}$

That moment of realization led Shapiro to a fifteen-year phase of constant composing for low-budget films, television shows and other needs of the commercial music industry. She mastered the process of writing quickly, in contrast to her scholastic

${ }^{28}$ Ibid.

${ }^{29}$ Moore, “An Interview with Alex Shapiro,” 4. 
training that involved months or years of composing just a few meticulously polished

works. She welcomed this change of pace and said in regard to its artistic advantages,

In fact, I venture to say that by writing in a more streamlined way, you are tuning in to your good instincts, whereas if you tweak and tweak and tweak a piece you are not necessarily doing it or yourself a favor. You could actually be "decomposing" the work, so to speak...

There is much to be said for the initial impetus of our instincts, if we get to be reasonably facile at what we do. ${ }^{30}$

Shapiro credits this period of her life for helping her gain many skills valuable in the music industry:

One good thing that I acquired by doing 15 years of commercial work was a knowledge of copyright and publishing, an area that many concert music composers don't always understand, because they haven't been in a world where they are actually making money directly from publishing, especially in the older days, when composers had publishers and didn't handle the publishing themselves. We are now firmly in the days of independent publishing. I credit my experience in commercial music with my understanding of how to exploit my copyrights, how to do things like sync licenses, how to own the masters of my recordings, how to own my copyrights for my scores, so that I can use that material endlessly in different ways, and control it. ${ }^{31}$

The business aspect of Shapiro's success is significant and she often educates others on the importance of understanding how the industry works, in addition to the artistic side of things.

${ }^{30}$ Moore, "An Interview with Alex Shapiro," 4.

${ }^{31}$ Moore, "An Interview with Alex Shapiro," 5. 
Despite the many advantages of her career in Los Angeles, apparent fate coincided with her final scoring project for a low-budget film titled Horses and Champions. This eventually led her back to the concert-music scene.

Being connected with what I wanted to write was significant, and that connection and reawakening actually had begun with the last feature film I scored, Horses and Champions, for which I had a ten-piece live ensemble - no synths at all. It was such a wonderful experience to do that score, and to work only with live musicians, because in that lower-budget world 95 percent of what I was doing was in the studio. Occasionally I would bring in players to play over tracks, but most of the time I was creating all those tracks. It all came together in the mid-to-late 90's, and by 1999 I had decided that concert chamber music was absolutely what I wanted to do for a living. ${ }^{32}$

Being the multifaceted person that she is, Shapiro's decision to return to concert music was led not only by her passion for chamber music but was also inspired by her love for nature, along with her desire to serve as an advocate in many roles, including conservationist, musician, and educator. In fact, when Moore asked if her publishing company, Activist Music, was named so for her positive and proactive attitude towards building the career she wanted and loved, she agreed. ${ }^{33}$

In a 2008 interview with Elizabeth Barker from the Vegetarian Times, Shapiro discussed why she moved from California to the serene shores of San Juan Island, off the coast of Washington State, as well as why she became a vegetarian. To Shapiro, these two decisions are one and the same.

\footnotetext{
${ }^{32}$ Ibid.

33 Ibid.
} 
In 1991, I scored a documentary for PETA, so I got an instant education about the appalling ways that animals are treated in this country. Six months later, I traveled through the Gobi Desert, where there are no gardens and no supermarkets and you're lucky to eat an unripe tomato. When I came back to America, I was so overwhelmed by all the food choices that I asked myself, "Why do you need to keep eating meat?" For me, vegetarianism is about heightened awareness of those choices, and of the living creatures around us. ${ }^{34}$

Shapiro goes on to say that her new awareness influenced her music as well:

“...About half my catalog is directly related to nature, and that includes animal life. So much of my creativity comes from the sea, in particular. If I weren't a musician, I'd be a marine biologist. ${ }^{" 35}$ Lastly, Shapiro talks about how her environment affects her work.

You hear everything when you're in such a quiet place, whether it's the rustling of leaves or the movement of an insect. You feel so much more dialed in, which is the most magical thing for a composer. ${ }^{36}$

Shapiro has proven herself a polymath not only as a prolific composer of various musical styles and timbres but also as a writer, speaker, educator, photographer, blogger, and master of technology. Her blog Notes from the Kelp is one example of how she utilizes her passion and abilities to promote herself as well as to share her experiences through words and pictures, in conjunction with her compositions. In 2007 Innova Records released Shapiro's CD, named after her blog. This CD consists of several of her chamber compositions as well as her first published solo keyboard composition, "For My

${ }^{34}$ Elizabeth Barker. 2008. "Q\&A with Alex Shapiro.” Vegetarian Times no. 360: 23. MasterFILE Premier, EBSCOhost (accessed February 5, 2015).

${ }^{35}$ Ibid.

${ }^{36}$ Ibid. 
Father" from Piano Suite No. 1, Op. 1, all of which were composed between 1996 and 2006, during her time living in Malibu. However, by the time of this CD's release, Shapiro had just moved to San Juan Island. This CD reflects the inspiration Shapiro gets from the ocean, whether on the shores of Malibu or the San Juan Islands. The following is a program note Shapiro wrote for tracks three through five on her $\mathrm{CD}$, the title of the work being Current Events, for string quintet. It beautifully displays the meaning of the ocean in her life, her music and as a symbol of world events.

Current Events ponders the ocean's tides as well as waves of a more internal, emotional nature. Living very near the water, communing with tide pools has been a constant in my life: if I weren't a musician I might well have become a marine biologist. As our above-sea level world continues on its restless and sometimes frightening path, I walk to the ocean for truth and a mirror. Staring into the water I seek out life forms that encounter their own dramas, good and bad, with each wave. I wonder how, like us, they endure.... The power of a storm surge creates a much higher tide level than predicted under normal weather conditions. In the case of this first movement, the storm to which the music refers is as related to world events as it is to oceanic ones. ${ }^{37}$

Whether through using technology to blog, update her website, connect through online rehearsals (what she calls "Skypehearsals") or to add prerecorded audio to her compositions, Shapiro makes every aspect of her professional networking and musical output personal and unique. In fact, she credits her web presence as giving her $90 \%$ of her best opportunities. ${ }^{38}$ Her thorough and easy-to-use website www.alexshapiro.org contains

${ }^{37}$ Alex Shapiro and John Steinmetz, Liner Notes, Notes from the Kelp, with Mike Aarvold, Phil Blackburn and Chris Campbell. Innova 683, 2007, compact disc. ${ }^{38}$ Moore, "An Interview with Alex Shapiro," 7. 
much more information than can be described in this short biographical sketch. Below are a few highlights of her diverse and inspiring career, taken from her website.

Shapiro has been an active member and leader in multiple music organizations, some of which include: The American Society of Composers, Authors and Publishers (ASCAP), Board of Directors 2014-Present; "Vice President" of the Society of Composers \& Lyricists, Board of Directors 1994-2000; "President” of the America Composers Forum of Los Angeles; and Chair of the Public Relations Committee for Women in Film's 1993 Crystal Awards. ${ }^{39}$ In addition, according to ASCAP's website, “...Shapiro was the sole artist invited to Washington, D.C. to testify in a 2009 Federal Communications Commission hearing on broadband access and digital rights. ${ }^{.40} \mathrm{Her}$ activism extends to conservational issues as well. "In 2008, Alex joined the Advancement Board of the University of Washington's renowned marine science research facility, the Friday Harbor Laboratories. ${ }^{41}$

Shapiro is the owner of Activist Music, an ASCAP publishing company, solely dedicated to the publication of her own compositions. She is a frequent motivational speaker and educator at universities, conservatories, conferences, and online, discussing building a career in music and commissioning works as well as her compositional approach and philosophy. While Shapiro's primary compositional focus within the world of concert music is chamber music, much of which involves wind ensembles and/or

\footnotetext{
39 “Biography," Alex Shapiro; Composer, accessed February 4, 2015, http://www.alexshapiro.org/ASBio.html - PInv. 40 "Board of Directors: Alex Shapiro," ASCAP: The American Society of Composers, Authors and Publishers, accessed February 5, 2015, http://www.ascap.com/about/boardintro/alex-shapiro.aspx.

41 "Home," Alex Shapiro; Composer, accessed February 5, 2015, http://www.alexshapiro.org/index.html.
} 
electronic tracks, there is no simple way of categorizing the impressive array of styles, timbres and ideas from which she draws. The following chapters present a discussion of Shapiro's keyboard works as a sample of her total compositional output, which will surely continue to evolve and grow. 


\section{Chapter Two \\ Single-Movement Works for Piano}

\section{Introduction}

This chapter looks at three individual piano compositions by Shapiro: Intermezzo (1998), Slowly, Searching (2009), and Spark (2011). The duration of these works ranges from four to seven minutes and each is inspired by an extramusical idea: a person, nature, or a past composer. In this sense, they can all be identified as programmatic pieces; each score includes short program notes written by the composer. Although the pieces were not composed at the same time, they do share some common characteristics that include: frequently changing meter; relatively thin textures; and persistently moving eighth- and sixteenth-note lines. Each piece has symbolic characteristics, such as the rolling arpeggiations in Intermezzo which symbolize the rolling of ocean tides. Another example is the energetic ostinato figure in Spark which represents the life of Dale Mara Bershad. Each of these three works is propelled by energetic harmonic figures, with the exception of a homophonic passage in the middle of Slowly, Searching. For each piece, Shapiro supplies written descriptions to assist the performer in understanding the story or idea that inspired each work. Some examples of these markings include "floating; lost," "very inwardly," "strongly," "joyously," and (at the beginning of Intermezzo) "Lilting, floating." 
A fascinating aspect of these pieces, like many of her other compositions, is the inclusion of irregular meter. In an email to the author, Shapiro describes how she makes the transition from a musical idea to putting it on paper.

Composers are constantly struggling to retain the musical and emotional gesture as we simultaneously try to figure out the math of seven against four, and whatever else we are hearing. It's a challenge to think about how to communicate an amorphous gesture at the same moment one is experiencing that gesture. I think of it as a battle of the right brain hemisphere versus the left one, and the need to build an easily walkable bridge between them. The longer I can stay in the right part of the brain, the better, so often I will draw an abstract picture, then write rhythms without meters, and later indicate the accents. Then I will go back and figure out where the natural downbeats are, and put this abstract gesture into a logical metric frame. It's almost like paint-bynumbers at that point, and I then begin to add the notes and the textures and the orchestration. It's a problem-solving process that keeps me as in tune with my immediate, emotional side as I can possibly be, while trying to make the sonic chaos from my head something that a complete stranger holding an instrument halfway around the world can reproduce. ${ }^{42}$

Discussion of each of the following pieces includes information on publications and recordings, arrangements of the same works for different instrumentation (where applicable), program notes from the composer, and the author's observations of significant musical characteristics. Lastly, emphasis is given to unique musical features as well as to offer opinions regarding levels of difficulty, based on musical and technical elements and the author's personal experience.

${ }^{42}$ Alex Shapiro, email message to author, June 16, 2015. 


\section{Intermezzo}

Date of Composition: 1998

Duration: 4:00 minutes

Description: One-movement work. 6 pages, 8.5 " x 11 "

Publisher: Activist Music (ASCAP)

Score Location: alexshapiro.org < Works < Piano < Intermezzo for Piano

Score Formats Available: Print or Digital

Available Recordings: mp3 audio clip only

Location of Recordings: alexshapiro.org < Works < Piano < Intermezzo for Piano

Related Arrangements: Intermezzo for Clarinet and Piano, Intermezzo for Cello and

Piano, Intermezzo for Clarinet and Harp, Intermezzo for Violin and Harp, Intermezzo for

Flute and Harp, Intermezzo for Bass Flute and Piano, Intermezzo for Bass Flute and

Harp

\section{Program Notes found on the inside cover of score:}

"Intermezzo" was composed as a response to the waves of the ocean, and as a reflection on the flow of a more introspective, emotional sea. A long and lyrical theme floats above a steadily rolling line, perhaps as a lengthy branch of kelp might dance from the force of each coming tide. ${ }^{43}$

The work begins with an ascending, harmonic arpeggiation that serves as an accompaniment. The slur over this asymmetrical seven-note figure seems to suggest that it be played with the left hand. Symbolically, it suggests the steady but uneven rolling of an ocean tide. Over this accompaniment in D-flat Lydian mode appears a long sustaining melody that with each statement seems to be carried a little further than before. The chromatic, melodic pitches of D-natural and A-natural in mm. 9-10 do not sound dissonant to the author; however, they may serve as example of Shapiro's often pantonal harmonic writing. In an email to the author, Shapiro explains how she views her use of harmonic language:

I often describe my music (and much music in general) as "pantonal". Meaning, making use of all tonalities...

${ }^{43}$ Alex Shapiro, Intermezzo (Activist Music (ASCAP), 1998) Program Note. 
Listening is subjective, and that which is quite tonally centered to me, might very well strike someone else as being somehow discordant...

There is almost always a tonal center-even if it is a fleeting one- in my work. Some pieces stay traditionally tonally grounded throughout, and others flit like a bird from one tonic branch to the next. In addition to my chromatic tendencies, I'm certainly very modal in my voice as well. There are some pieces, such as "For My Father," that are chromatic in an almost mid-20th century German way, and others, like "Arcana," that are very modal and open-sounding, parallel fifths and all. ${ }^{44}$

Based on this insight, the author views much of Shapiro's writing as either chromatic, pantonal, or some combination of these approaches. However, as Shapiro pointed out, what may sound dissonant to one listener may not to another. Also, unless otherwise noted, the author's use of the term "tonal center" throughout this document is to be interpreted within a modern sense of tonality, rather than in a traditional classical sense of functional harmony. For example, the "tonal centers" of C and D in Luvina, discussed in chapter three, are considered such because of the frequent appearance of these pitches in the bass, along with right-hand extended harmonies that relate to the bass line.

Returning to the discussion of Intermezzo, one may observe that as a wave tosses its objects, sometimes towards their destination and often away as well, the musical line seems at times to be propelled, intermittently digressing back to where it began, but slowly and eventually reaching its destination. This could also be said of the harmonic progressions and digressions. As an example, the first complete statement in mm. 1-10

\footnotetext{
${ }^{44}$ Alex Shapiro, email message to author, July 9, 2015.
} 
(see Excerpt 2.1) is followed by subtle harmonic development of the opening figure, as if the waves are building momentum, then returning to where they started.
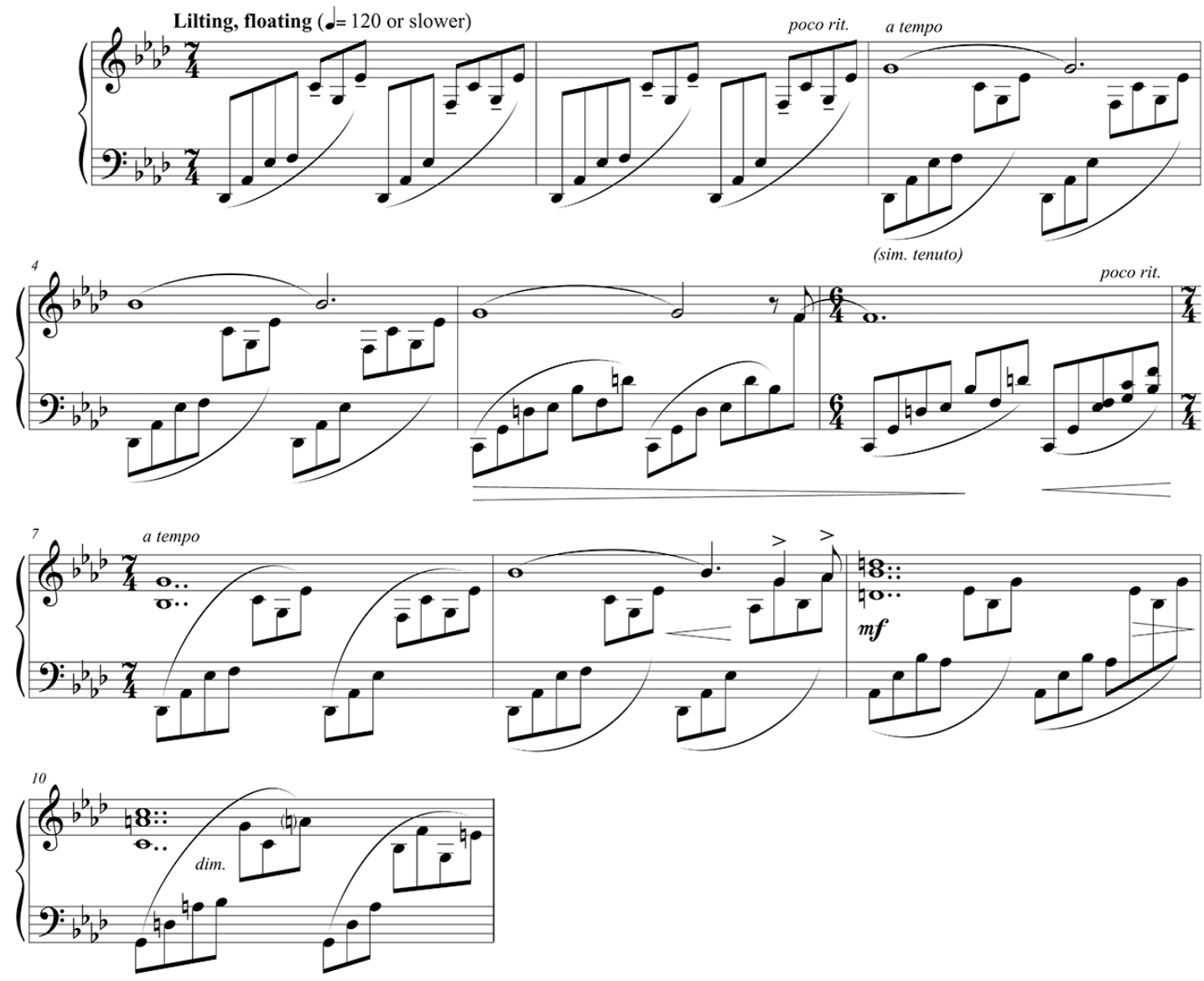

Musical Excerpt 2.1: Alex Shapiro, Intermezzo, mm. 1-10

The second large phrase occurs in mm. 17-23 and is a repetition of the first, but an octave higher. It climaxes on a high $\mathrm{D}$ at $\mathrm{mm}$. 23 , only to withhold arrival of the final expected pitch, C. Instead, Shapiro offers momentary harmonic resolution in a short closing statement in mm. 24-28 (see Excerpt 2.2), concluding with a fermata over a bass E-flat. 


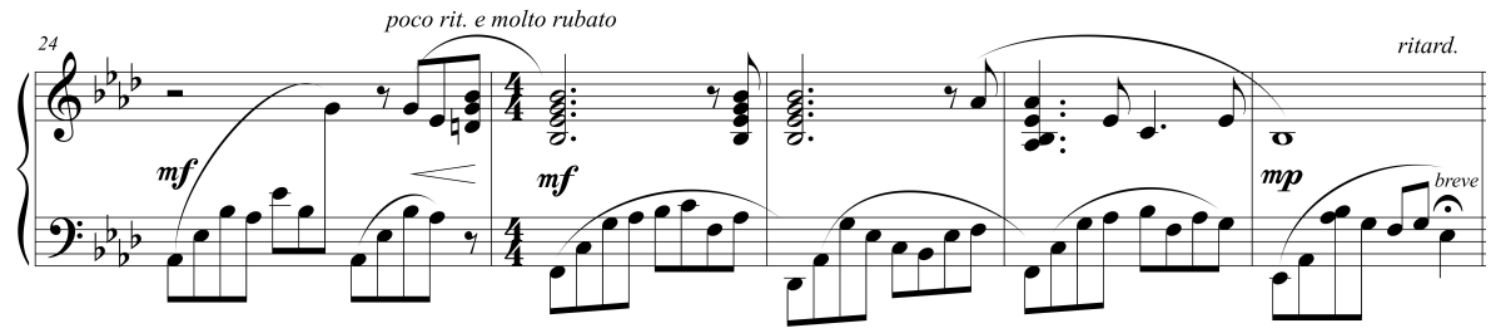

Musical Excerpt 2.2: Alex Shapiro, Intermezzo, mm. 24-28

In the following section of music, Shapiro plays with fragments of her melodic material, continuing to build momentum but still carefree and indefinite. As seen in Excerpt 2.3, the climax in mm. 40-43 is followed by a more resolved closing statement, perhaps symbolically reassuring us that the branch of kelp, symbolizing a person on their life journey, achieves its ultimate destination. Further confirmation that this piece is in Dflat Lydian is given in mm. 46-48 (see Excerpt 2.3), where the complete scale of this mode is written out in the treble clef. As the left-hand arpeggiations symbolize a rolling tide throughout this short work, the right hand melodic line perhaps tells the story of the one who is traveling on the sea.

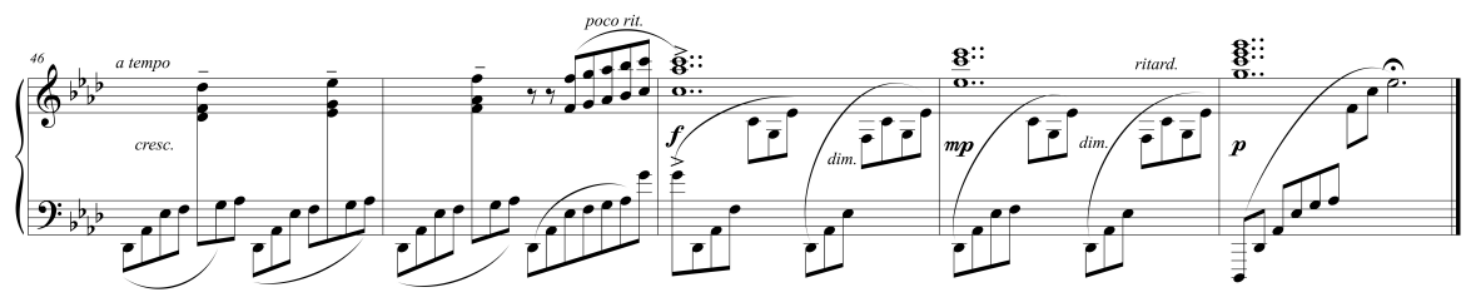

Musical Excerpt 2.3: Alex Shapiro, Intermezzo, mm. 46-50

This piece also serves as an example of Shapiro's use of asymmetrical meter, alternating between time signatures of $7 / 4$ and $6 / 4$ with accents placed strategically over 
major beats, as well as tenuto markings over inner voices, echoing the primary melodic material (see Excerpt 2.1).

This piece is appropriate for late-intermediate pianists. Although the tempo is relaxed, the seven-note figure in the left hand must be executed smoothly and without accents. Tenuto marks emphasize a subtle accompanying countermelody but should not draw attention away from the long melodic line in the right hand. 


\section{Slowly, Searching}

Date of Composition: 2009

Duration: 6:00 minutes

Description: One-movement work. 5 pages, 8.5 " x 11 "

Publisher: Activist Music (ASCAP)

Score Location: alexshapiro.org < Works < Piano < Slowly, Searching

Score Formats Available: Print or Digital

Available Recordings:

1. mp3 audio clip

2. Susanne Kessel's 2010 CD, An Robert Schumann

Location of Recordings:

1. alexshapiro.org < Works < Piano < Slowly, Searching

2. alexshapiro.org $<$ Purchase $<$ Purchase CDs

\section{Related Arrangements: N/A}

Program Notes found on inside cover of score:

Slowly, searching is a modern day homage to the lyricism, melancholy and passion of Robert Schumann. German pianist Susanne Kessel created a project titled Kreisleriana 2010, asking eight composers to choose a movement of Schumann's beloved suite as inspiration for their own voice. I was touched by the fourth, Sehr Langsam, and chose a few notes from it as my point of departure, and later, development. Two hundred years since this great composer's birth, the themes of peacefulness, joy, madness and deep pain remain a human constant. ${ }^{45}$

This work is one of two that Shapiro wrote with a specific composer in mind as a source of inspiration and musical material. According to Shapiro: "In the case of both 'abstract homages' to Schumann and Beethoven, these pieces were written at the request of the fabulous Susanne Kessel."46 She goes on to say, "I'm usually not one to go down that path, but I love her playing and her spirit, and when her invitations came to delve into the essence of these great composers, I could not say no." ${ }^{47}$ Her more recently

45 Alex Shapiro, Slowly, Searching (Activist Music (ASCAP), 2009) Program Note.

${ }^{46}$ Alex Shapiro, email message to author, February 17, 2015.

${ }^{47}$ Ibid. 
composed piece Chord History is based on favorite chords selected from Beethoven's piano-sonata collection and is discussed in chapter six. However, it is the Romantic composer Robert Schumann who inspires Slowly, Searching. Shapiro offered insight into what inspired her to reflect on Schumann's works and life:

I would sum up the Schumann piece by saying that I was most taken by his struggle with insanity, and the tragic effect on his life. The meditative nature of the first page of "Slowly, searching" is a very uneasy, melancholy one; a troubled mind is never at peace. ${ }^{48}$

This piece evokes many of the same emotions created in the fourth movement of Schumann's Kreisleriana. The opening of Shapiro's score is marked "with hesitation and a sense of loss," similar to Schumann's opening markings "Sehr langsam," which means "very slowly," and "Lento assai," which conveys almost the same meaning. Although the musical material is different, both pieces open with a very slow, meditative feeling (see Excerpts 2.4 and 2.5). Interestingly, a connection may also exist between Schumann's choice of writing in B-flat major and Shapiro's use of B-flat and other pedal points.

${ }^{48}$ Alex Shapiro, email message to author, February 17, 2015. 


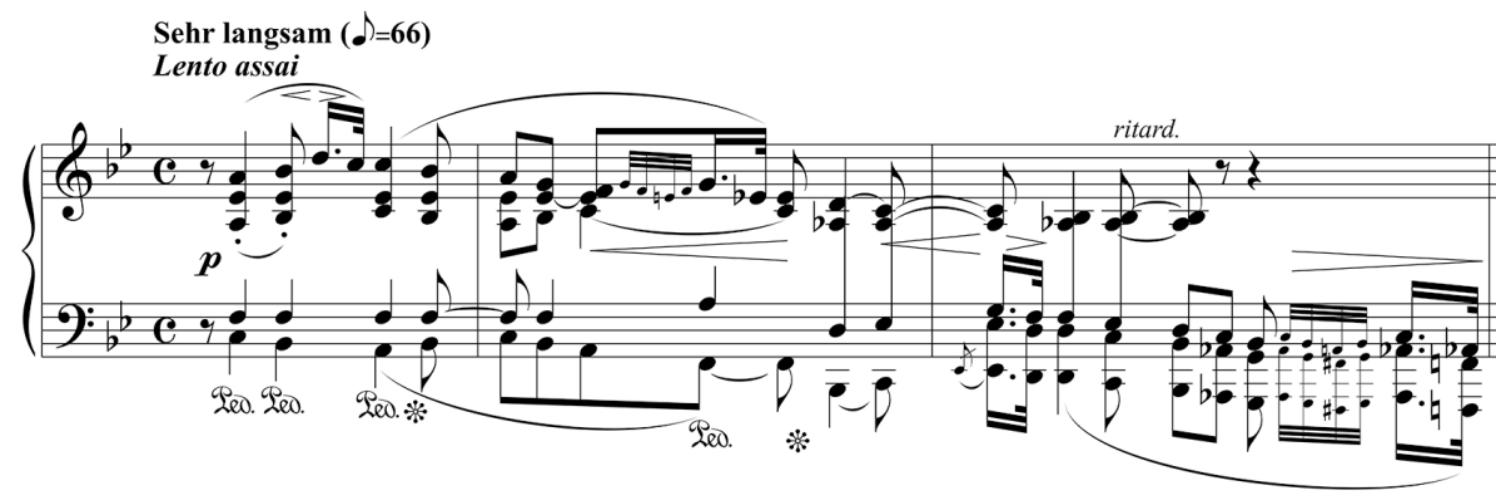

Musical Excerpt 2.4: Robert Schumann, Kreisleriana Op. 16, no. 4 "Sehr langsam," mm. 1-3

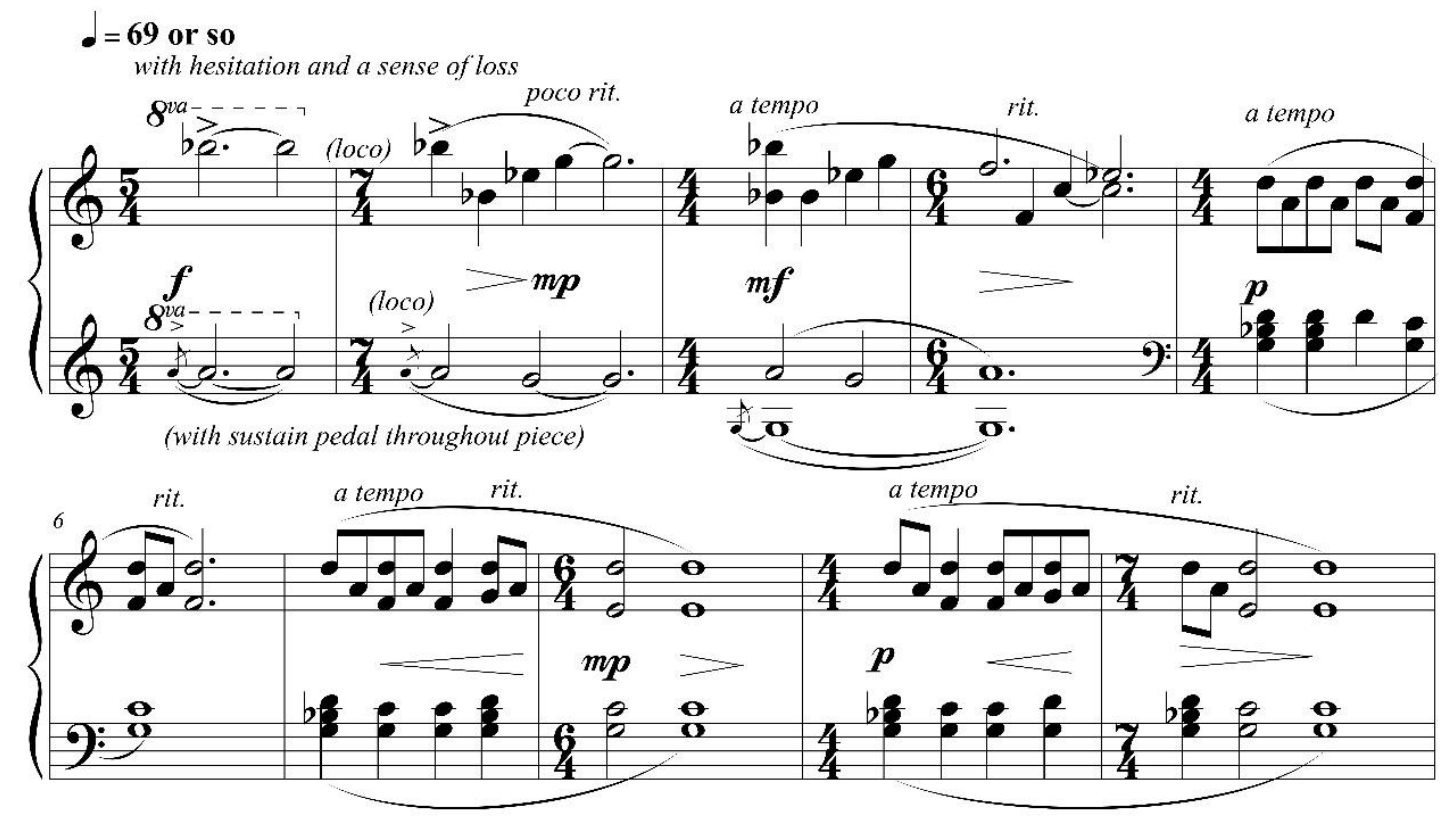

Musical Excerpt 2.5: Alex Shapiro, Slowly, Searching, mm. 1-10

Slowly Searching depicts conflicting emotions parallel to those in Kreisleriana, such as uneasy rest and turmoil. Shapiro achieves this by means of contrast between harmonic stability and tension. Mainly, the opening and closing passages of her work lend themselves to modal harmonies and more homophonic textures, whereas the middle of the work is much more chromatic and rhythmically active. One example of the more chromatic, dissonant writing is the use of half steps by both composers. In Schumann's 
work it is the first two pitches, D and E-flat, in the Bewegter (meaning "more agitated") section (see Excerpt 2.6). In Shapiro's piece there are several instances. One is in the opening and closing of the piece where she clashes A and B-flat against one another, as well as E against $\mathrm{F}$ at the end, underneath a sustained B-flat (see Excerpts 2.5 and 2.7).

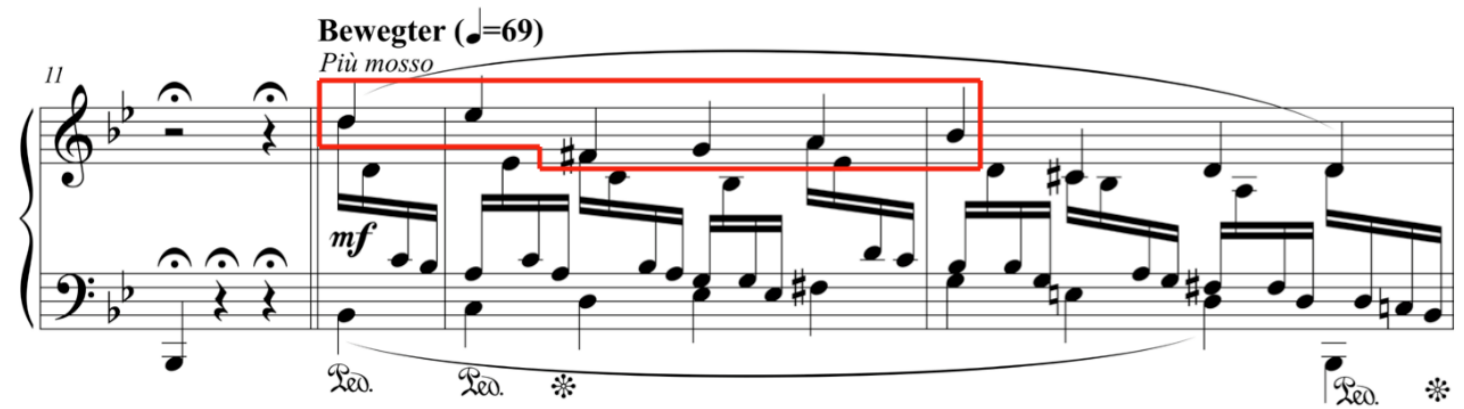

Musical Excerpt 2.6: Robert Schumann, Kreisleriana Op. 16, no. 4 "Sehr langsam," mm. 11-13

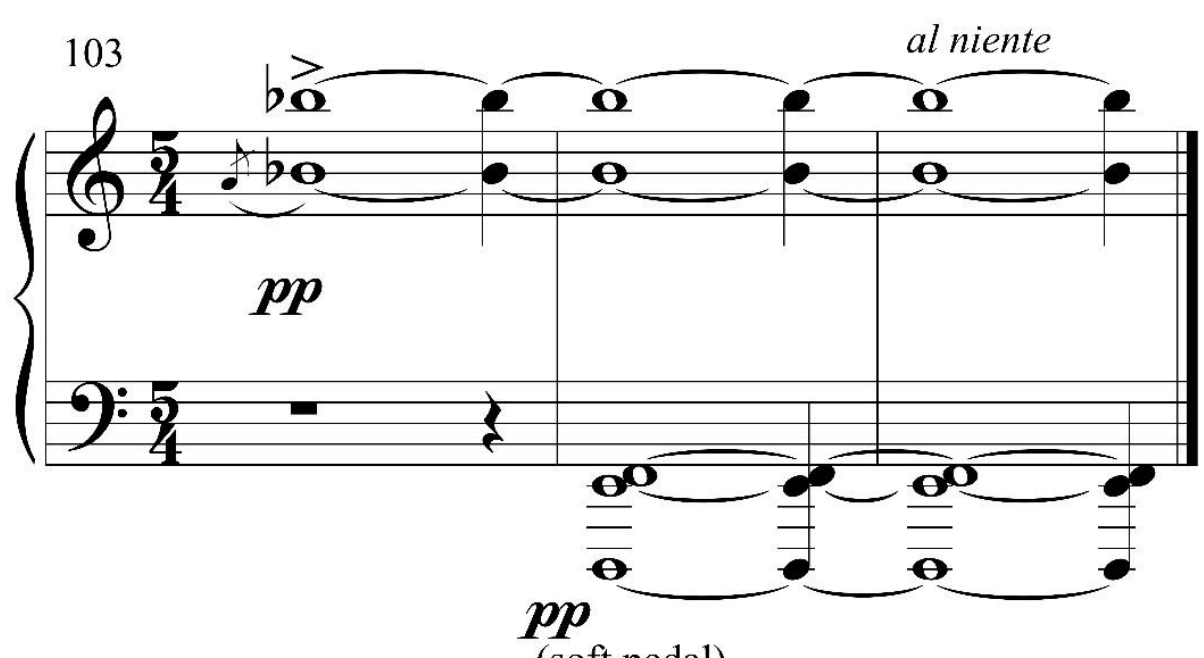

Musical Excerpt 2.7: Alex Shapiro, Slowly, Searching, mm. 103-105 
Another instance is much more obvious to the listener. The sustained, homophonic texture in mm. 29-33 of Slowly, Searching creates a tranquil aura of meditation. However, in m. 34 the listener is jolted out of this place of peace into a faster, driving, and increasingly dissonant section. This opens with a clash of A and B-flat in the tenor voice, with persistent, dissonant sevenths in the upper register (see Excerpt 2.8).

Shapiro revealed additional insight about this section in an email to the author:

As you wrote, everything starts to fall apart more evidently at bar 34 , and the subsequent fury that unleashes is a manic one of insanity and internal chaos. I return to a very, very uneasy calm at the end, because I can't imagine any other way to leave the listener. The piece is about internal pain. ${ }^{49}$

${ }^{49}$ Ibid. 


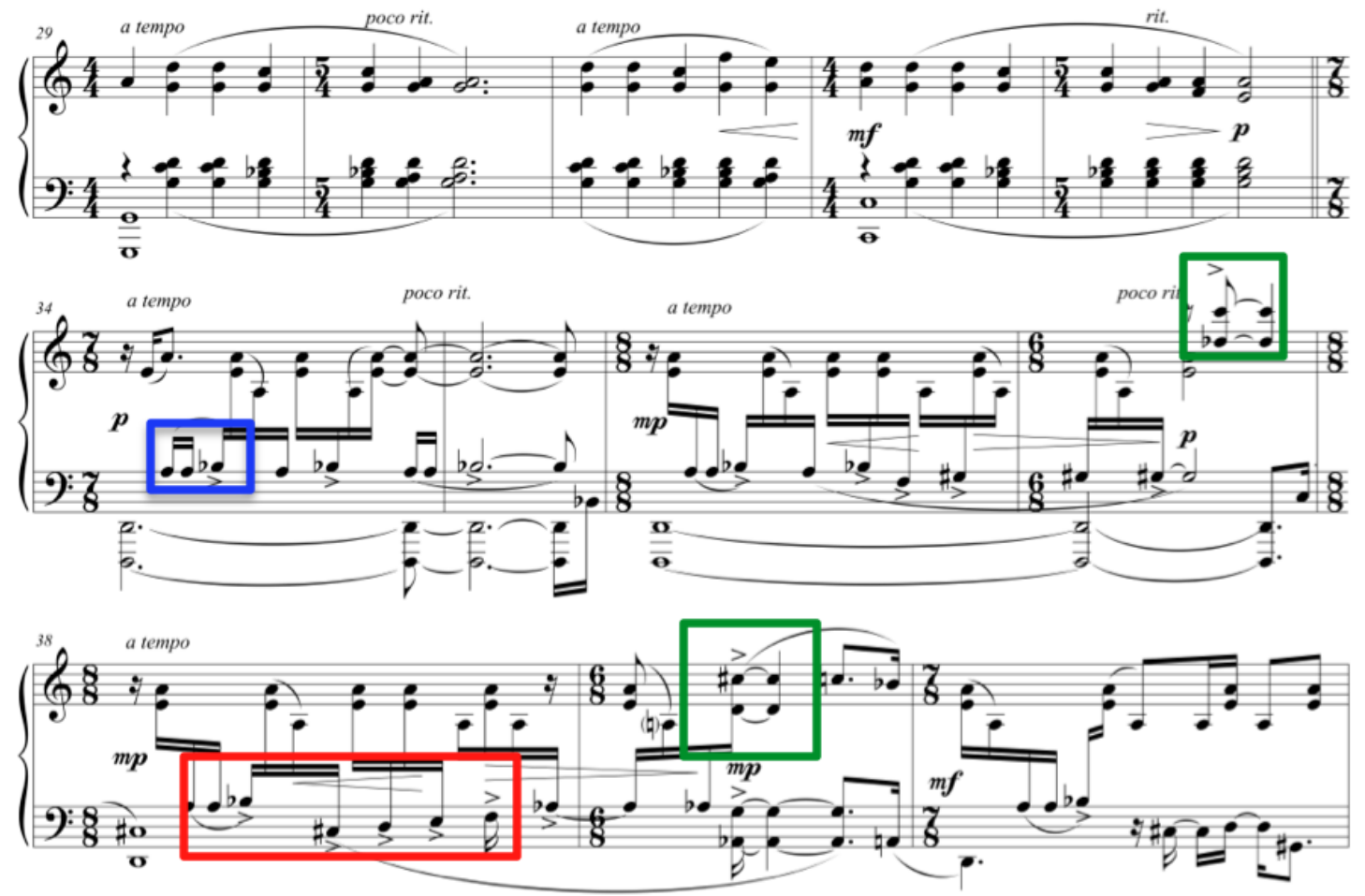

Musical Excerpt 2.8: Alex Shapiro, Slowly, Searching, mm. 29-40

Finally, this transitions into what in her program notes Shapiro calls the "point of departure" 50 and leads the listener into a presentation of melodic fragments taken from the similarly more intense middle section of Schumann's work. Here the tenor pitches A, B-flat, C-sharp, D, E, and F are transposed directly from Schumann's melody, in which the pitches are D, E-flat, F-sharp, G, A, and B-flat. Compare Schumann's passage in Excerpt 2.4 with the parallel section in Shapiro's work (m. 38 in Excerpt 2.8).

As a matter of observation but not assumption, it is interesting to note that Shapiro seems to use the same sets of pitches in her piece, but in a more harmonically obscure way. The texture thickens and the sense of longing and being lost meet at the

\footnotetext{
${ }^{50}$ Alex Shapiro, Slowly, Searching (Activist Music (ASCAP), 2009) Program Note.
} 
climax in $\mathrm{m}$. 52. The forward motion implies a persistent search for something of meaning or value, along with the top-voice B-flat in mm. 52-56 (see Excerpt 2.9 below) that cries as an extension of the same B-flat crying out in the opening of the piece- or even the persistently lost D's of mm. 5-16 (see Excerpt 2.5). Shapiro offered her insight to the author as to why she composed the music in this way:

...I don't want to re-hash Schumann! I have a broader harmonic palette available to me than he did, and it would be a mistake not to use it. I think the trick in these homages is to reference the past but remain solidly in the present. ${ }^{51}$

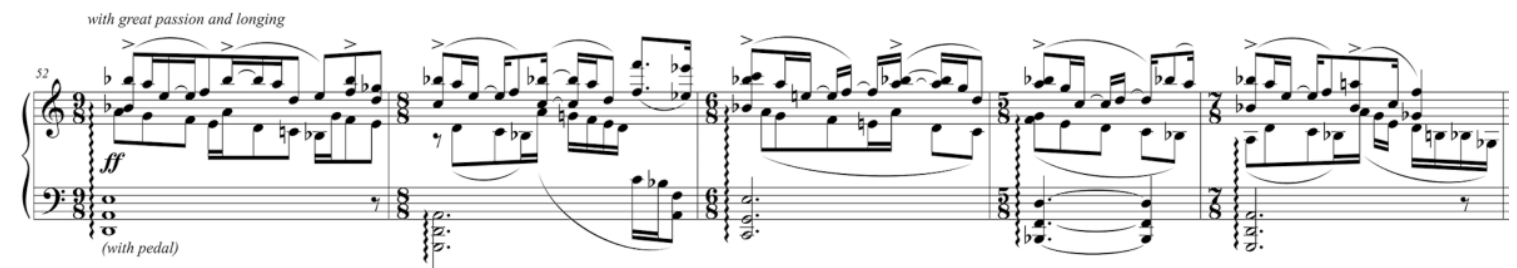

Musical Excerpt 2.9: Alex Shapiro, Slowly, Searching, mm. 52-56

Another interesting observation is the way Shapiro uses sustaining pitches in the treble clef, similar to how she uses the pedal tones in the bass, creating another layer of longing and searching. This is noticeable in the descent in $\mathrm{mm}$. 67-88 from $\mathrm{D}$ to $\mathrm{C}$, to Bflat, and finally to A. Upon arrival, the air clears, so to speak, and the music closes, marked "very inwardly" at m. 89, with decreasing tempo and a descending bass line (see Excerpt 2.10). The dissonances at mm. 96-97 and in the final measures perhaps symbolize a searching and longing that find peace without total resolution.

${ }^{51}$ Alex Shapiro, email message to author, February 17, 2015. 

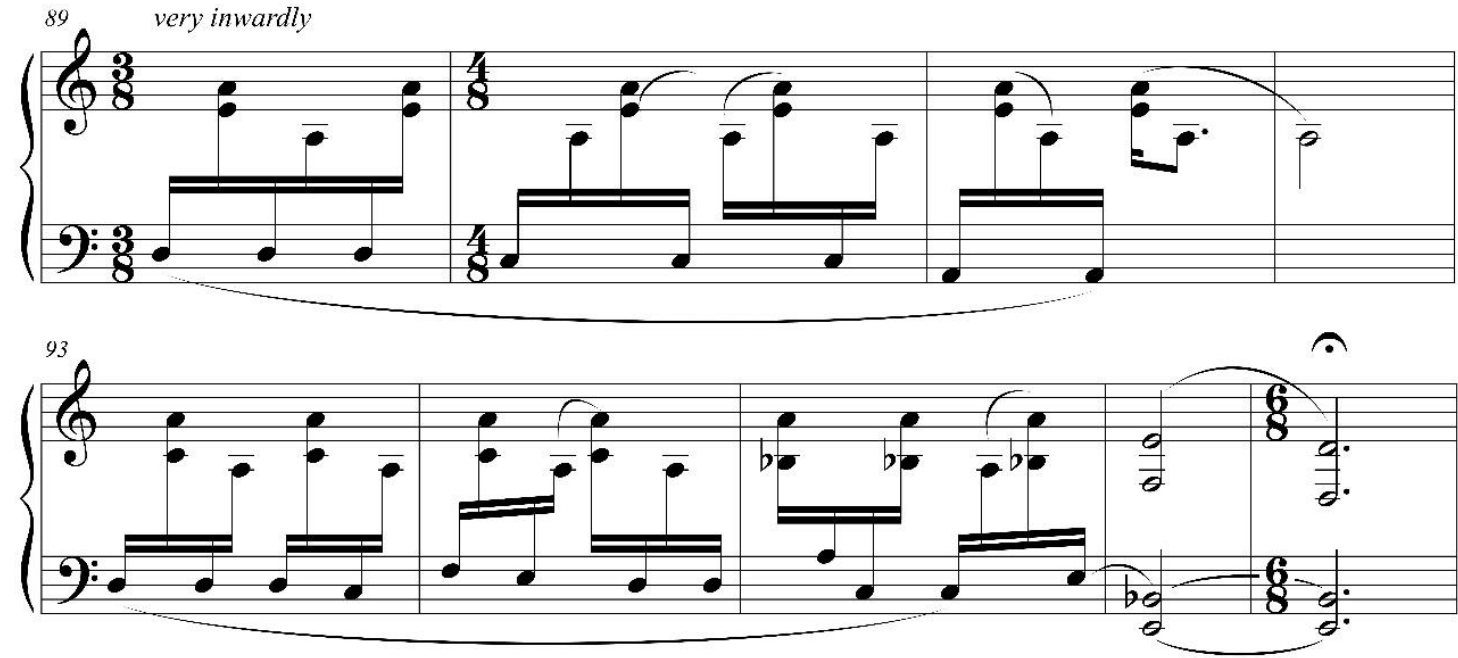

Musical Excerpt 2.10: Alex Shapiro, Slowly, Searching, mm. 89-97

(Note: There is a pointed fermata in the original score, $\mathbf{m} .97$ )

This work is significantly more difficult than Intermezzo. In addition to irregular meters, the accented melodic lines (often in inner voices) are difficult to bring out because of voicing and rhythmic complexity. The driving middle section requires good technique and musical understanding to balance the voicing and hear the direction of the longer line. Additionally, the timing of this piece is crucial, especially in bringing contrast to the slower and faster sections, while also understanding how this loosely knit ternary form fits together. Shapiro summed up the essence of this piece in her email to the author: 
...in a short period of time, the piece spans several moods, styles, and almost genres, and to me that represented Schumann's brilliant and devastating insanity. ${ }^{52}$

Table 1. Comparison of Robert Schumann's "Kreisleriana" No. 4 and Alex Shapiro's "Slowly, Searching"

\begin{tabular}{|c|c|}
\hline $\begin{array}{c}\text { Robert Schumann's Kreisleriana, no. } 4 \\
\text { Sehr langsam }\end{array}$ & Alex Shapiro's Slowly, Searching \\
\hline $\begin{array}{c}\text { Tempo 66 = eighth note } \\
\text { "Lento assai"; "Bewegter" } \\
\text { (Very slowly; Agitated) }\end{array}$ & $\begin{array}{c}\text { Tempo 69 or so = quarter note } \\
\text { "with hesitation and a sense of loss" }\end{array}$ \\
\hline $\begin{array}{c}\text { Begins in B-flat major; Ends on D-major } \\
\text { chord }\end{array}$ & $\begin{array}{c}\text { Makes use of B-flat, G and D pedal } \\
\text { points throughout; dissonant ending } \\
\text { with D in bass }\end{array}$ \\
\hline & $\begin{array}{c}\text { Lost/persistent D's (m. 5-16) and } \\
\text { B-flats (m. 52-56) }\end{array}$ \\
\hline $\begin{array}{c}\text { Dissonant half steps in m. 11-13 } \\
\text { "Bewegter" section }\end{array}$ & $\begin{array}{c}\text { Dissonant half steps in opening (A to B- } \\
\text { flat) and closing (E against F) }\end{array}$ \\
\hline "Bewegter" melodic pattern (m. 11-13) & $\begin{array}{c}\text { Exact, transposed quote of Schumann's } \\
\text { "Bewegter" melody (m. 38) and } \\
\text { subsequent fragmentation of "s" }\end{array}$ \\
\hline
\end{tabular}

${ }^{52}$ Ibid. 


\section{Spark}

Date of Composition: 2011

Duration: 7:00 minutes

Description: One-movement work. 9 pages, 8.5 " x 11 "

Publisher: Activist Music (ASCAP)

Score Location: alexshapiro.org < Works < Piano < Spark

Score Formats Available: Print or Digital

Available Recordings:

1. mp3 audio clip only

Location of Recordings:

1. alexshapiro.org < Works $<$ Piano $<$ Spark

Related Arrangements: Perpetual Spark for flute/piccolo, violin, viola, cello, double bass and piano

\section{Program Notes found on inside cover of score:}

Spark was inspired by the life, love, energy and heart of Dale Mara Bershad, a gifted musician who often used her talents to share the joy of expression and wonder with young children. As a mother, teacher, and performer, Mara's remarkable inner light cast an indelible glow. Her essence remains radiant and present: a spark from a life filled with passion and delight, burning brightly, intensely, and without end. ${ }^{53}$

This is one of the author's personal favorites among Shapiro's solo keyboard works. Whereas many of her works are introspective and consequently marked with relatively slow or meditative tempos, Spark maintains a reflective nature within a faster, bravura tempo. It is one of her three most virtuosic piano works. The other two pieces which compare to Spark in technical demands are the third movement (marked "Scherzo") of the Sonata for Piano, and the sixth movement (titled "Touch It") from the recent piano suite Arcana (2014).

The music begins with a right-hand, seven-note ostinato that provides perpetual motion throughout the work, except in the contrasting middle section from mm. 75-118.

53 Alex Shapiro, Spark (Activist Music (ASCAP), 2011) Program Note. 
Representing a spark of fire, the ostinato also symbolizes the life of Dale Mara Bershad, to whom the work was dedicated. One musically and technically challenging element for the performer is learning to execute the ostinato and to balance it with the left-hand melodic line, which often lies in close proximity and sometimes crosses over the right hand. A performance note by the composer reads:

All right-hand ostinatos flow quickly and mechanically, without regard for meter. The accents in those figures do not need to be strong. Alignment accuracy with left hand is less important than the overall gesture. The left hand lines should float. ${ }^{54}$

This is easier said than done. The accents within the seven-note ostinato alternate with each repetition, first occurring on the first of seven notes, then on the second and continuing in a similar pattern. These local accents appear within common-time meter, which also sometimes changes to $5 / 4,6 / 4$ and even $7 / 4$. This multi-layer complexity is a good example of Shapiro's practice of creating a musical line, then adding accents, and lastly figuring out the meter. If the performer attempts to emphasize the larger meter, this will override the intended emphases on the melodic gestures and the gently accented ostinato accompaniment, and the music will sound too mechanical. Additionally, the tempo marking is very fast and the beginning of the score is marked "a burning fuse of energy" as well as "legato with some pedal." 55 The performer must make the fast energy and flow of the music govern the accents and meter, not the reverse. See Excerpt 2.11, taken from the middle of the first section of the piece.

\footnotetext{
${ }^{54}$ Alex Shapiro, Spark (Activist Music (ASCAP), 2011) Note in Score, 1.

${ }^{55}$ Ibid.
} 

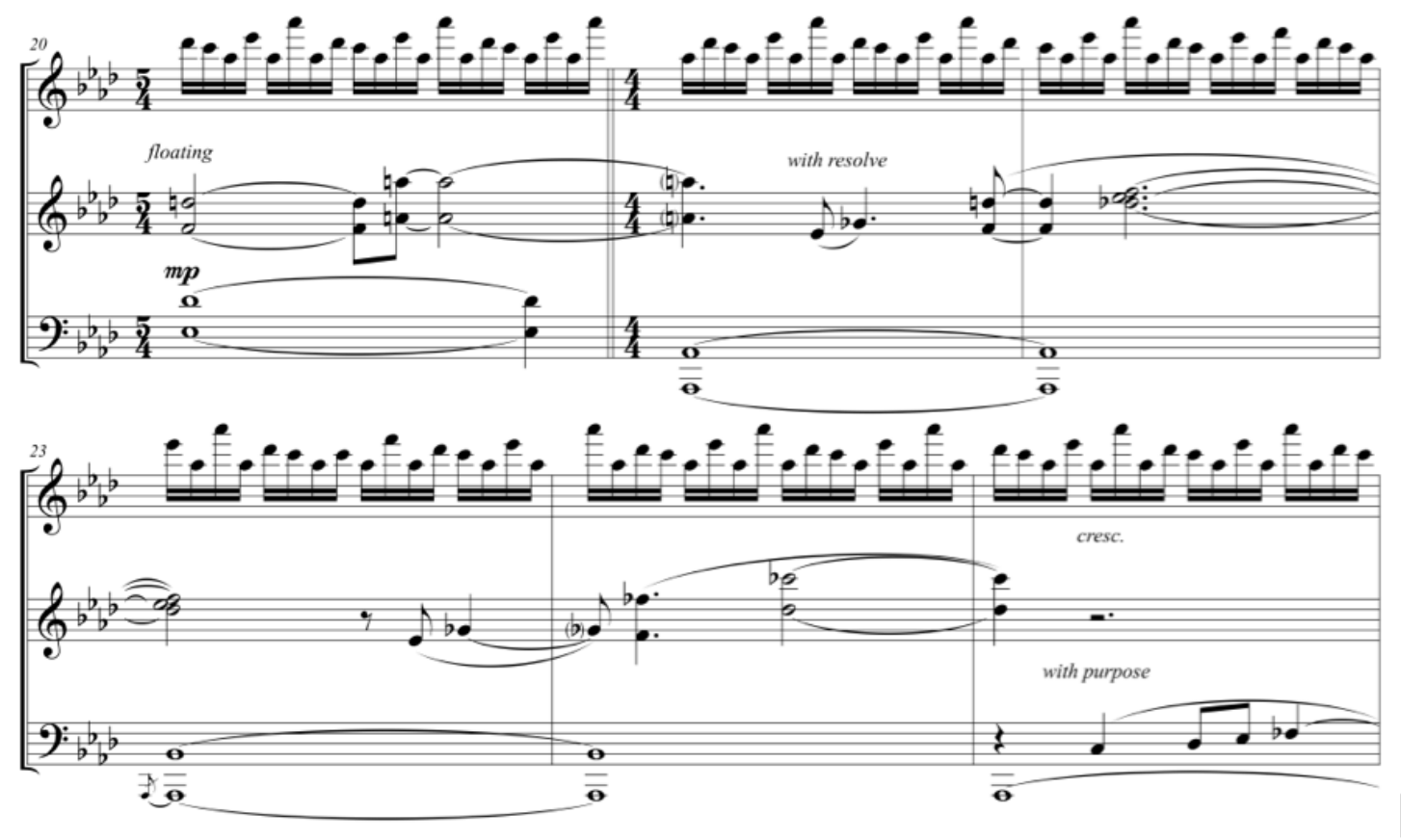

Musical Excerpt 2.11: Alex Shapiro, Spark, mm. 20-25

Structurally, this piece reveals a loose ternary form. It begins and ends with the same material, both in the key of A-flat. However, it contains many modulations in between that make use of pantonal and modal writing, as Shapiro describes. For example, melodic whole-tone patterns coexist with clear A-flat pedal tones and ostinatos. These techniques are similar to those seen in compositions by Debussy as well as Ravel, including the use of three staves instead of two.

Despite Shapiro's chromatic writing, this piece is among her more solidly tonal works. Relationships among key changes, while not always conventional, are easier to identify, partially due to the consistent and progressive recurrence of bass pedal points throughout. Also, modal changes from major to minor in the right hand ostinato as well as emphasis placed on chromatic alterations, such as the presence of G-flats in section $\mathrm{C}$ and F-flats in section D, are transparent in the texture. 
The harmonic motion in the middle of the piece becomes increasingly exploratory but still remains tonally grounded. It is marked by a slower tempo with rubato, and a thick, sustained homophonic texture (see Excerpt 2.12). It develops into an intensely passionate section with building momentum that leads to a return of the opening material.

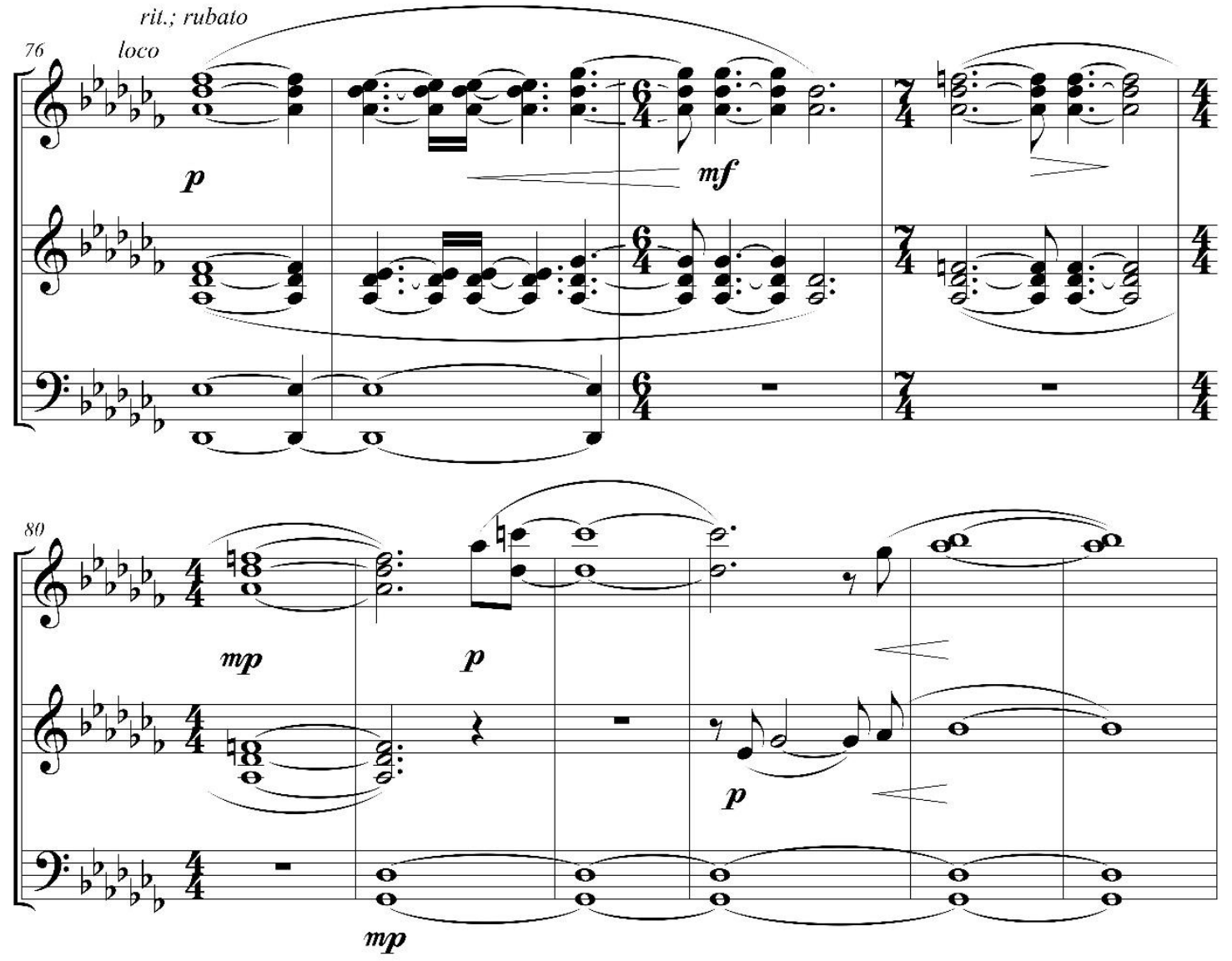

Musical Excerpt 2.12: Alex Shapiro, Spark, mm. 76-85

The opening ostinato and melodic idea both return at m. 119 in what seems to hint at A-flat minor, but within the G-flat major/E-flat minor key signature. This music can probably be described as pantonal, but in a very loose sense. Pantonal music includes the presence of many equal tonalities, preventing any specific tonal center from dominating 
the music. In this piece, there are moments that present clear tonal centers, but the music often wanders from them, creating an illusion of more than one tonal center striving for dominance. Eventually the music finds its way back to the beginning key of A-flat major and ends with as much energy as the flame-inspired opening, representing a life that was lived all the way to the end with a contagious passion and commitment to music and to life.

Shapiro's use of three staves, layers of sounds, and sustained pedal tones is not new. However, her use of these techniques is unique and effective. Because of the fast tempo, the rhythmic challenges posed by the ostinato figure, the long and wide-ranged left-hand melodic lines, and the careful pedaling required to sustain multiple layers of musical lines, this is one of Shapiro's most technically advanced pieces for piano. 


\section{Conclusion}

In conclusion, these three short, independent works by Shapiro, Intermezzo, Slowly, Searching, and Spark, were composed over the span of more than a decade, 19982011. Certain elements are consistent throughout these works, including long melodic lines and changing meters. There are also some evolving characteristics, such as her use of increasingly thick textures, including the three staves of music in Spark, or the increasing frequency of harmonic dissonances, with times of pantonality. Shapiro explores the relationships between the musical material and concepts expressed in words, including her own program notes for each piece. These are excellent works for solo piano and range in difficulty from late intermediate to advanced. 


\section{Chapter Three \\ Luvina and Vendaval de Luvina}

\section{Introduction}

This chapter looks at two piano compositions by Shapiro: Luvina (2007) and Vendaval de Luvina (2010). The duration of the works, about five to six minutes each, is similar because the musical material is almost identical. There are some minor differences, but the major difference between the two is that the latter was composed with the addition of a pre-recorded electronic track with two layers: one of sound effects, musical and otherwise, such as the sounds of someone breathing; and another of Juan Rulfo, the author of the fictitious short story, Luvina, on which the music is based, speaking the words to his story in its original Spanish language. The piano part is intended for live performance with the prerecorded track. This is another example of programmatic music in the truest sense. The program notes to both scores are identical as they are based on Rulfo's short story.

The mood for these two works is morbidly dark. Luvina is a place of perpetual hopelessness and lifelessness. Shapiro skillfully portrays the spirit of this desolate land in both of her musical arrangements. In addition, she is a musical storyteller in a more literal sense, in that both arrangements contain words from the story in the piano score, so that the pianist can clearly understand the mood and intention of each phrase. In Luvina she abbreviates the story with specific moments, whereas in Vendaval de Luvina excerpts from the story are spelled out in the original language, as well as in English translation. 
The piano score includes a separate musical line, which indicates the rhythmic pacing of the spoken part. Because the voice part is already on the pre-recorded tape, the purpose of this is to help the pianist keep pace with the storyteller. This is the only solo piano work by Shapiro to date to include a pre-recorded audio track, but it is one of many examples among her entire compositional output to employ electronic sounds as part of her music. 


\section{Luvina}

Date of Composition: 2007

Duration: 5:00 minutes

Description: One-movement work. 5 pages, 8.5 " x 11 "

Publisher: Activist Music (ASCAP)

Score Location: alexshapiro.org < Works < Piano < Luvina

Score Formats Available: Print or Digital

Available Recordings:

1. mp3 audio clip

2. Ana Cervantes' 2007 CD, Solo Rumores

Location of Recordings:

1. alexshapiro.org $<$ Works $<$ Piano $<$ Luvina

2. alexshapiro.org < Purchase $<$ Purchase CDs

Related Arrangements: Vendaval de Luvina (similar score with addition of pre-recorded digital audio)

Program Notes found on inside cover of score:

"Wherever you look in Luvina, it's a very sad place. You're going there, so you'll find out. I would say it's the place where sadness nests... the breeze that blows there moves it around but never takes it away." Such is the bleak world described in Juan Rulfo's short story, Luvina. When pianist Ana Cervantes asked me to compose a piece in response to the late Mexican author's writing, I had not read any of his work and looked forward to the books that would soon appear in my mailbox. Sitting in my studio, immersed in the grim desert of dire poverty and hopelessness Rulfo describes in this and other equally moving writings, I cried. Long since finishing the music, my thoughts still return to a landscape that is unspeakably sad and, through Rulfo's words, a place where slow and insistent burdens are met with simple, unquestioning acceptance. ${ }^{56}$

Shapiro portrays the fictional land of Luvina musically through means of

repetitive and stagnant phrases, and she provides quite enough harmonic unrest to create a sense of unsatisfied longing. The music opens with a simple but dissonant arpeggiated

${ }^{56}$ Alex Shapiro, Luvina and Vendaval de Luvina (Activist Music (ASCAP), 2007, 2010) Program Note. 
figure, with $\mathrm{C}$ as its tonal center (see Example 3.1). The harmonies appropriately reflect Shapiro's opening remark, "Sadly, lyrically, loosely."

The initial melodic figure enters in mm. 6 and 7 while the opening material continues underneath it (see Excerpt 3.1). Soon after, the melody reaches a high C-sharp in $\mathrm{m} .10$, near where Shapiro entered words from the story, “...you'll never see a blue sky in Luvina..." ${ }^{n 7}$ The isolated C-sharp seems to symbolize the thought of a blue sky but then descends and returns to the opening figure, as a realization that it will never be seen.

${ }^{57}$ Alex Shapiro, Luvina (Activist Music (ASCAP), 2007) Note in Score, 1. 


\section{Luvina}

for Ana Cervantes

and the haunted memories of Juan Rulfo

Sadly, lyrically, loosely $\downarrow=72$ or slower

Alex Shapiro
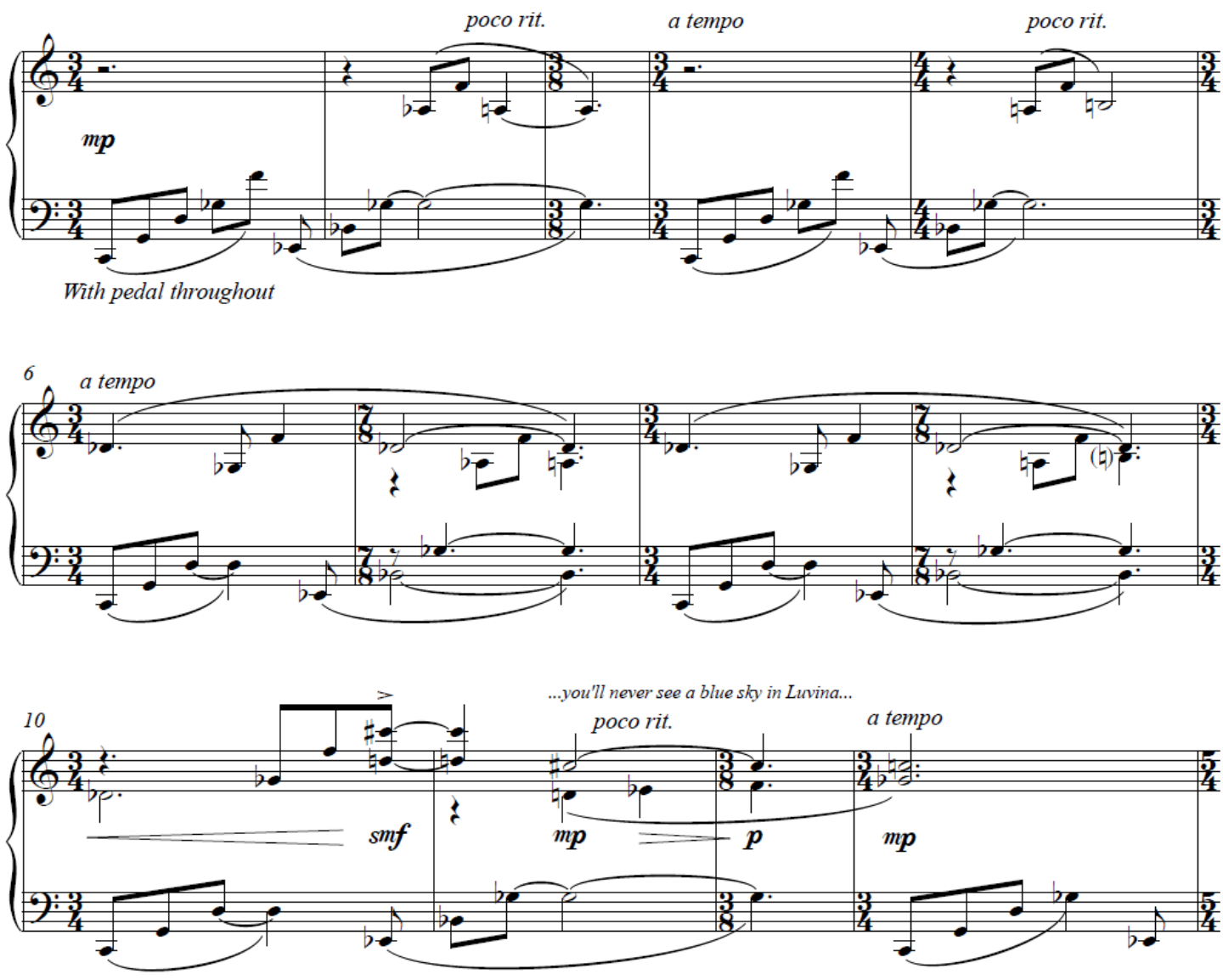

Musical Excerpt 3.1: Alex Shapiro, Luvina, mm. 1-13

As seen in Excerpt 3.2, the second melodic figure enters in mm. 14-16. 


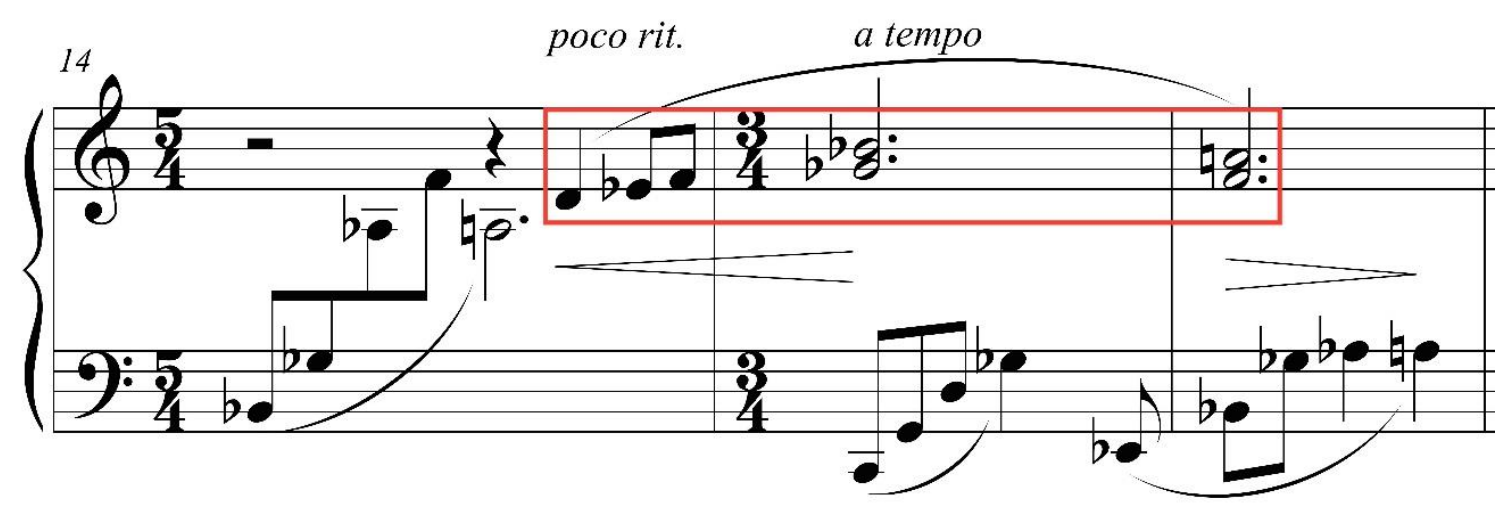

Musical Excerpt 3.2: Alex Shapiro, Luvina, mm. 14-16

These two melodic figures will never be repeated the same way. Only fragments of them occur throughout, often transposed, as in the use of the second melodic figure in mm. 30-34 (Excerpt 3.3), and the first figure in mm. 35-38 (Excerpt 3.4). Again, Shapiro uses repetition of the melodic and harmonic material but with varied, seemingly aimless harmonic direction, that makes sense of the next excerpt of the story, "...the place where sadness nests... the image of despair..."58

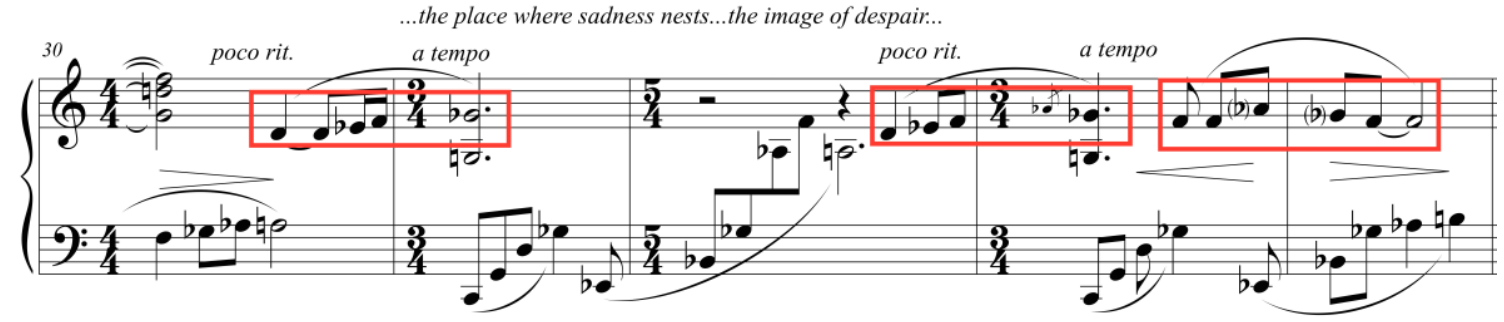

Musical Excerpt 3.3: Alex Shapiro, Luvina, mm. 30-34

${ }^{58}$ Alex Shapiro, Luvina (Activist Music (ASCAP), 2007) Note in Score, 2. 


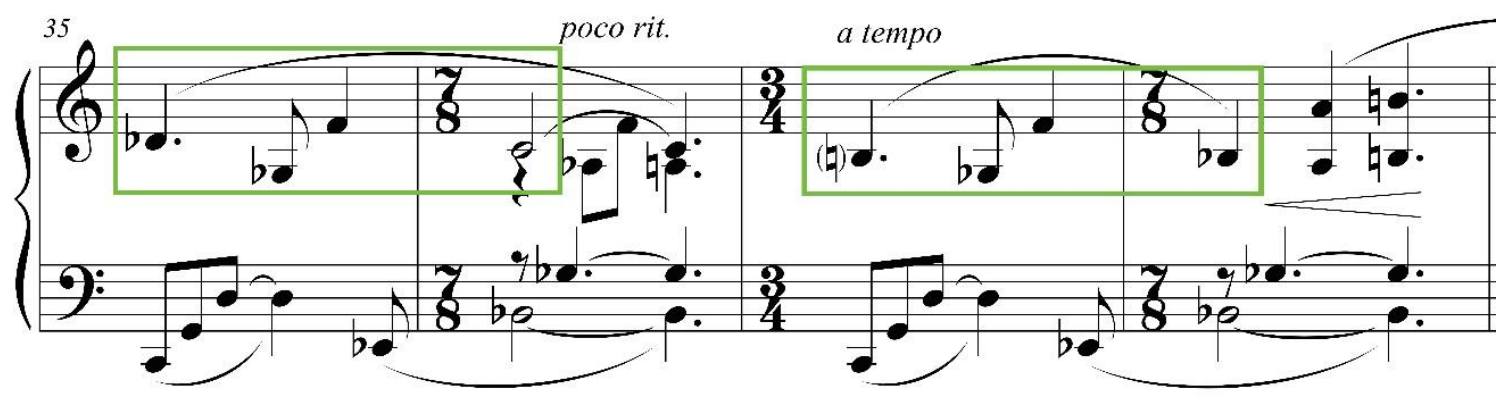

Musical Excerpt 3.4: Alex Shapiro, Luvina, mm. 35-38

Melodically, this piece contains many tritones. Some examples, which can be seen in Excerpt 3.5, include the melodic notes E-flat to A-natural in $\mathrm{m}$. 24, the chord in m. 29 E-flat, B-natural, E-flat, and each melodic motion in mm. 45-48 from G to D-flat, F to B-natural, and (enharmonically the same idea) G to C-sharp.

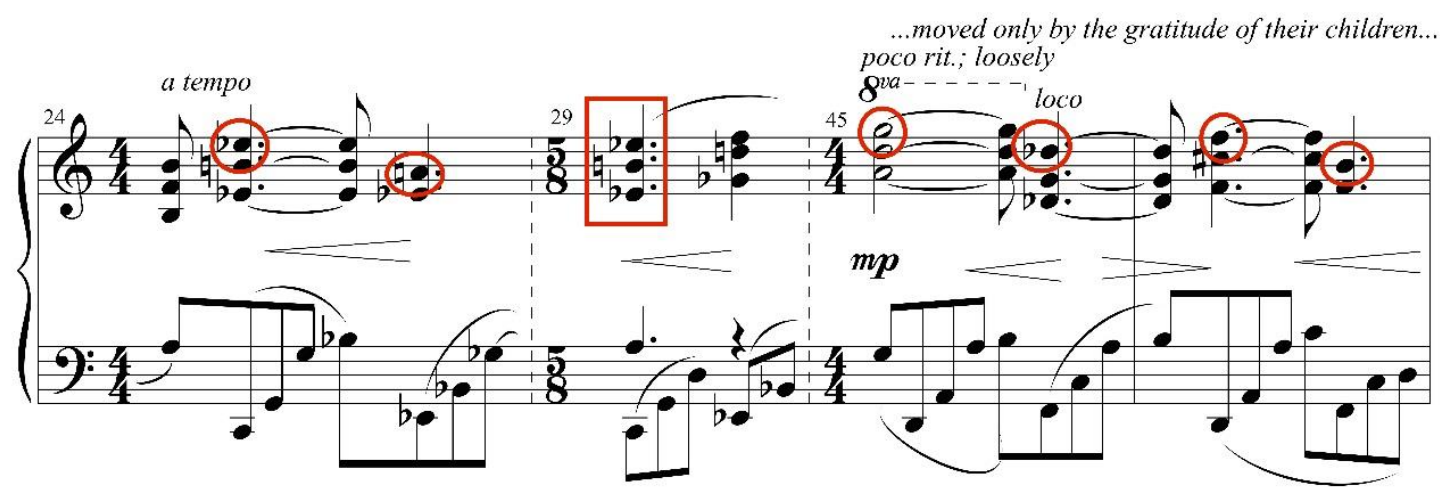

Musical Excerpt 3.5: Alex Shapiro, Luvina, mm. 24; 29; 45-46

In addition to these elements, one of the most obvious and significant characteristics of the music is the monotonous repetition of $\mathrm{C}$ in the bass, from the beginning to $\mathrm{m}$. 40 , then changing to $\mathrm{D}$ from $\mathrm{m}$. 41 to the end. Using a modern sense of harmonic language, these two pitches can be understood as tonal centers that help unify 
the piece by providing harmonic stability underneath an otherwise very chromatic and dissonant texture.

There are also many examples of symbolism worth looking at in this piece. In mm. 45-50 the words "...moved only by the gratitude of their children..."59 are symbolized by the sighs created by the descending melodic tritones (see Excerpt 3.5), as well as by the use of long tied notes and ties across bar lines, which makes the music feel long and drawn out. The phrase, “...Nobody counts the hours...”is perhaps symbolized in mm. 52-57 by the repetitive left-hand figure D, A, E and by the monotonously even, sustained melody notes in 5/8 meter (see Excerpt 3.6).

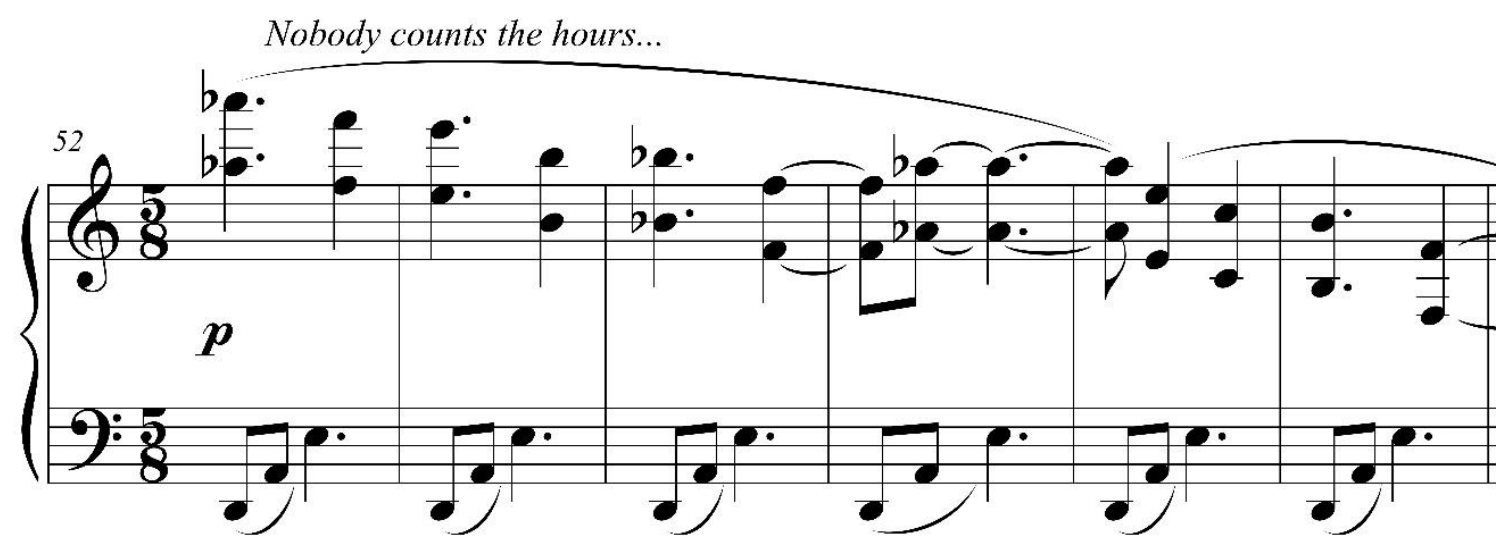

Musical Excerpt 3.6: Alex Shapiro, Luvina, mm. 52-57

The music continues to surrender to the weight of hopelessness in mm. 60-63, where the text "...until the day of death, which for them is a hope..."60 is portrayed through a mostly descending melodic line, a repetitive bass figure on $\mathrm{D}$, and a long sustained B-flat in the tenor voice, that resolves on A-flat (see Excerpt 3.7).

${ }^{59}$ Alex Shapiro, Luvina (Activist Music (ASCAP), 2007) Note in Score, 3.

${ }^{60}$ Ibid. 


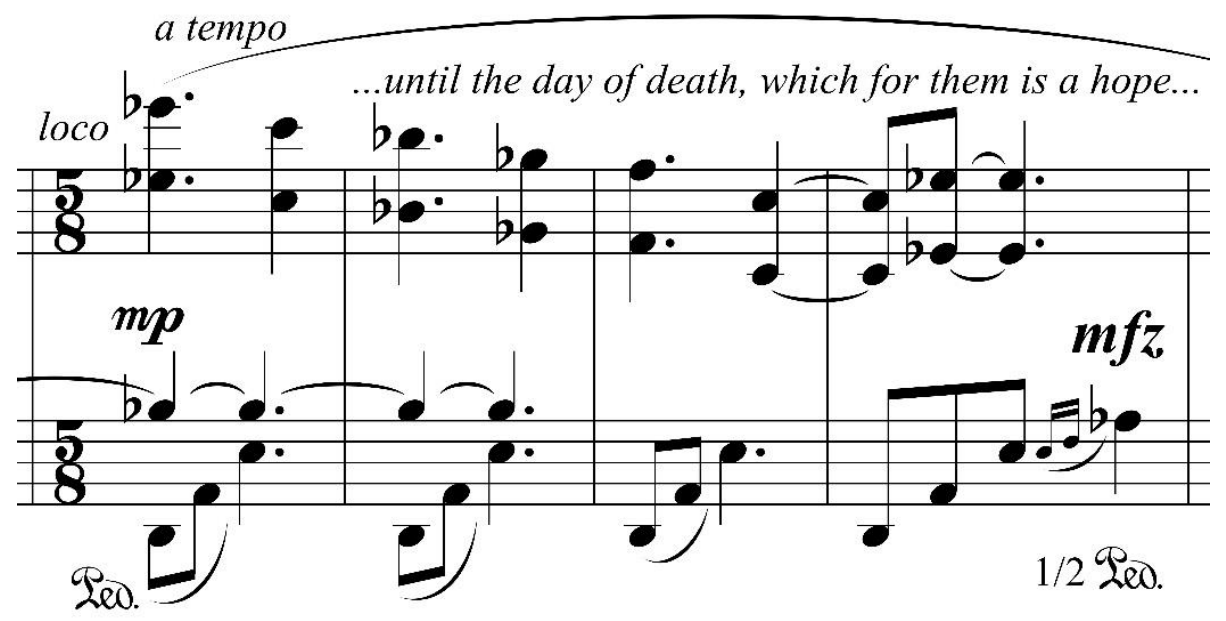

Musical Excerpt 3.7: Alex Shapiro, Luvina, mm. 60-63

The next textual reference, “...each gust of wind like the gnashing of teeth..."61 marks an increase in musical intensity through ringing bass-note D's, and fast ornaments which emphasize dissonance between the two hands, such as the clashing of G and G-flat in $\mathrm{m} .66$, or the dissonance created by the minor second in the right hand, over a bass $\mathrm{E}$ in the left hand, in m. 68 (see Excerpt 3.8).

${ }^{61}$ Alex Shapiro, Luvina (Activist Music (ASCAP), 2007) Note in Score, 4. 


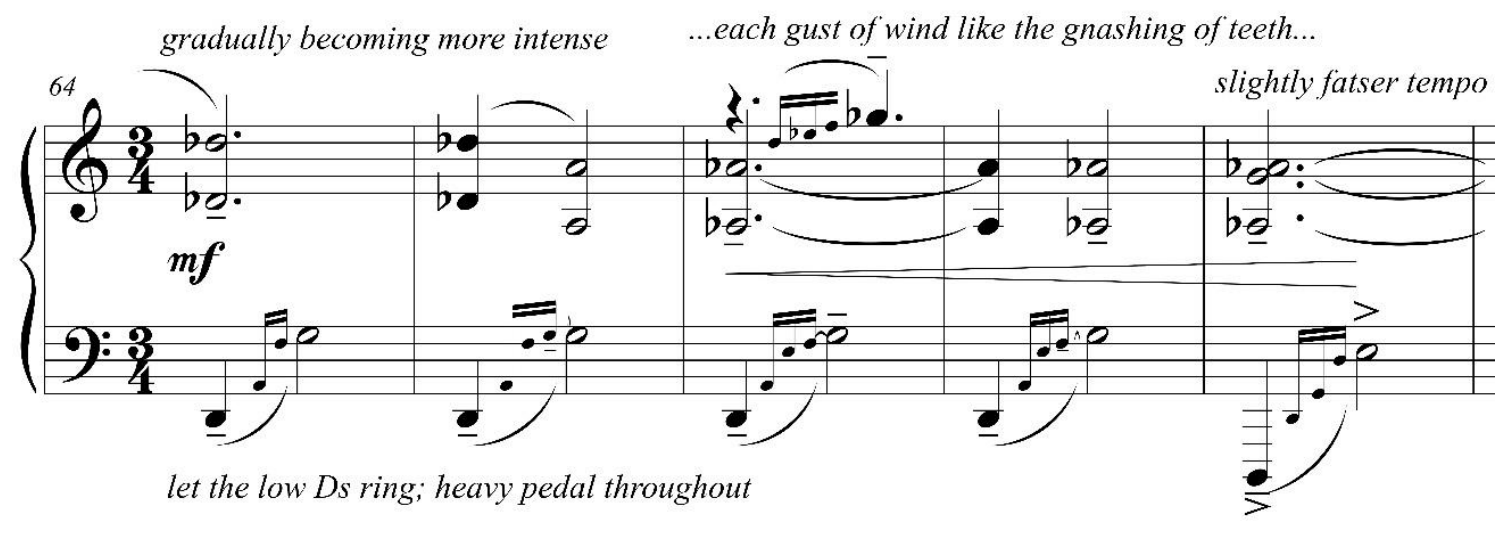

Musical Excerpt 3.8: Alex Shapiro, Luvina, mm. 64-68

This section, mm. 64-91, has a climactic and cadenza-like feeling in the use of written-out asymmetrical rhythms, increasing chromaticism, and incessant ornamentation of accented notes. The imminent insanity brought on by the music and text's hopelessness reaches its peak in this section with Rulfo's text “...But if we leave, who'll bring along our dead ones?...."; this is followed by Shapiro's own marking "nearing insanity; unraveling, tumbling" and, as noted in the parallel measure of Vendaval de Luvina, one can assume that m. 90 of the original Luvina should also read "horrifying." Musically, the terrifying conclusion of the piece is marked by the high-ranged interval of a seventh from D-flat to C, over a very loud D in the lowest range of the piano, and the dynamic marking fff (see Excerpt 3.9). 


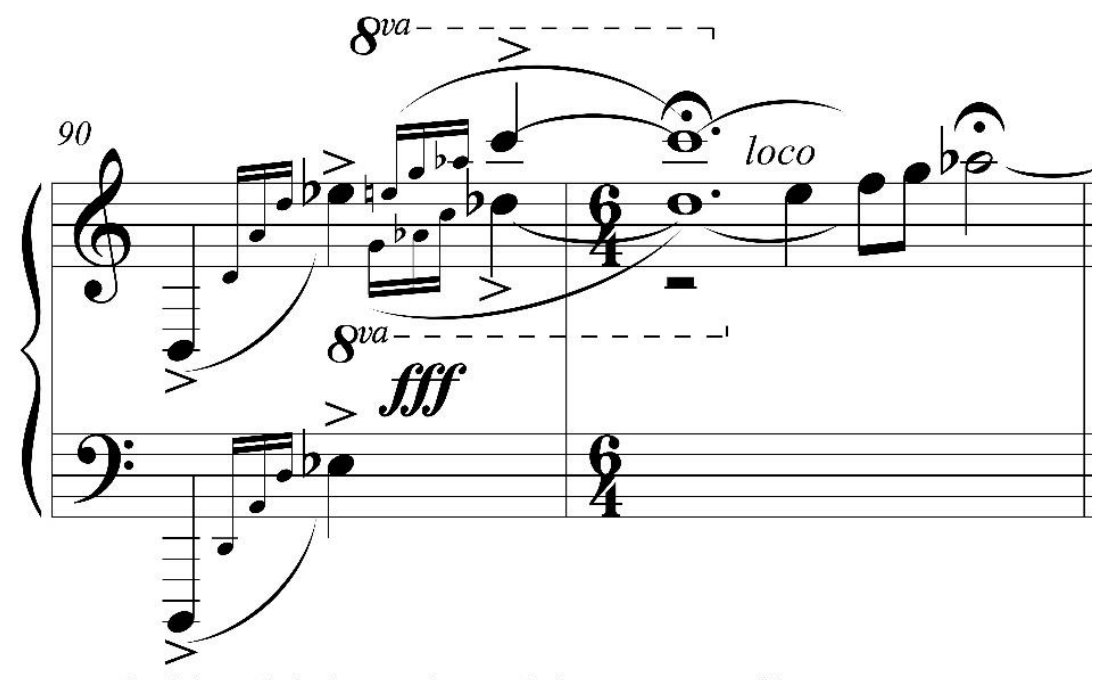

hold pedal down through beginning of bar 96

Musical Excerpt 3.9: Alex Shapiro, Luvina, mm. 90-91

Here the music lingers for a moment on a high A-flat before concluding with long descending melodic octaves over the continuous bass figure on D, marked by Shapiro as "floating" 62 and by Rulfo's text "...there's not a creature to bark at the silence..."63 Lastly, it is interesting to note that the pitch E natural is seldom used throughout the work, occurring only once in $\mathrm{m}$. 68 , then as part of the ornaments in mm. $79-89$, and also at the climax in $\mathrm{m} .91$ in the melodic line where Shapiro marks "loco." ${ }^{64}$ However, it is the final melodic note at the end of the piece, perhaps symbolizing an ending that is incomplete and incomprehensible (see Excerpt 3.10). Also noted is the recurrence of Eflats throughout the work, which strengthens the argument that the final E-natural is intended to provide resolution.

${ }^{62}$ Alex Shapiro, Luvina (Activist Music (ASCAP), 2007 Note in Score, 5.

63 Ibid.

${ }^{64}$ Ibid. 


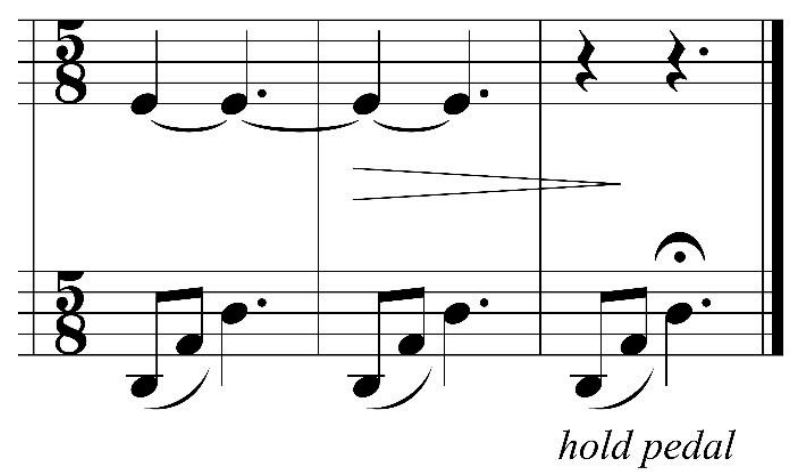

Musical Excerpt 3.10: Alex Shapiro, Luvina, mm. 100-102 


\section{Vendaval de Luvina}

Date of Composition: 2010

Duration: 5:40 minutes

Description: One-movement work. 10 pages, 8.5 " x 11 "

Publisher: Activist Music (ASCAP)

Score Location: alexshapiro.org < Works < Piano < Vendaval de Luvina

Score Formats Available: Print or Digital with audio download

Available Recordings: mp3 audio clip only

Location of Recordings: alexshapiro.org < Works < Piano < Vendaval de Luvina)

Related Arrangements: Luvina (original score with no audio tracks)

Program Notes found on inside cover of score: (same as in Luvina)

As previously mentioned in the introduction, there are only a few differences

between this arrangement and the original score Luvina. This arrangement contains the complete text to Juan Rulfo's short story, as opposed to parts of it in Luvina. This is due to the fact that Shapiro added a pre-recorded digital audio track to Vendaval de Luvina; this audio track includes Rulfo reading his own story in the original Spanish, along with abstract sounds. As a result, the text excerpts in the original Luvina serve only as a reference for the pianist. However, in this 2010 arrangement, excerpts from the entire text are written out in both the original Spanish and in English translation; these excerpts are also given their own rhythmic line in the score, so that the pianist can follow along with the recording. Additionally, the piano score also has a staff beneath the piano part for the electronic track, again so the pianist can time his or her performance with both layers of the pre-recorded track. Because of the synchronization that is required to keep the live piano performance and recording together, some of the rhythmic notation and, consequently, the musical meters in Vendaval de Luvina are different, often resulting in slightly longer rhythmic notation than in the original Luvina. ${ }^{65}$

${ }^{65}$ Alex Shapiro, Vendaval de Luvina (Activist Music (ASCAP), 2010) Note in Score, 9. 
The most interesting difference between Vendaval de Luvina and the original score is the sound effects created by the electronic track, underneath Juan Rulfo telling his own story. Specific pitches are given in some parts, such as the opening A against G marked as an "abstract wind sound" followed by a G and G-flat diminished octave. In some instances, such as mm. 47-48, the electronic sounds double the piano part for added emphasis. In this case, a low D (marked "bowed piano, 8vb") doubles the ringing bass note $\mathrm{D}$ in the piano part. However, there are also instances in which pitches from the soundtrack differ from the piano part, adding another layer of dissonance. For example, in mm. 75-78 the pitches $\mathrm{C}$, A-flat, and G occur on the soundtrack, while the piano part emphasizes other pitches, specifically the F-natural, F-sharp and G-sharp in m. 78 which clash with the G-natural on the soundtrack (see Excerpt 3.12). Some of the other sounds included in the music are that of "breathing," "bowed piano," "abstract wind," an "odd roar," "high shriek," and "haunted souls." ${ }^{, 66}$ Excerpt 3.11 below is from the middle of the work, and displays many elements mentioned above which make this presentation of the land of "Luvina" even more explicit and effective than the original.

\footnotetext{
${ }^{66}$ Alex Shapiro, Vendaval de Luvina (Activist Music (ASCAP), 2010) Notes throughout score.
} 


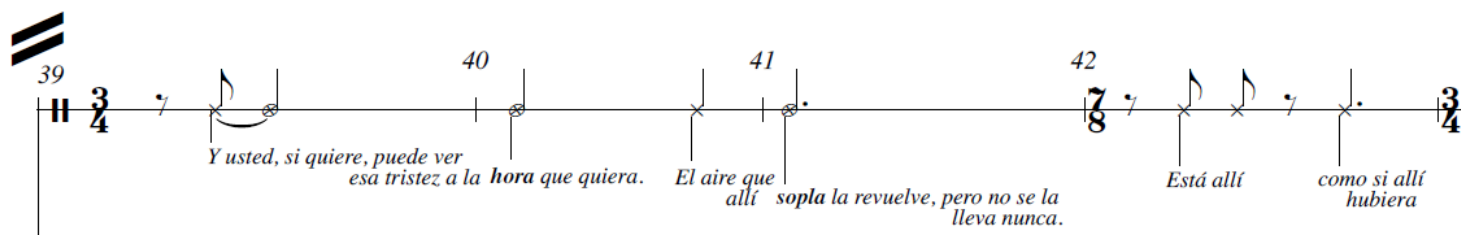

And, if you like, you can see that sadness just any time. The breeze that blows there moves it around but never takes it away. It seems like it was born there.
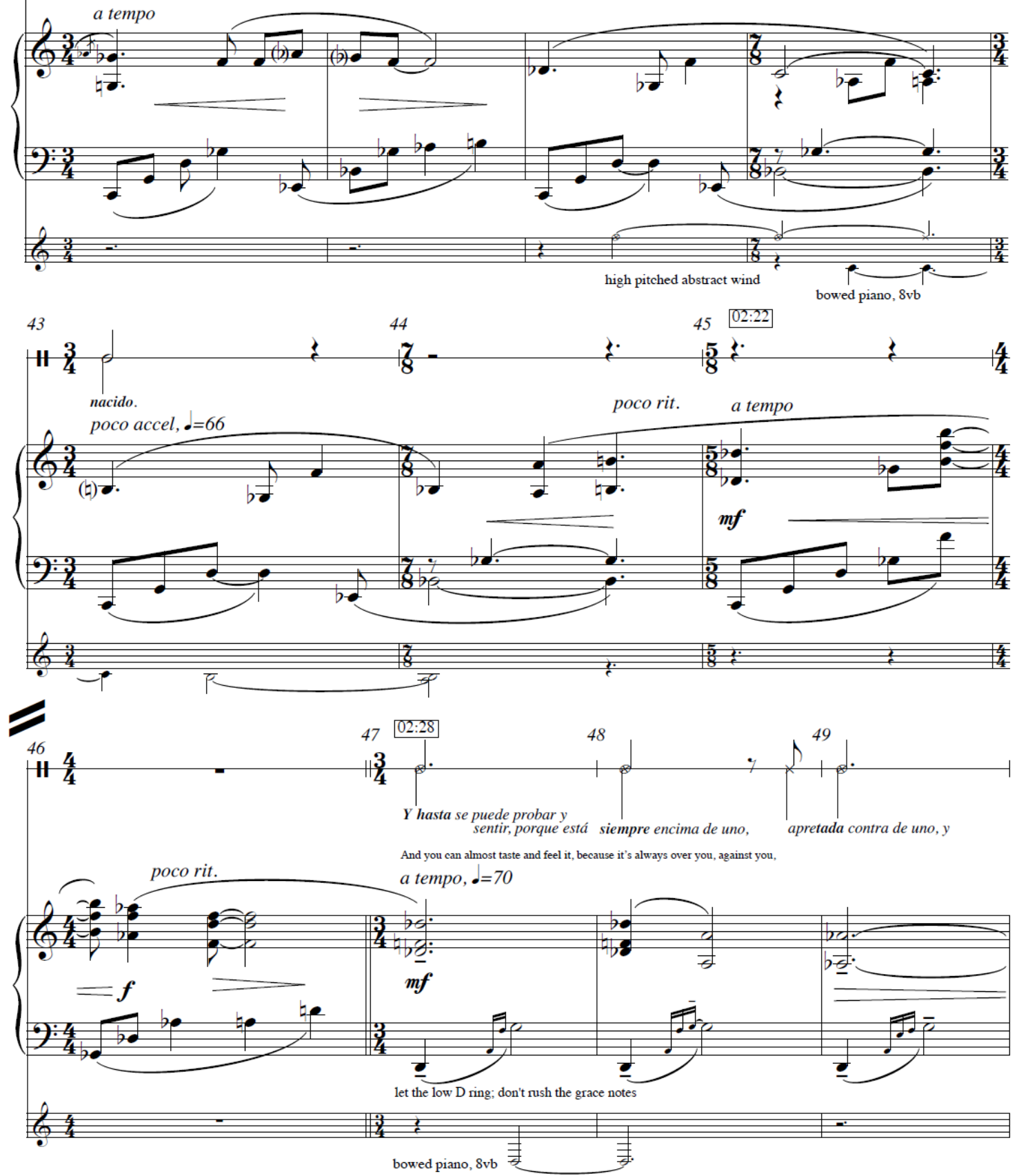

Musical Excerpt 3.11: Alex Shapiro, Vendaval de Luvina, mm. 39-49 


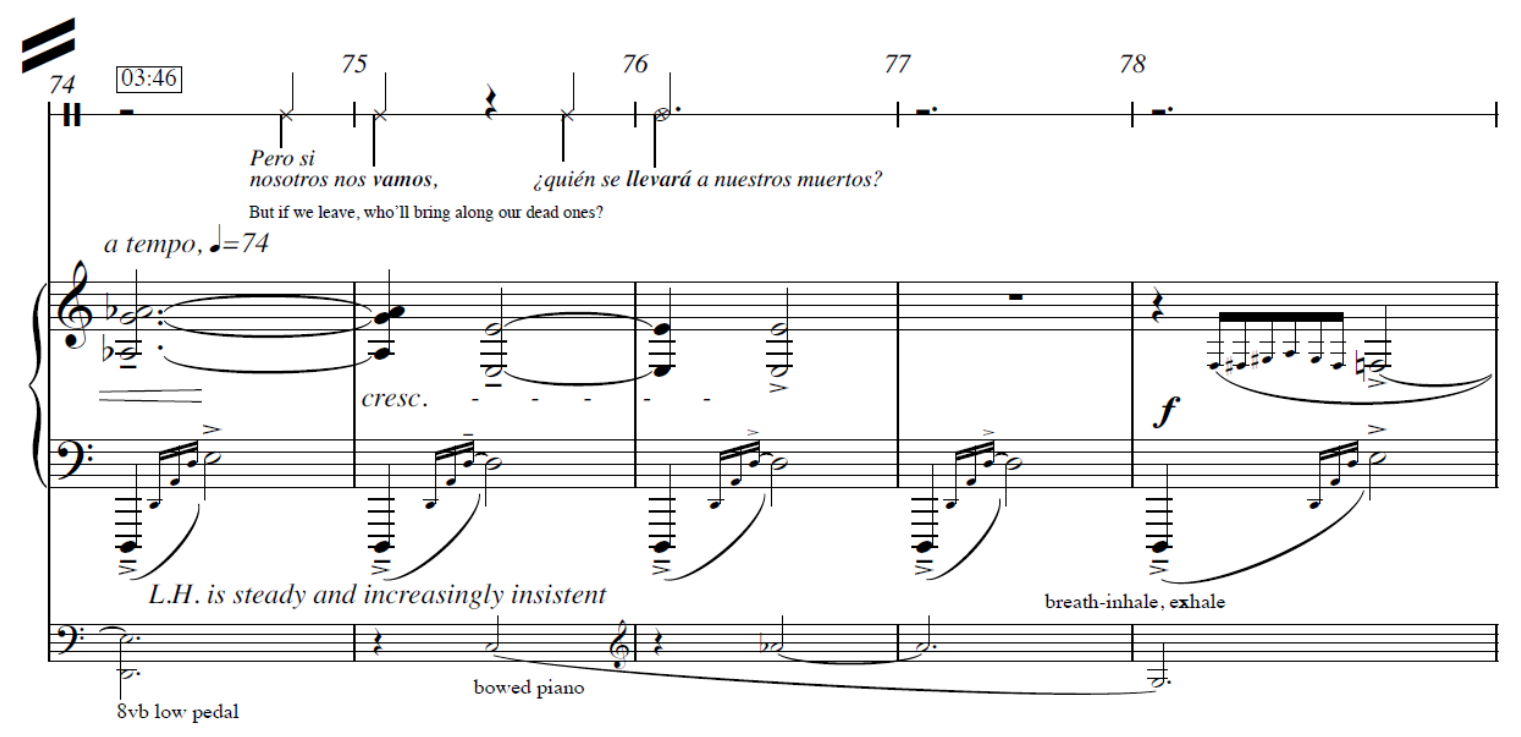

Musical Excerpt 3.12: Alex Shapiro, Vendaval de Luvina, mm. 74-78 


\section{Conclusion}

In conclusion, the original piano score Luvina was composed in 2007 and is based on the short story by Latin-American author Juan Rulfo. In 2010, Shapiro arranged a similar version of the score and titled it Vendaval de Luvina, adding a pre-recorded duallayer digital audio track: Juan Rulfo speaking his story in the vernacular Spanish, along with electronic sound effects. The music and message convey deep sadness, hopelessness, and despair to the point of insanity. Shapiro effectively shares the message of this powerful story through her hauntingly repetitive harmonic figures and dissonant melodies, increasingly disjunct ranges, asymmetrical rhythms and meters, and long pedal tones. This piece requires advanced technical and musical facility, especially in Vendaval de Luvina, due to the meticulous timing required to synchronize a live performance with a pre-recorded track. Although the only fast playing required is in the ornamentation and the cadenza-like passage near the middle, pianists may also find challenges in the wide range of motion between the two hands, the frequently changing rhythms, and, most importantly, a mature sense of timing and dynamics. This music is advanced in an emotional sense and, although it really speaks for itself, the performer needs to pay accurate and effective attention to the text and the composer's markings. 


\section{Chapter Four \\ Piano Suite No. 1: The Resonance of Childhood}

\section{Introduction}

This chapter looks at Shapiro's first concert-music work from the period of writing that followed her time spent in commercial-music scoring. Although this collection recalls experiences from her childhood, it is also important because it inspired her to return to composing for the world of concert music, where her career began. Below are Shapiro's words in an interview with Tom Moore from 2010:

It's easy for me to remember Opus 1 , because it came at a very definitive point. I was thirty-seven, it was the mid-90's, and I had just lost the third of three consecutive composing jobs for small feature films that I had been hired to score, because each of them lost funding just as we got into post-production. One rainy day, I found myself with nothing to do, since I had cleared my calendar for these projects. I began rifling through a folder that contained some concert music pieces I had written when I was 19, at the Manhattan School of Music. I propped some of them up on the piano desk, played through them, and though they were far from brilliant, there were shards of ideas within some of the pieces that were usable, and inspired me. It was an emotional moment, because it reminded me why I had become a composer to begin with. It reconnected me with my love of chamber music, concert music, and music in general.... Because I had nothing else to do with my time, I started to rework one of the pieces. I took a piano suite of several short movements, tightened it up, and the result was a 12-minute piece in five movements, called Piano Suite No. 1 - The Resonance of Childhood[.. ${ }^{67}$

${ }^{67}$ Tom Moore, “An Interview with Alex Shapiro," $21^{\text {st }}$ Century Music 17, no. 10 (2010): 5. 
The titles for the movements of the suite are as follows: "Variations on a Memory”; “On My Mother"; “Quiet Child”; “For My Father”; and, finally, “Older.” Each movement is short and highly chromatic. Each has a quiet, reflective, and sometimes curious character, with numbers three and five being a little quicker and more energetic. The texture is basically consistent throughout (three to four voices) and each movement maintains a relatively conjunct range on the piano. Shapiro favors the use of two-note open chords, often a sign of her modal harmonic language, as well as pantonal harmonies. As in many of her other works, it is easier to identify the emphasis of specific pitches or scalar patterns than to assign traditional harmonic or tonal labels. Much of what holds each of these short movements together is the way Shapiro develops the melodic and harmonic motivic material throughout, as well as the recurring harmonies, or even individual pitches, contributing effectively to the form of the work.

\section{Date of Composition: 1996}

Duration: 12:00 minutes

Description: Five-movement work: "Variations on a Memory," "On My Mother," "Quiet Child," "For My Father," and "Older." 19 pages, 8.5" x 11"

Publisher: Activist Music (ASCAP)

Score Location: alexshapiro.org < Works < Piano < Piano Suite No. 1: The Resonance of Childhood

Score Formats Available: Print or Digital

Available Recordings:

1. mp3 audio clips for all five movements

2. Susanne Kessel's 2006 CD, California Concert (mv. 4 only)

\section{Location of Recordings:}

1. alexshapiro.org < Works < Piano < Piano Suite No. 1: The

Resonance of Childhood

2. alexshapiro.org < Purchase $<$ Purchase CDs

\section{Related Arrangements: N/A}




\section{Program Notes found on inside cover of score:}

"Piano Suite No. 1: The Resonance of Childhood" was composed as a set of personal reflections exploring early years, difficult parental relationships and ultimately the acceptance of complex emotions. Intentionally simple, this piece is a personal reflection of a childhood that remains unsettling. The opening set of variations sets the tone for the entire Suite: searching and hope that are met with the uncomfortable combination of disappointment and acquiescence. Of the five short movements, perhaps the most intimate is the fourth, entitled "For My Father," which was written in response to a beloved parent's descent into dementia. ${ }^{68}$

${ }^{68}$ Alex Shapiro, Piano Suite No. 1: The Resonance of Childhood (Activist Music (ASCAP), 1996) Program Note. 


\section{I. "Variations on a Memory"}

This opening set of variations begins with a chromatic melody in the right hand, revealing a swirling contour; when played as marked ("Hesitantly, loosely"), ${ }^{69}$ it conveys a dreamlike feeling, as if reflecting upon old memories (see Excerpt 4.1).

\section{Variations on a Memory \\ I}

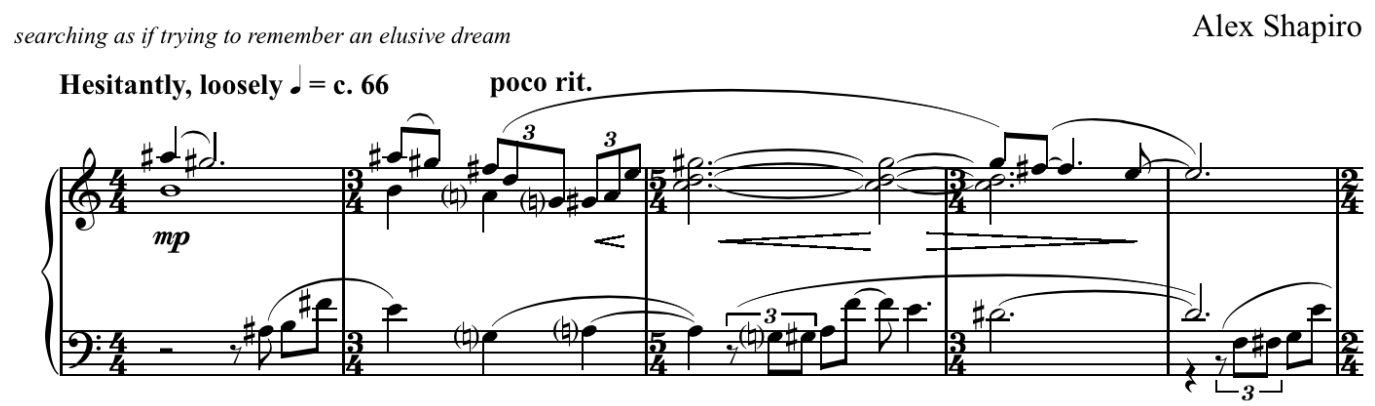

Musical Excerpt 4.1: Alex Shapiro, Piano Suite No. 1: The Resonance of Childhood, I. Variations on a Memory, mm. 1-5

The left hand imitatively answers the right hand, as well as providing bass pedal tones at inconclusive cadential points, such as at mm. 10-11, 22-23, 29-31, and at the end of the movement (see Excerpt 4.2).

${ }^{69}$ Alex Shapiro, Piano Suite No. 1: The Resonance of Childhood (Activist Music (ASCAP), 1996) Note in Score, 1. 

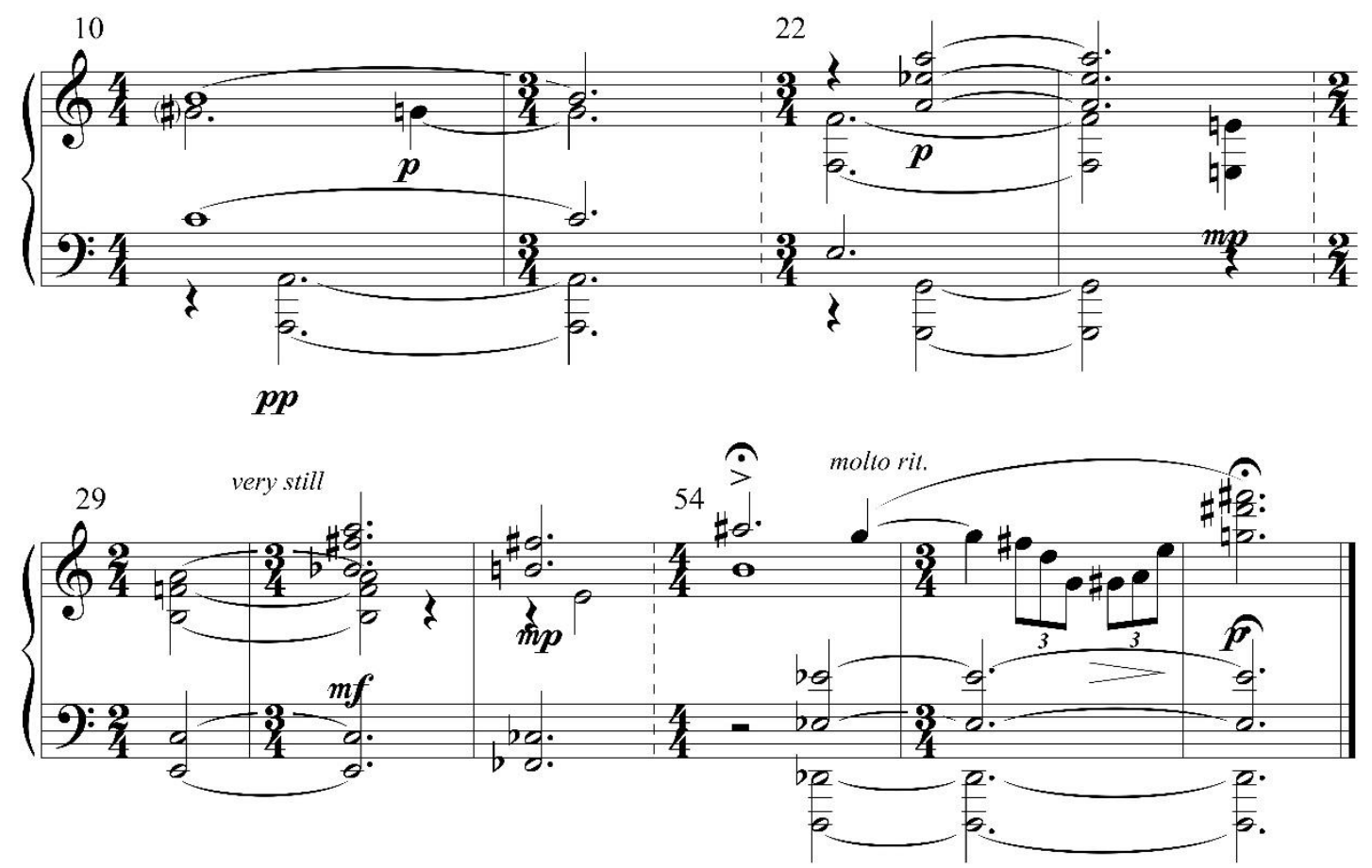

200.

Musical Excerpt 4.2: Alex Shapiro, Piano Suite No. 1: The Resonance of Childhood, I. "Variations on a Memory," mm. 10-11; 22-23; 29-31; 54-56

Symbolically, the chromatic melodies and shifting harmonies represent searching through memories that Shapiro mentions in her introduction. With each cadential point, the music becomes increasingly less settled and more dissonant. Mm. 44-45 mark the most dissonant point in the music (see Excerpt 4.3). Here Shapiro writes the descriptive word "hauntingly." 70 The music then returns to the original faster tempo for the final presentation of the opening melodic figure, which begins on the same A-sharp as at the beginning but continues to wander harmonically further and further away.

${ }^{70}$ Alex Shapiro, Piano Suite No. 1: The Resonance of Childhood (Activist Music (ASCAP), 1996) Note in Score, 2. 


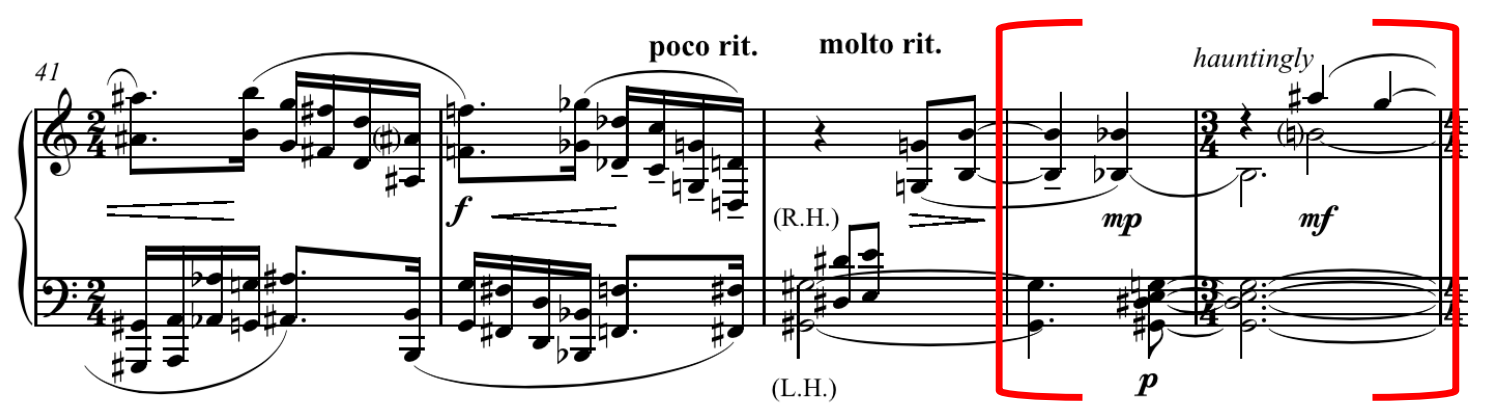

Musical Excerpt 4.3: Alex Shapiro, Piano Suite No. 1: The Resonance of Childhood, I. "Variations on a Memory," mm. 44-45

Another interesting observation is that the momentary and dissonant cadential points serve as a contrast from the restlessness of each varied presentation of the melody. Shapiro marks the one at mm. 22-23 "floating""71 and the next at mm. 29-31 "very still" (see Excerpt 4.2 above) ${ }^{72}$ Perhaps these moments of stillness represent the attitude of "acquiescence," ${ }^{73}$ as Shapiro put it. In other words, the music seems to wander with persistent hopefulness, a different kind of wandering from the hopeless type felt in the poetry of Luvina. However, it continually arrives at the conclusion that nothing is as it should be or how she may have wanted it to be; regardless, nothing can be changed.

\footnotetext{
${ }^{71}$ Alex Shapiro, Piano Suite No. 1: The Resonance of Childhood (Activist Music (ASCAP), 1996) Note in Score, 1.

${ }^{72}$ Alex Shapiro, Piano Suite No. 1: The Resonance of Childhood (Activist Music (ASCAP), 1996) Note in Score, 2.

${ }^{73}$ Alex Shapiro, Piano Suite No. 1: The Resonance of Childhood (Activist Music (ASCAP), 1996) Program Note.
} 


\section{II. “On My Mother”}

The second movement in this set begins with a composer's note that sets the scene: "Adrift at sea; a distant foghorn signals hope across otherwise bleak and stormy waters" and beneath it, "Floating, ominous." ${ }^{\text {"T }}$ The music begins with a low F-sharp pedal in the bass clef and seventh chords in the treble clef that sound like a foghorn's signal (see Excerpt 4.4). It can safely be assumed that the quiet foghorn represents a glimpse of hope on a very distant horizon, amidst a stormy and unpredictable emotional sea. In mm. $3-5$, the right-hand melody enters over a relatively disjunct left hand that continually returns to the bass F-sharp throughout the movement (see Excerpt 4.4). This melodic figure occurs five more times throughout, sometimes extended and sometimes fragmented, always with some change to the harmonies beneath it or following it. The music seems to wander aimlessly, perhaps symbolizing the "bleak and stormy waters" mentioned in the beginning. However, the "foghorn" interval of A-flat and G continually presents itself throughout, almost always with the bass F-sharp.

The harmonic language of this movement appears to be pantonal, one of the primary tonal centers being $\mathrm{C}$ minor, marked by a key signature of three flats. The repeated opening chord contains the dominant note $\mathrm{G}$ and the two semitones on either side of the G, A-flat and F-sharp, respectively. Although there is no C in this chord, the A-flat and F-sharp suggest an augmented-sixth chord in $\mathrm{C}$ minor. These chromatic tones resolve at the end of the work to a $\mathrm{G}$ bass note in $\mathrm{m} .60$ (see Excerpt 4.6), further supporting a sense of the C-minor tonality.

\footnotetext{
${ }^{74}$ Alex Shapiro, Piano Suite No. 1: The Resonance of Childhood (Activist Music (ASCAP), 1996) Note in Score, 4.
} 
The other primary tonal center is A-flat, marked by the recurring use of its dominant E-flat (see mm. 48-50 in Excerpt 4.5). Along with these tonal centers and their dominant pitches, Shapiro adds chromaticism through alterations of these pivotal pitches. For example, E-flat becomes E-natural, as shown in m. 56 in Excerpt 4.6 or m. 43 in Excerpt 4.5, over its tonic A-flat. A similar example is the chromatic alteration of A-flat to A-natural (see m. 4 in Excerpt 4.4 and m. 60 near the end of the work, in Excerpt 4.6).

4

II

\section{On My Mother}

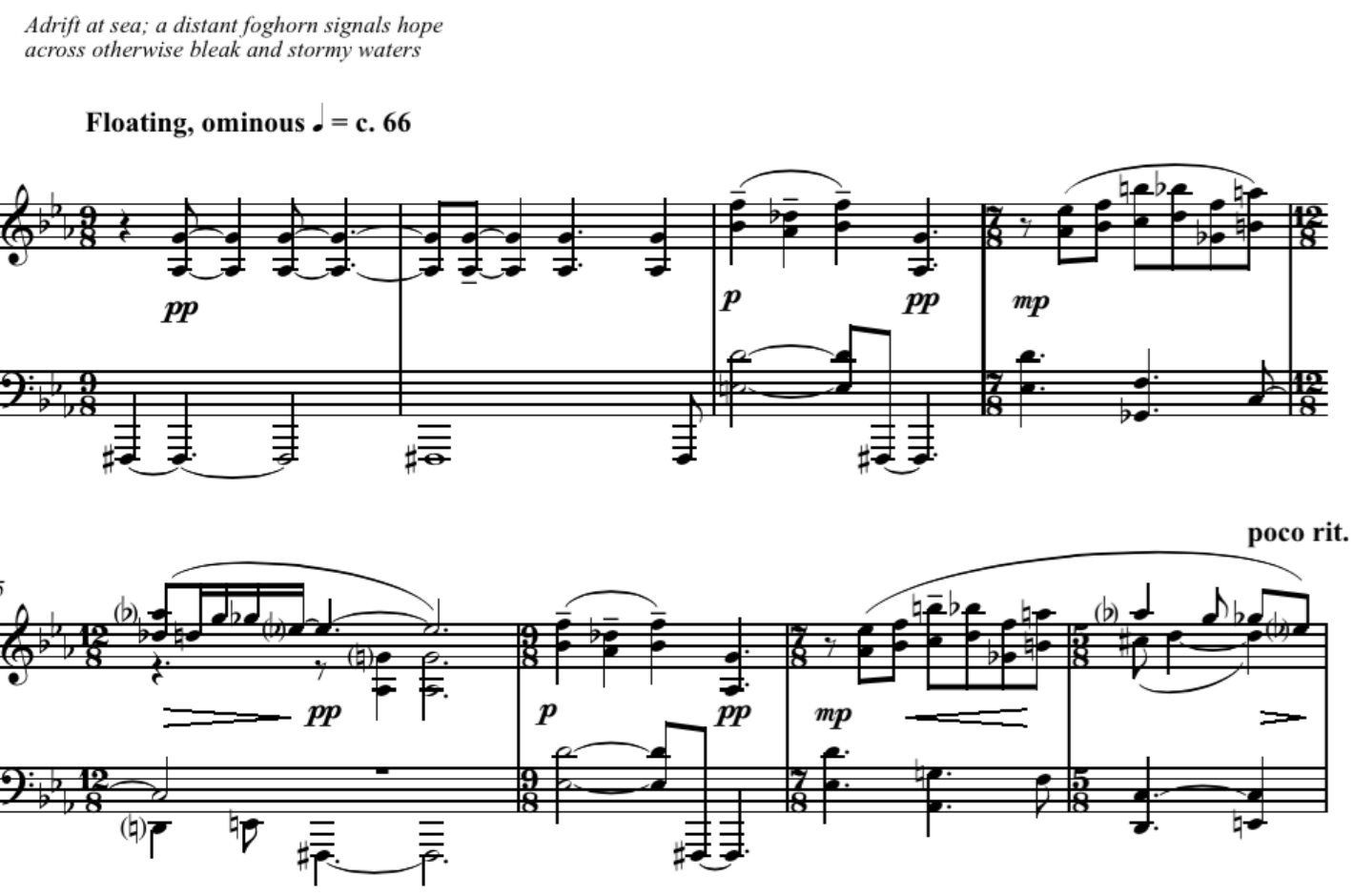

Musical Excerpt 4.4: Alex Shapiro, Piano Suite No. 1: The Resonance of Childhood, II. “On My Mother," mm. 1-8

Around the middle of the movement, beginning in m. 27 until the climax around mm. 49-50, the foghorn interval and the F-sharp bass both disappear. A fragment of the melody is presented in mm. 39-40 but with increasingly unsettled harmonies beneath it. 
Here, the music may figuratively represent the middle of the storm; just in time the foghorn interval returns in $\mathrm{m} .49$, both in the original register and an octave higher, as if crying out (see Excerpt 4.5).

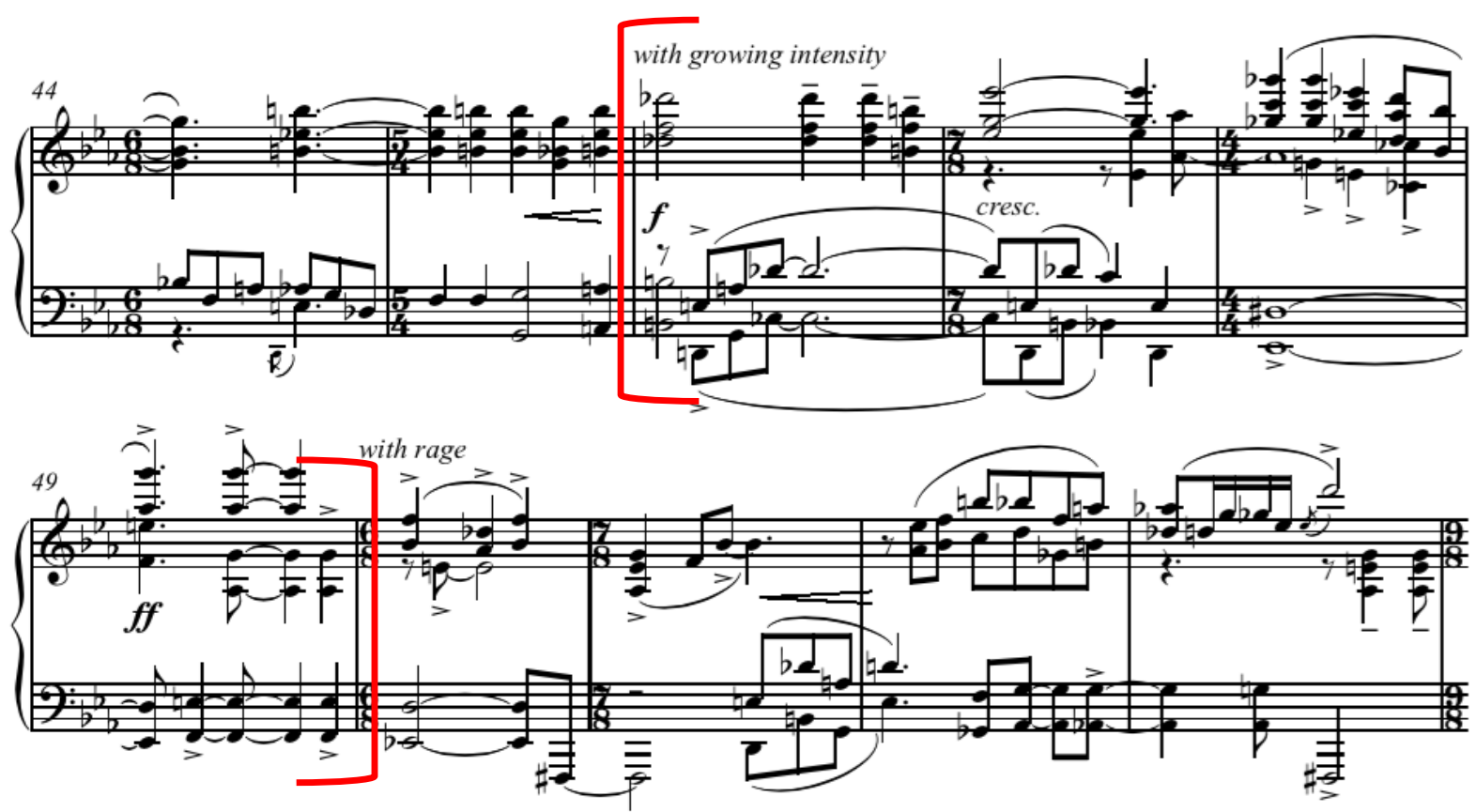

Musical Excerpt 4.5: Alex Shapiro, Piano Suite No. 1: The Resonance of Childhood, II. "On My Mother," mm. 46-49

This introduces the last entrance of the melody in $\mathrm{m}$. 50. The music ends with material similar to the middle section, as if the waves are still present but gentler. Near the end, we see the markings "calmer" and "quiet and dry,"75 as well as echoes of the opening three notes of the melody. The conclusive E-flat 7 chord (with an added $9^{\text {th }}$ and omitted 3rd, over a resolved bass note $\mathrm{G}$ ) gives the ending a subdued sense of resolution. (see Excerpt 4.6).

${ }^{75}$ Alex Shapiro, Piano Suite No. 1: The Resonance of Childhood (Activist Music (ASCAP), 1996) Note in Score, 6. 

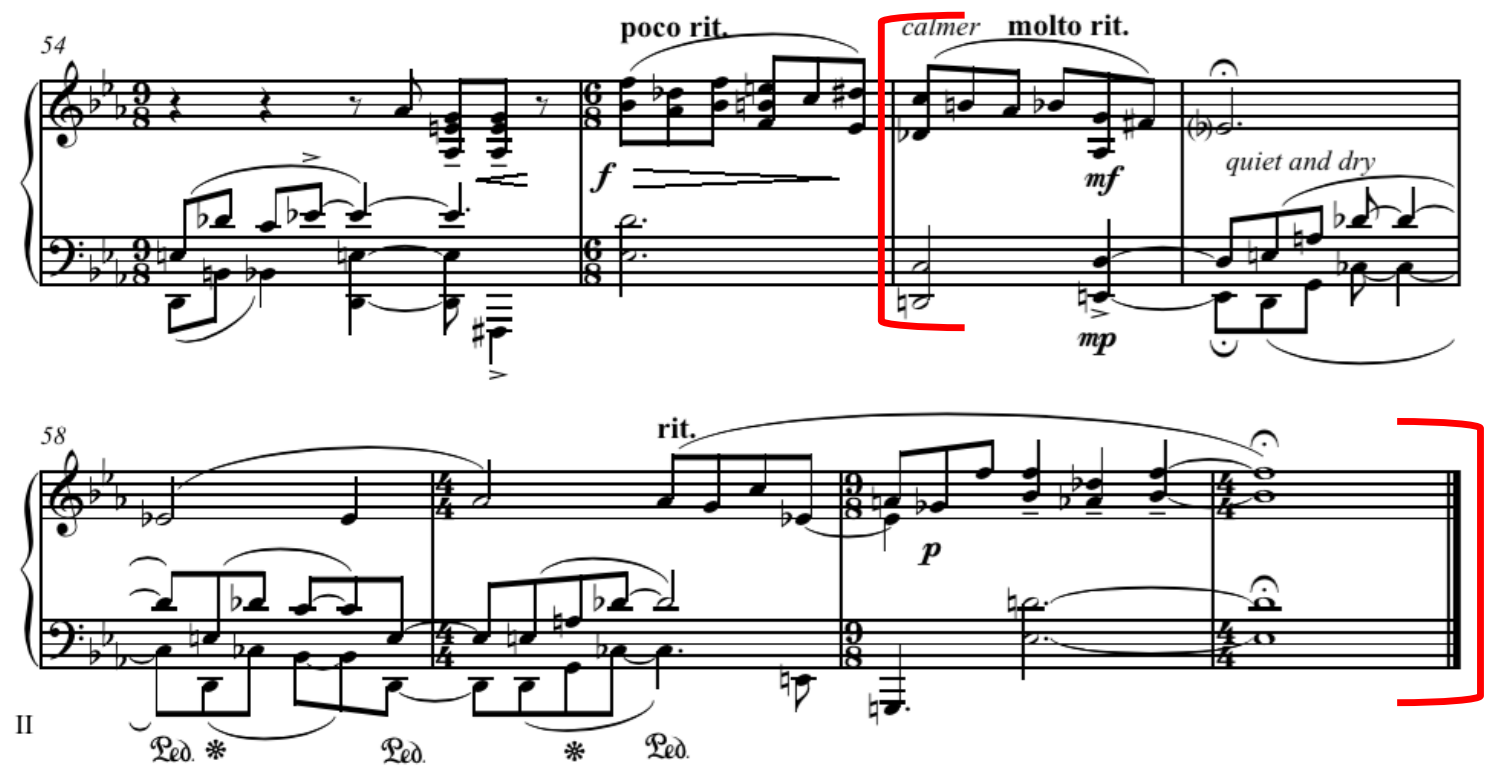

Musical Excerpt 4.6: Alex Shapiro, Piano Suite No. 1: The Resonance of Childhood, II. "On My Mother," mm. 56-61 


\section{III. "Quiet Child”}

As an appropriate contrast from the slower tempi of the first two movements, this movement is twice as fast, but marked "Lightly." Shapiro writes at the beginning of the movement, "curious and sensitive, the child seeks answers to lingering doubts."76 The movement opens with a two-measure motivic figure that represents the character of a curious child. While the eighth-note pulse remains consistent, the top number of the time signature changes in almost every measure, giving the music a natural speech-like rhythm (see Excerpt 4.7).

${ }^{76}$ Alex Shapiro, Piano Suite No. 1: The Resonance of Childhood (Activist Music (ASCAP), 1996) Note in Score, 8. 
curious and sensitive, the child seeks answers to lingering doubts
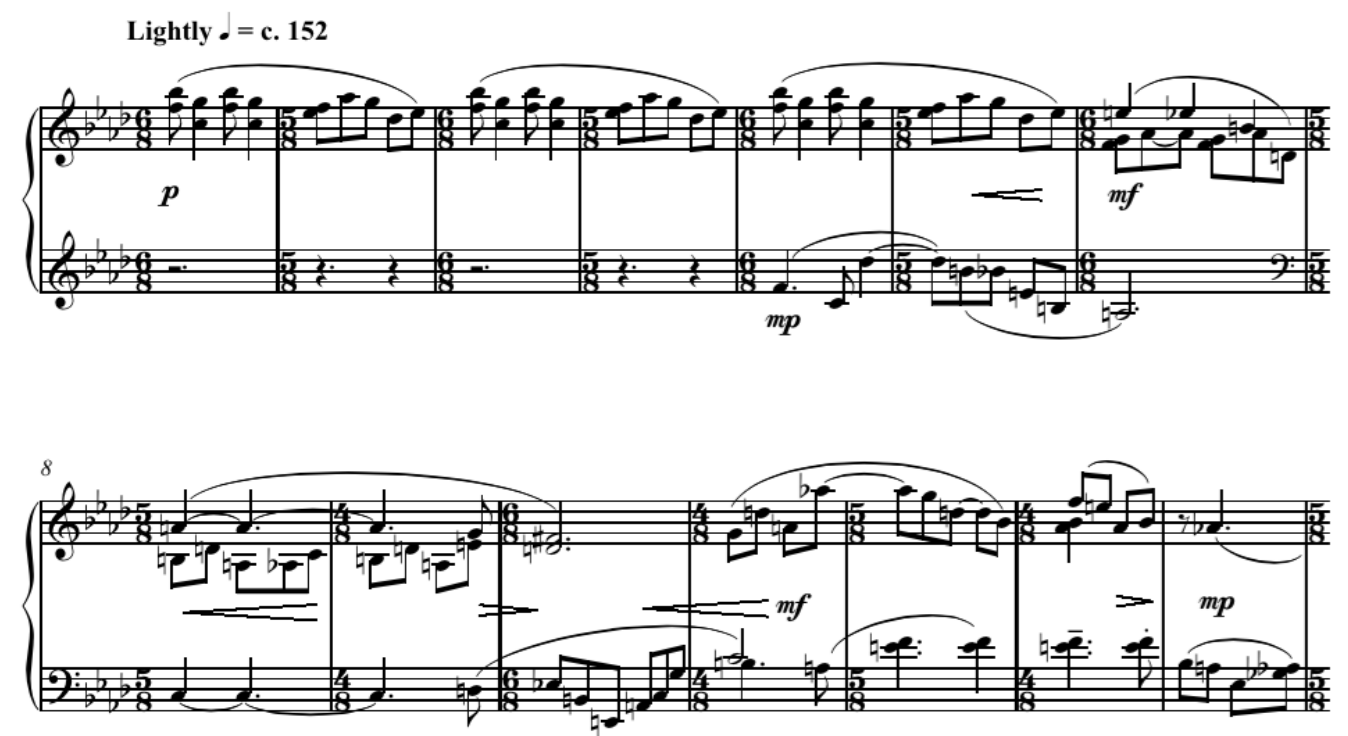

Musical Excerpt 4.7: Alex Shapiro, Piano Suite No. 1: The Resonance of Childhood, III. "Quiet Child," mm. 1-14

In addition to the main motivic material, other harmonically obscure motives occur throughout, such as the motives in mm. 5-7 and 7-10, which recur in mm. 20-22 and 22-25, respectively (see Excerpt 4.7 above). The music continues to weave in and out of the familiar opening motivic material, as well as with seemingly random harmonic figurations until m. 44, where it returns to the opening idea and becomes relatively less chromatic. At this point, the right hand imitates the opening motivic figure, but with a varied rhythmic pattern; the B-flat-to-G interval is reversed to G-to-B-flat (see Excerpt 4.8). The music closes the way it began, but ends on an inconclusive chord of G, E-flat and F.

Similar to Shapiro's favored use of pantonal and oftentimes very chromatic harmonies, such as seen in the previous movement, the "seemingly aimless" harmonies in 
"Quiet Child" are somewhat grounded by a tonal center of F minor. This is marked by a key signature with four flats, which is consistent throughout, along with the recurrence of $\mathrm{F}$ and its dominant $\mathrm{C}$ bass pitches throughout (see m. 5 and mm. 8-9 in Excerpt 4.7, as well as mm. 44-45 in Excerpt 4.8). One interesting element of this work is the interval of a fourth, F and B-flat, in the opening and recurring melodic figures. To the author's ears, this appears to be "upside down," suggesting the B-flat as a primary tonal pitch and F as its dominant. However, the motive is inverted in $\mathrm{m} .44$ and also transposed to the dominant $\mathrm{C}^{7}$ chord in $\mathrm{F}$ minor. This is interesting because the "upside down" version in m. 44 more clearly states the dominant-seventh chord of $\mathrm{F}$ minor, which perhaps satisfies the curious presentation of the opening melodic statement. Musically, this seems to fit the opening marking of the piece: "curious and sensitive, the child seeks answers to lingering doubts." $" 77$

77 Ibid. 

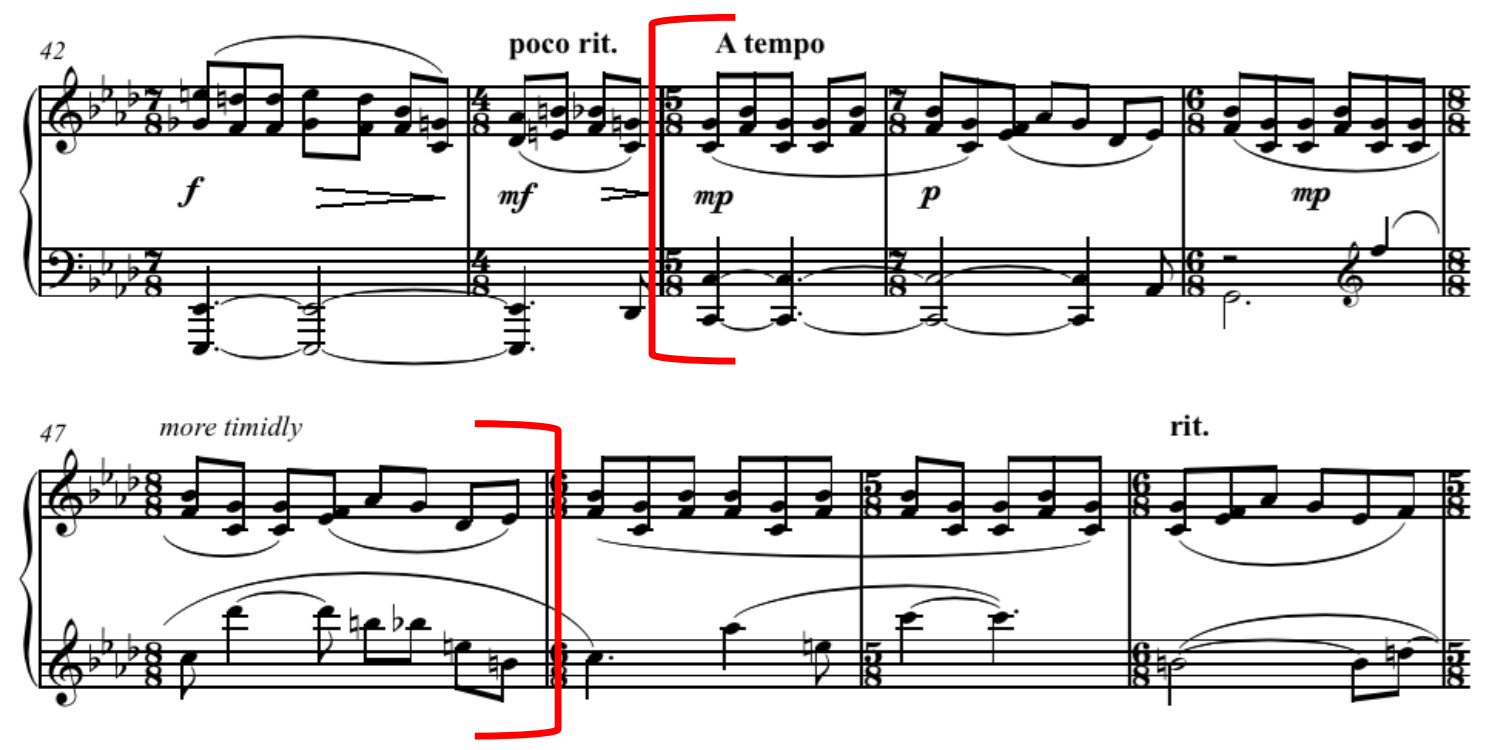

Musical Excerpt 4.8: Alex Shapiro, Piano Suite No. 1: The Resonance of Childhood, III. "Quiet Child," mm. 44-47 


\section{IV. "For My Father"}

The fourth movement of this set is one of Shapiro's more serious compositions, as it reflects the slow and painful loss of her own father to dementia. At the opening of the piece Shapiro writes, “A cruel descent: the loss of memory brings the evaporation of self." 78 The movement begins with a haunting right-hand melody over sustained perfect fifths in the left hand, followed by a dissonant seventh (see Excerpt 4.9). The music is marked "Pensive" and with 69 to the quarter note, "con rubato."79 The character of thoughtful wandering continues through varied repetition of the opening melody, followed by a new phrase in m. 16 that begins on a high G-flat marked "hauntingly." 80 Each consecutive phrase uses either repetition of melodic fragments or new but similar phrases that wander both harmonically and rhythmically.

${ }^{78}$ Alex Shapiro, Piano Suite No. 1: The Resonance of Childhood (Activist Music (ASCAP), 1996) Note in Score, 10.

${ }^{79}$ Ibid.

${ }^{80}$ Ibid. 

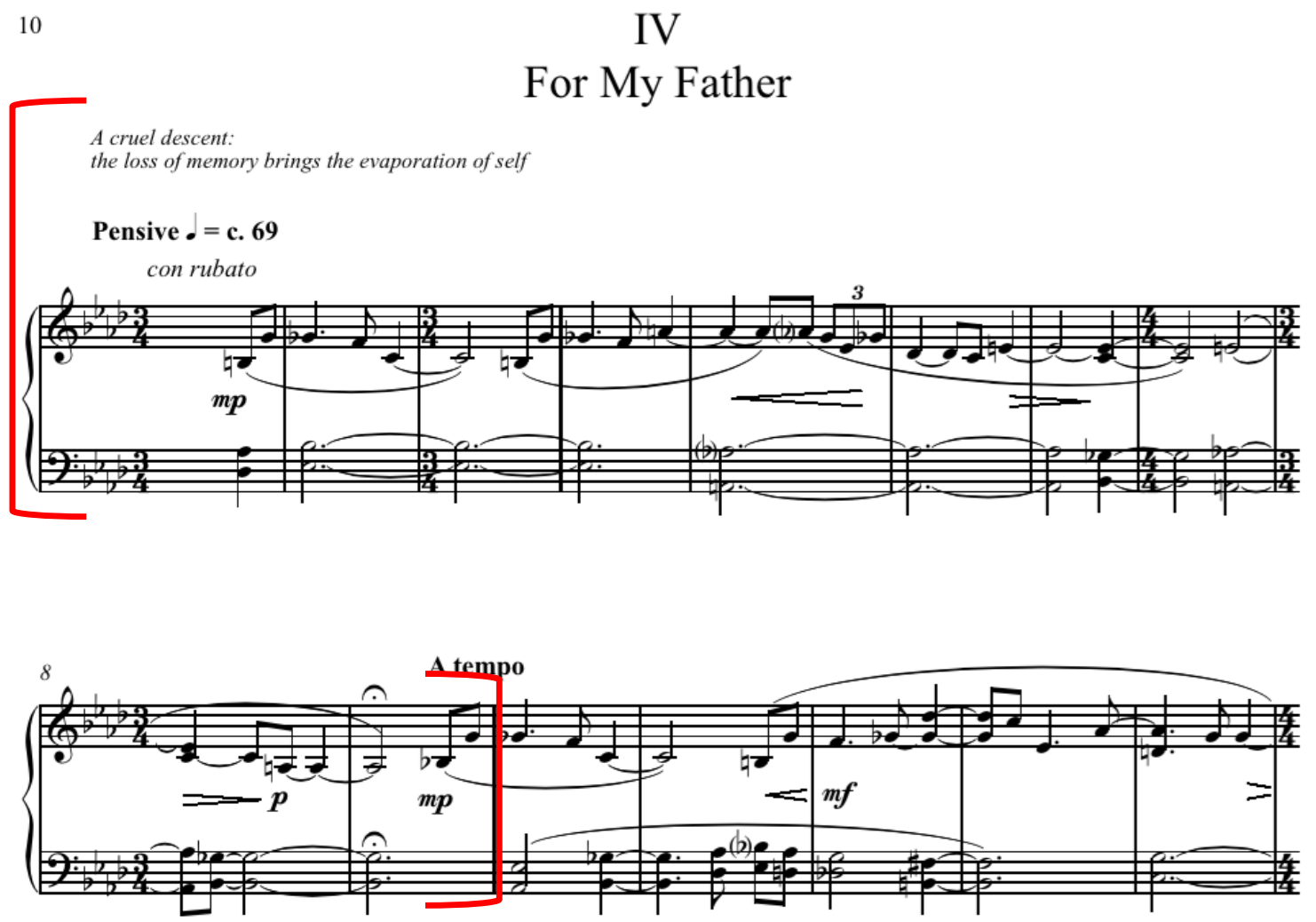

Musical Excerpt 4.9: Alex Shapiro, Piano Suite No. 1: The Resonance of Childhood, IV. "For My Father," mm. 1-9

Similar to the increasing loss of memory suffered by those with dementia, the music frequently slows down, as if searching, and then returns to the "a tempo." One example is the phrase ending in m. 34-35, where consonant, sustained open fifths and an unsettled right hand are followed by the climax in mm. 36-40 (see Excerpt 4.10). 


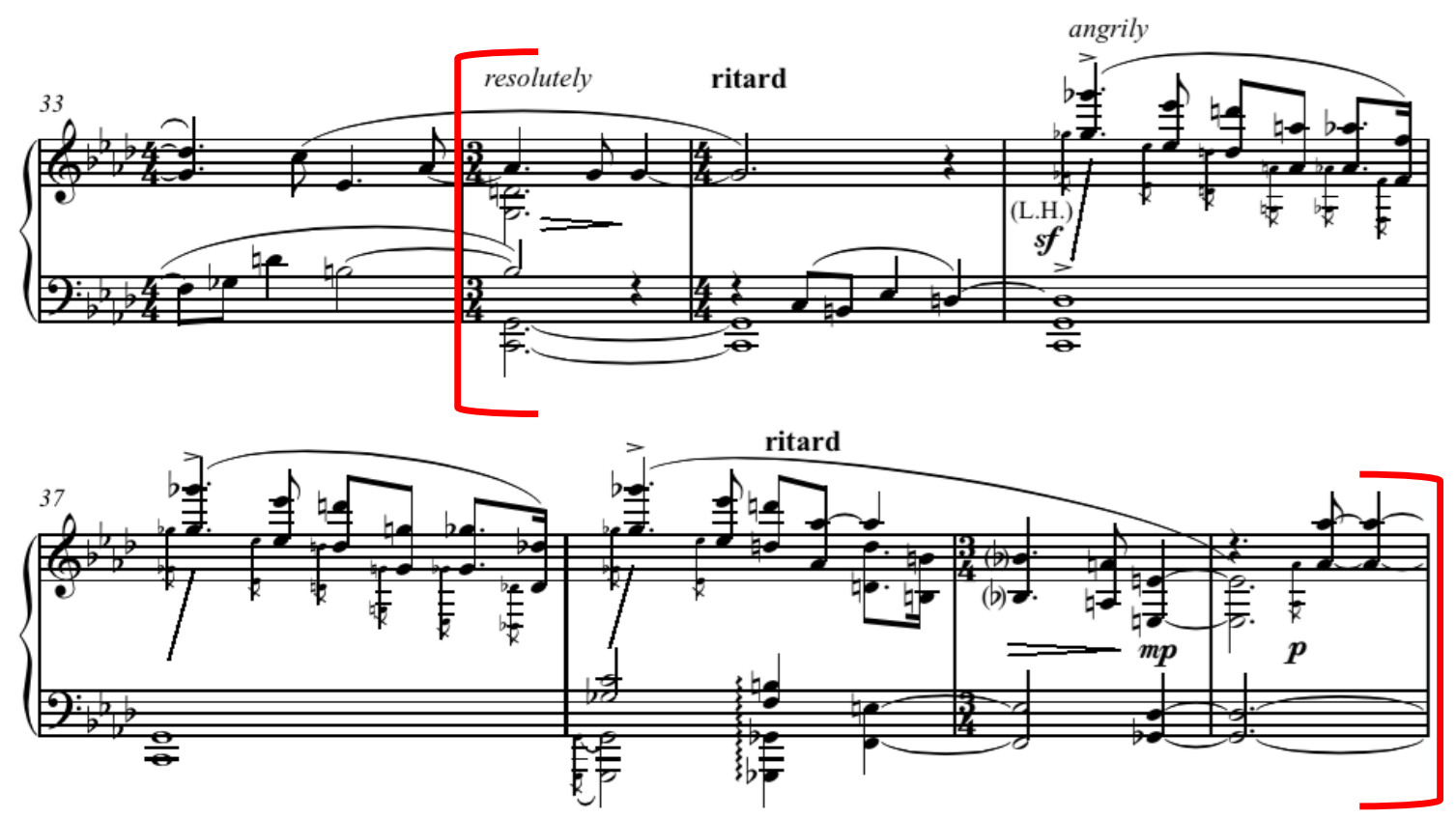

Musical Excerpt 4.10: Alex Shapiro, Piano Suite No. 1: The Resonance of Childhood, IV. "For My Father," mm. 34-40

Here the material in mm. 16-19 is presented an octave higher and in octaves. The music is marked "angrily" 81 and is followed by more repetition of previous material at the octave and with increasing intensity. Following the phrase in m. 51, marked "heavily," 82 represented by $\mathrm{F}$ and G-flat octave chords in the bass and an echo of melodic material in the right hand, the music finally closes in mm. 54-63, similar to the beginning with a resolute sustained perfect fifth on D-flat in the bass, and unresolved material above it (see Excerpt 4.11).

As initially stated in chapter two, Shapiro describes this work as "chromatic in an almost mid- $20^{\text {th }}$ century Germany way." $" 83$ Touchingly, the closing phrases are marked

\footnotetext{
${ }^{81}$ Alex Shapiro, Piano Suite No. 1: The Resonance of Childhood (Activist Music (ASCAP), 1996) Note in Score, 11.

${ }^{82}$ Alex Shapiro, Piano Suite No. 1: The Resonance of Childhood (Activist Music (ASCAP), 1996) Note in Score, 12.

${ }^{83}$ Alex Shapiro, email message to author, July 9, 2015.
} 
"floating: otherworldly" and "very quietly," 84 symbolizing the "evaporation of self" 85 noted at the beginning of the movement.
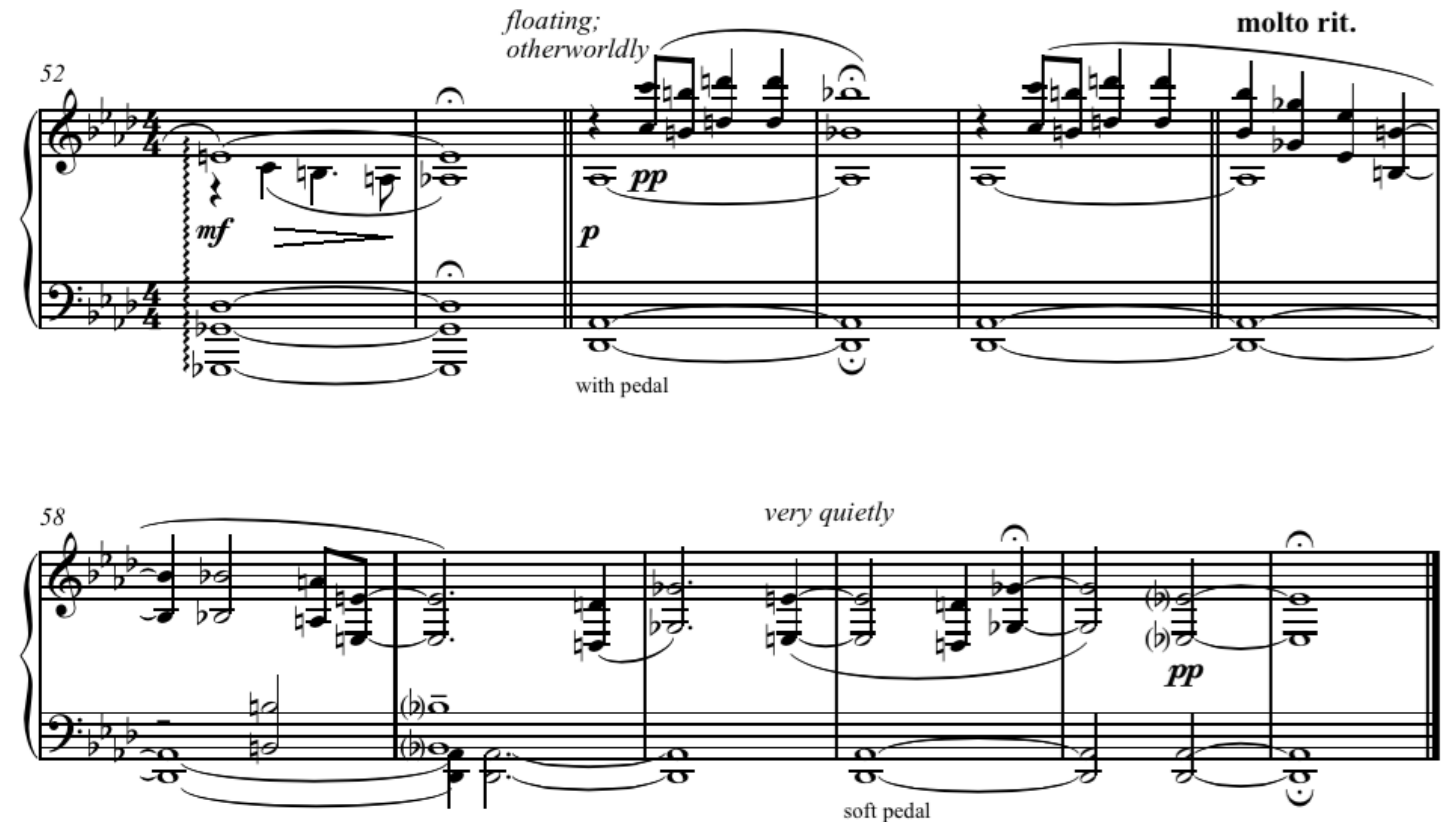

Musical Excerpt 4.11: Alex Shapiro, Piano Suite No. 1: The Resonance of Childhood, IV. "For My Father," mm. 54-63

${ }^{84}$ Alex Shapiro, Piano Suite No. 1: The Resonance of Childhood (Activist Music (ASCAP), 1996) Note in Score, 12.

${ }^{85}$ Alex Shapiro, Piano Suite No. 1: The Resonance of Childhood (Activist Music (ASCAP), 1996) Note in Score, 10. 


\section{V. "Older"}

The closing movement of the suite symbolizes the wisdom that only a life of experiences, both joyful and painful, can gain. At the beginning of this movement, Shapiro writes, "Time brings acceptance; hope remains persistent in the wake of pain." 86 The tempo marking reads "With hope" $" 87$ and the quarter note is marked 200.

Structurally, this movement is similar to the previous ones in the set in that the phrases seem to weave in and out aimlessly. It is at least as dissonant as the rest of the suite and makes use of modal and pentatonic harmonies. Repetition of melodic material with shifting harmonies conveys a sense of familiar, but ever-changing, territory to the listener. For example, compare mm. 1-4 with mm. 5-8 in Excerpt 4.12.

Pervasive use of parallel motion occurs throughout, often in contrast to more polyphonic textures. For example, the first section of music, from mm. 1-16, with the exception of parallel fifths in mm. 13 and 14, has a less orderly feel, marked by restless phrases with ties that cross over barlines and an imitative bass-clef line (see Excerpt 4.12). In contrast, the thicker texture of parallel octaves and chords in mm. 17, 22 and similar sections suggests resoluteness (see Excerpt 4.13).

\footnotetext{
${ }^{86}$ Alex Shapiro, Piano Suite No. 1: The Resonance of Childhood (Activist Music (ASCAP), 1996) Note in Score, 13.

${ }^{87}$ Ibid.
} 


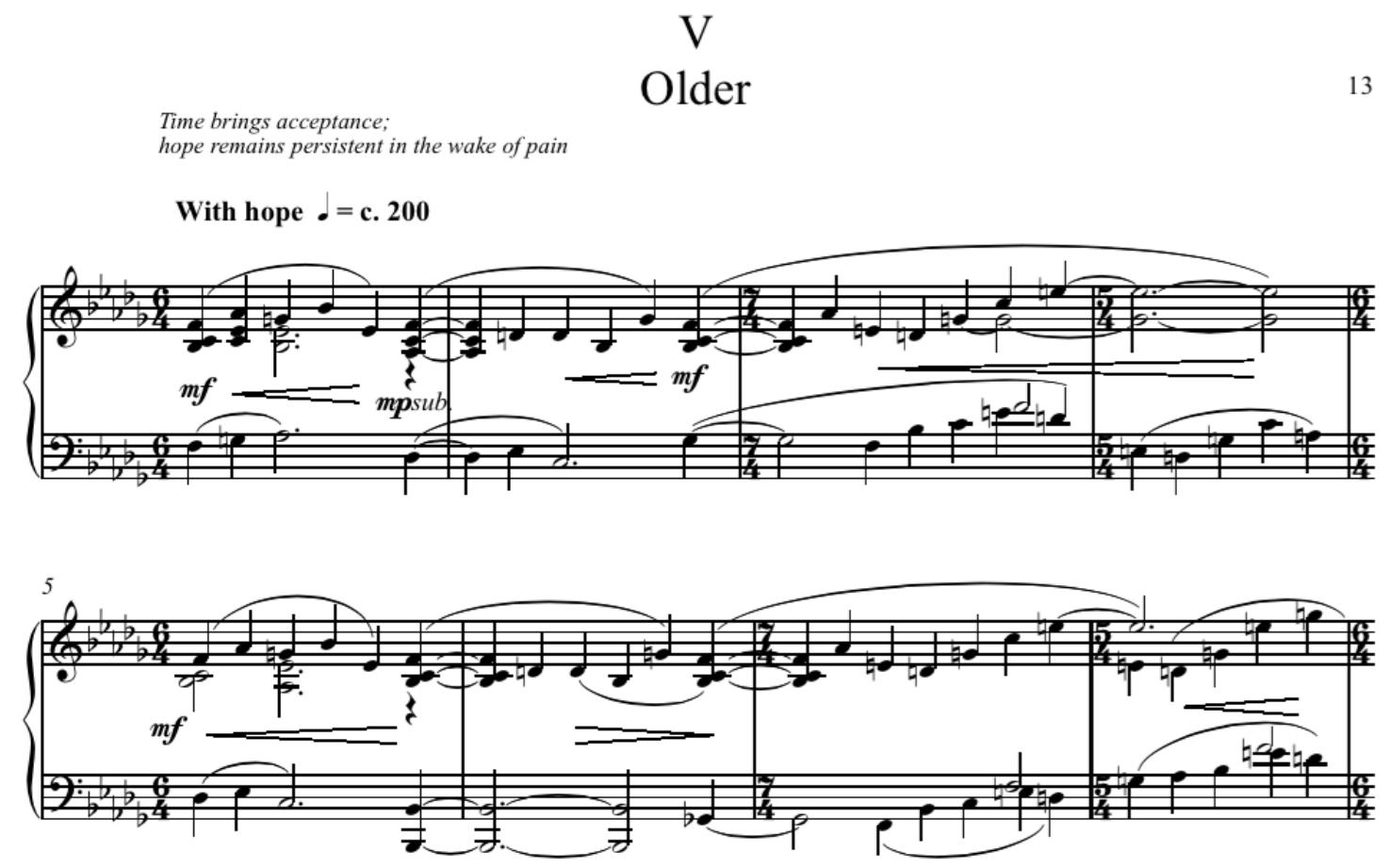

Musical Excerpt 4.12: Alex Shapiro, Piano Suite No. 1: The Resonance of Childhood, V. "Older," mm. 1-8

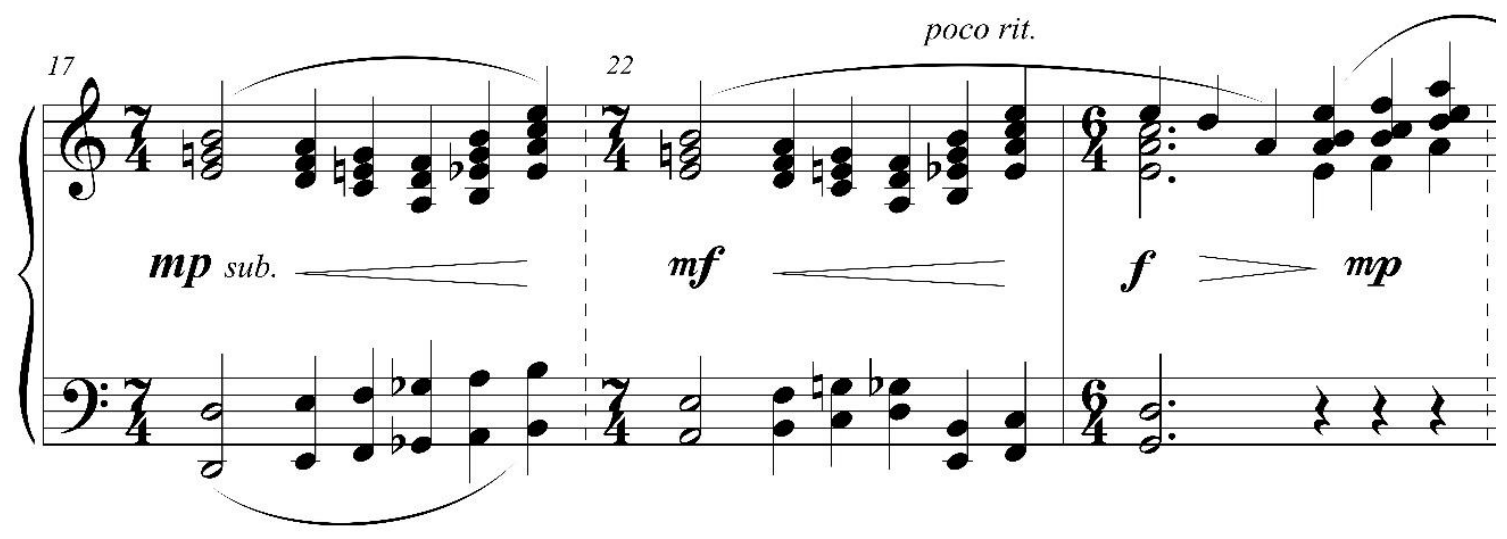

Musical Excerpt 4.13: Alex Shapiro, Piano Suite No. 1: The Resonance of Childhood, V. "Older,"

mm. 17, 22-23

The overall spirit of this movement is uplifting, especially in contrast to the previous movements. The combination of sonorous, chordal textures, often with pantonal harmonies, irregular meter, rising melodic contour and faster tempo, gives the movement 
an unresolved, yet refreshing, perspective. As seen in Excerpt 4.14, the movement ends with an ascending line that reaches a high register on the piano. The music is marked "rising up like a balloon." 88
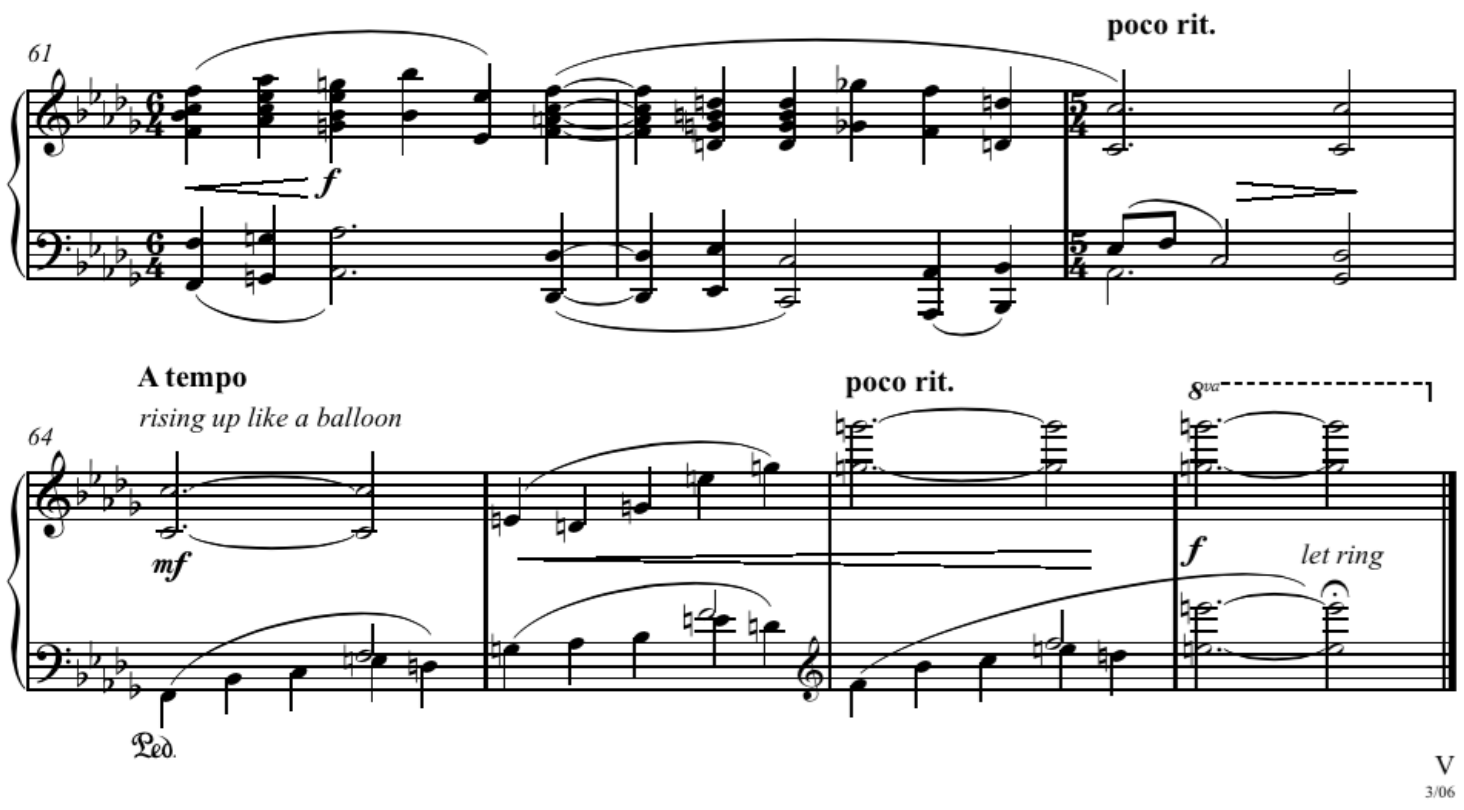

Musical Excerpt 4.14: Alex Shapiro, Piano Suite No. 1: The Resonance of Childhood, V. "Older," mm. 61-67

${ }^{88}$ Alex Shapiro, Piano Suite No. 1: The Resonance of Childhood (Activist Music (ASCAP), 1996) Note in Score, 15. 


\section{Conclusion}

Shapiro's Piano Suite No. 1: The Resonance of Childhood is a five-movement suite that was composed in 1996, following her period of film and television score writing in Hollywood. Each movement in the suite symbolizes a part of her own childhood, from memories of her parents to reflections of herself, ending with her own older and wiser reflection on the past. Each movement is short, highly chromatic, and held together by the development of motivic material, both harmonic and melodic. Most importantly, this music is highly symbolic. Whether it is the foghorn that signals unattainable hope lingering on a far-off horizon (in "On My Mother”) or the reflective, wandering phrases that represent her father's slip into dementia (in “For My Father”), each movement simply and profoundly reflects the composer's past. This suite is most appropriate for advanced pianists. While the music does not require virtuoso technique, it does contain some wide leaps, faster passages that must remain light (such as in "Quiet Child"), and challenges for harmonic and melodic voicing. It requires mature listening skills and a refined sense of timing and meter to appreciate and express the harmonic ambiguities as well as long phrases amidst frequently changing meter. 


\section{Chapter Five}

\section{Sonata for Piano}

\section{Introduction}

Sonata for Piano is a three-movement work that was composed in 1997 and revised in 1999. Although the work structurally follows the traditional classical sonata design, almost every other aspect of the music can be described as modern. For example, tonal centers are often fleeting and filled with thick chromaticism and extended harmonies such as jazz chords. The range is often disjunct and covers a wide range of the piano, while motivic and rhythmic patterns help to unify the work in the absence of traditional harmonic relationships. As the composer explains, "Throughout the piece, there's an emphasis on strong melodies and rhythms and a lush use of the keyboard." 89

The Sonata for Piano is one of the composer's most played pieces. According to Shapiro's website, the first version was premiered in May 1998, in Los Angeles, California, by Barbara Burgan. The revised version, with a new first movement, was premiered in April 1999, in Santa Clara, California by pianist Teresa McCollough, who has performed and recorded many of Shapiro's works. ${ }^{90}$ McCollough's CD New American Piano Music is the culmination of a project at the turn of the millennium in which she received three hundred original scores by American composers, and chose what she considered to be the seven best. Shapiro's sonata was among those seven. Since

89 "Sonata for Piano," Alex Shapiro; Composer, accessed February 19, 2015, http://www.alexshapiro.org/Sonatapg1s.html.

${ }^{90}$ Ibid. 
then, the work has received much attention, in part through international performances by McCollough, as well as by pianist Arlene Goter, who "toured extensively with the Sonata in 2002 and gave the piece its New York premiere at Carnegie Hall in April 2002."91

Shapiro's Sonata has received favorable reviews, such as this 2001 review by critic

Gordon Rumson, of Music \& Vision Magazine: “[Shapiro's] piano sonata is tough, tightly controlled motivically in the manner of mid-century American serious composers, but it is also musically tense and expressive. This is the genuine article." ${ }^{92}$

Date of Composition: 1997; revised 1999

Duration: 16:00 minutes

Description: Three-movement work: "Moderato," "Lento," "Andante," and "Scherzo." 21 pages, 8.5 " x 11 "

Publisher: Activist Music (ASCAP)

Score Location: alexshapiro.org < Works $<$ Piano $<$ Sonata for Piano

Score Formats Available: Print or Digital

Available Recordings:

1. $\mathrm{mp} 3$ audio clips for all three movements

2. Teresa McCollough's 2001 CD, New American Piano Music

3. Beatrix Klein, 2006 William Garrison Piano Competition CD ("Scherzo" only)

Location of Recordings:

1. alexshapiro.org $<$ Works $<$ Piano $<$ Sonata for Piano

2. alexshapiro.org $<$ Purchase $<$ Purchase CDs

Related Arrangements: N/A

91 "New American Piano Music: Sonata for Piano," Alex Shapiro; Composer, accessed February 19, 2015, http://www.alexshapiro.org/ASSonataCD1.html.

${ }^{92}$ Gordon Rumson, “Alex Shapiro," Music \& Vision, May 7, 2001, accessed March 6, 2015, http://www.mvdaily.com/articles/2001/05/cooman.htm. 


\section{Program Notes found on inside cover of score:}

"Sonata for Piano" is loosely written in the structural tradition of many classical sonatas. The first movement, Moderato, explores two themes that are first developed independently and ultimately are interwoven as two parts of a whole. A set of jazz harmonies are implied against more angular melodic lines. The second movement, Lento; Andante, takes the listener on an emotional, dreamlike journey leading to a passionate outburst, and the final movement, Scherzo, is just that - an impish romp that ends with a laugh. ${ }^{93}$

93 Alex Shapiro, Sonata for Piano (Activist Music (ASCAP), 1999) Program Note. 


\section{I. "Moderato"}

As Shapiro mentions in her program notes for the piece, the opening movement of her Sonata for Piano combines traditional elements such as the development of two themes, first independently and then together as one musical unit. Other than the loose structural resemblances to traditional sonata-allegro form, this work is modern in every sense. The opening phrase, mm. 1-3, serves as an introductory statement that is used at pivotal points throughout, each time slightly varied, sometimes with other motivic material woven into it. Excerpt 5.1 shows the opening phrase and theme one, which begins in m. 4 . 


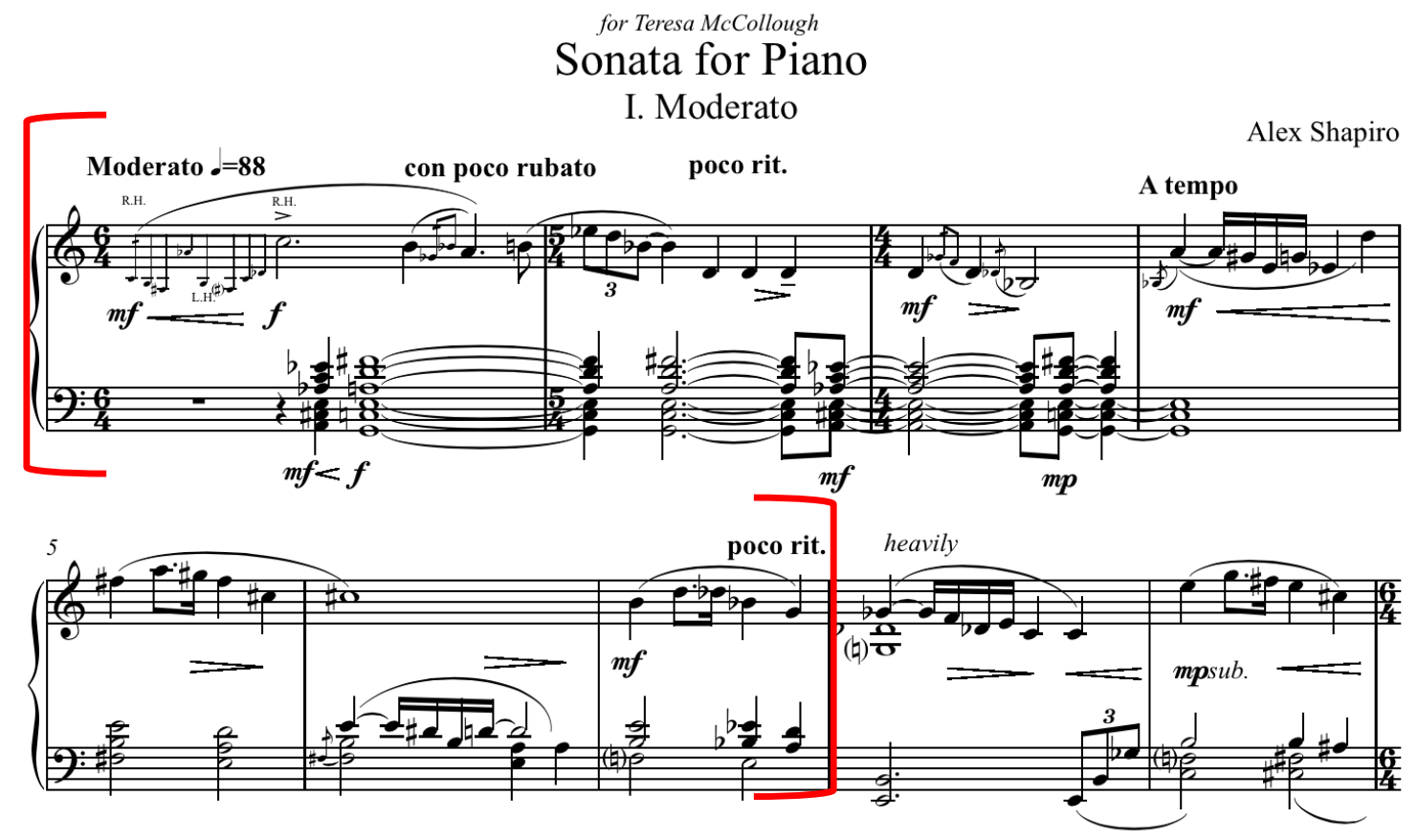

Musical Excerpt 5.1: Alex Shapiro, Sonata for Piano, I. "Moderato," mm. 1-7

A varied restatement of the opening material occurs in mm. 59-62, harmonically altered and including the frequently used motivic material of the first theme (see Excerpt 5.3). This is a significant moment in the music because it follows development of the second theme, seen below in Excerpt 5.2. Even after the presentation of this short, motivic second theme, Shapiro weaves elements of the first and second themes together, making the arrival in m. 59 more decisive than surprising. 

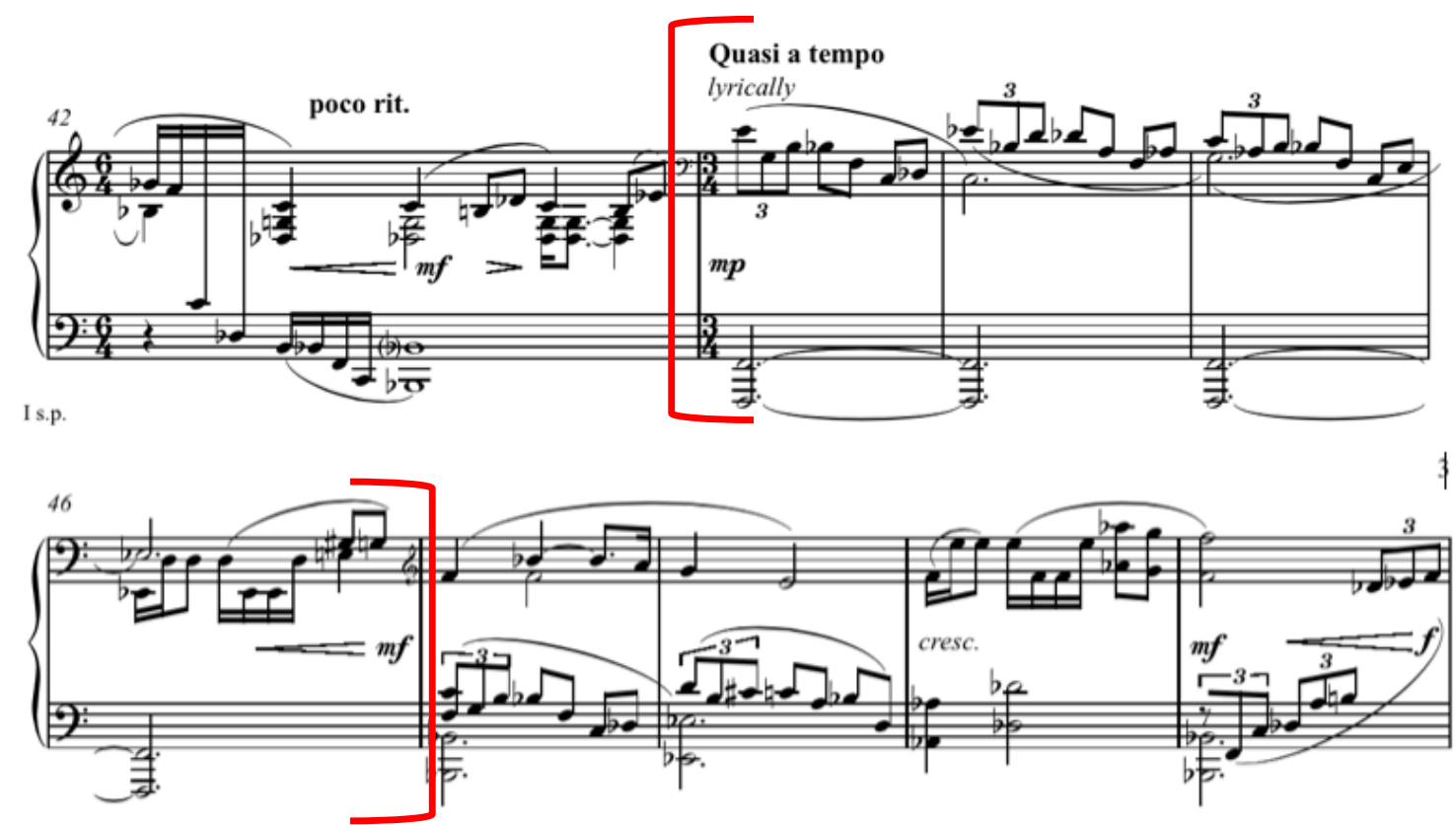

Musical Excerpt 5.2: Alex Shapiro, Sonata for Piano, I. "Moderato," mm. 43-46
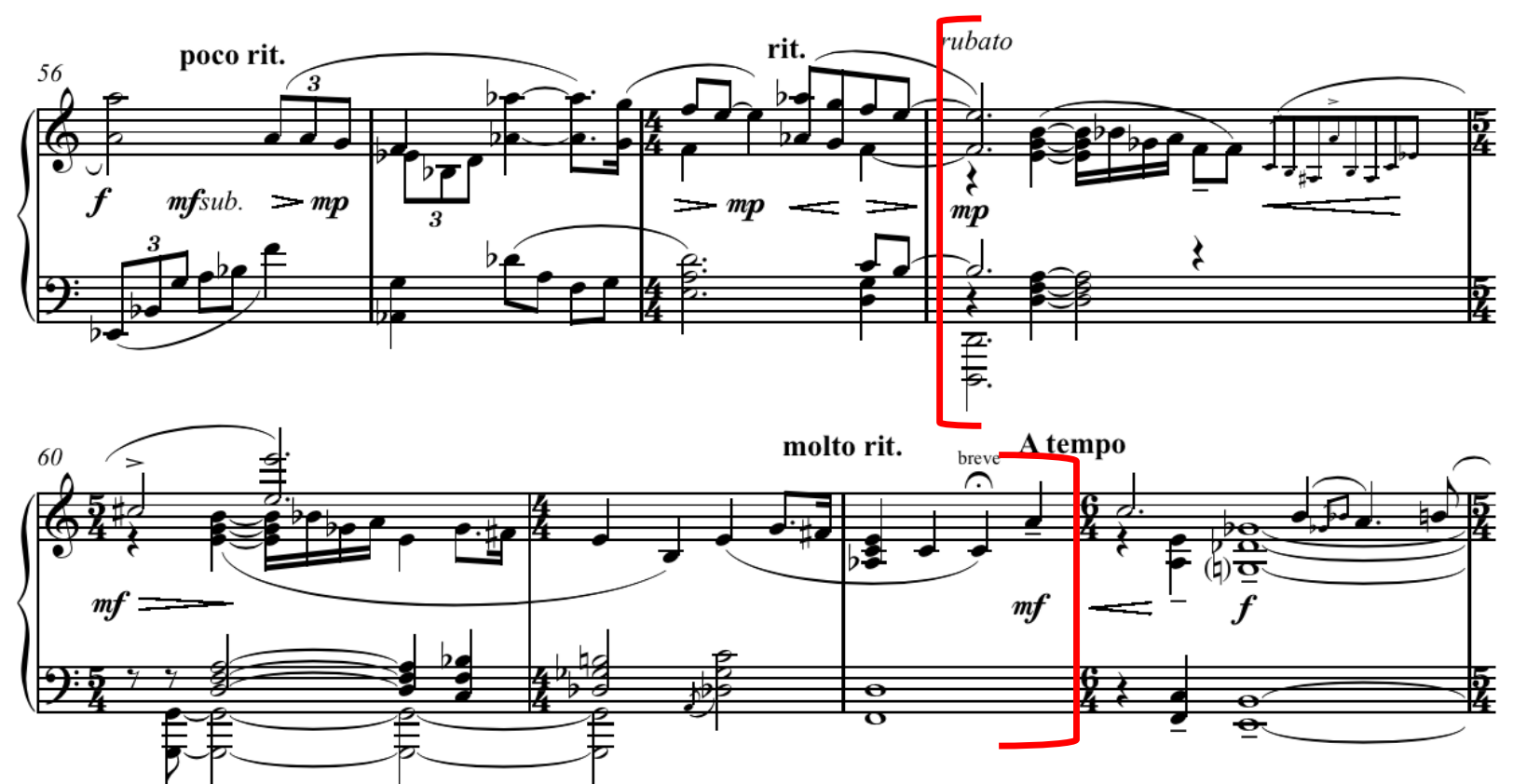

Musical Excerpt 5.3: Alex Shapiro, Sonata for Piano, I. "Moderato," mm. 59-62 
This material begins the transitional section from the end of theme two's development to the final section in m. 80, marked "Quasi a tempo," in which themes one and two are presented simultaneously (see Excerpt 5.4).
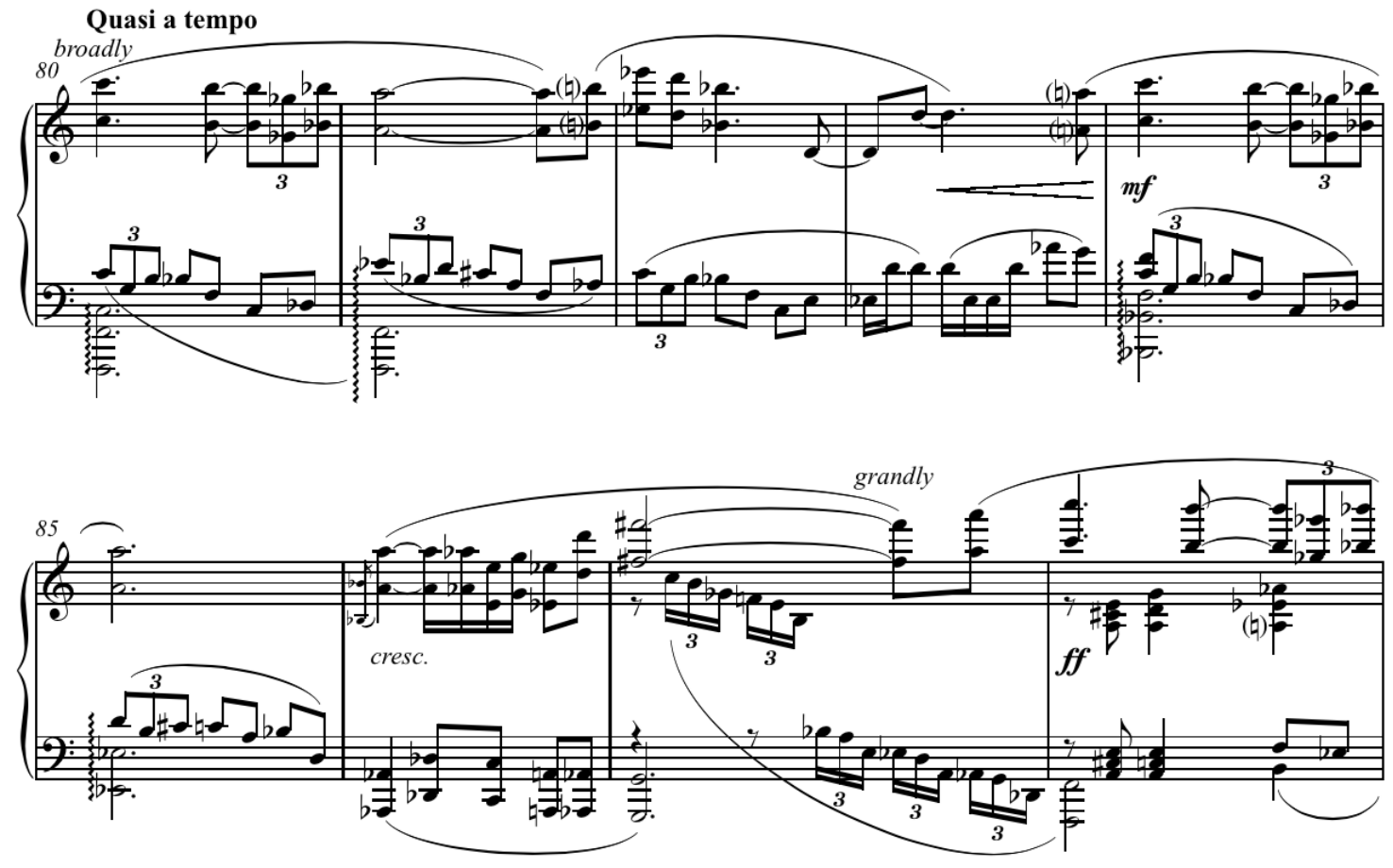

Musical Excerpt 5.4: Alex Shapiro, Sonata for Piano, I. "Moderato," mm. 80-88

The traditional listener's sense of harmony is jolted from the very beginning with bitonal chords in the left hand whose roots are only a half or whole step apart. The angular melodic line of the right hand is deeply chromatic and disjunct. There is no traditional sense of tonality in this movement; rather, as in many of her other works, the motivic material holds this movement together. In addition, there are some notable harmonic patterns such as the ascending dotted-half notes in the bass of mm. 43-49 (see Excerpt 5.2), which move by intervals of perfect fourths. Although there is no tonal 
center in this section of second-theme material, it is comparatively more grounded harmonically than the constant harmonic unrest of the first-theme area. This harmonic pattern recurs in $\mathrm{mm} .80-86$ and briefly in $\mathrm{mm} .92-93$, in the "Quasi a tempo" section which fuses elements of both themes into one.

It is interesting to observe how Shapiro distinguishes the two themes from each other. Theme one, mm. 4-5, marked $m f$, resides in the treble register, and rhythmically consists of quarter and sixteenth notes. In contrast, theme two, first presented in m. 43 , occurs in the bass register, is marked $m p$, and consists of a distinctive triplet rhythm. These two themes characteristically follow a common Classical tradition of making the second theme softer, more lyrical, and sometimes even slower, than the first. Here we see Shapiro's intentional reference to this tradition as the music is also marked "Quasi a tempo" and "lyrically." 94

This movement displays some of Shapiro's most serious writing. Her use of jazz, chromatically-altered, and extended chordal harmonies, combined with her skillful development of motivic material indicates her ability to write successfully in large forms without losing her own musical voice. This movement is most appropriate for the advanced pianist. While not as challenging technically as the final movement, "Scherzo," it poses many difficulties which include: controlling a wide range of the piano; executing rapid octave passages, especially in the climactic final section, from $\mathrm{m} .80$ to the end; solving complex opposing rhythms; executing rapid ornamentations; and understanding the various presentations of motivic material as well as balancing them in performance.

\footnotetext{
${ }^{94}$ Alex Shapiro, Sonata for Piano (Activist Music (ASCAP), 1999) Note in Score, 2.
} 


\section{II. "Lento; Andante"}

The second movement of Shapiro's Sonata for Piano continues in the Classical tradition with a slower, more meditative middle movement. However, it only begins slowly (see Excerpt 5.5) before quickly spiraling into an intense work of perpetual motion.

\section{Lento; Andante}

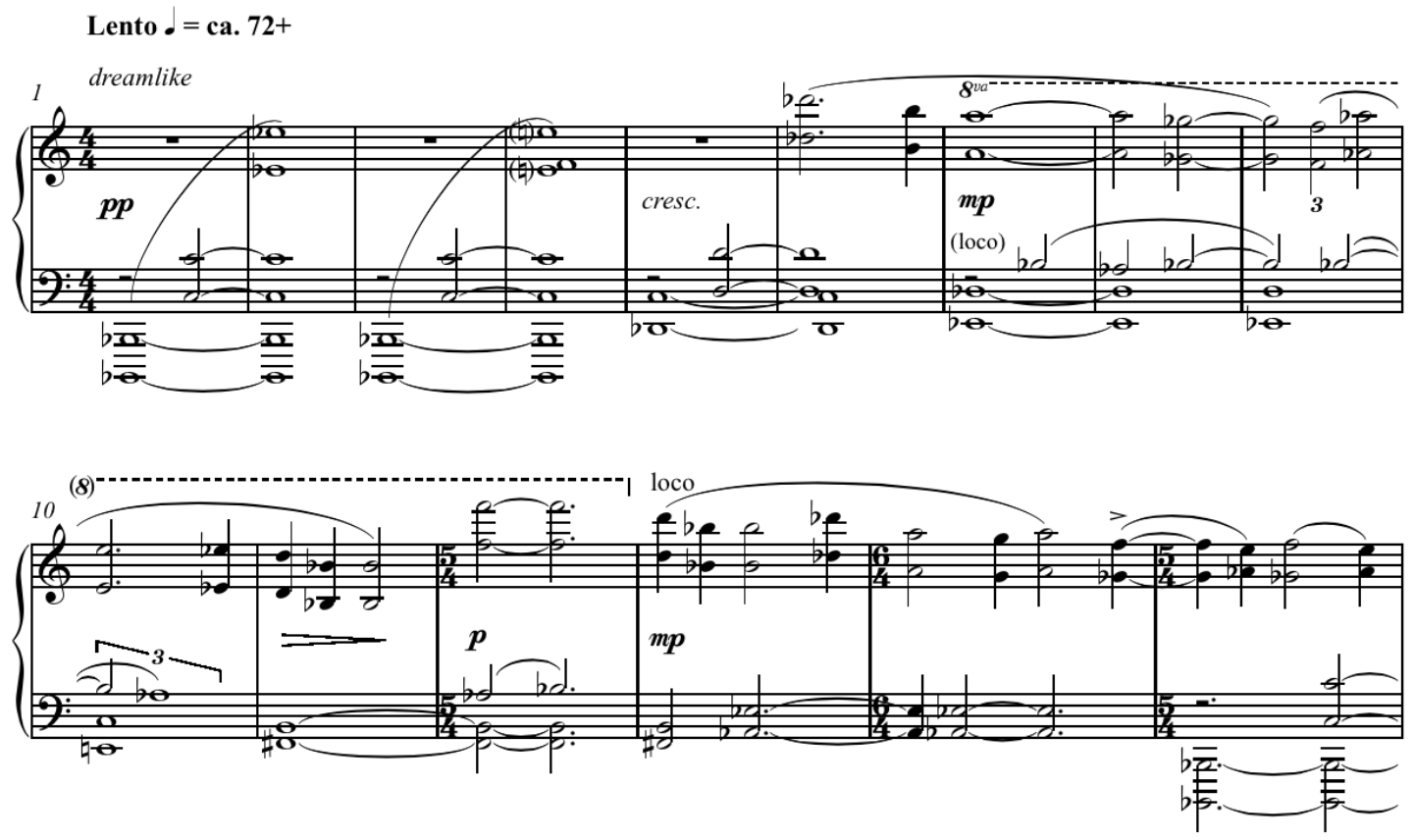

Musical Excerpt 5.5: Alex Shapiro, Sonata for Piano, II. "Lento; Andante," mm. 1-15

This movement consists of three main layers: characteristically long and restless melodic lines, sustained bass pedal tones, and a teetering, three-note motivic idea that travels between the middle and high ranges of the piano. It is by far the longest movement in the sonata and, as Shapiro describes it, "an emotional, dreamlike journey 
leading to a passionate outburst." 95 The music conveys a timeless, improvisatory feeling and holds the listener's attention in several ways, among which are the sense of perpetual motion and the restless melodic and motivic material throughout. In $\mathrm{m} .32$, the tempo increases significantly (quarter note $=200$ ) and Shapiro manipulates her three-note motivic idea to build intensity: It is first presented as a half-step motion in the soprano voice in $\mathrm{mm} .15-16$ and then as minor thirds in $\mathrm{mm} .27-28$; this is followed by a presentation an octave higher in mm. 36-40 and becomes more ambiguous as the movement develops. Shapiro achieves ambiguity through means of various intervallic presentations of the motive, as well as changes in rhythm and voicing — it serves as both melodic and harmonic material, sometimes simultaneously (see Excerpt 5.6).

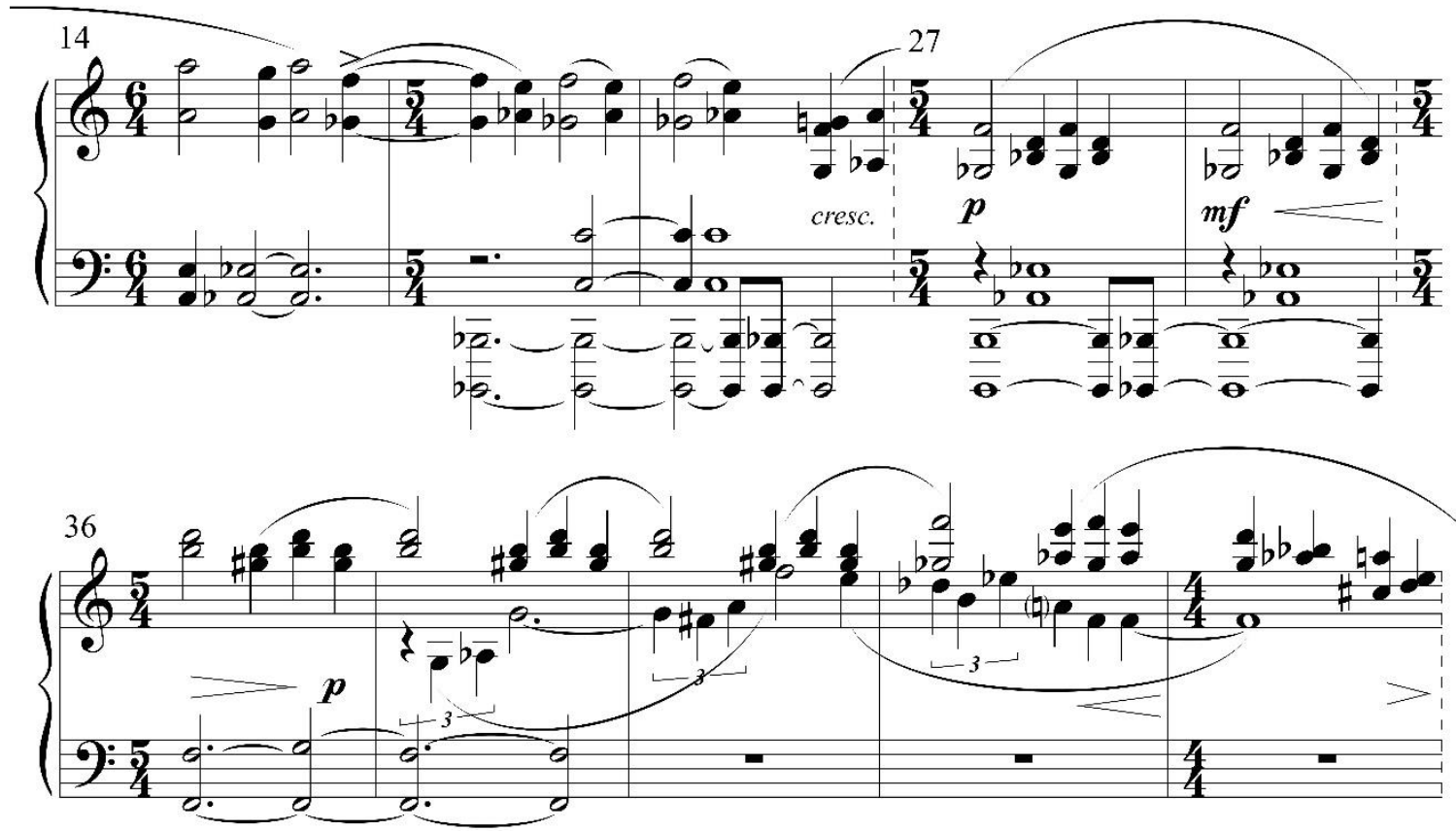

Musical Excerpt 5.6: Alex Shapiro, Sonata for Piano, II. "Lento; Andante,” mm. 14-16, 27-28, 36-40

${ }^{95}$ Alex Shapiro, Sonata for Piano (Activist Music (ASCAP), 1999) Program Note. 
In m. 53 Shapiro writes "lilting," 96 adding to the playful character of this motif. The music then climaxes by means of thicker chords, wider ranges on the piano, and increasingly disjunct melodic intervals. Shapiro also creates a sense of forward motion and intense playfulness by passing the motif between the left and right hands, such as in mm. 82, 90 and 98 (see Excerpt 5.7).

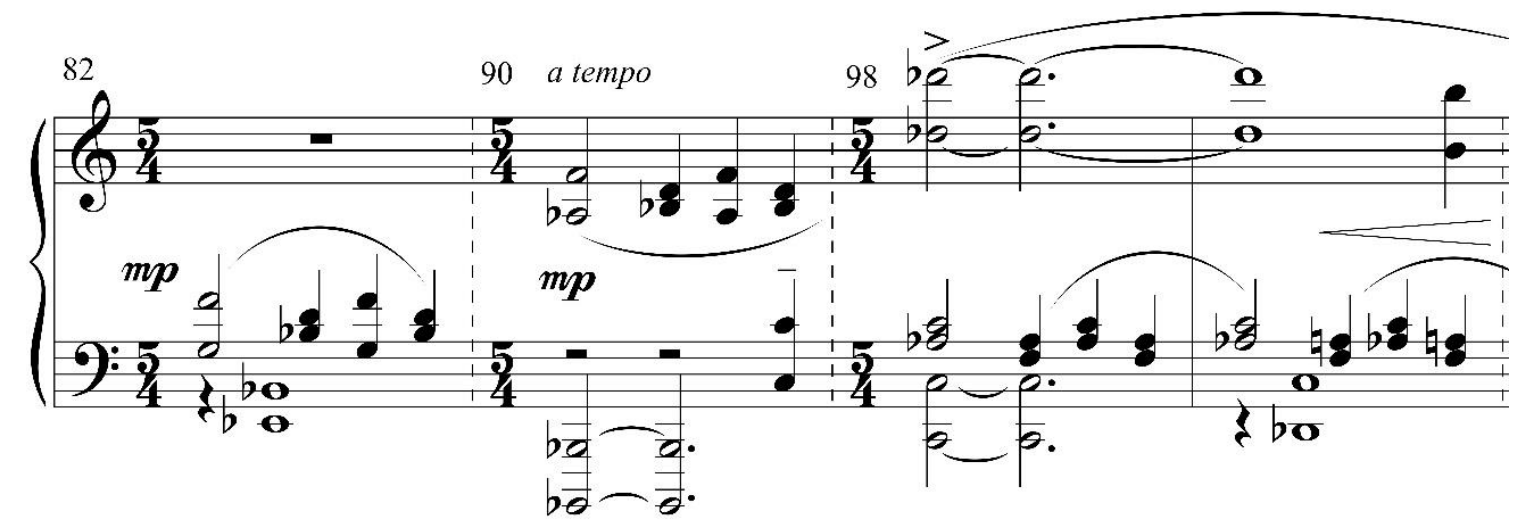

Musical Excerpt 5.7: Alex Shapiro, Sonata for Piano, II. "Lento; Andante," mm. 82, 90, 98-99

Another significant element of this movement is the use of a wide range on the piano. For example, in mm. 113-123, long, sonorous melodic lines in the high register contrast with octave pedal tones in the low-bass register (see Excerpt 5.8).

${ }^{96}$ Alex Shapiro, Sonata for Piano (Activist Music (ASCAP), 1999) Note in Score, 8. 

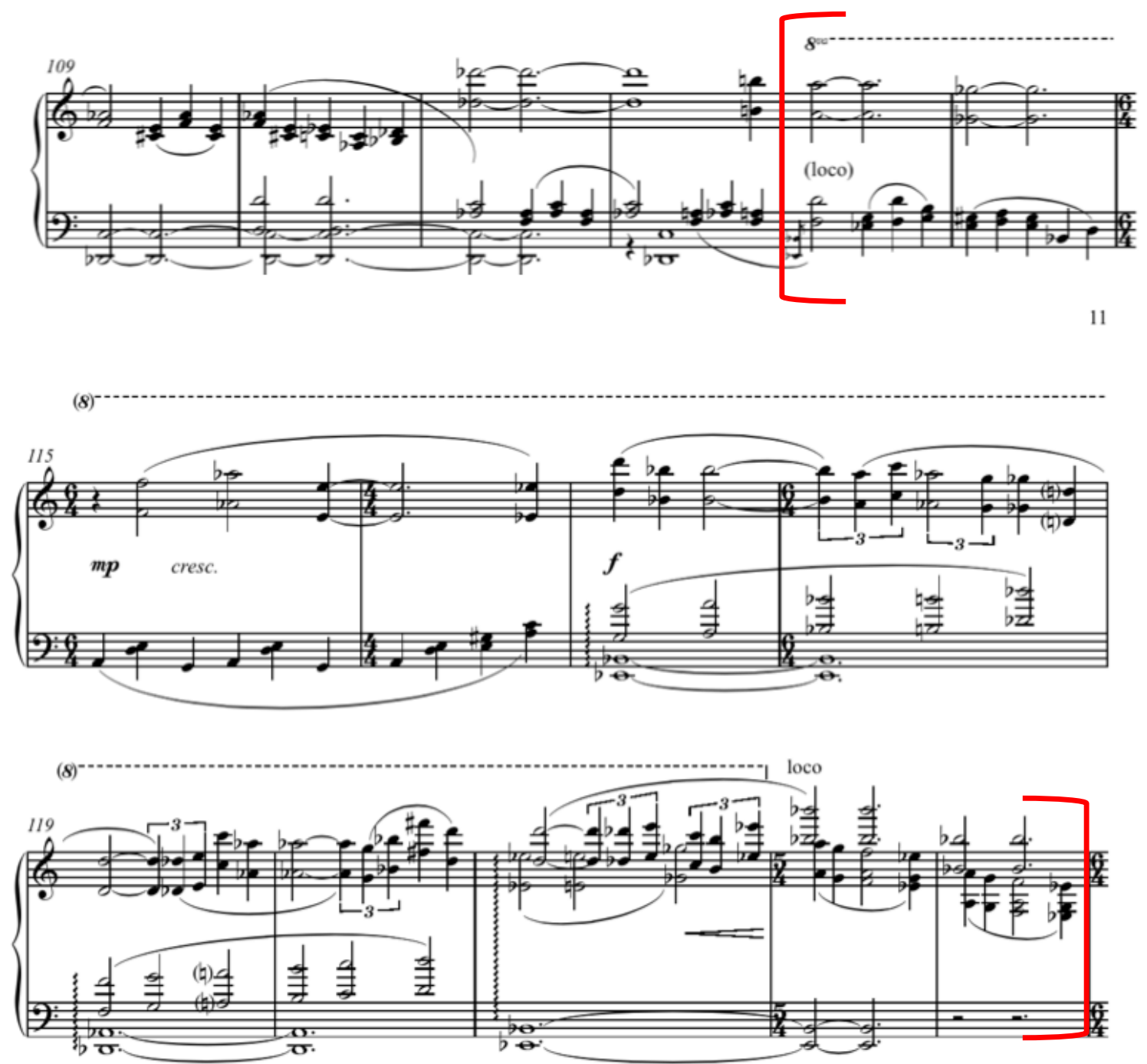

Musical Excerpt 5.8: Alex Shapiro, Sonata for Piano, II. "Lento; Andante," mm. 113-123

As in several of her other works, Shapiro sets the main material in octaves in climactic sections, as is seen in this example, followed by increasingly thick textures. Another example in mm. 124-132 consists of melodic octaves, overall thicker textures and a wide range between the left and right hands. Lastly, the movement makes use of pervasive triplet rhythms such as in mm. 118-145 (for example, see Excerpt 5.9). 


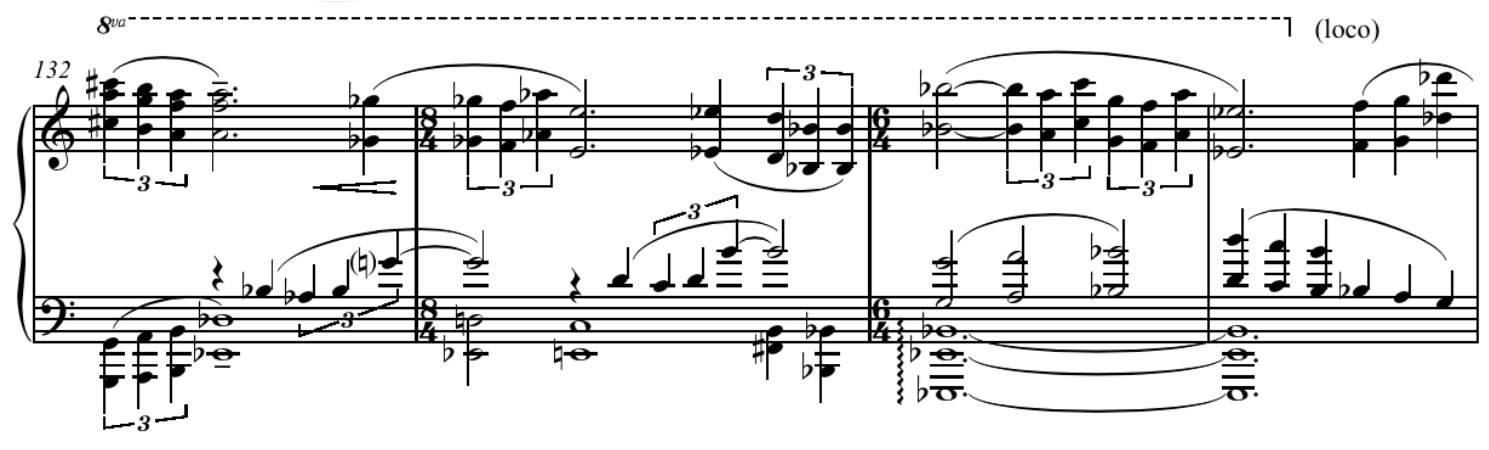

Musical Excerpt 5.9: Alex Shapiro, Sonata for Piano, II. "Lento; Andante," mm. 132-135

Overall, this movement is highly chromatic, motivically saturated, and restless. Tonal centers are achieved by frequent pedal tones on several pitches. B-flat pedal tones occur in the opening 29 measures and perhaps more frequently than any of the other pitches. Other important pedal notes include D, F, D-flat, E-flat and finally E, which remains for the last 14 measures of the movement.

The atmosphere is spacious and grandiose, especially when compared to the more tightly knit form of movement one and the dense, chaotic texture of movement three. In terms of rhythm, texture, range, balance and phrasing, the level of difficulty for performers is similar to that of movement one. 


\section{III. "Scherzo"}

The final movement of Shapiro's Sonata for Piano is very possibly her most challenging, virtuosic work for the performer. It is comparable in difficulty to her 2011 work Spark and to the sixth movement, entitled "Touch It," from her recent piano suite, Arcana (2014). The duration of this finale is under two minutes and can satisfy any pianist's craving for an exciting, playful work of perpetual motion. The movement begins with a rapid, repetitive sixteenth-note triadic figure in the treble clef, played with both hands overlapping. The left hand takes over the melody, often crossing over the right hand, hopping playfully between the treble and bass clef registers (see Excerpt 5.10).
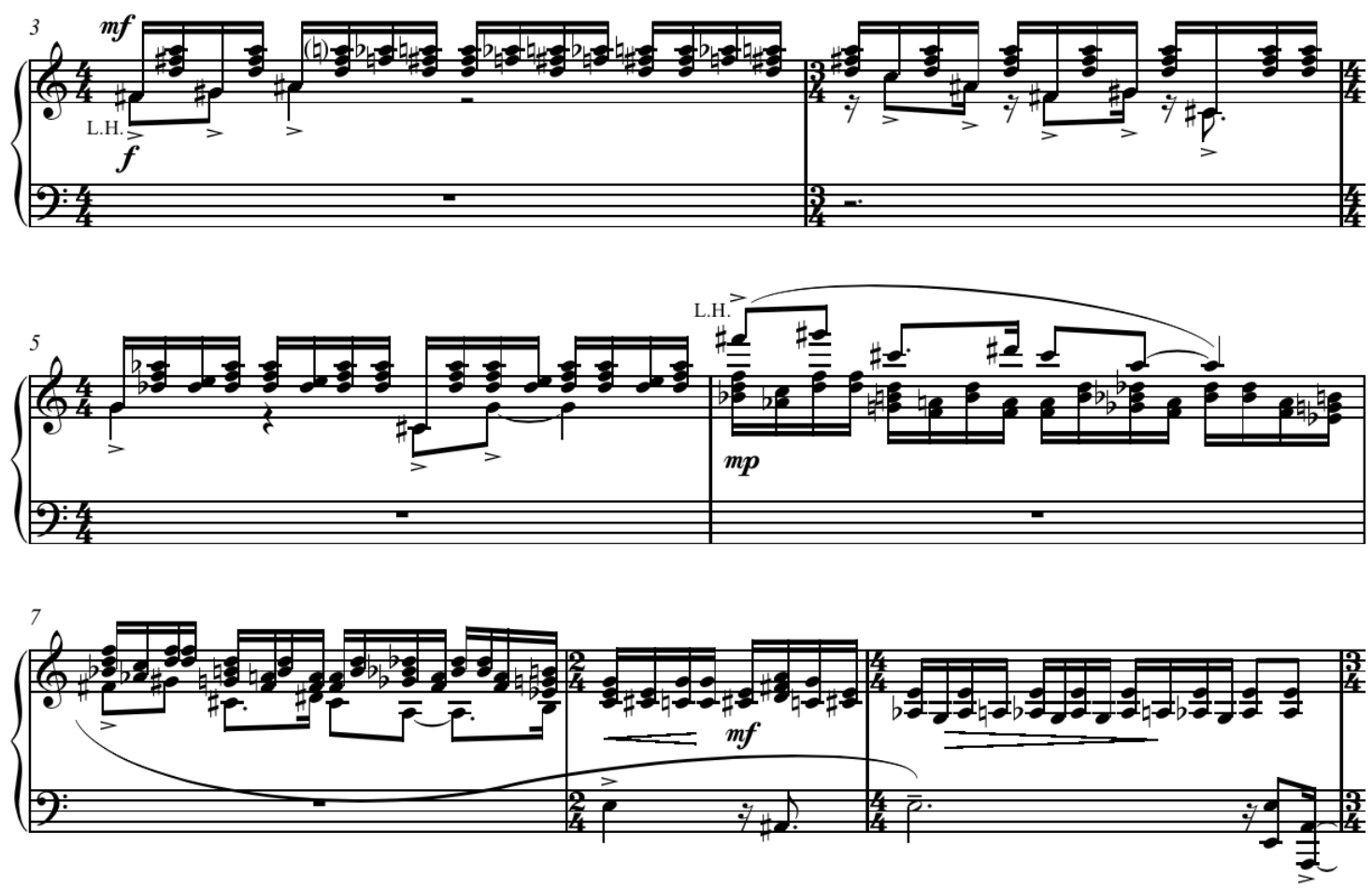

Musical Excerpt 5.10: Alex Shapiro, Sonata for Piano, III. "Scherzo," mm. 3-9 
In $\mathrm{m} .18$ the music makes an exciting, three-and-a-half-octave chromatic plummet into the bass register. Here the right hand continues with the exhausting triadic sixteenth figures while the left hand again presents the melody above and below the range of the right hand. The melody is detached and heavily accented, bouncing around as if being chased. In addition, the triadic figures are persistently and heavily accented on syncopated beats (see Excerpt 5.11).
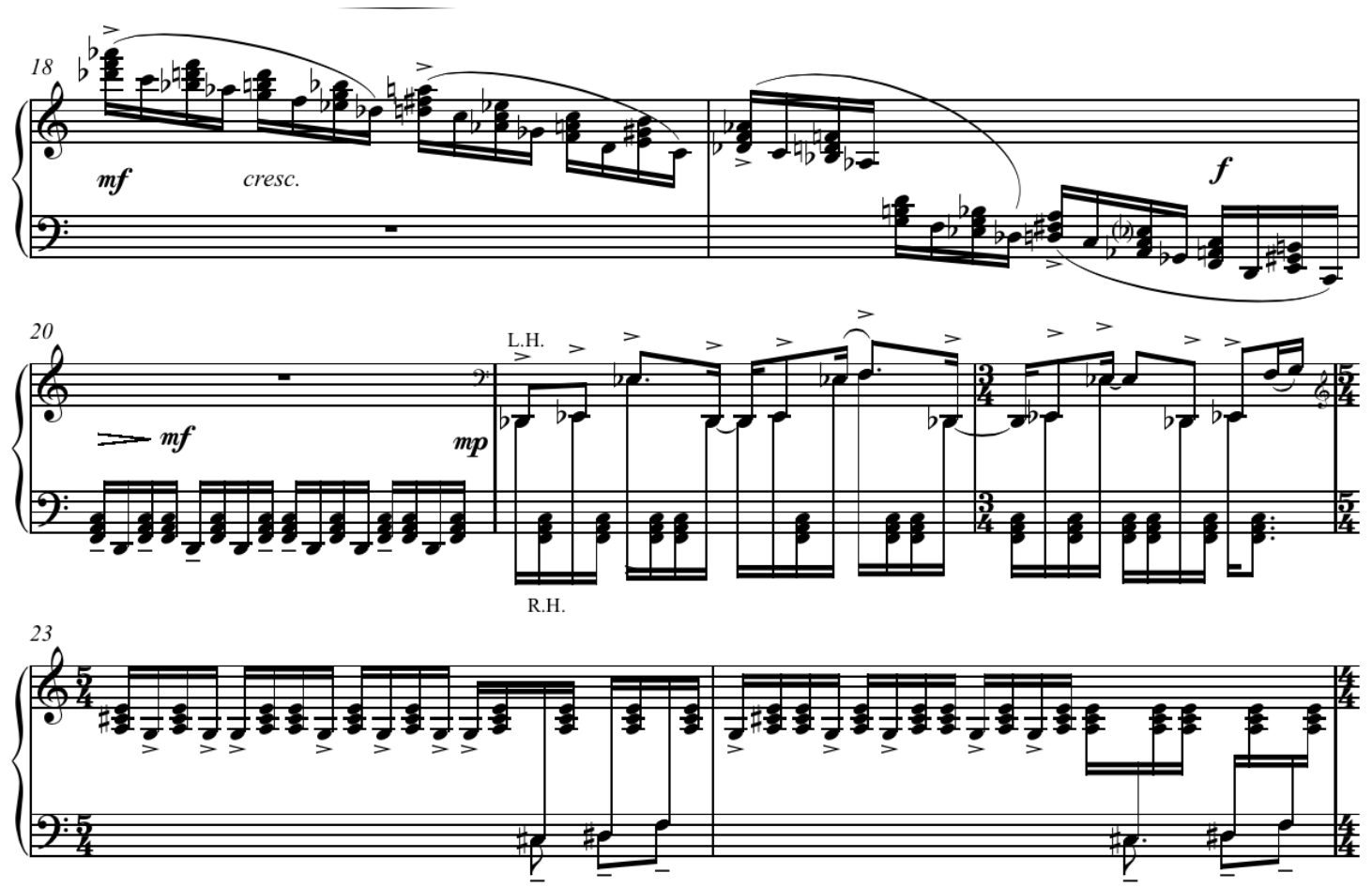

Musical Excerpt 5.11: Alex Shapiro, Sonata for Piano, III. "Scherzo," mm. 18-24

While this movement is highly chromatic, the repetition of triads and the accented bass notes emphasize harmonic regions enough for the listener to feel jolted from one pitch area to another. For example, A-flat triads are heavily emphasized from mm. 29-35 
and then the music abruptly changes to D-flat triads in mm. 36-38, D major in mm. 3942, back to D-flat in m. 43, and finally becomes increasingly chromatic to the end, landing on a $\mathrm{C}$ major chord jokingly marked $f f f$ and "like a brat." ${ }^{, 97}$ Example 5:12 provides evidence of these harmonic changes and Excerpt 5.13 displays the bravura ending.
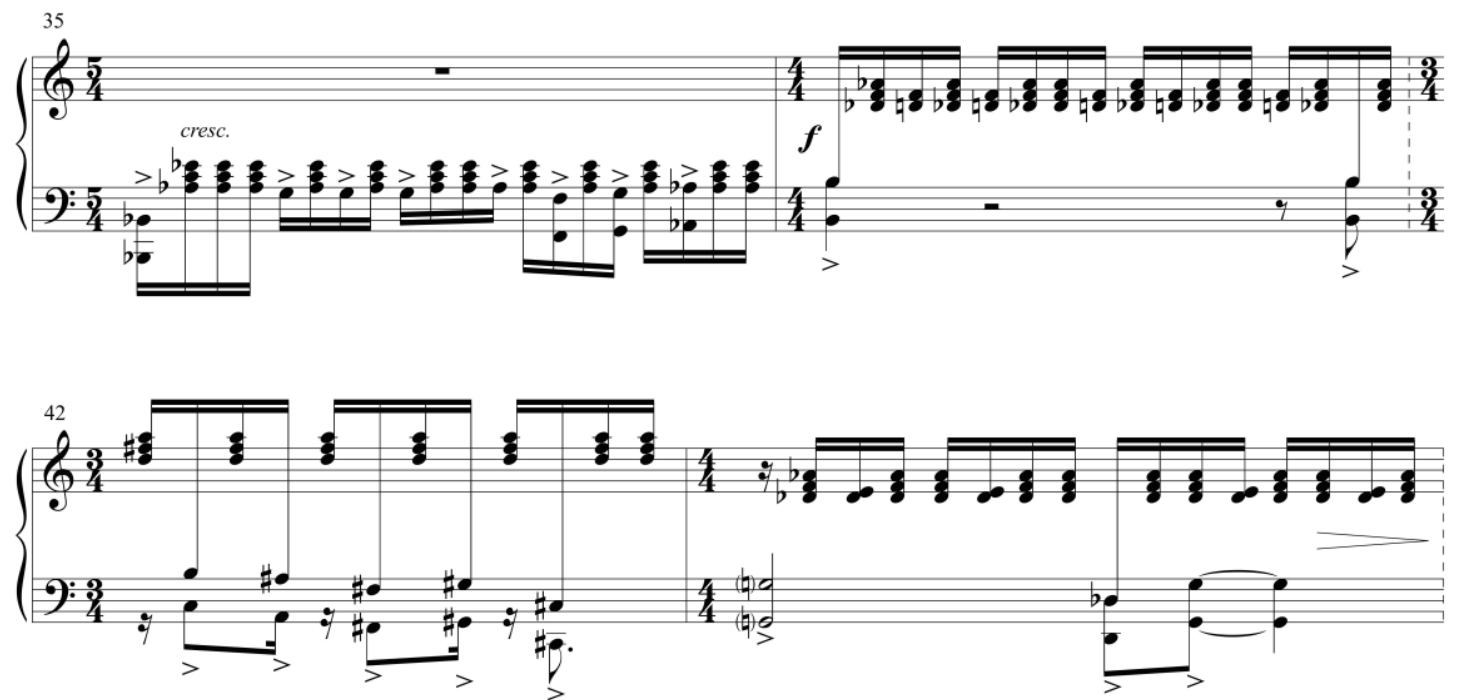

Musical Excerpt 5.12: Alex Shapiro, Sonata for Piano, III. "Scherzo," mm. 35-36, 42-43

${ }^{97}$ Alex Shapiro, Sonata for Piano (Activist Music (ASCAP), 1999) Note in Score, 21. 

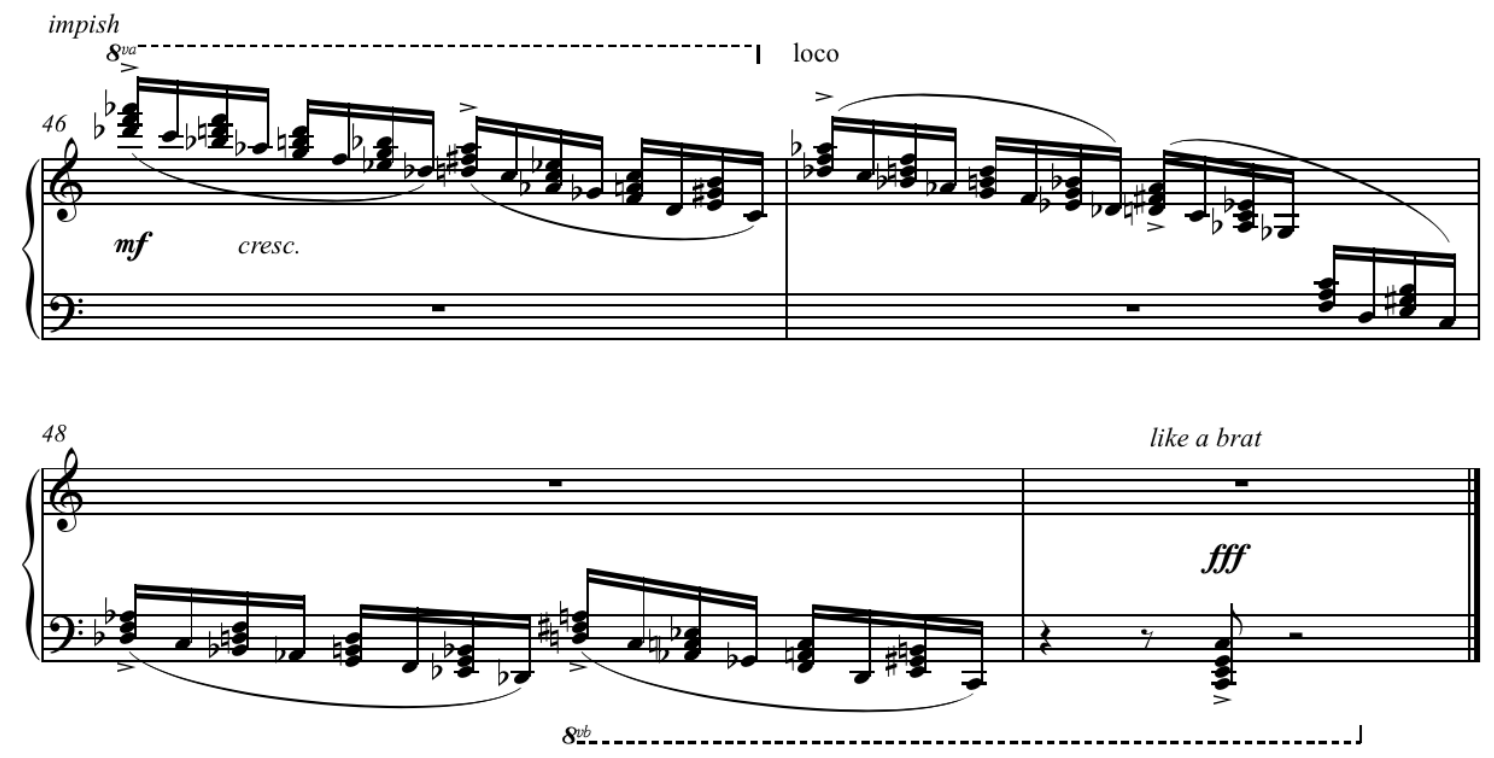

Musical Excerpt 5.13: Alex Shapiro, Sonata for Piano, III. "Scherzo," mm. $46-49$

Shapiro's sense of humor is very evident in this movement, not only in the character of the music but also in her written markings in the score. For example, she writes "bombastic"98 over the heavy octave chords in m. 41, and "impish" 99 over m. 46, where the music quickly and playfully descends to the end of the movement.

98 Ibid.

${ }^{99}$ Ibid. 


\section{Conclusion}

Shapiro's Sonata for Piano is one of her few large-scale piano works, written loosely in the traditional form of the Classical sonata. The first movement consists of two highly chromatic themes, which are developed independently and later as one unit. The middle movement is the longest of the three and creates a dreamlike atmosphere characterized by restless and wide-ranging melodic and motivic phrases over long pedal tones. The final movement is a playful and technically advanced scherzo. Lasting less than two minutes, it is an exercise in physical endurance, rhythmic syncopation, handcrossing and musical humor. Having received positive international attention both through live performances, recordings, and articles by music critics, Sonata for Piano is an excellent example of a modern-day composition inspired by older, traditional musical forms. 


\section{Chapter Six \\ Recent Compositions: Chord History and Arcana}

\section{Introduction}

Shapiro's two most-recent works for piano, Chord History and Arcana, were both completed in the latter part of 2014. She refers to both of these new works in an email to the author:

...I hope you'll be pleased to know that in addition to CHORD HISTORY, which was recorded in Germany this past October, and will be published this spring, most significantly, I just delivered the commission I had mentioned to you about herbs, which later grew into a larger statement about the fragile relationship between humans and plants on this planet. It's now a 25 minute solo piano suite titled Arcana. It's been beautifully received, and will be premiered later in 2015. I think it's among my strongest works; I'll welcome your impressions. ${ }^{100}$

Chord History is a one-page homage to Ludwig van Beethoven and consists of seven of German pianist Susanne Kessel's favorite Beethoven chords, ${ }^{101}$ as well as reference to the corresponding sonata and the individual movement and specific measure where each chord occurs. The finished work is a short composition whose harmony consists of a series of the seven aforementioned chords, along with a simple right hand melody to link them together. The composition was written as part of a large project in the making: a compilation of 250 compositions by various composers from around the globe, to be completed and presented by the year 2020 , in honor of the $250^{\text {th }}$ anniversary of

${ }^{100}$ Alex Shapiro, email message to author, December 22, 2014.

101 "Chord History," Alex Shapiro; Composer, accessed February 1, 2015, http://www.alexshapiro.org/ChordHistorypg1.html. 
Beethoven's birth. ${ }^{102}$ Chord History is one of the first compositions to be added to the set.

Shapiro's other recent work, Arcana, is a piano suite in eight parts. The titles of the individual movements in Arcana are as follows: "Cradle These Roots," "Unfurl," "Heal From Within," "Reach To Light," "Branches and Vines," "Touch It," "Search,” and "From Earth To Sky." One interesting element of this collection is the way that the first and last pieces in the set envelop the entire suite. For example, they each begin and end with the highest and lowest notes on the piano. In addition, the composer offers the following instructions and notes at the beginning of the opening movement:

Pianist begins by slowly lowering head to keys and grasping both ends of piano with hands, to lovingly embrace the meaning of healing plants, as these ledger lines and ties are purposely drawn to surround and embrace the meaning of the notes. The piano, perhaps glowing with a colored light placed inside, embodies the earth we love. ${ }^{103}$

Shapiro supplies similar textual notes to the closing movement, instructing the pianist to portray the ideas of the music visually by means of bodily gestures and the use of visual aids such as a flashlight. In this way, the pianist and the music become inseparable, and the connection between the person and this resonant piece of wood is symbolic of the relationship between humans and plants.

102 Ibid.

${ }^{103}$ Alex Shapiro, Arcana 1: Cradle These Roots (Activist Music (ASCAP), 2014) Program Note. 


\section{Chord History}

Date of Composition: 2014

Duration: 2:00 minutes

Description: Single-movement, short work. 2 pages, 8.5 " x 11 "

Publisher: (Special Note from Composer)

Because it's a small part of a larger international project, I am not the publisher for CHORD HISTORY; it will be included in a set of the first pieces from the "250 Pieces for Beethoven" series, published by Editions Musica Ferrum out of Athens, Greece. There will be additional books, released between 2015 and 2020, Ludvig's 250th birthday year! ${ }^{104}$

Score Location: Score will be available from Editions Musica Ferrum in 2015 Score Formats Available: To Be Announced Available Recordings:

1. mp3 audio clips coming soon in 2015

\section{Location of Recordings:}

1. alexshapiro.org < Works < Piano < Chord History (not yet available)

\section{Related Arrangements: N/A}

\section{Program Notes found on inside cover of score:}

My friend, the superb pianist Susanne Kessel, shares something significant with one of our mutual muses, Ludwig van Beethoven: they both hail from Bonn, Germany. Eyeing the upcoming occasion of Beethoven's $250^{\text {th }}$ birth year in 2020, Susanne devised a beautiful plan: to shepherd 250 short new pieces of music into the world in the composer's honor, from the hearts of artists who would happily consider themselves among his protégés. If only Beethoven could know the enduring power of his legacy.

So what better way to compose an homage to this giant, than to ask the devoted pianist for whom I was writing the piece what some of her favorite Beethoven piano chords might be? I knew the answer to mine: the iconic, imposing, foreboding, $\mathrm{C}$ minor start to Sonata No. 8, Opus 13, the "Pathétique." My teenage hands passionately played each phrase thousands of times, and while poor Ludwig might have been rolling over in his grave (there's good reason I chose to compose rather than perform), the influence of his music in my life has been monumental.

${ }^{104}$ Alex Shapiro, email message to author, December 22, 2014. 
Susanne submitted several fine suggestions, which are found throughout my little offering. And thus Beethoven, Kessel, and Shapiro, have become bound for a brief and touching moment in this CHORD HISTORY. ${ }^{105}$

To date, Chord History is Shapiro's shortest individual work for solo piano. This 22-measure piece was written, as Shapiro indicates, in honor of Ludwig van Beethoven. It contains some of pianist Susanne Kessel's favorite Beethoven chords, as well as Shapiro's favorite C-minor chord from the opening measure of Beethoven's famous Pathétique sonata. This C-minor chord occurs in $\mathrm{m} .13$, following the F-minor chord from Beethoven's equally famous Appassionata sonata. Below is a comment from Shapiro regarding the process that motivated this composition.

I can tell you that one of the chords-- the big $\mathrm{C}$ minor opening from the Pathetique - was my choice, and it was this initial idea that led me to ask Susanne what her favorite Beethoven chords were. It was a lot of fun to receive PDFs from her of the pages from her scores with her indication of which measure and which chord. I wanted to see them, so that I would get the voicings entirely accurate as I earmarked my own Beethoven scores. Happily, she really loves the piece! ${ }^{106}$

The fact that this work consists primarily of references to several of Beethoven's greatest compositional moments adds a poignancy to the music. It is refreshingly simple in that the melodic line remains contemplative and serves only as a link between the chords, not taking away attention from the original harmonies.

Many of Shapiro's typical compositional approaches are evident in this short work: frequently changing meters, along with disjunct, floating melodic lines, and frequently shifting tonal centers; her descriptive notes also help to maintain a specific

${ }^{105}$ Alex Shapiro, Chord History (Copyright @2014 Alex Shapiro) Program Note. ${ }^{106}$ Alex Shapiro, email message to author, February 1, 2015. 
mood or idea throughout the work. The piece is marked about 72 to the quarter and "rubato; like a memory."107 Throughout the work she uses descriptive phrases such as: "slightly stronger," "pushing forward," "quietly," "stronger," and "very still.,"108

One interesting observation, as a matter of opinion only, is the correlation between Beethoven's often surprising but still tonal harmonic changes and the successive arrangement Shapiro chose in putting these very different chords together into one work. It is truly "like a memory" as Shapiro indicates, not only in a literal compositional sense of evoking memories of Beethoven but also in the atmospheric effect that she achieves. However, it is important to distinguish between Beethoven's logical, albeit surprising harmonic language and Shapiro's modern use of tonal centers, which are often local and fleeting. The relationship between measures of Beethoven's chords in Chord History has nothing in common with Beethoven's original use of the harmonies.

Excerpt 6.1 is a complete copy of this short and beautiful work. Likewise, Excerpt 6.2 is a complete copy of the referenced Beethoven chords, with their correlating composition and measure numbers. Both were borrowed with permission of the publisher. ${ }^{109}$

${ }^{107}$ Alex Shapiro, Chord History (Copyright @2014 Alex Shapiro) Note in Score, 1. ${ }^{108}$ Ibid.

${ }^{109}$ Permission granted on July 7, 2015 by email from Nikolas Sideris, publisher of Chord History. 


\section{Chord History}

for Susanne Kessel

and Ludwig van Beethoven, for the occasion of

the 250th anniversary of his birth, in 2020

Alex Shapiro
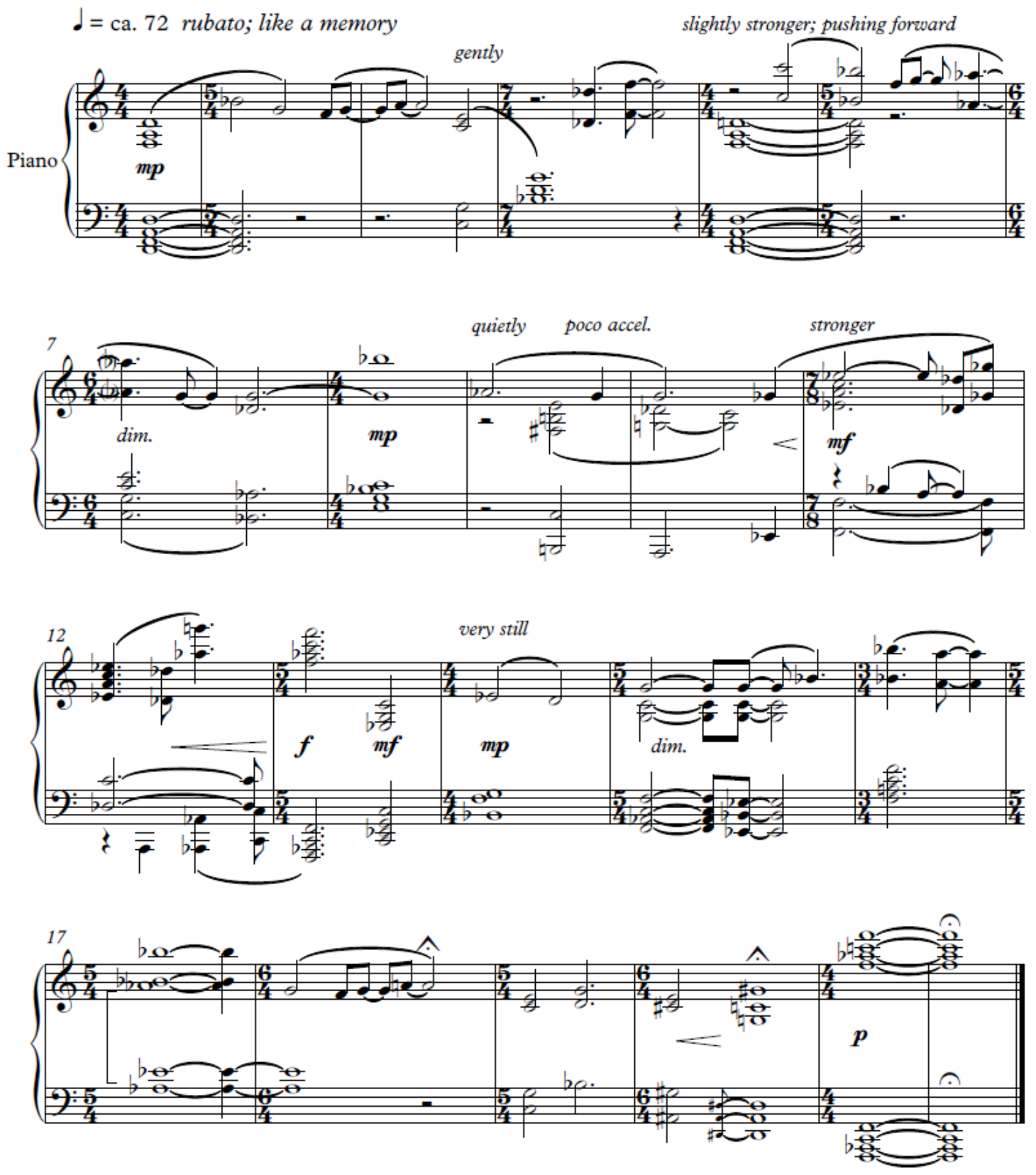

Copyright $\mathbb{C} 2014$ by Alex Shapiro (ASCAP)

Musical Excerpt 6.1: Alex Shapiro, Chord History. 
Here is a reference for where Beethoven's hidden chords may be found amidst the measures of CHORD HISTORY:

\section{Beethoven's Chords}

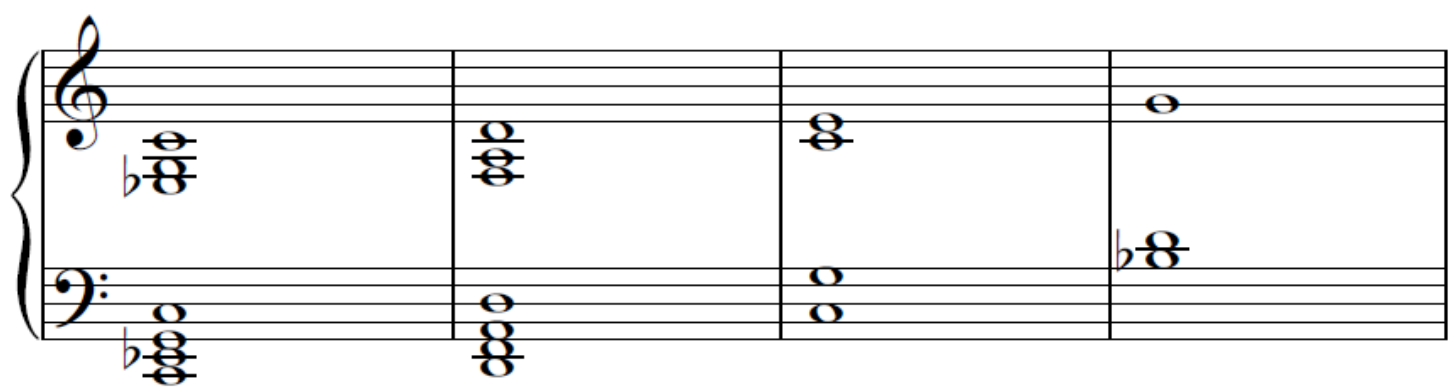

Op. 13, m. 1;

in $m .13$.
Op. 10 No. 3 , m. 1 of Largo e mesto; in $\mathrm{mm}$. 1, 5 .
Op. 2 No. 3, m. 1; in mm. 3, 7, 19.
Op. 49 No. 1, m. 1; in $m$. 19.

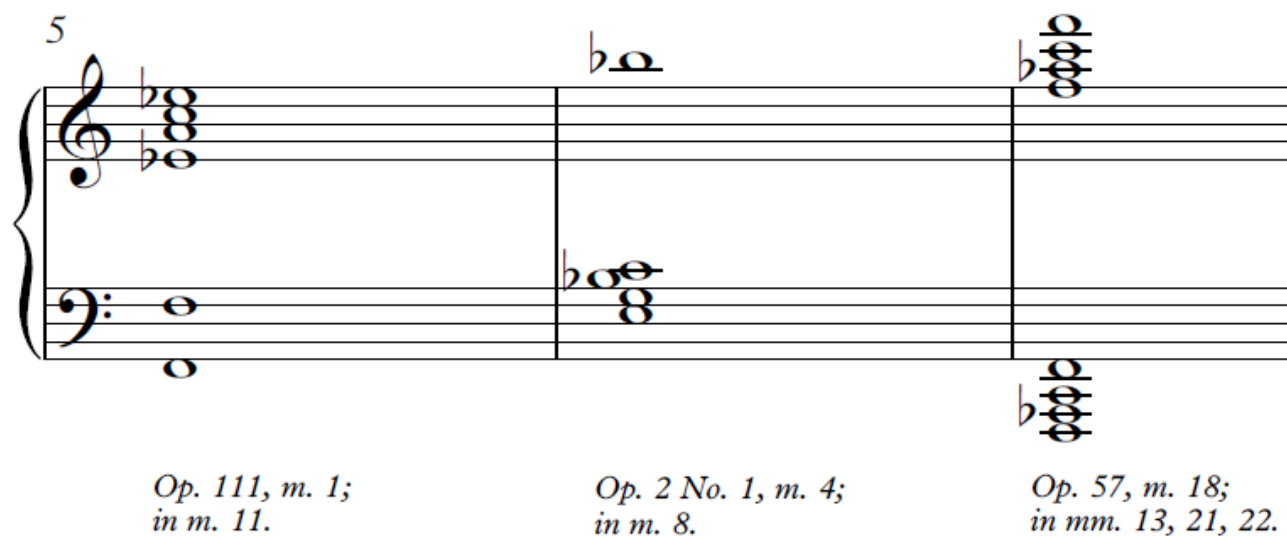

Musical Excerpt 6.2: Alex Shapiro, Chord History reference of Beethoven's chords. 
Date of Composition: 2014

Duration: 20:00 minutes

Description: Eight-movement work: "Cradle These Roots," "Unfurl," "Heal from Within," "Reach to Light," "Branches and Vines," "Touch It," "Search," and "From Earth To Sky." 29 pages, 8.5" x 11"

Publisher: Activist Music (ASCAP)

Score Location: alexshapiro.org < Works < Piano < Arcana

Score Formats Available: Print or Digital

Available Recordings:

1. mp3 audio clips coming soon in 2015

\section{Location of Recordings:}

1. alexshapiro.org < Works < Piano < Arcana (not yet available)

\section{Related Arrangements: N/A}

\section{Program Notes found on inside cover of score:}

Arcana explores the painfully fragile and often perilous relationship between humans and the secrets of earth's abundant plant life. The music often does so from the perspective of the plants themselves, with healing herbs as protagonists of a story that begins with a dire warning, and ends with the faith that wisdom and grace shall ultimately triumph.

In the pursuit of better health, a "healing crisis" can occur, during which someone may feel even worse after the start of a curative regime, before they feel better. Accordingly, the eight movements of this suite journey through some very dark and frightening places before arriving to the light. The toxins of conflict are a powerful subject, whether a struggle with one's inner demons, or a battle against outer threats to the wellbeing of our planet.

An everlasting mystery in both examples is the poignant attempt to achieve balance. Renowned herbalists Michael Tierra and his wife Lesley are among those who succeed in this challenge beautifully, as they work to improve the bodies, minds and spirits of others while honoring the natural world, always respectful of its power to harm as well as to heal. Representing their shared passion through the sphere of music has been a passage of joy and discovery for which I'll always be grateful. 
As above, so below; as within, so without. Creation is a form of magic. And the world of roots seeking good soil, and leaves turning upward to pure air, is one that we must protect, always.

Alex Shapiro

San Juan Island, Washington ${ }^{110}$

${ }^{110}$ Alex Shapiro, Arcana (Activist Music (ASCAP), 2014) Program Note. 


\section{I. "Cradle These Roots"}

The narrative perspective of this suite comes from plant life. Movement I opens with the highest and lowest pitches of the piano, the pianist symbolically grasping both ends of the instrument. Shapiro marks the beginning "something very precious, and fragile," followed by instructions to "play loosely, with a heavily pensive, floating feeling." "111 Throughout each movement, Shapiro provides narration, guiding the pianist. The fragility of Movement I is gradually abandoned in favor of more intense passages marked: "the secret must be protected," "more forcibly," "with anger," "hauntingly subdued," "roots sinking in grief, their points digging into sacred soil," and finally ending with "we are harming the earth and its healing gifts."112 Just as Shapiro indicates in her

program notes, we see examples throughout of melodic material in the inner voices being protected by the surrounding ties. The melody is representative of the suffering of plants (see Excerpt 6.3).

111 Alex Shapiro, Arcana (Activist Music (ASCAP), 2014) Note in Score, 1.

112 Alex Shapiro, Arcana (Activist Music (ASCAP), 2014) Note in Score, 1-3. 


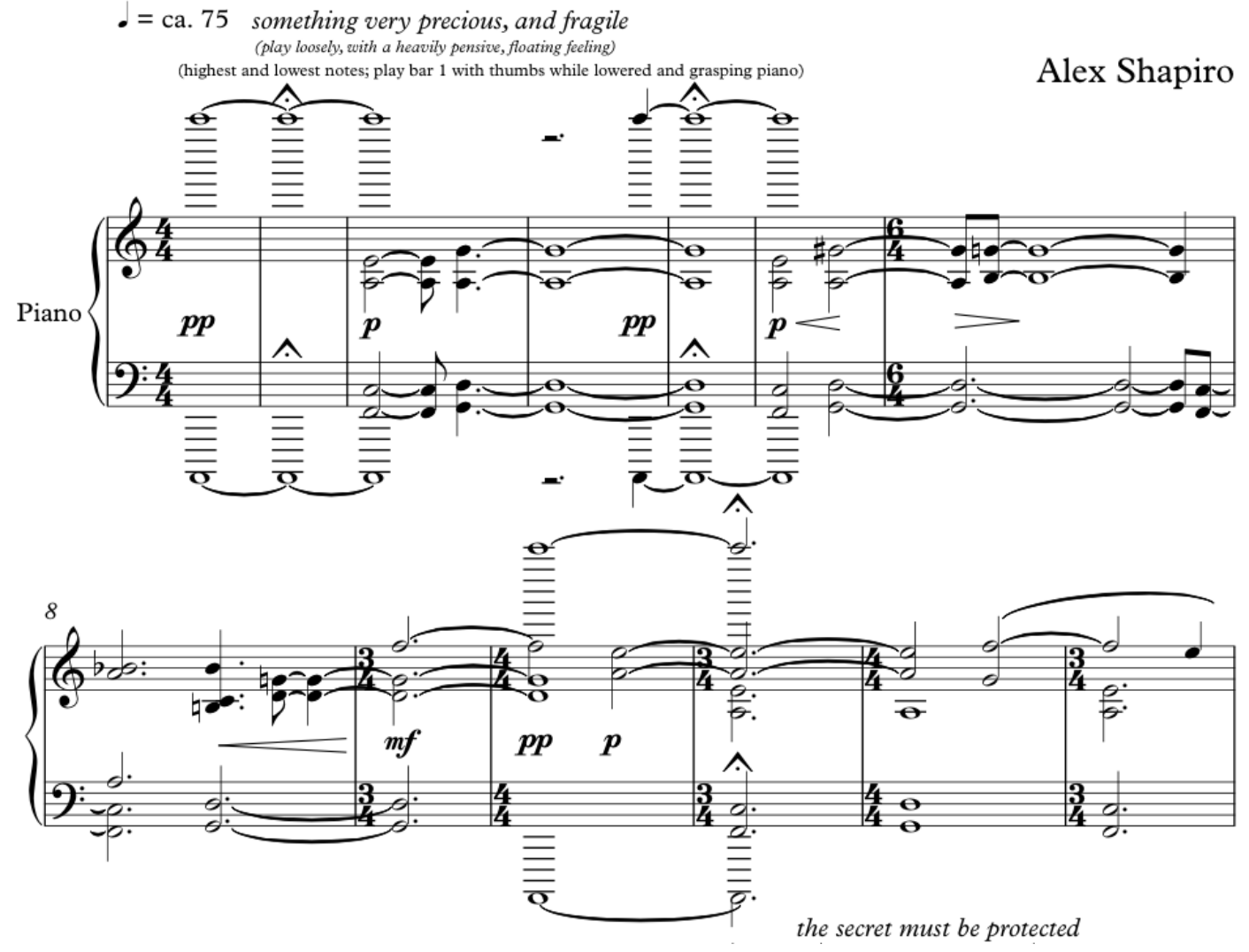

Musical Excerpt 6.3: Alex Shapiro, Arcana 1: "Cradle These Roots," mm. 1-13

She achieves a sense of anger and forcefulness in mm. 27-32 through accents, increasing dynamics and widening ranges to both extreme ends of the piano (see Excerpt 6.4). 

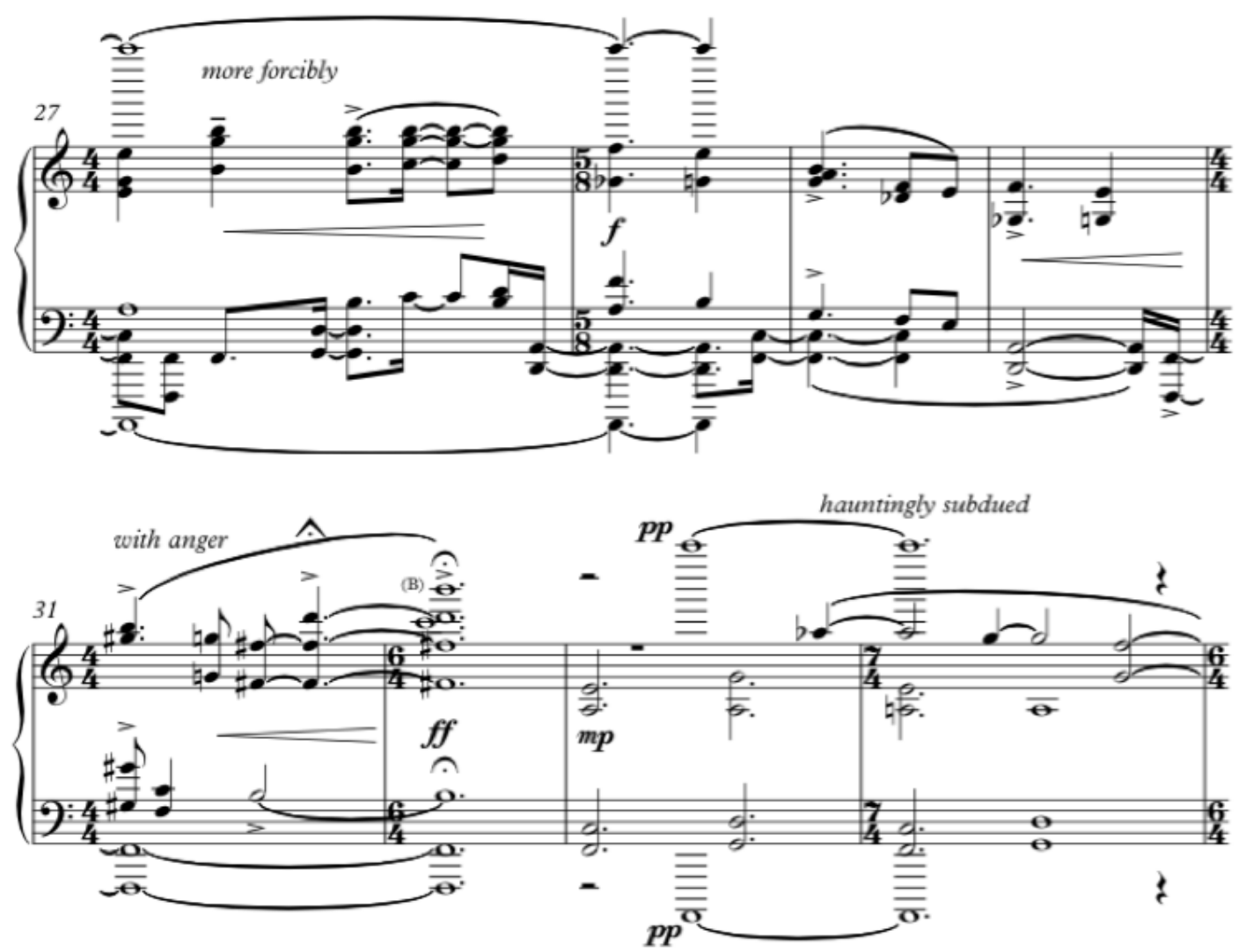

Musical Excerpt 6.4: Alex Shapiro, Arcana 1: "Cradle These Roots," mm. 27-34

From m. 36 to the end, the words "roots sinking in grief, their points digging into sacred soil," ${ }^{113}$ are symbolized by a descending bass line (see Excerpt 6.5 ). The movement ends as gently as it began but with the harsh truth written above the notes, that we (humans) are harming the earth. Shapiro instructs: "Pianist lowers head to rest on the keys and grasps both ends of piano with hands," 114 as it was in the beginning.

Shapiro provided the author with the following information regarding her harmonic language in Arcana. This same email message was originally referenced in

${ }^{113}$ Alex Shapiro, Arcana (Activist Music (ASCAP), 2014) Note in Score, 3.

${ }^{114}$ Ibid. 
chapter one, providing insight into her compositional approach to harmonic and tonal

writing:

There is almost always a tonal center- even if it is a fleeting one- in my work. Some pieces stay traditionally tonally grounded throughout, and others flit like a bird from one tonic branch to the next. In addition to my chromatic tendencies, I'm certainly very modal in my voice as well. There are some pieces, such as "For My Father," that are chromatic in an almost mid-20th century German way, and others, like "Arcana," that are very modal and open-sounding, parallel fifths and all. ${ }^{115}$

The first movement of this suite contains pervasive use of open parallel fifths. Even in the more chromatically dissonant passages, such as seen below in m. 41 of Excerpt 6.5 , Shapiro sustains a spaciousness in her texture, which effectively contributes to her use of sonorities. The bottom note on the piano, A, is recurrent and can be defined as the tonal center of this movement.

115 Alex Shapiro, email message to author, July 9, 2015. 

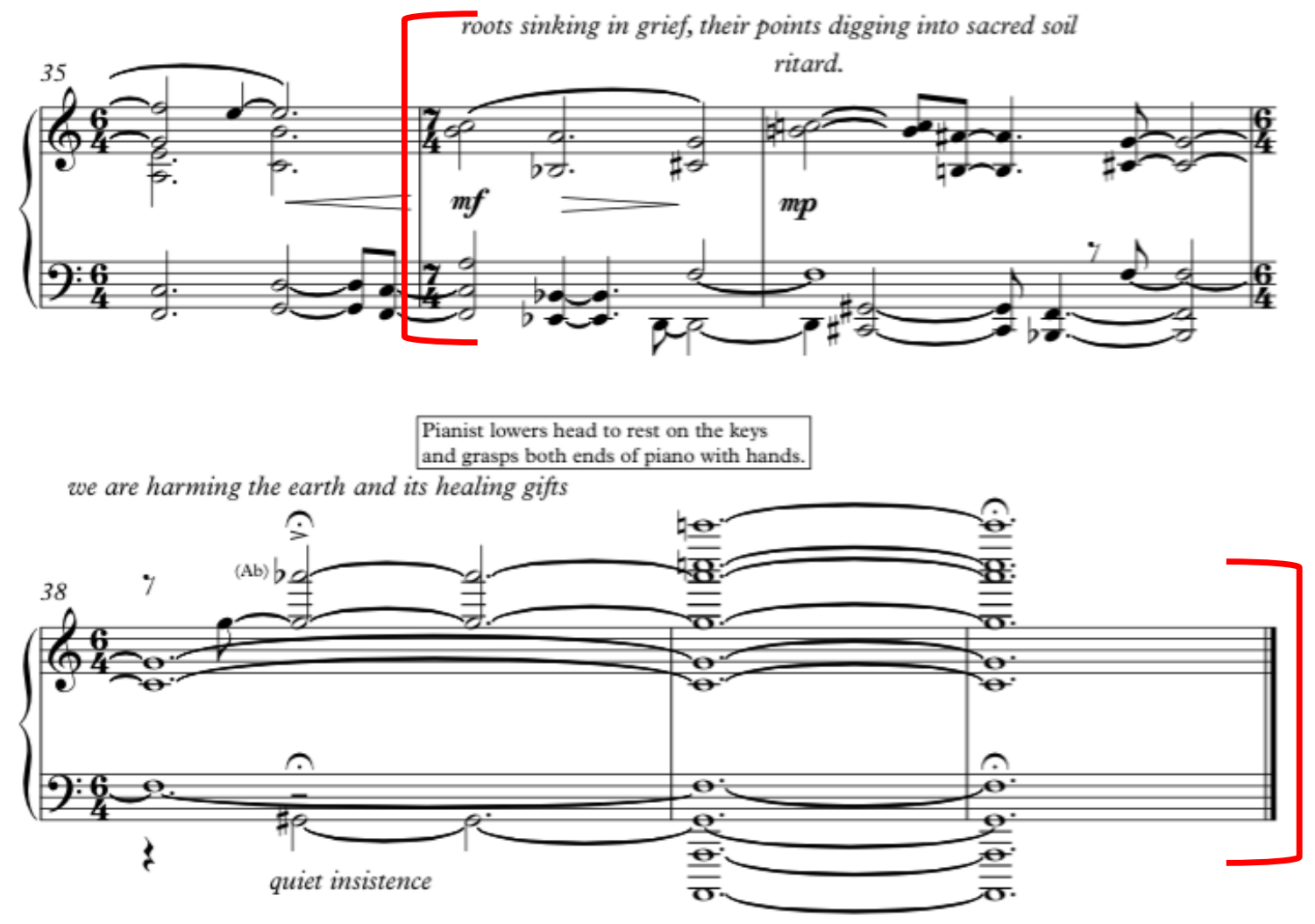

Musical Excerpt 6.5: Alex Shapiro, Arcana 1: "Cradle These Roots," mm. 36-40 


\section{II. "Unfurl"}

The second movement is representative of the plants' struggle to trust again. The title of this movement is itself symbolic, representing the conflict between humans and plants, each having internal as well as external struggles with trust. Just as something must face opposition in order to grow and thrive, it is also a risk one must take, as one cannot know the power that those perceived threats might possess. Musically, the opening melody is pure and innocent, gradually increasing in tempo, with widening range and thickening texture (see Excerpt 6.6).

\section{Arcana 2: \\ Unfurl}

For Michael Tierra
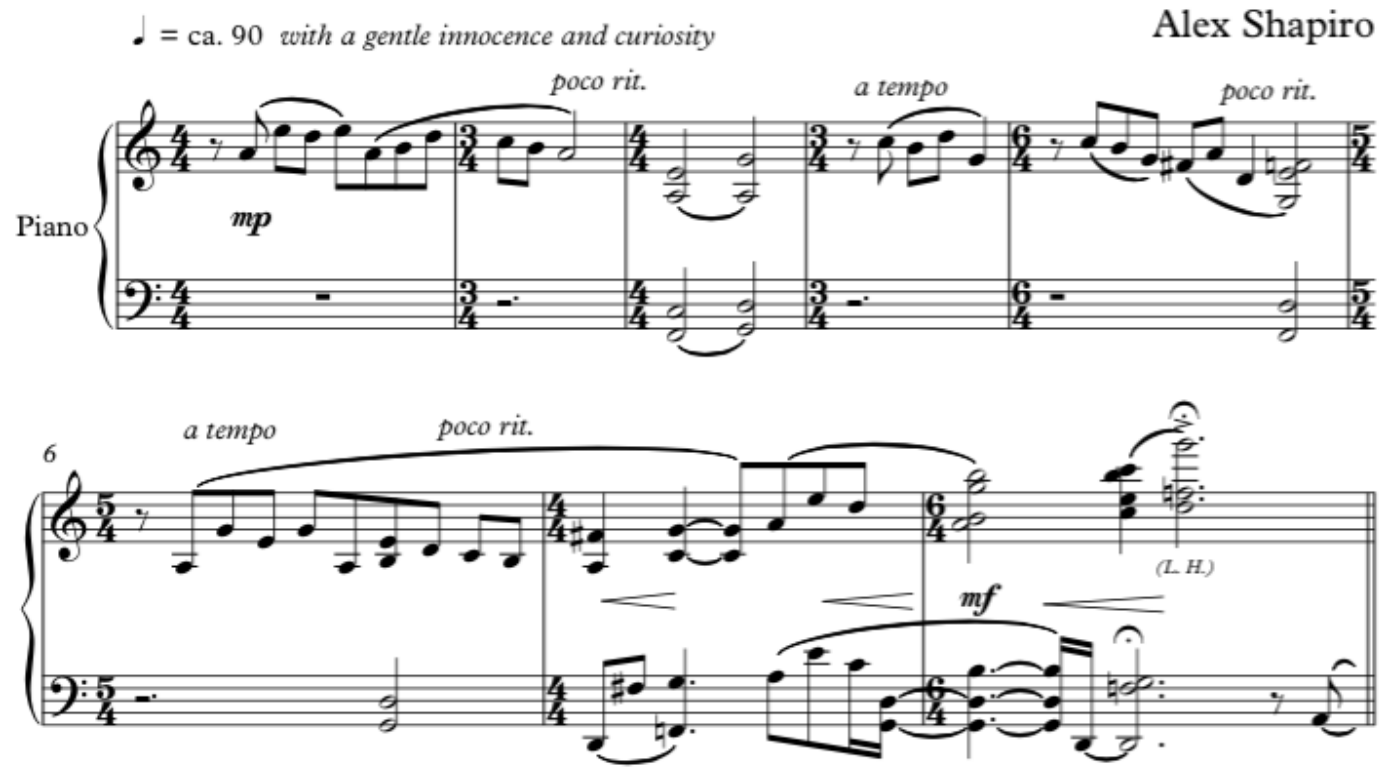

Musical Excerpt 6.6: Alex Shapiro, Arcana 2: "Unfurl," mm. 1-8 
In m. 9 Shapiro marks "somewhat hesitantly; lilting; delicately opening to trust." ${ }^{116}$ However, it soon becomes apparent that a threat exists and the music begins to move forward with rolling eighth notes, followed by m. 21 marked "holding on to trust." 117 This moment musically represents the struggle between moving forward and holding back with caution, while wanting to trust (see Excerpt 6.7).
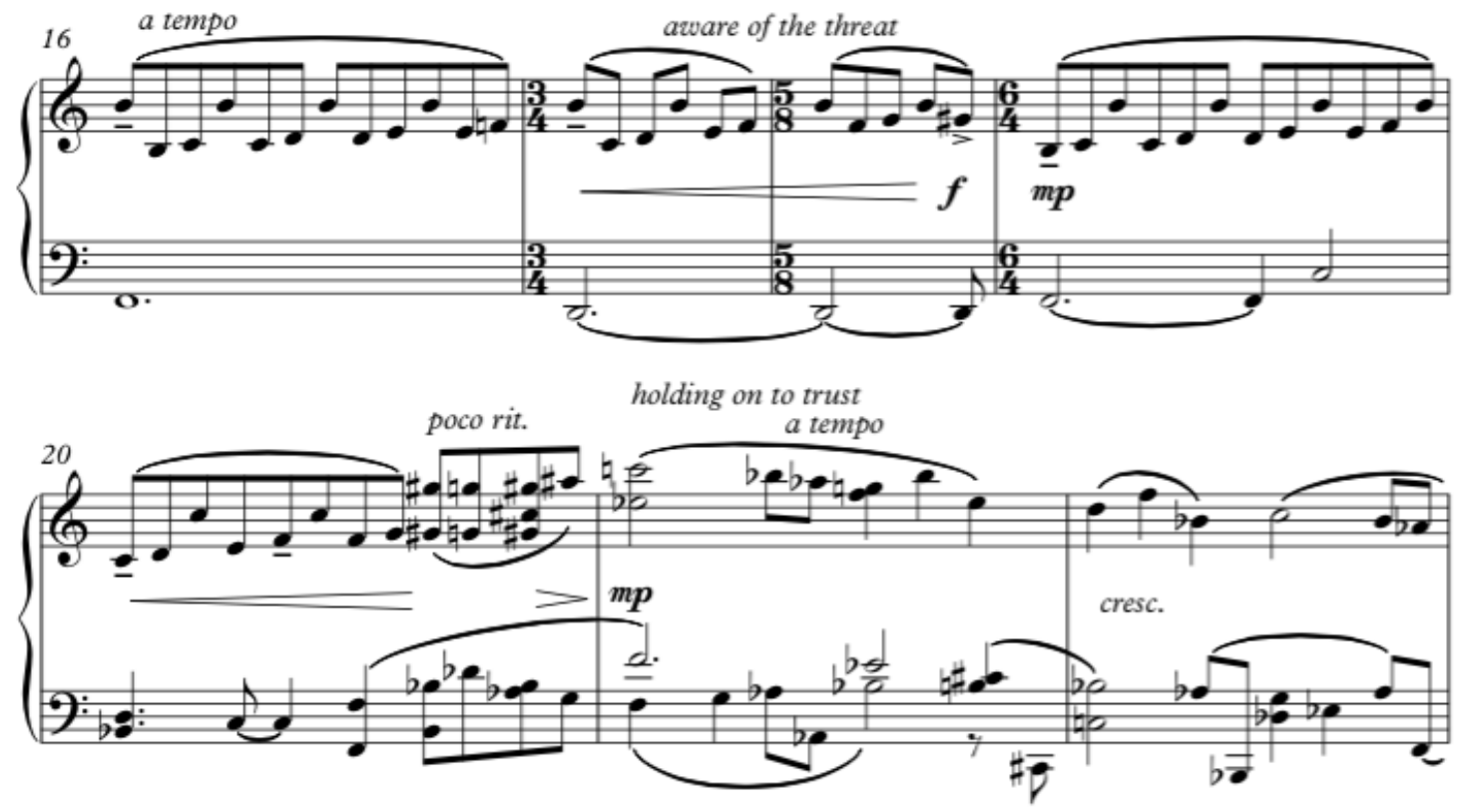

Musical Excerpt 6.7: Alex Shapiro, Arcana 2: "Unfurl," mm. 16-22

A sense of perpetual motion exists in the eighth-note passages, which recur in $\mathrm{m}$. 28 and become a prominent musical element through the end of the movement. The movement reaches its climax in mm. 31-34, a passage marked "passionate struggle,"118 represented by a peak on a high G-sharp in the melodic line, thicker texture, and increasingly dissonant harmonies (see Excerpt 6.8). It is followed by a continued struggle

116 Alex Shapiro, Arcana (Activist Music (ASCAP), 2014) Note in Score, 3. ${ }^{117}$ Alex Shapiro, Arcana (Activist Music (ASCAP), 2014) Note in Score, 5. ${ }^{118}$ Ibid. 
to be strong, ending on a final resolution in $\mathrm{G}$ major, marked "resolved, to trust and grow" ${ }^{119}$ (see Excerpt 6.9).

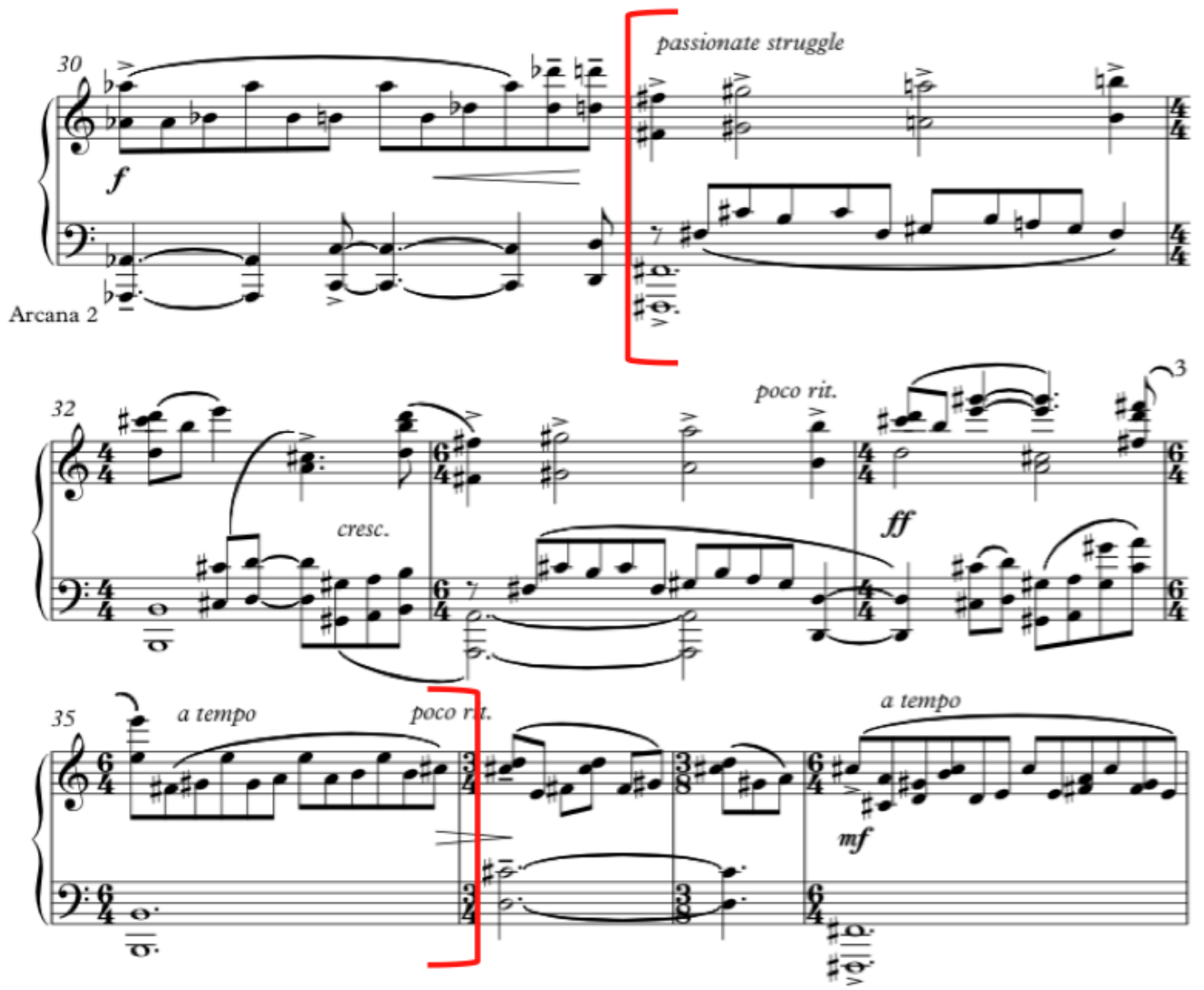

Musical Excerpt 6.8: Alex Shapiro, Arcana 2: "Unfurl," mm. 31-35

${ }^{119}$ Alex Shapiro, Arcana (Activist Music (ASCAP), 2014) Note in Score, 6. 


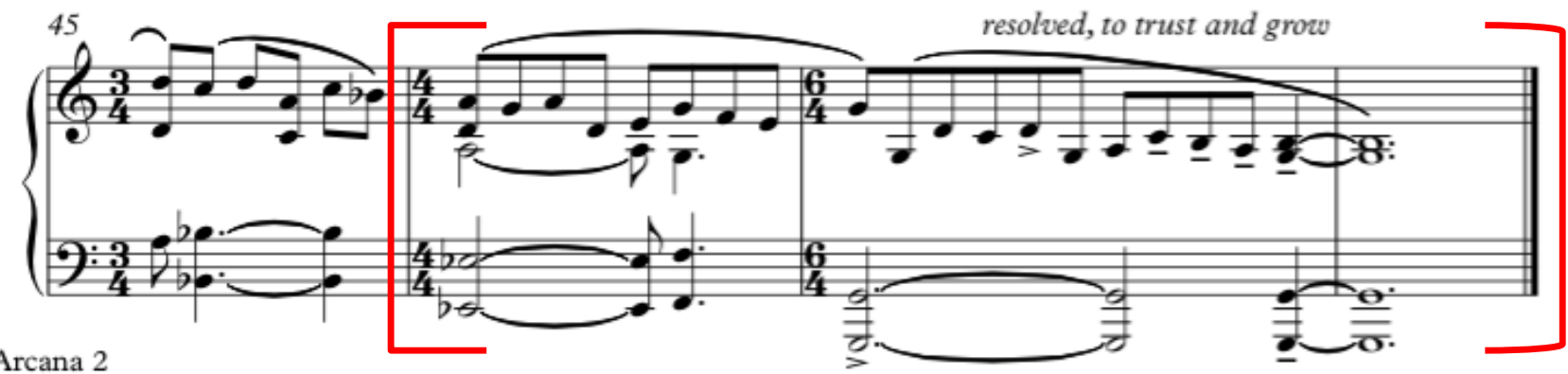

Musical Excerpt 6.9: Alex Shapiro, Arcana 2: "Unfurl," mm. 46-48 


\section{III. "Heal from Within"}

The message of Movement III is one of healing and, consequently, essential pain. In the previous two movements Shapiro musically tells the story of the fragility of plant life and the threats that humans impose on it, as well as the repercussion of these actions on humanity. In this movement, as Shapiro explains in the score's program notes, healing is a process which inevitably involves pain or increased illness, prior to ultimate healing. Whether the pain and healing are emotional, physical, or spiritual remains to be explained. Perhaps the process is a combination of the three.

Shapiro marks the beginning of this movement "very melancholy; wistfully"120 and instructs the pianist to "play languidly, with pedal, molto rubato, as a jazz ballad."121

The music digresses from melancholy (Excerpt 6.10) to "the pain of grief"122 in mm. 9-12 (Excerpt 6.11), marked with accelerandos and ritardandos that guide the increasingly dissonant and persistent musical phrases to a sigh and exhale ${ }^{123}$ in mm. 15-16 (Excerpt $6.12)$.

${ }^{120}$ Alex Shapiro, Arcana (Activist Music (ASCAP), 2014) Note in Score, 7.

121 Ibid.

122 Ibid.

${ }^{123}$ Alex Shapiro, Arcana (Activist Music (ASCAP), 2014) Note in Score, 8. 


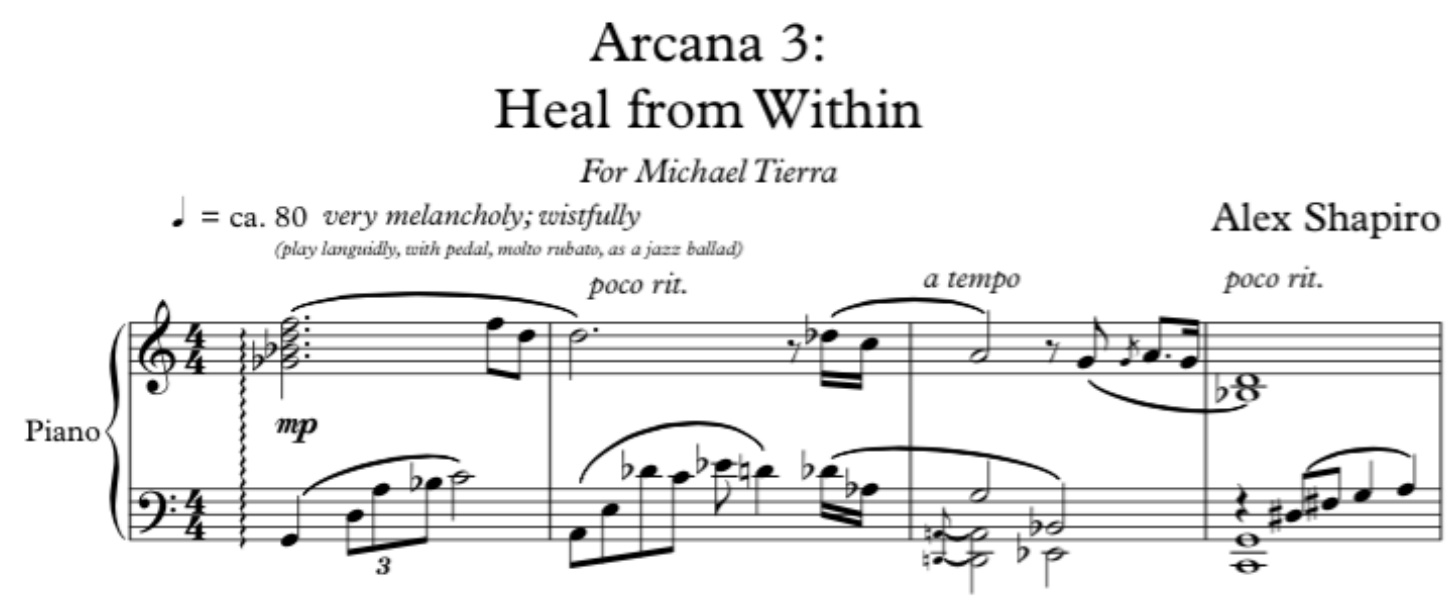

Musical Excerpt 6.10: Alex Shapiro, Arcana 3: "Heal from Within," mm. 1-4

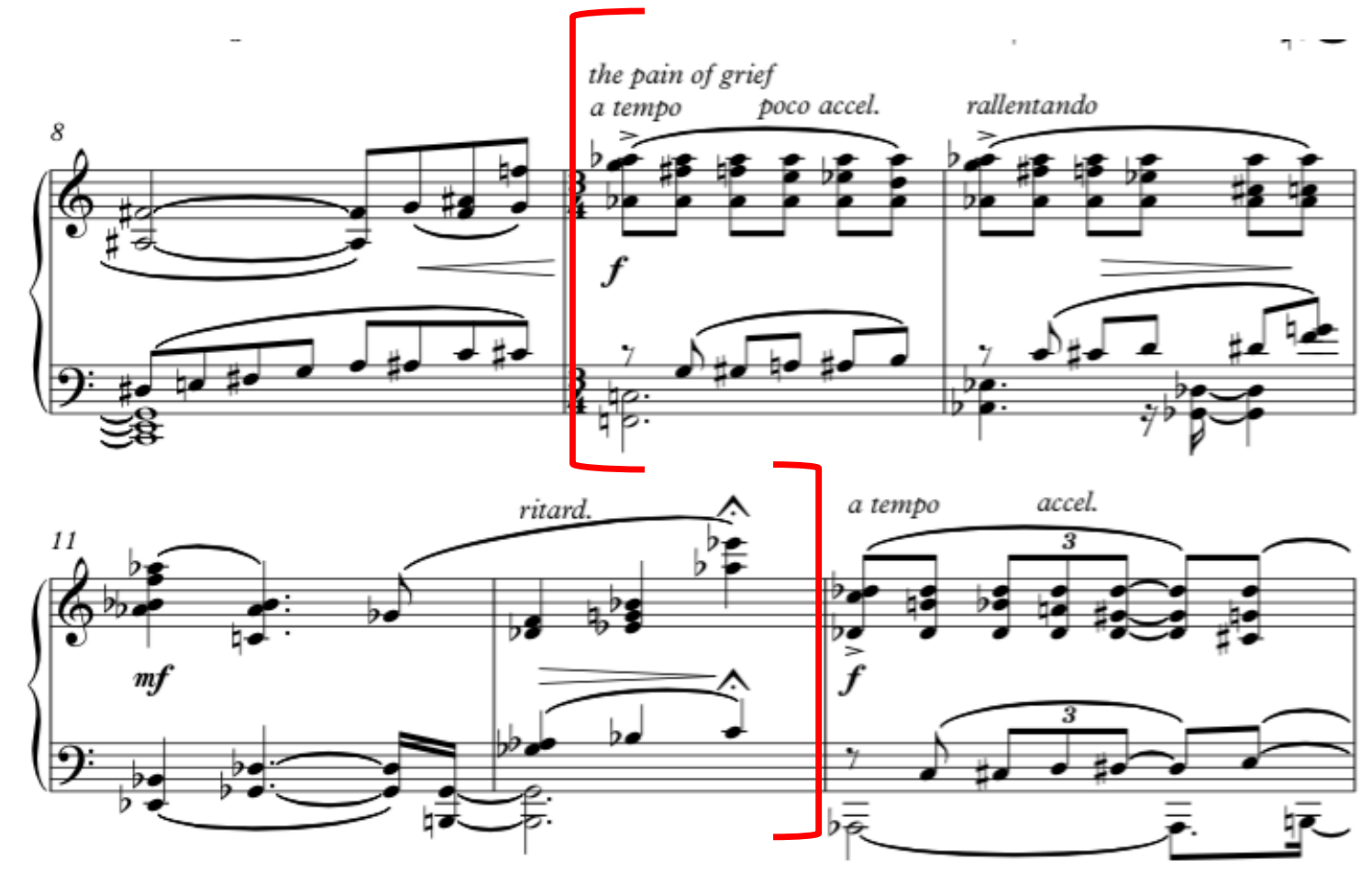

Musical Excerpt 6.11: Alex Shapiro, Arcana 3: "Heal from Within," mm.9-12 


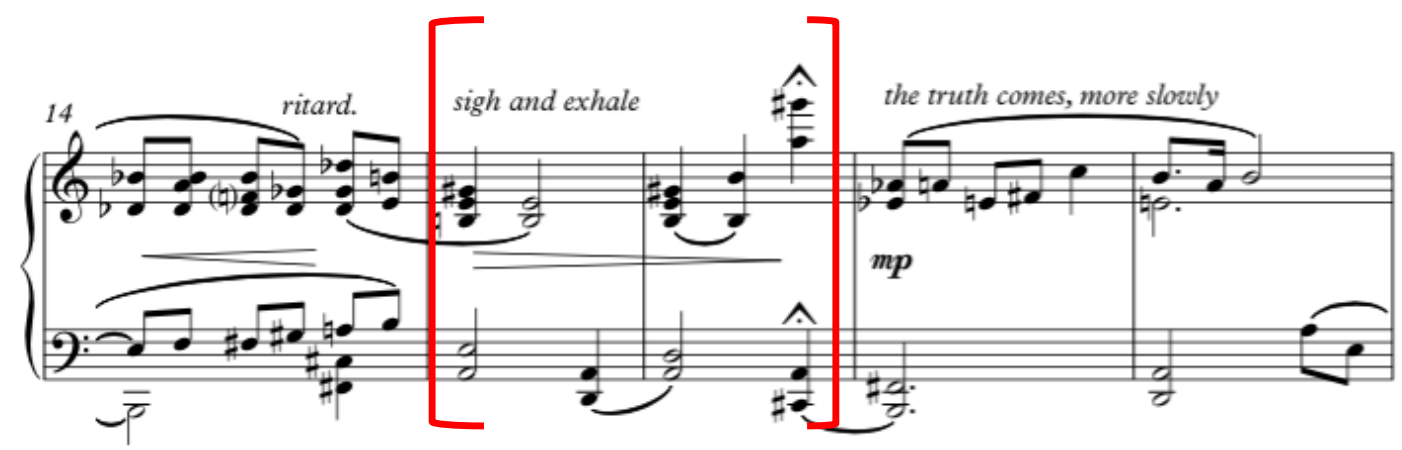

Musical Excerpt 6.12: Alex Shapiro, Arcana 3: "Heal from Within," mm. 15-16

The following phrases bring a search for truth, followed by despair, and finally a moment of "exhausted resignation," 124 marked by a decrescendo and fermata that momentarily bring peace (see Excerpt 6.13).

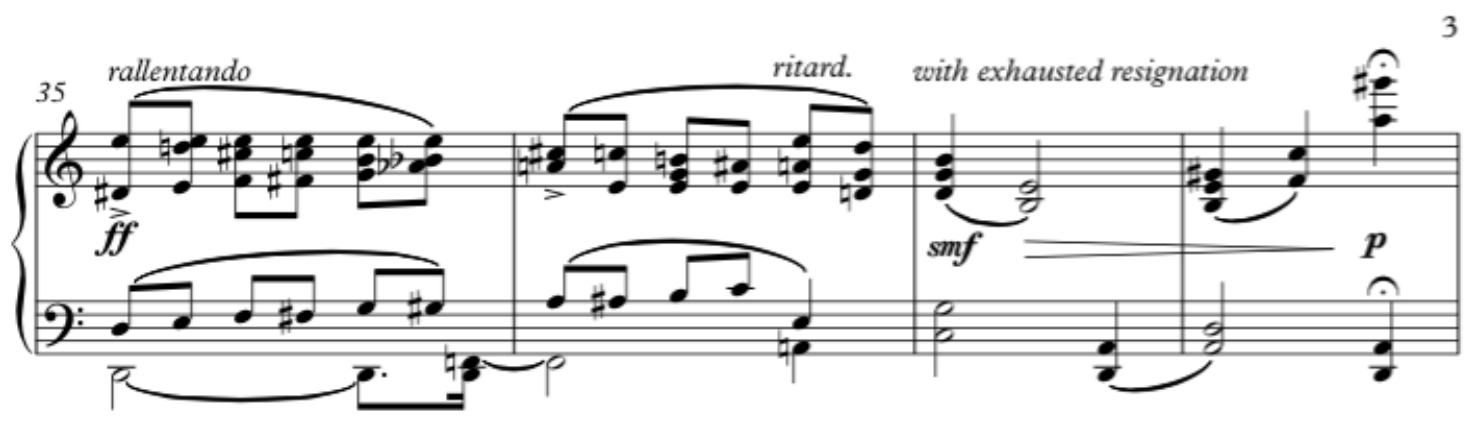

Musical Excerpt 6.13: Alex Shapiro, Arcana 3: "Heal from Within," mm. 35-38

The final phrases are consequently marked: "accepting the law of cure,"125 marked by a return of the opening melodic material and similar left-hand material; the movement concludes with two brief and relevant excerpts from one of the projects commissioned by pianist Michael Tierra, a deck of tarot cards with an herbal guide,

${ }^{124}$ Alex Shapiro, Arcana (Activist Music (ASCAP), 2014) Note in Score, 9.

125 Ibid. 
called "The Herbal Tarot."126 Musically, the movement ends with a pensive, open chord: a diminished octave of G and G-flat with the third above G, B-flat. (see Excerpt 6.14).
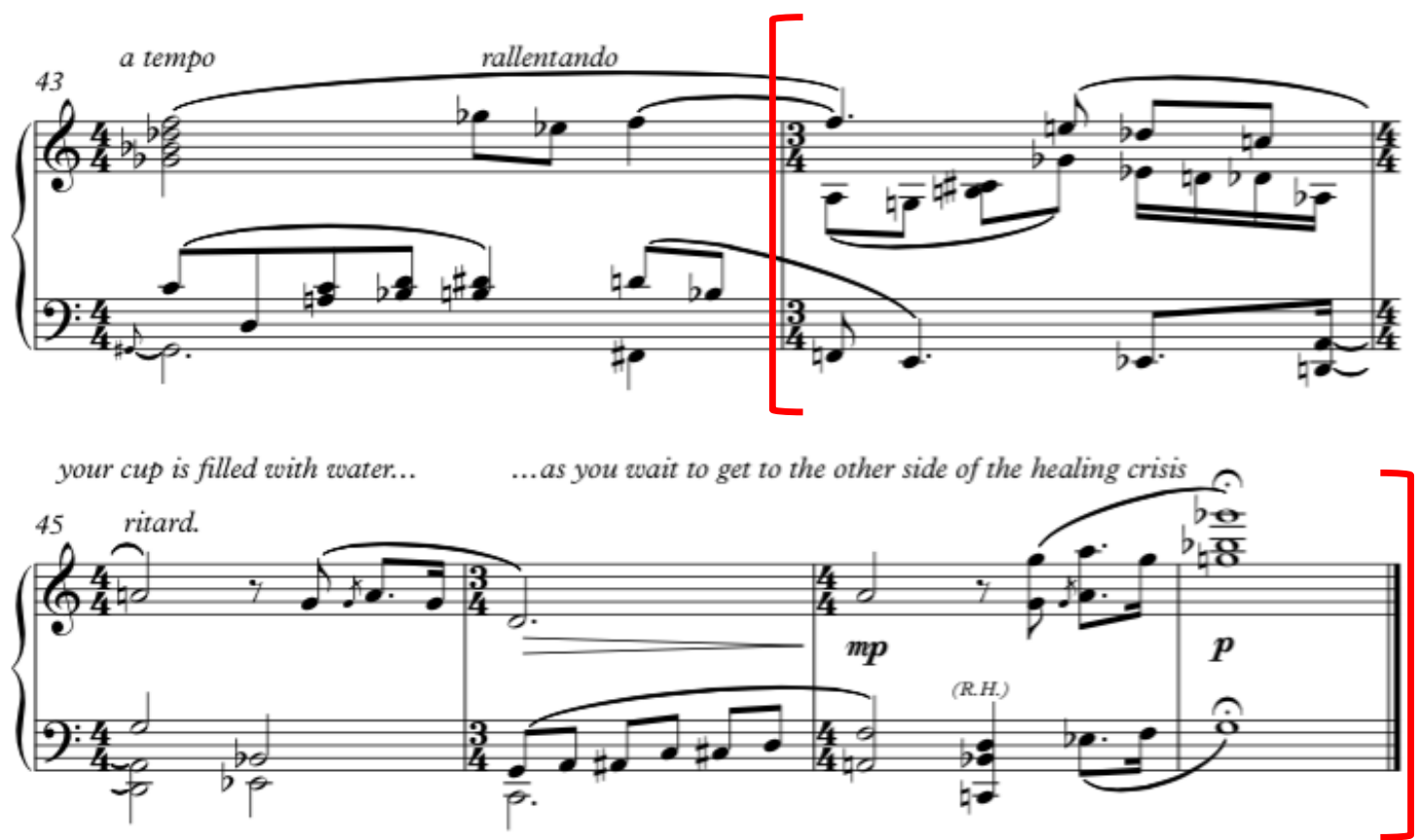

Musical Excerpt 6.14: Alex Shapiro, Arcana 3: "Heal from Within," mm. 44-48

It is interesting to note here that Shapiro often alternates consonant and then dissonant endings among the individual pieces of this suite. For example, Movement II ends in G major, Movement III ends very dissonantly (however still achieving a sense of momentary resignation), and the fourth movement, as we shall see, ends consonantly in D major.

${ }^{126}$ Alex Shapiro, email message to author, June 15, 2015. 


\section{IV. "Reach to Light"}

The fourth movement brings an optimistic perspective and one can confidently assume that the much needed healing process in the third movement was successfully achieved. Shapiro marks the opening "with relief; an exploration of unlimited

possibility."127 The tempo is faster than in the first three movements, marked 140 to the quarter note. It is refreshingly simple and consonant, and makes use of modal harmonies, as in the other movements (see Excerpt 6.15). Open fifths and major triads, most prevalently A major, occur throughout.

${ }^{127}$ Alex Shapiro, Arcana (Activist Music (ASCAP), 2014) Note in Score, 10. 

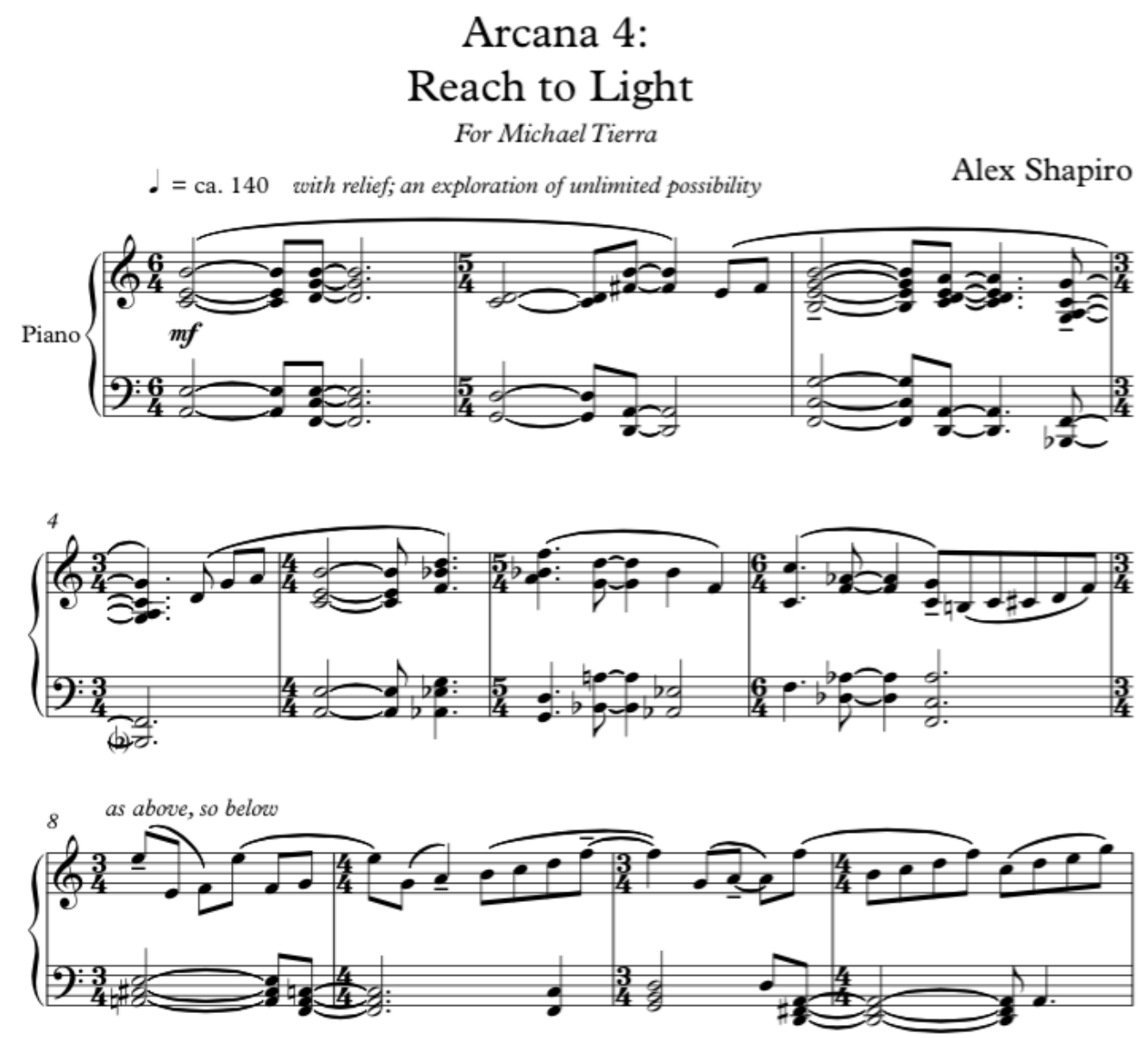

Musical Excerpt 6.15: Alex Shapiro, Arcana 4: "Reach to Light," mm. 1-11

A homophonic texture supports a sustained, cantabile melody and feels much like an improvisatory prayer. In m. 8, Shapiro inserts the mantra "as above, so below"128 as well as a concluding phrase "as within, so without" 129 in $\mathrm{m} .62$; this ancient saying also appears in her opening program notes (see Excerpt 6.16).

${ }^{128}$ Ibid.

${ }^{129}$ Alex Shapiro, Arcana (Activist Music (ASCAP), 2014) Note in Score, 13. 


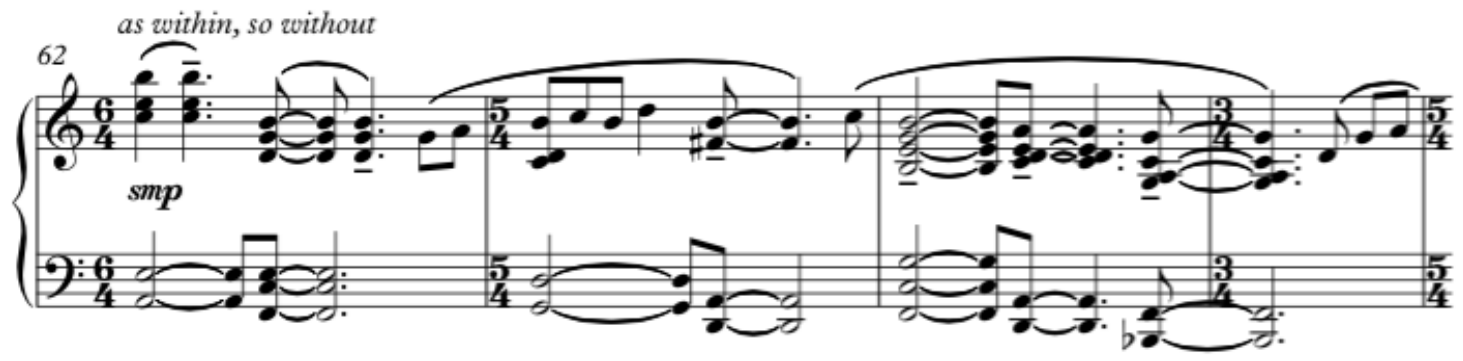

Musical Excerpt 6.16: Alex Shapiro, Arcana 4: "Reach to Light," mm. 62-64

The first half of this movement consists of gradually increasing motion through the use of moving eighth notes, alternating with calmer moments based on the opening material. The overall mood is hopeful and, in addition to open fifths and major triads, also contains several jazz harmonies and opportunities for improvisation. In fact, as seen in Example 6.17, at m. 40 Shapiro inserts seven measures marked only with the suggested successive pitches A, F, G, D, A, C, G, and D. Above these measures she writes: "improvisation of any length and nature is invited if desired, allow all possibilities...."130 This serves as a good example of aleatoric writing, also known as "chance music," in which some element of the performance is left to chance or individual interpretation.

Most of the remainder of the movement, mm. 47-67, is very similar to the opening material in mm. 8-27, continuing the free, improvisatory style (see Excerpt 6.17). The music ends with a sustained jazz chord on E-flat followed by a resolved Dmajor chord marked "at peace"131 (see Excerpt 6.18).

${ }^{130}$ Alex Shapiro, Arcana (Activist Music (ASCAP), 2014) Note in Score, 12. ${ }^{131}$ Alex Shapiro, Arcana (Activist Music (ASCAP), 2014) Note in Score, 13. 

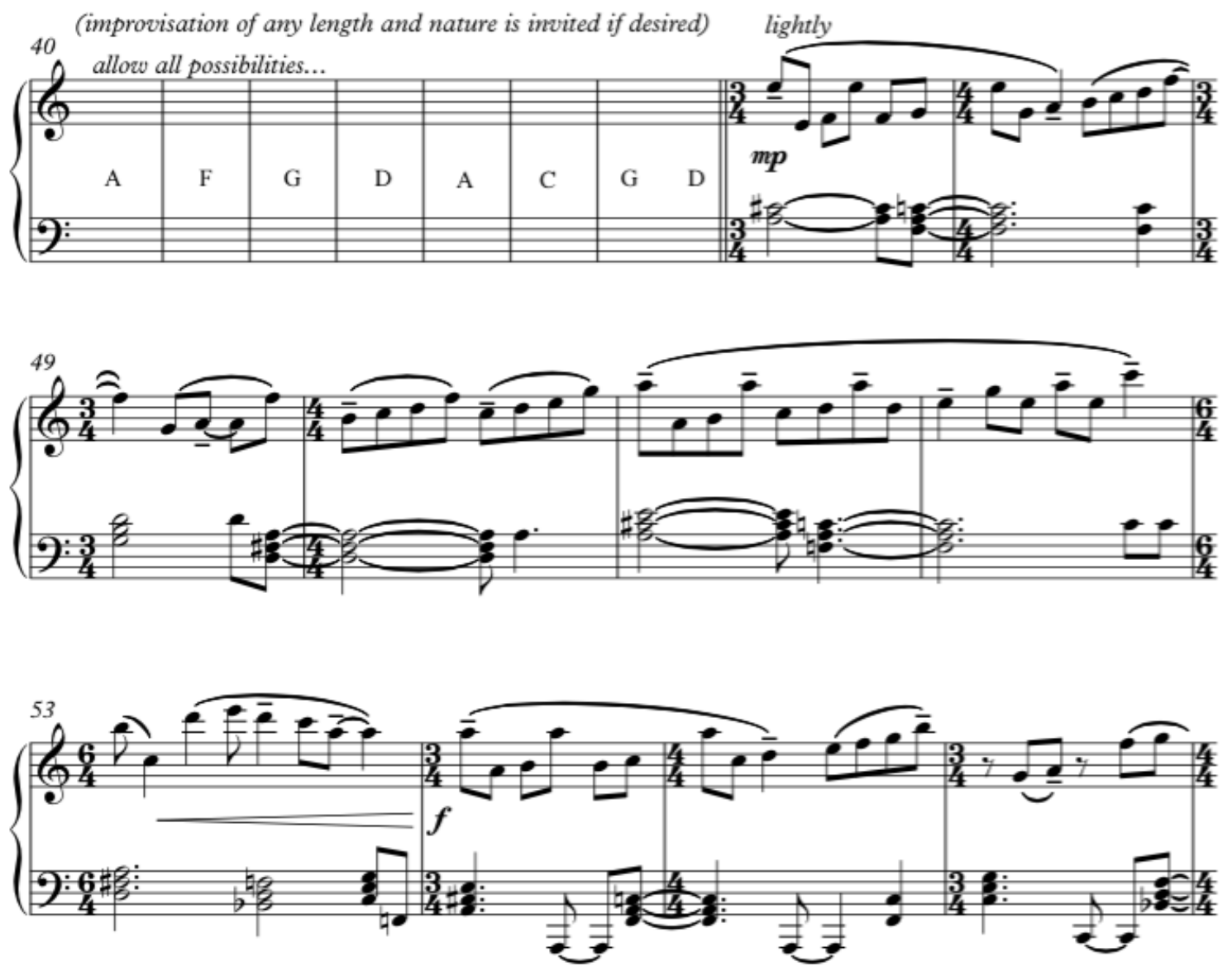

Musical Excerpt 6.17: Alex Shapiro, Arcana 4: "Reach to Light," mm. 40-56

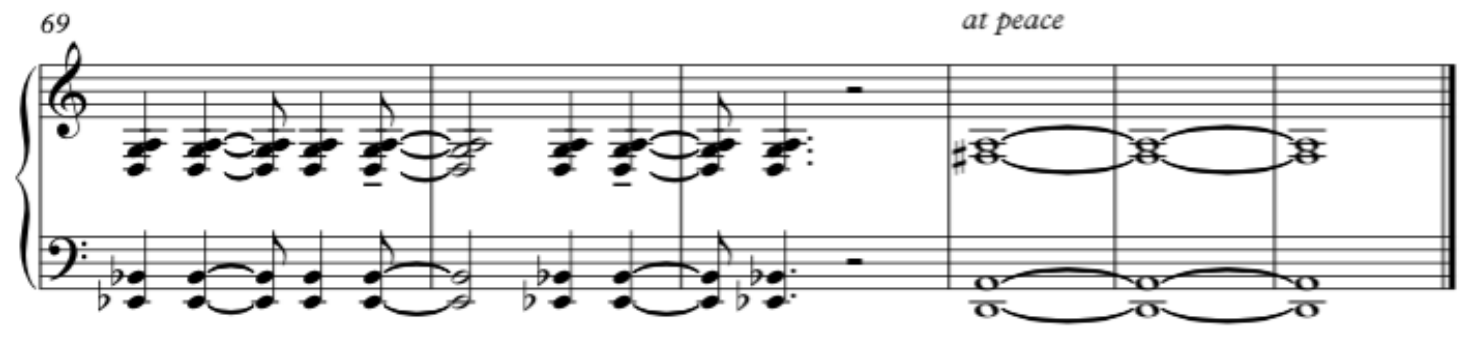

Musical Excerpt 6.18: Alex Shapiro, Arcana 4: "Reach to Light," mm. 69-74 


\section{V. "Branches and Vines"}

The fifth movement in the suite brings the listener back to a more introspective mindset, contrasting with the refreshingly confident and hopeful fourth movement. The opening is marked "very hesitantly; questioning; very rubato" and the tempo is much slower than in the previous movement, marked 70 to the quarter note. ${ }^{132}$ The meter is mostly $3 / 4$ or $6 / 8$, with one measure of $5 / 8$ in the final phrase. This supports the dancing motion; however, the slower tempo, use of rubato, hesitation, and thick, dissonant harmonies make it anything but a happy, carefree dance. In fact, this is the most disjunct and dissonant movement in the set. The right-hand melodic line is almost always in octaves throughout and the left hand is saturated with highly chromatic octaves and arpeggiated figures that are as aimless harmonically as the right hand's material. Excerpt 6.19 displays these elements in the opening of the piece.

${ }^{132}$ Alex Shapiro, Arcana (Activist Music (ASCAP), 2014) Note in Score, 14. 


\section{Arcana 5: \\ Branches and Vines}

For Michael Tierra
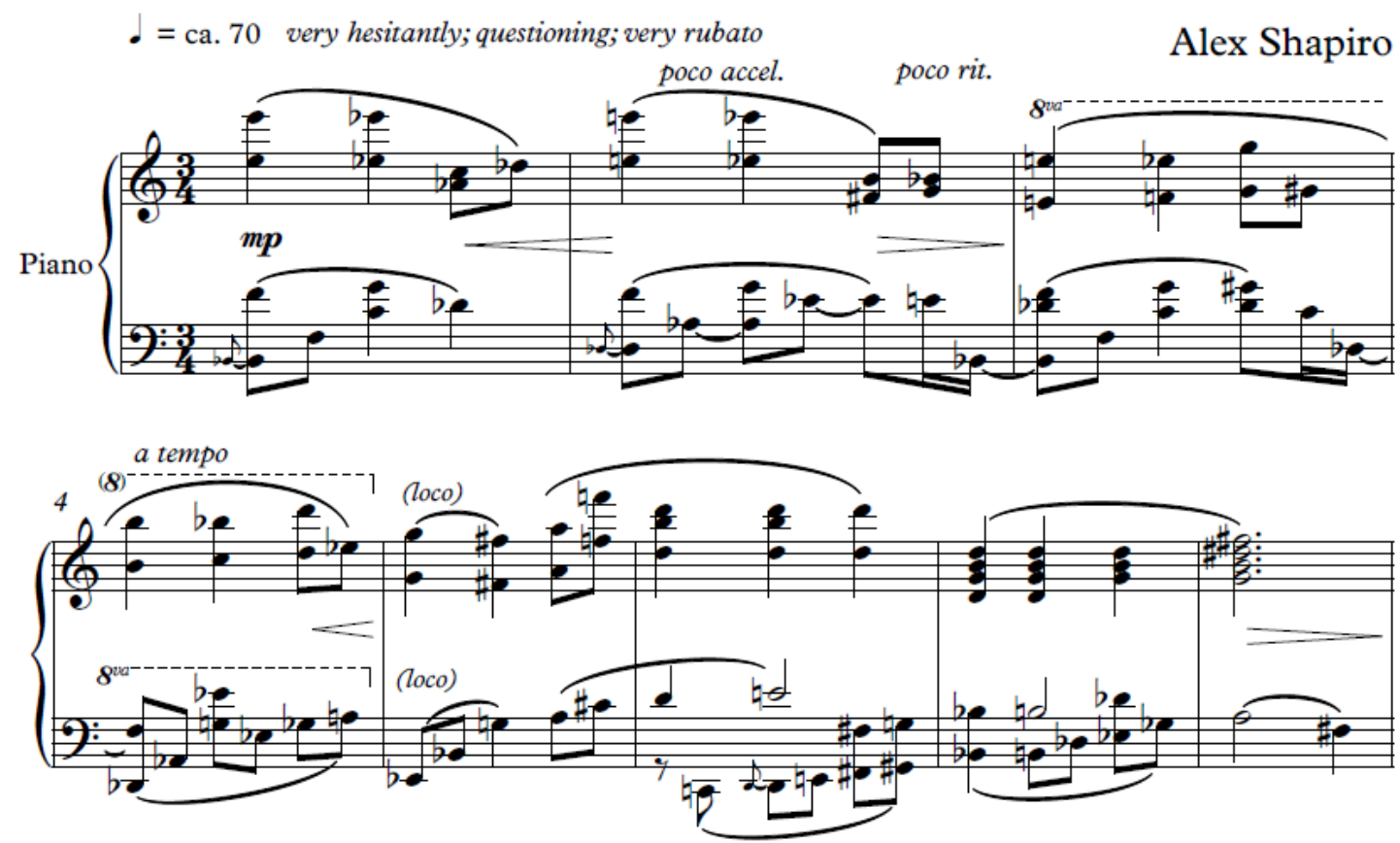

Musical Excerpt 6.19: Alex Shapiro, Arcana 5: "Branches and Vines," mm. 1-8

The hesitant mood of the opening changes in m. 18, marked by a shift from $3 / 4$ to $6 / 8$ meter, a return to the original tempo, and the marking "jaunty and relaxed; thickly confident"133 (see Excerpt 6:20).

${ }^{133}$ Alex Shapiro, Arcana (Activist Music (ASCAP), 2014) Note in Score, 15. 

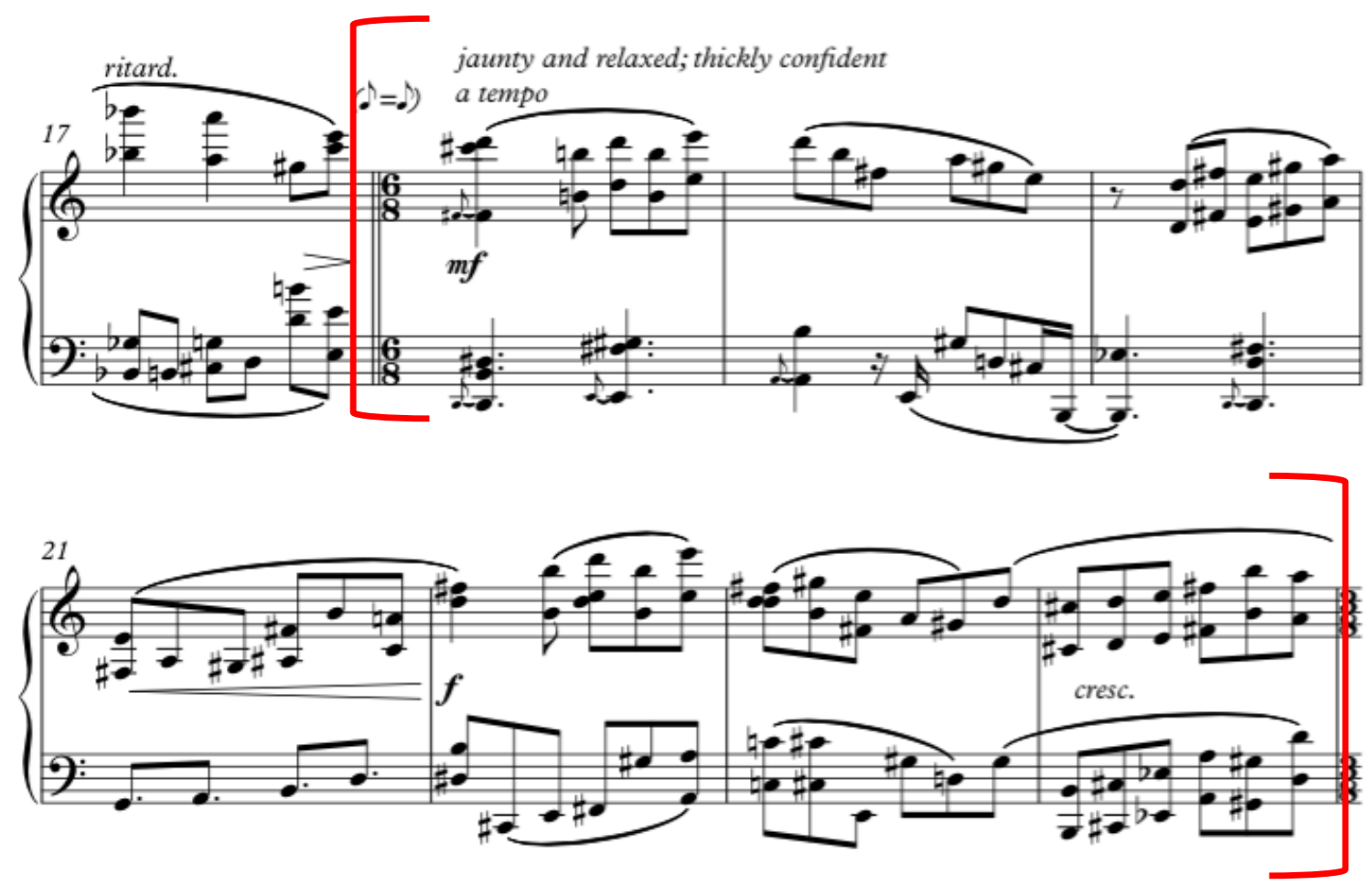

Musical Excerpt 6.20: Alex Shapiro, Arcana 5: "Branches and Vines," mm. 18-24

The harmonies of this section are just as chromatic and dissonant as in the first;

but it feels more confident, or at least more urgent. The eighth-note melodic motion in the $6 / 8$ passage provides a sense of forward motion, contrasting with the $3 / 4$ meter that returns in measure 26 (see Excerpt 6.21). 


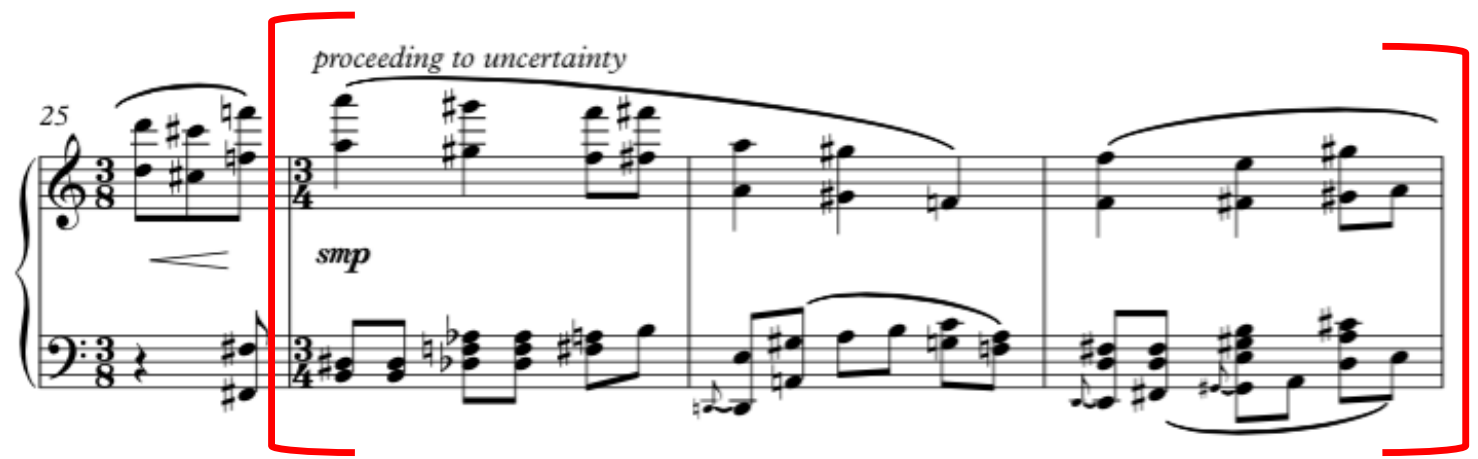

Musical Excerpt 6.21: Alex Shapiro, Arcana 5: "Branches and Vines," mm. 26-28

Here the music is marked "proceeding to uncertainty," 134 followed by a final section in $6 / 8$, which represents a compromise between the two opposing emotions of confidence and caution (see Excerpt 6.22). This final section is marked accordingly: "the meeting of two selves jaunty and assured, but questions linger." ${ }^{135}$ The music ends on a sustained, dissonant chord that is marked "doubt remains"136 (see Excerpt 6.23).

${ }^{34}$ Ibid.

135 Alex Shapiro, Arcana (Activist Music (ASCAP), 2014) Note in Score, 16. ${ }^{136}$ Ibid. 

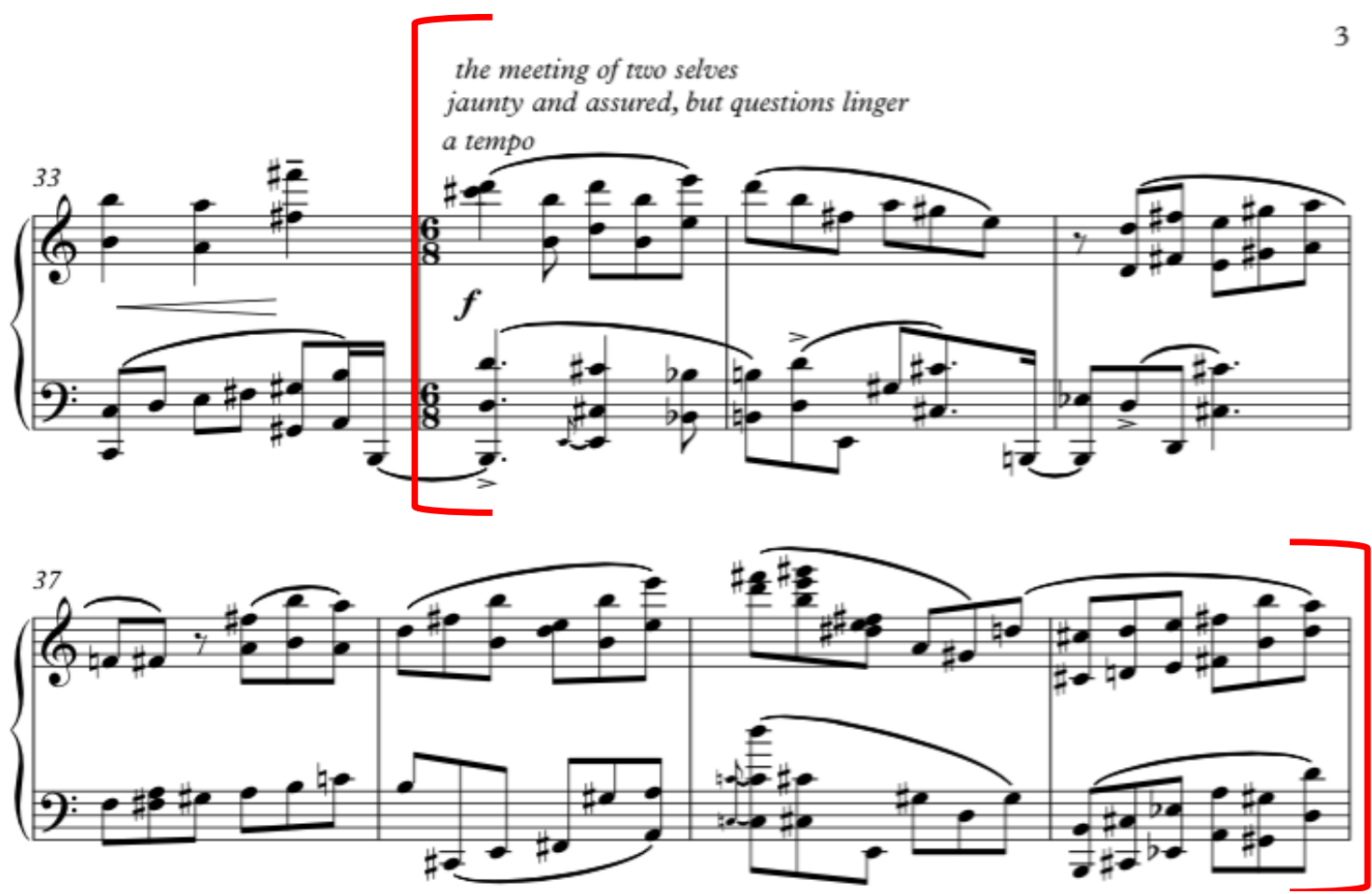

Musical Excerpt 6.22: Alex Shapiro, Arcana 5: "Branches and Vines," mm. 34-40 


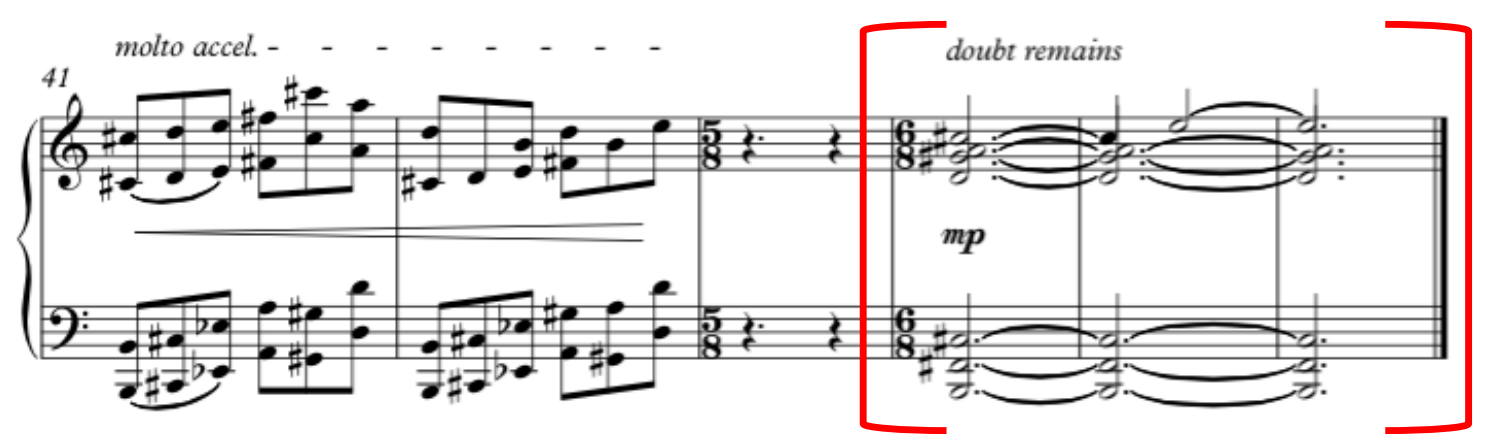

Musical Excerpt 6.23: Alex Shapiro, Arcana 5: "Branches and Vines," mm. 44-46 


\section{VI. "Touch It"}

Movement six is the most spirited piece in this suite. Here Shapiro's pianistic background comes to light. Using a common idiomatic piano genre, the toccata, (meaning "to touch"), she applied this concept not only to the piano part but also to the theme of the suite. Here Shapiro expanded the concept of touch to embrace the many wonders of life and the power that humans have to experience and influence life itself.

The opening is marked 105 to the quarter note, with the annotation "a spritely toccata." ${ }^{137}$ Both hands are in unison at the octave until m. 5 (see Excerpt 6.24). Throughout the movement, Shapiro marks the syncopated melody with accents, amidst a constant sixteenth-note, broken-chord texture (see Excerpt 6.25). She is more concerned with the presentation of the melody than the rest of the notes. In fact, she comments at the opening of the movement, "while the exact ink is preferred, pianist may pay most attention to the L.H. melody and rhythm, and allow the R.H. ostinato to fall where it may."138

${ }^{137}$ Alex Shapiro, Arcana (Activist Music (ASCAP), 2014) Note in Score, 17. ${ }^{138}$ Ibid. 


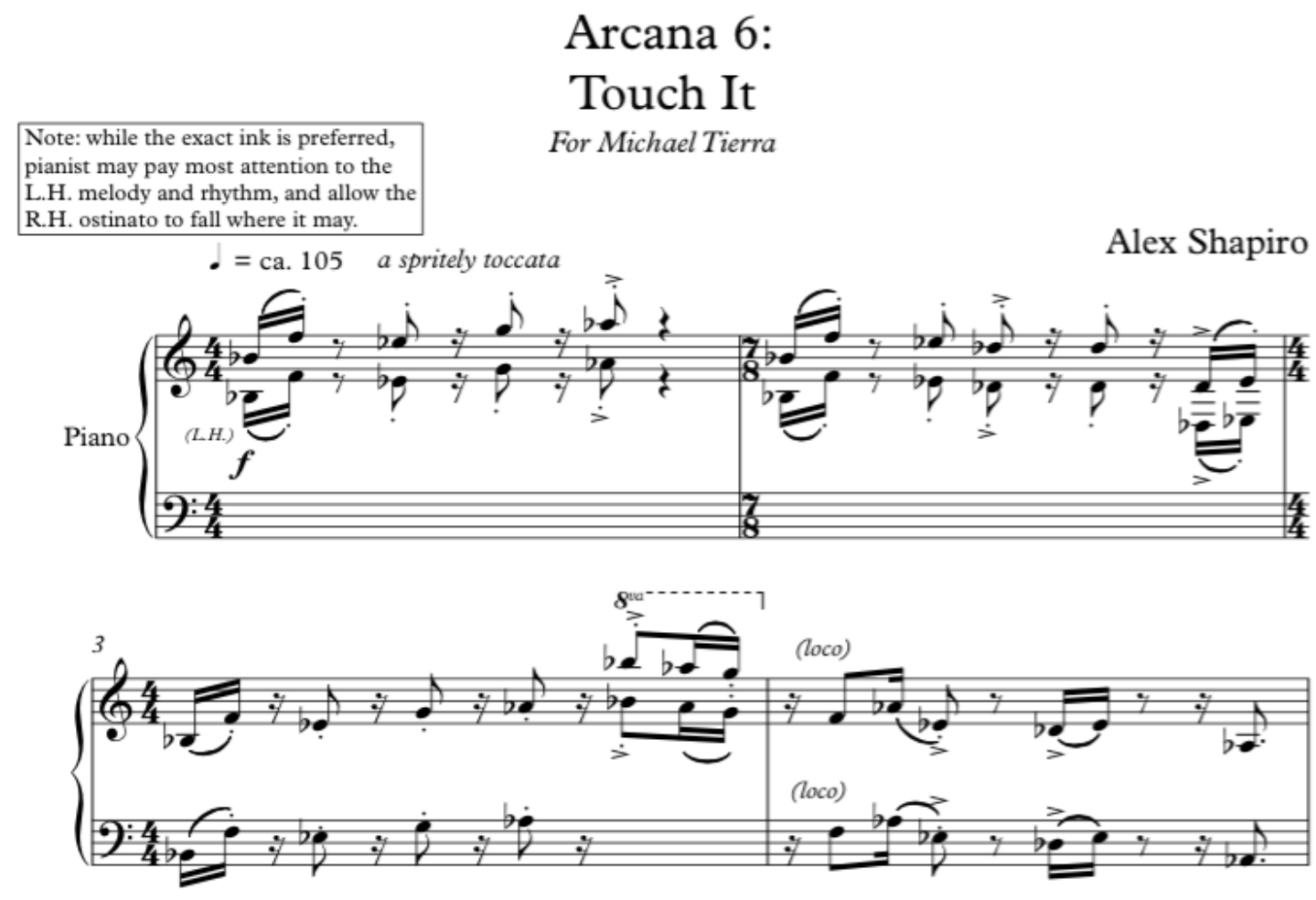

Musical Excerpt 6.24: Alex Shapiro, Arcana 6: "Touch It," mm. 1-4
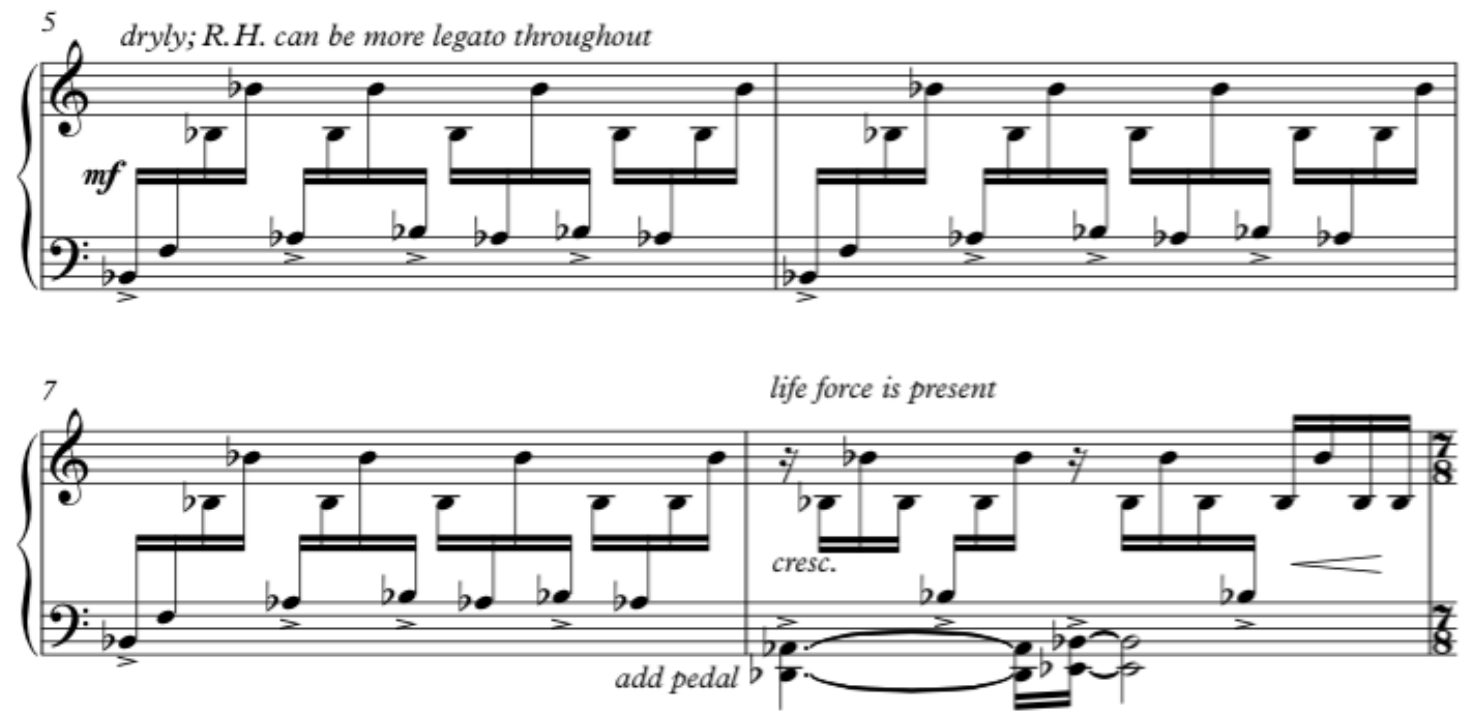

Musical Excerpt 6.25: Alex Shapiro, Arcana 6: "Touch It," mm. 5-8 
The music has a strong sense of perpetual motion and, as in all the other

movements, contains written suggestions such as "life force is present,"139 "the senses thrive," 140 and "energy abounds." 141 Shapiro guides the pianist as to how much or how little pedal to use throughout, providing variation amidst a very repetitive texture (see Excerpt 6.26).

${ }^{139}$ Ibid.

${ }^{140}$ Alex Shapiro, Arcana (Activist Music (ASCAP), 2014) Note in Score, 18. ${ }^{141}$ Alex Shapiro, Arcana (Activist Music (ASCAP), 2014) Note in Score, 20. 

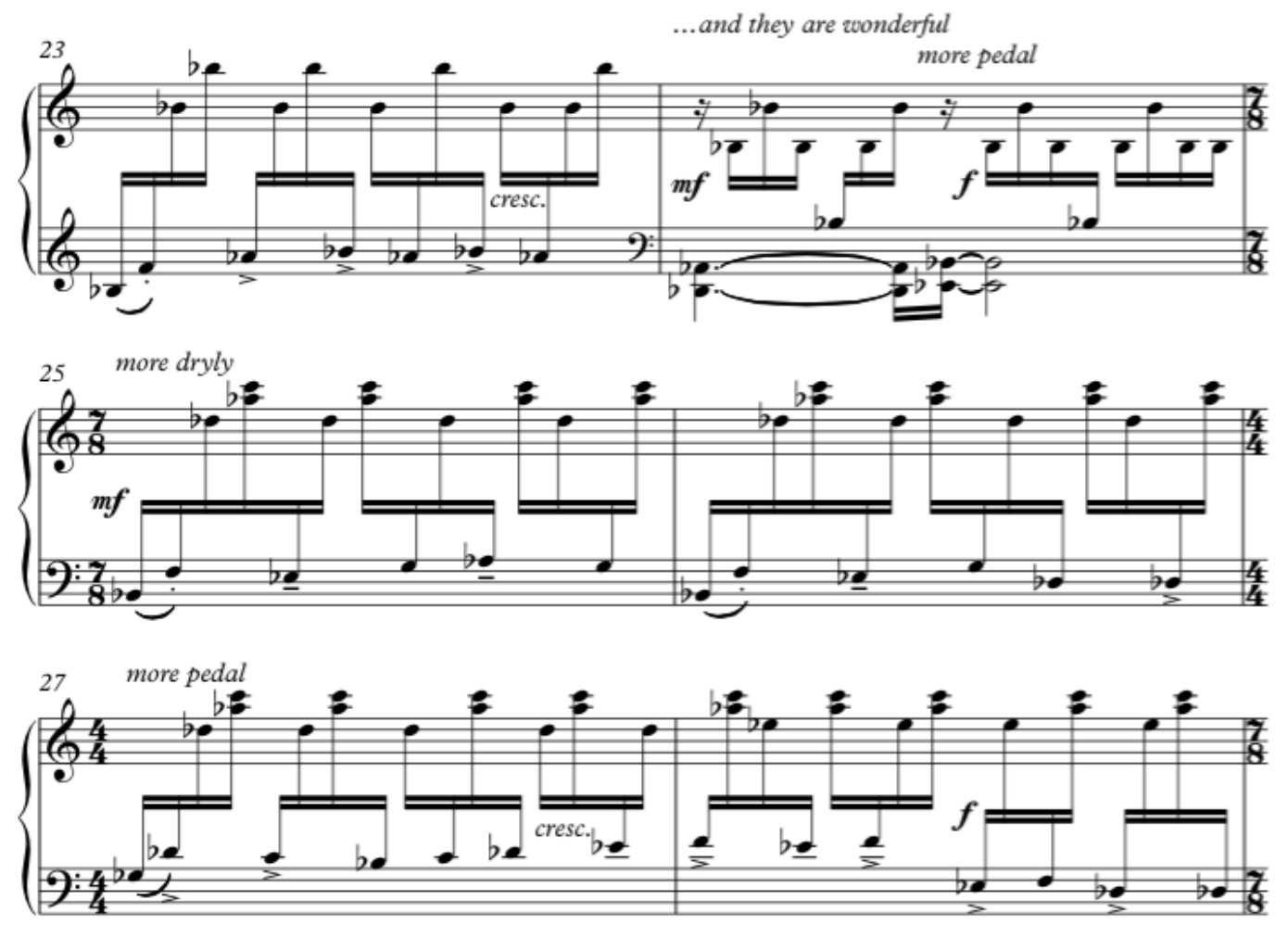

Musical Excerpt 6.26: Alex Shapiro, Arcana 6: "Touch It," mm. 23-28 
Excerpt 6.27 shows the ending, which is highly climactic, with octaves in both hands and the marking "slightly bombastic," 142 followed by the final passionate suggestion to "go towards life's fire and touch it with your wand."143 This phrase is also from herbalist/pianist Michael Tierra's project called "The Herbal Tarot."144

While this movement is similar in modal language to the other movements of Arcana, it also has a clear tonal center of B-flat that occurs in the bass line throughout the movement.

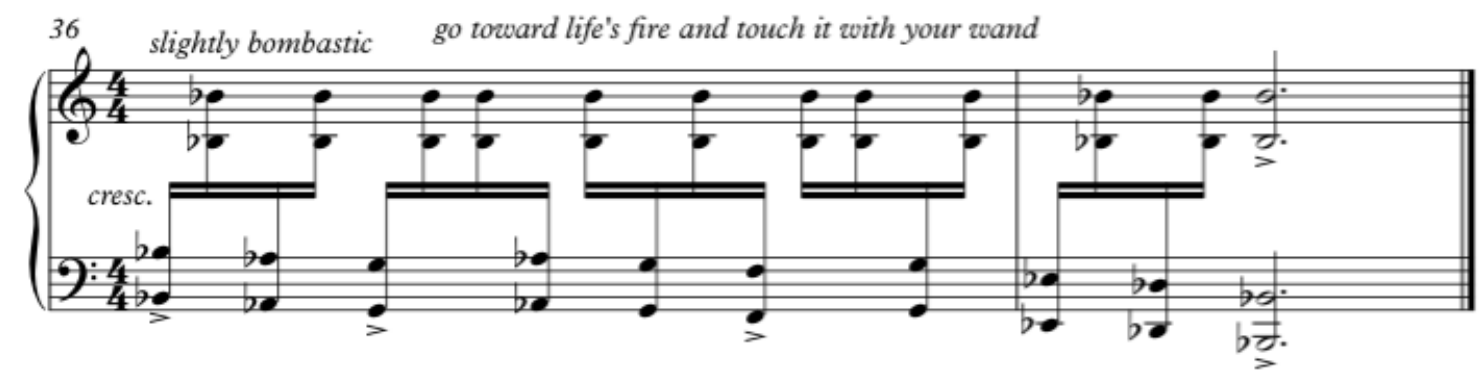

Musical Excerpt 6.27: Alex Shapiro, Arcana 6: "Touch It," mm. 36-37

${ }^{142}$ Ibid.

${ }^{143}$ Ibid.

${ }^{144}$ Alex Shapiro, email message to author, June 15, 2015. 


\section{VII. "Search"}

The seventh movement in the suite contains a narrative similar to that of movement two, the concept of attempting to grow, finding the ability to trust or have faith, and facing opposing threats. Whereas in the second movement trust and strength seem to win over or persevere through fear and doubt, the seventh movement portrays a darker theme. Here the musical material and narrative take the listener to places where fears and threats are real, overwhelming, and confusing to the one "searching."

The opening is meditative and spacious, consisting of a simple arpeggiated figure. The music is marked 110 to the quarter note and "quietly, at first; floating." 145 Time stands still for a moment while the right hand sustains an F octave in the high register of the piano (see Excerpt 6.28).

${ }^{145}$ Alex Shapiro, Arcana (Activist Music (ASCAP), 2014) Note in Score, 21. 


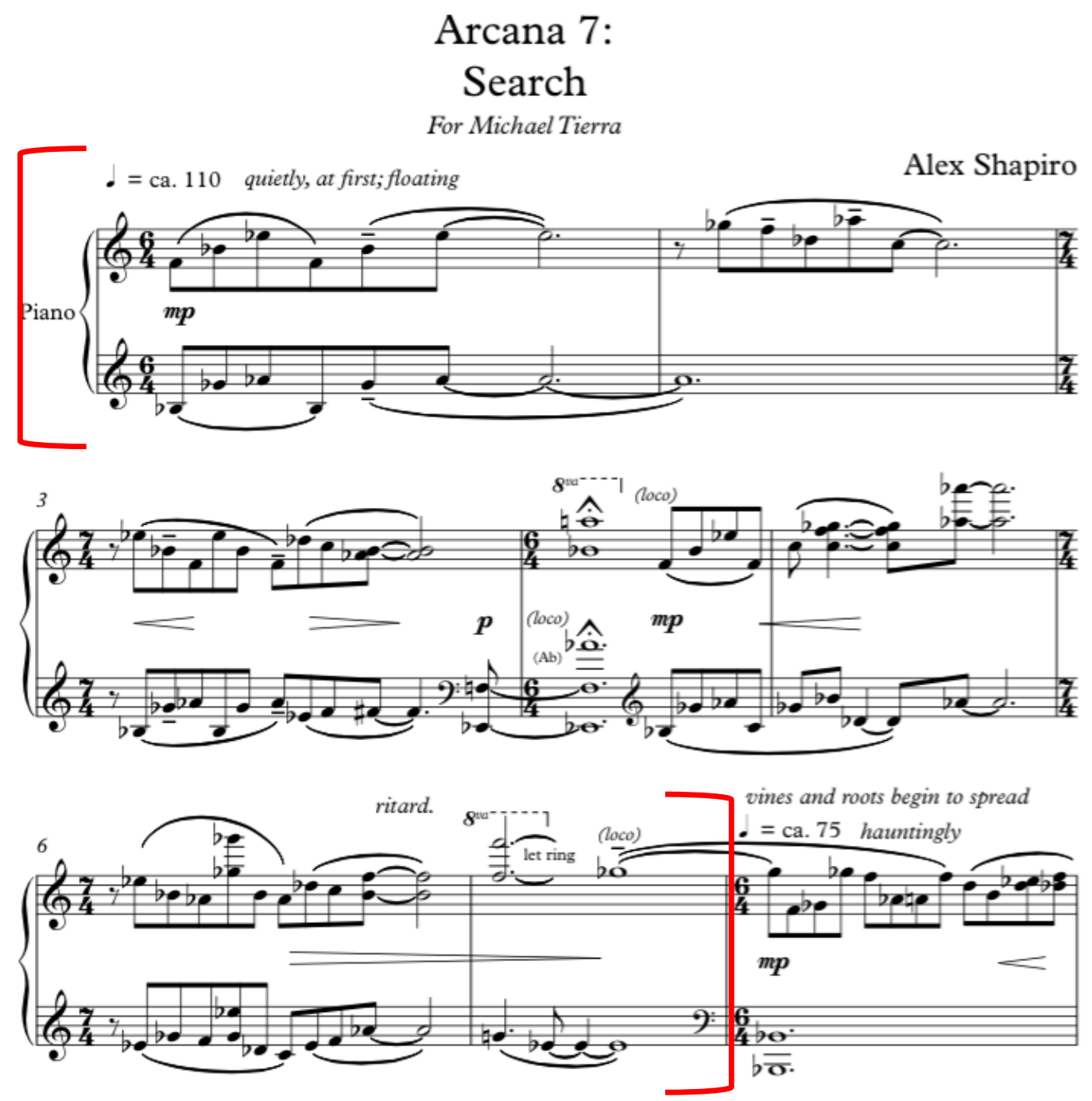

Musical Excerpt 6.28: Alex Shapiro, Arcana 7: "Search," mm. 1-7

This is followed by a shift in the atmosphere. The music is marked "vines and roots begin to spread," and "hauntingly" 146 in $\mathrm{m}$. 8, with the quarter note slowing down to 75 beats per minute. A haunting minor and dissonant melody gives the effect of "searching," as the title indicates, over long pedal tones in the bass. The augmented-fifth motion from E-flat to B-natural in the bass at $\mathrm{m} .11$ and the increasingly dramatic ${ }^{146}$ Ibid. 
ascending melodic line in the right hand are accompanied by the text "alarming changes have altered the ground and air"147 (see Excerpt 6:29).
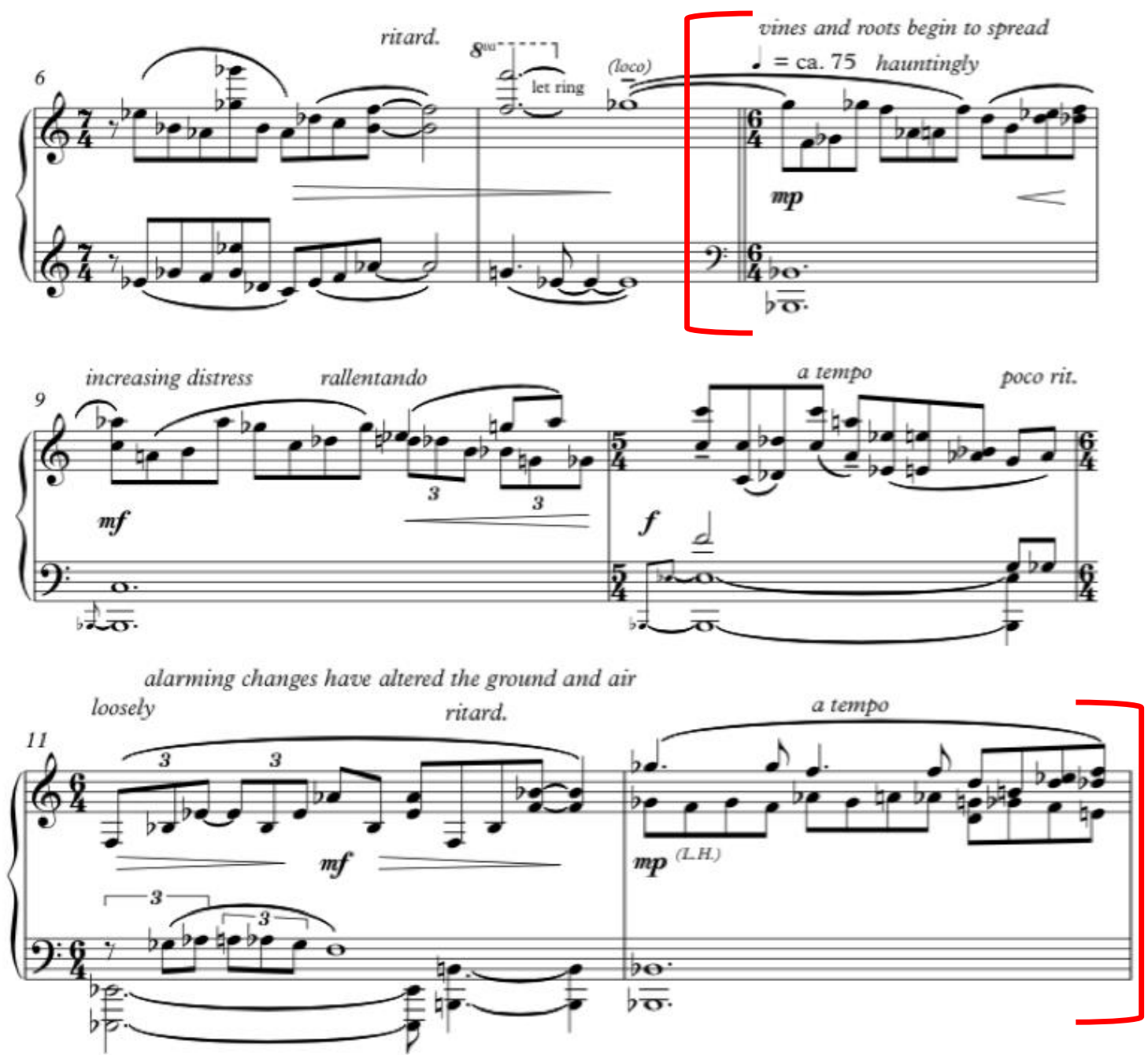

Musical Excerpt 6.29: Alex Shapiro, Arcana 7: "Search," mm. 8-12

By m. 14, the melody has reached three octaves above middle $\mathrm{C}$ and is heavily emphasized in octaves and with accents, as if crying out. It is supported by a sonorous interval of an eleventh from B-flat and E-flat in the left hand (see Excerpt 6.30).

${ }^{147}$ Alex Shapiro, Arcana (Activist Music (ASCAP), 2014) Note in Score, 22. 


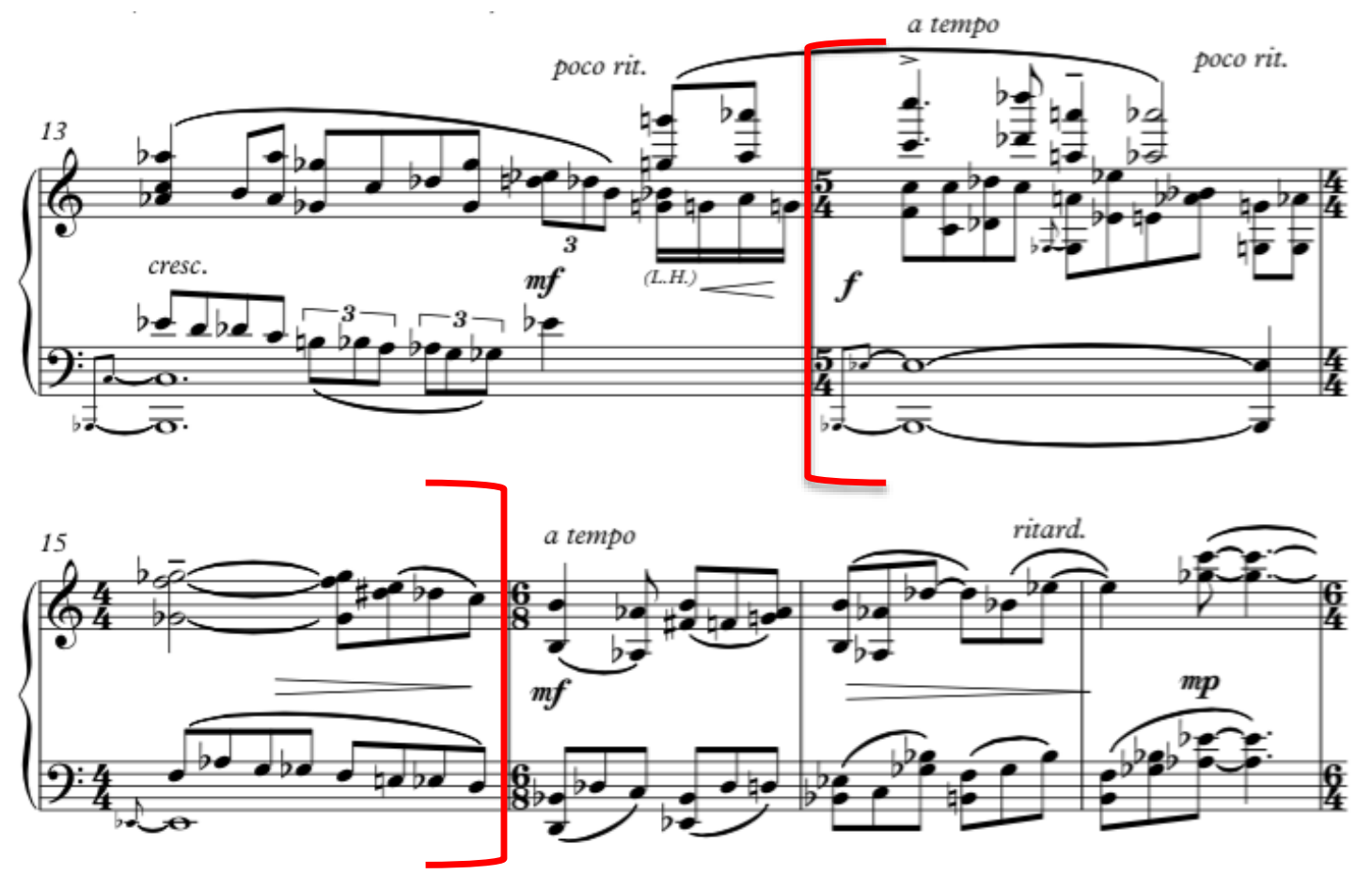

Musical Excerpt 6.30: Alex Shapiro, Arcana 7: "Search," mm. 14-15

Over the next eight measures the mood becomes increasingly dark. The text reads: "quietly menacing," 148 marked by a momentary ritard and a dissonant, minor-key melody; Shapiro also indicates "near terror,"149 "fear interrupted," reassurance." ${ }^{151}$ In $\mathrm{m} .26$ the opening faster tempo and similar melodic figures return, marked "an uneasy calm"; ${ }^{152}$ but this lasts only for six measures before returning to increased chaos and fear (see Excerpt 6.31).

148 Ibid.

${ }^{149}$ Alex Shapiro, Arcana (Activist Music (ASCAP), 2014) Note in Score, 23.

${ }^{150}$ Ibid.

151 Ibid.

152 Ibid. 


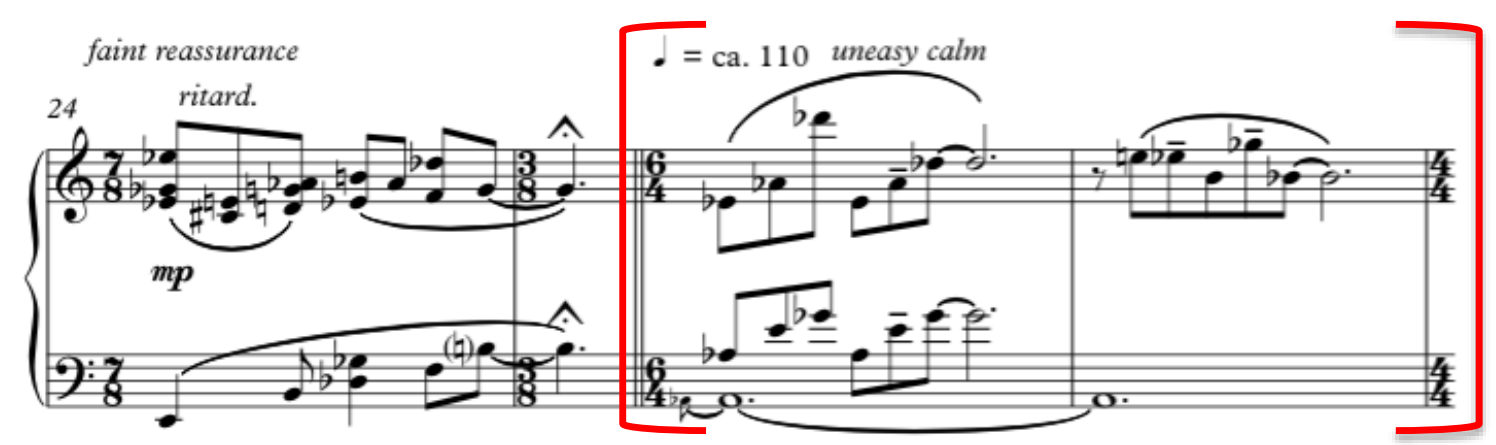

Musical Excerpt 6.31: Alex Shapiro, Arcana 7: "Search," mm. 26-27

The remainder of the piece is increasingly tumultuous, with the exception of a final brief moment of optimism in m. 52-54, marked "undeterred, roots and vines continue reaching toward what they need"153 (see Excerpt 6.32). The remaining textual suggestions include "a threatening horizon,"154 "with urgency,"155 "a storm of conflict approaches,"156 "furious,"157 “a desperate search,"158 and finally "doom and dread."159

${ }^{153}$ Alex Shapiro, Arcana (Activist Music (ASCAP), 2014) Note in Score, 25.

${ }^{154}$ Ibid.

${ }^{155}$ Ibid.

${ }^{156}$ Alex Shapiro, Arcana (Activist Music (ASCAP), 2014) Note in Score, 24.

${ }^{157}$ Ibid.

${ }^{158}$ Alex Shapiro, Arcana (Activist Music (ASCAP), 2014) Note in Score, 25.

${ }^{159}$ Alex Shapiro, Arcana (Activist Music (ASCAP), 2014) Note in Score, 26. 
undeterred, roots and vines continue reaching toward what they need
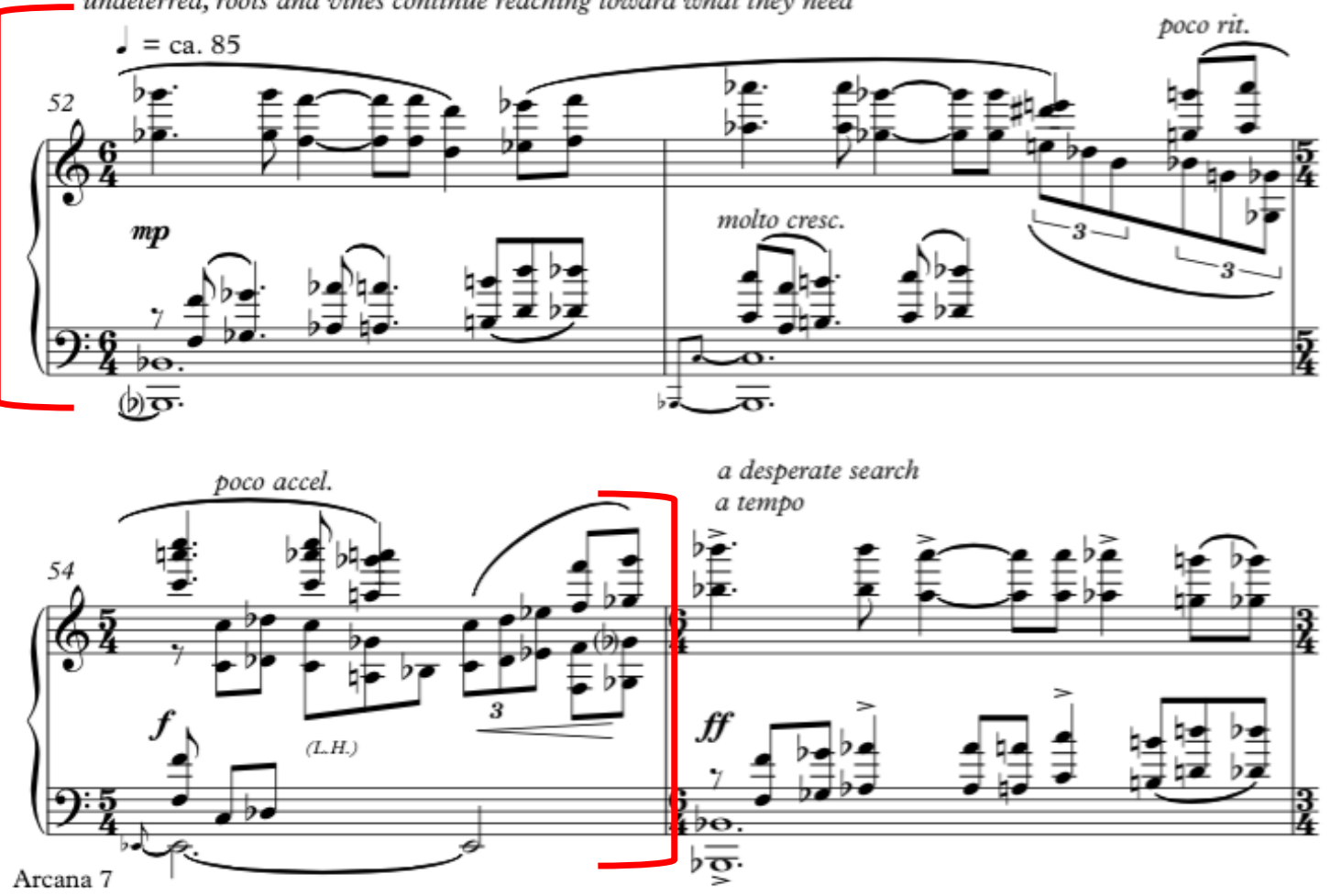

Arcana 7

Musical Excerpt 6.32: Alex Shapiro, Arcana 7: "Search," mm. 52-54

The final measures consist of octave passages in both hands; the right hand carries a restless melodic line further into the high registers of the piano, effectively displaying the desperate search for light, necessary for the plant's survival. It concludes with a sudden drop in both hands to the bass register, an echo of the unsettling main motivic idea and the foreboding words "doom and dread"160 (see Excerpt 6.33).

"Search" contains many modal harmonies, as in the rest of the suite, and a tonal center of B-flat, provided by pedal tones, as in the previous movement. However, it is more chromatic and harmonically unstable than in the previous movement, appropriately depicting the title of the piece.

${ }^{160}$ Ibid. 

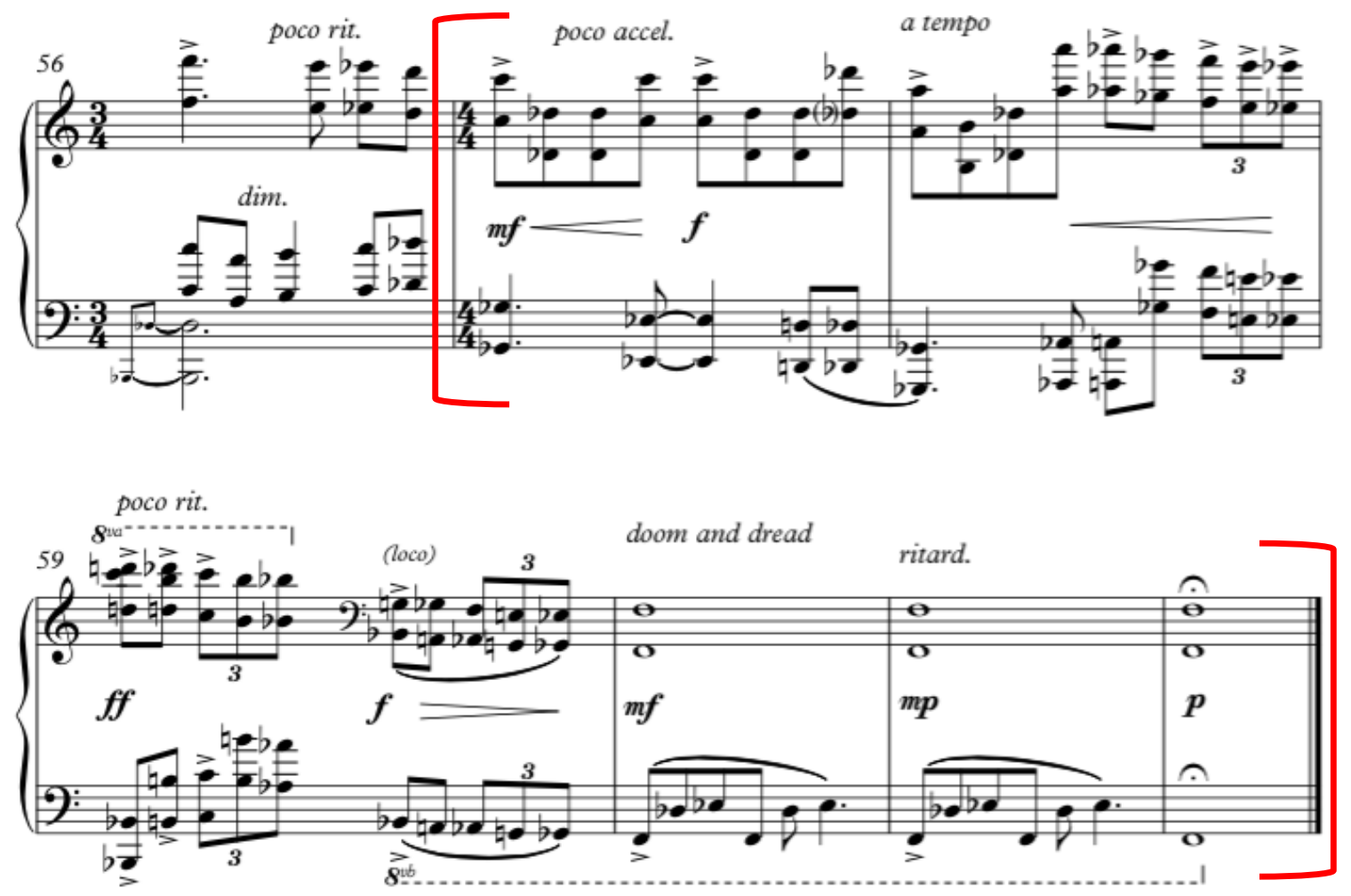

Musical Excerpt 6.33: Alex Shapiro, Arcana 7: "Search," mm. 57-62 


\section{VIII. "From Earth To Sky"}

The final movement in this suite begins the same way the first one did: the pianist plays the highest and lowest pitches on the piano, while embracing the instrument. Shapiro gives the same programmatic instructions as in the first movement,

Pianist begins by slowly lowering head to keys and grasping both ends of piano with hands, to lovingly hug the meaning of the healing plants, as these ledger lines and ties are purposely drawn to surround and embrace the meaning of the notes. The piano embodies the earth we love. ${ }^{161}$

As a conclusion to the entire set, this movement is the most resolved, both narratively and harmonically. Following the meditative introduction, $\mathrm{m} .12$ begins with a calm, peaceful message, written in 6/4 meter, with relatively more consonant harmonies.

Shapiro writes, "gently, with grace; a little slower."162 Her use of extended harmonies and disjunct ranges is still evident; but the overall mood of this movement is comparatively calmer and more resolved (see Excerpt 6.34).

${ }^{161}$ Alex Shapiro, Arcana 8: From Earth To Sky (Activist Music (ASCAP), 2014) Program Note.

162 Alex Shapiro, Arcana (Activist Music (ASCAP), 2014) Note in Score, 27. 

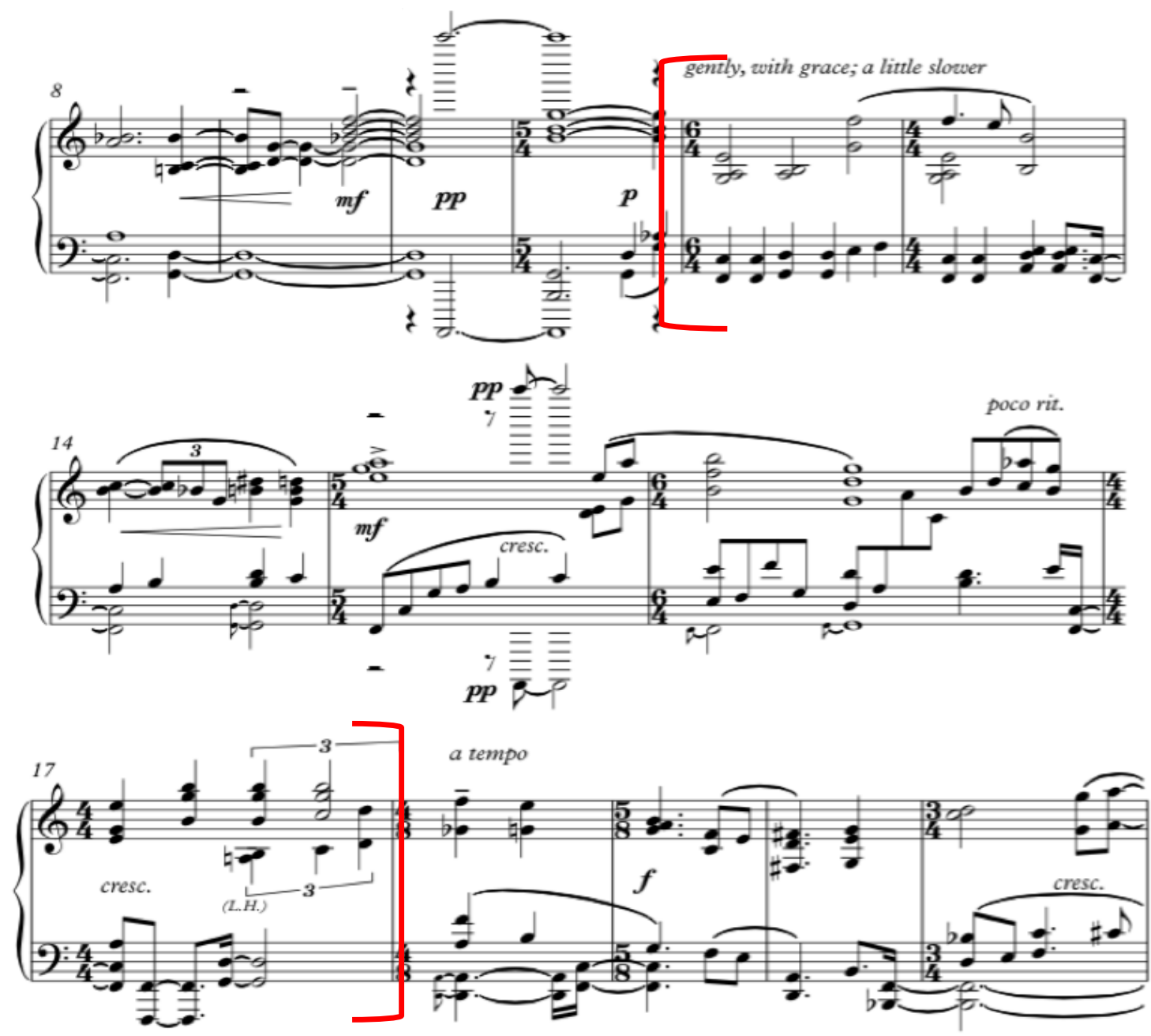

Musical Excerpt 6.34: Alex Shapiro, Arcana 8: "From Earth To Sky," mm. 12-17 
In m. 34 she writes, "arriving at magic and understanding."163 The music symbolizes this idea in several ways: The melody reaches into the high range of the piano and consists of simple, sustained material that sounds magical in its own right. In addition, Shapiro uses imitation, passing fragments of the melody through the alto and tenor voices, as if answering oneself with understanding (see Excerpt 6.35).
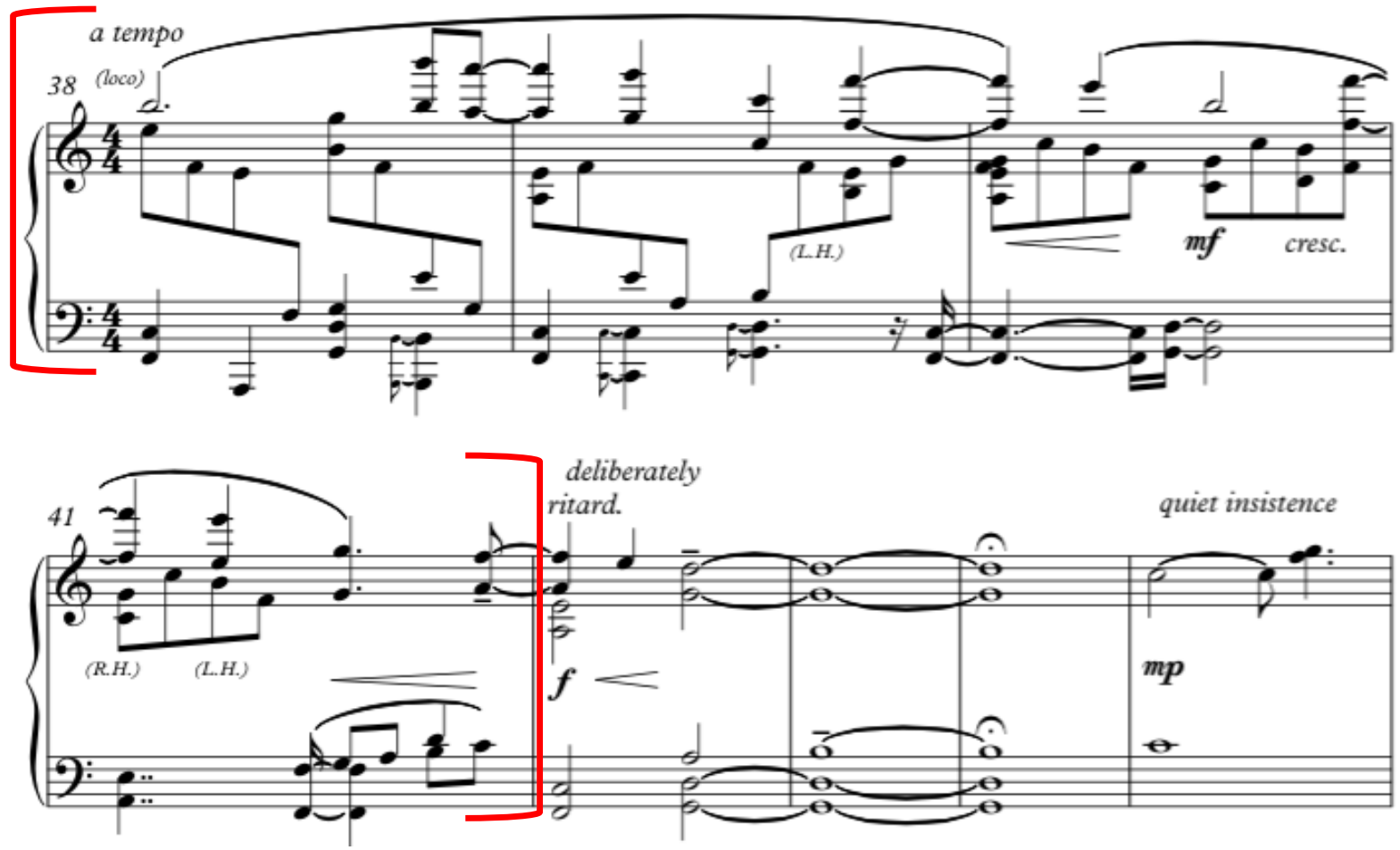

Musical Excerpt 6.35: Alex Shapiro, Arcana 8: "From Earth To Sky," mm. 38-41

${ }^{163}$ Alex Shapiro, Arcana (Activist Music (ASCAP), 2014) Note in Score, 29. 
In mm. 42-44, marked “deliberately," the music resolves on a refreshing G-major chord, followed by a "quiet insistence," 164 with a simple statement in the right hand (see Excerpt 6.36).

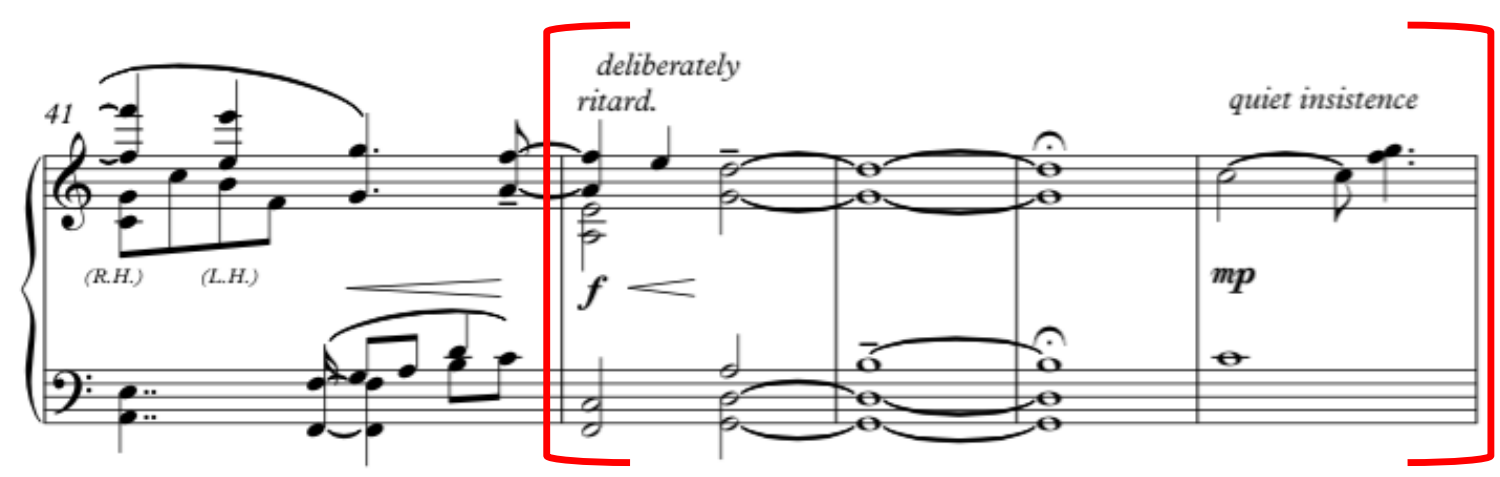

Musical Excerpt 6.36: Alex Shapiro, Arcana 8: "From Earth To Sky," mm. $42-45$

At the conclusion, the music becomes increasingly loud and is marked by long, sustained, tied chords and the text "raise your sword of wisdom to the air," and "we have the power to protect the earth and its healing gifts." 165 The final chord is marked fortissimo and consists of a $\mathrm{C}$ major 7 chord with an added $9^{\text {th }}$ and $11^{\text {th }}$, the $7^{\text {th }}$ occurring in the lowest bass and top voices. It spans seven octaves (see Excerpt 6.37)! The message conveyed is one of resolution, truth, hope and responsibility.

${ }^{164}$ Ibid.

${ }^{165}$ Ibid. 


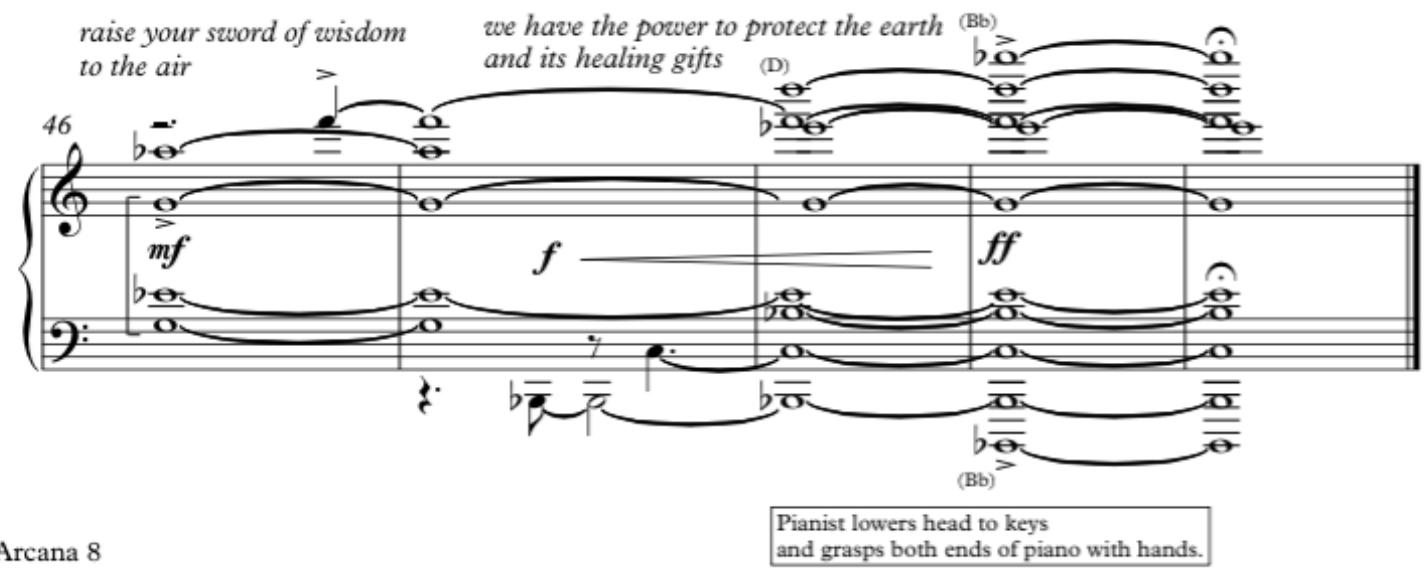

Musical Excerpt 6.37: Alex Shapiro, Arcana 8: "From Earth To Sky," mm. 46-50 


\section{Conclusion}

Shapiro's eight-part piano suite Arcana is her most-recent piano work; in her opinion (and also the author's), it is one of her most successful to date. Part of what makes this piece so successful is the effective way that Shapiro combines all eight

movements by means of programmatic writing based on similar themes of life, nature and the struggle to coexist. For example, written and visual cues, such as placing a light inside the piano, and embracing the instrument, symbolize unity of humans and plant life. Ideas such as this are used at both the beginning and end of the suite, adding to unity of the whole work. In addition, throughout each movement, the suite embodies the theme of life, specifically the healing powers of plants and nature; it also speaks to the fragile, often perilous, relationship between humans and plants.

Many of Shapiro's compositional characteristics are evident in this work: frequently changing meters, disjunct ranges, the use of extended and jazz harmonies, frequent dissonance and shifting tonal centers, modal writing, and soaring melodic lines. There are also many examples of idiomatic piano writing in this set, such as in the toccata in Movement VI, the effective use of the full range of the piano, and various sounds created by use of the damper pedal. In addition, Shapiro employs extremes in dynamics and creates variety through articulation and depth of pedal. Much of the suite is legato, but contains frequent changes in tempi, meter and rhythmic pulse. Shapiro combines these techniques to give the music a natural sense of breath, turning the piano into a symbolic representation of plant life, a living and breathing organism. This composition is most appropriate for advanced pianists. The wide jumps, sensitivity to timing and 
meter, ability to improvise, and overall understanding of the harmonic and melodic material require maturity in musical artistry as well as good technique. 


\section{Chapter Seven}

\section{Chamber Works with Piano or Harpsichord; and Solo Repertoire for other Keyboard Instruments}

\section{Introduction}

As is evident in the previous study of Shapiro's solo piano works, she is a composer who loves to break the mold, especially when it comes to exploring timbres. This chapter serves as a reference for her many instrumental collaborative works including piano or harpsichord, as well as her one solo piece for organ. While the pieces discussed in this chapter are studied in less detail than previous chapters, the purpose is to introduce all of her keyboard works, giving a more complete picture of her compositional output. In addition, these works are evidence of Shapiro's diverse use of compositional techniques, including various genres, timbres and electronic sounds, beyond her solo keyboard repertoire.

Some pieces excluding keyboard instruments will also be mentioned, where they relate to themes that do include works for keyboard. For example, Shapiro wrote a series of pieces based on the theme of desert land for various solo instruments as well as instrumental chamber music, some of which include the piano. Many of her pieces make use of prerecorded audio, sometimes even incorporating sounds from nature, a consistent element in much of her music, as she is also a passionate wildlife advocate. Most of the comments on each work are taken, with permission from Alex Shapiro, directly from her webpage, of which she is the author and owner. 


\section{Duets with Piano}

To date, Shapiro has composed fourteen duets with piano. They can be organized into four sets: seven arrangements of one work based on the theme of touch; three arrangements of Intermezzo, originally composed for solo piano; three humorous arrangements titled Brat, for various combinations with piano, plus one arrangement for harpsichord instead of piano; and one work titled Music for Two Big Instruments, also arranged as Music for Four Big Instruments. Intermezzo includes additional arrangements for instrumental combinations not including piano. There are no examples of prerecorded audio among these duets, but there is an abundance of variety in instrumental combinations, as well as a bit of comedy.

\section{Of Breath and Touch and Related Arrangements}

Date of Composition: 1999

Duration: 10:00 minutes

Description: One-movement work. 16 pages, 8.5 " x 11 "

Instrumentation: Bassoon and Piano

Publisher: Activist Music (ASCAP)

Score Location: alexshapiro.org < Works < Piano < Duets < Of Breath and Touch

Score Formats Available: Print or Digital

Available Recordings:

1. mp3 audio clip

2. Carolyn Beck's 2005 CD, Beck and Call

Location of Recordings:

1. alexshapiro.org < Works < Duets < Of Breath and Touch

2. alexshapiro.org $<$ Purchase $<$ Purchase CDs

\section{Related Arrangements With Piano:}

1. Of Bow and Touch (2000) for Double Bass and Piano

2. Of Air and Touch (2001) for Oboe and Piano

3. Of Wood and Touch (2001) for Cello and Piano 
4. Of String and Touch (2006) for Viola and Piano

5. Of Wind and Touch (2006) for Baritone Saxophone and Piano

6. Of Song and Touch (2011) for Euphonium and Piano

\section{Related Arrangements Without Piano: None}

\section{Composer's Webpage Notes on the Score:}

At the time I began composing Of Breath and Touch, I happened to be listening to works by the French composers Ravel, Debussy and Satie as well as to traditional music from Egypt and Turkey. There are unexpected parallels in the types of minor scales used by each country's musicians, as well as between the disparate cultures' use of reed instruments. The bassoon is remarkably well suited for some of the long, floating melodies that are often heard in Middle Eastern music, usually played by wind instruments like the ney or the mizmar. Two years later, I chose to adapt this piece for oboe for similar reasons.

While I couldn't easily explore microtonality in a duet that strongly features the all-too-well tempered piano, I did reference the driving rhythms of some Middle Eastern music in a hypnotic and ostinatic piano part that's fun to play, and the double reed writing showcases the extraordinary range and tone of the instrument in the hands of a fine player. The result is a uniquely American piece that is informed by other cultures. The title refers to the nature of each instrument, as well as to a more sensual pair of pleasures. ${ }^{166}$

\section{Intermezzo and Related Arrangements}

Date of Composition: 1998

Duration: 4:00 minutes

Description: One-movement work for solo piano. 6 pages, 8.5 " x 11 "

Publisher: Activist Music (ASCAP)

Score Location: alexshapiro.org < Works < Piano < Intermezzo for Piano

Score Formats Available: Print or Digital

Available Recordings:

1. mp3 audio clip

2. Jenny Olson's 2012 CD, The Dreams of Birds (version for bass flute and harp)

\section{Location of Recordings:}

1. alexshapiro.org < Works $<$ Piano $<$ Intermezzo for Piano

166 “Of Breath and Touch,” Alex Shapiro; Composer, accessed March 14, 2015, http://www.alexshapiro.org/OfBreathandTouchpg1.html. 
2. alexshapiro.org < Purchase $<$ Purchase CDs

\section{Related Arrangements With Piano:}

1. Intermezzo for Clarinet and Piano (1998)

2. Intermezzo for Bass Flute and Piano (2010)

3. Intermezzo for Cello and Piano (2011)

\section{Related Arrangements Without Piano:}

1. Intermezzo for Clarinet and Harp (1999)

2. Intermezzo for Violin and Harp (2001)

3. Intermezzo for Flute and Harp (2008)

4. Intermezzo for Bass Flute and Harp (2012)

\section{Composer's Webpage Notes on the Score:}

Intermezzo was written in as a response to the waves of the ocean, as well as a reflection of the waves of a more introspective, emotional sea. A long and lyrical theme floats above a steady ostinato, perhaps as a lengthy branch of kelp might dance from the force of each coming tide. ${ }^{167}$

\section{Brat for Various Instruments}

Date of Composition: 2013

Duration: 2:00 minutes

Description: One-movement duet for piano and various instrumental combinations. 8 pages, 8.5 " x 11 "

Publisher: Activist Music (ASCAP)

Score Location: alexshapiro.org $<$ Works $<$ Piano $<$ Duets $<$ Brat

Score Formats Available: Print or Digital

Available Recordings:

1. mp3 audio clip

2. Youtube recording of pianist Kristin Elgersma and saxophonist Vanessa

Sielert

\section{Location of Recordings:}

1. alexshapiro.org $<$ Works $<$ Duets $<$ Brat

2. alexshapiro.org $<$ Works $<$ Duets $<$ Brat

\section{Related Arrangements With Piano:}

1. Brat for Alto Saxophone and Piano (2013)

167 “Intermezzo," Alex Shapiro; Composer, accessed March 14, 2015, http://www.alexshapiro.org/IntermezzoforPianopg1.html. 
2. Brat for Clarinet and Piano (2013)

3. Brat for Oboe and Piano (2013)

\section{Related Arrangements Without Piano:}

1. Brat for Viola and Harpsichord (2013)

\section{Composer's Webpage Notes on the Score:}

Brat is an encore showpiece that features something rare in concert music: physical comedy! After the two minutes flat in which the duo play — and, acts - "as fast as clownishly possible," the audience may go home thinking that they just went to the circus with the ghosts of Sergei Prokofiev, Bela Bartok and Victor Borge. ${ }^{168}$

The musical content of Brat was taken from the third movement of Shapiro's

Sonata for Piano, titled "Scherzo."

\section{Music for Two Big Instruments (and Four)}

Date of Composition: 2000

Duration: 7:00 minutes

Description: One-movement work. 16 pages, 8.5 ” x 11 "

Instrumentation: Tuba and Piano

Publisher: Activist Music (ASCAP)

Score Location: alexshapiro.org < Works < Duets < Music for Two Big Instruments Score Formats Available: Print or Digital

Available Recordings:

1. mp3 audio clip

2. Alan Baer's 2005 CD, Coast to Coast

3. Alex Shapiro's 2007 CD, Notes from the Kelp

\section{Location of Recordings:}

1. alexshapiro.org $<$ Works $<$ Duets $<$ Music for Two Big Instruments

2. alexshapiro.org $<$ Purchase $<$ Purchase CDs

3. alexshapiro.org $<$ Purchase $<$ Purchase CDs

168 "Brat," Alex Shapiro; Composer, accessed March 14, 2015, http://www.alexshapiro.org/Bratpg1.html. 


\section{Related Arrangements With Piano:}

1. Music for Four Big Instruments (2006) jazz quartet adaptation for Tuba, Piano, Double Bass and Drum Set

\section{Related Arrangements Without Piano: None}

\section{Composer's Webpage Notes on the Score:}

Whenever I mentioned to non-musician friends that I was composing a work for tuba and piano, the response was usually one of surprise and barely muffled laughter. The exclamation, "Tuba, eh? What a funny instrument!" was often accompanied by exaggerated hand and mouth gestures that somewhat resembled a trout attempting to inflate a balloon. I knew I had my work cut out for me. Thus, the arrival of Music for Two Big Instruments, born of my desire to create good PR for a sometimes beleaguered and misunderstood instrument. ${ }^{169}$

169 "Music for Two Big Instruments," Alex Shapiro; Composer, accessed March 14, 2015, http://www.alexshapiro.org/MusicforTwoBigInstpg1.html. 


\section{Trios with Piano}

To date, Shapiro has composed eleven trios with piano, five of which are based on the theme of the desert. The other works include: Flea Circus, a short and comical performance with live actors, for which no music score is available; Trio for Clarinet, Violin and Piano, the third movement of which was adapted to create the music for Flea Circus; three similar adaptations of one work known as Elegy, Piano Trio No. 1: Elegy, and Elegiac, dedicated to the memory of Shapiro's late father Ivan Shapiro; and, finally, At the Abyss, which is a reflection on many frightening world events that occurred around 2002, the year of this piece's creation. As a whole, many of Shapiro's trios with piano are as thought-provoking as they are refreshing to the ears. They are also among her most programmatic compositions. Some include the use of prerecorded sounds.

\section{Desert Notes and Related Trios}

Date of Composition: 2001

Duration: 10:00 minutes

Description: One-movement work. 20 pages, 8.5 " x 11 "

Instrumentation: Oboe, Bassoon and Piano

Publisher: Activist Music (ASCAP)

Score Location: alexshapiro.org $<$ Works $<$ Trios $<$ Desert Notes

Score Formats Available: Print or Digital

Available Recordings:

1. mp3 audio clip

2. Douglas Masek's 2007 CD, Saxtronic Soundscape (featuring Desert Tide)

Location of Recordings:

1. alexshapiro.org $<$ Works $<$ Trios $<$ Desert Notes

2. alexshapiro.org < Purchase < Purchase CDs 


\section{Related Arrangements With Piano:}

1. Desert Run (2007) for Oboe, Clarinet and Piano

2. Desert Passage (2001) for Violin, Cello and Piano

3. Desert Passage (2001) for Violin, Tenor Saxophone and Piano

4. Desert Thoughts (2008) for Flute, Clarinet and Piano

\section{Related Arrangements Without Piano:}

1. Desert Waves (2001) for 5 string Electric Violin and Electronic soundscape on $\mathrm{CD}$

2. Desert Waves (2001) for 5 string Electric Viola and Electronic soundscape on $\mathrm{CD}$

3. Desert Tide (2005) for Soprano Saxophone and Electronic soundscape on CD

\section{Composer's Webpage Notes on the Score:}

Desert Notes is some of the most programmatic music I've composed, to the point where even the score itself contains maniacal little outbursts describing the visions that swept through my mind as the music wrote itself. The scene: the desert's arid stillness and the weight of the morning's expanding heat. A sudden rainstorm overtakes the landscape, forming instant pools of water over the cracked earth. The storm passes as quickly as it arrived, and as the birds and reptiles emerge to greet the fleeting moisture, the music ends as flowers strain upward against the bluest sky for those few passionate moments of their fullest bloom. Ahhh.

Well, none of the above was floating around in my head as I began the first measures; my initial working title had something to do with the ocean and being near it. But just after I started the piece, I took a road trip from my Malibu home to Tucson, Arizona. The drive was meditative, and best of all, the desert was in the full bloom of a May preceded by heavy rainfall. Everywhere I turned there were brilliant flowers bursting from inhospitable looking cactuses and scrub. It was truly beautiful.

All the stunning drives I've taken through deserts came to my senses at once, from a trip across the Sinai on a desolate road, to a trek across Mongolia's Gobi on no road at all. I also thought a lot about the extraordinary ten days I spent alone one July in the Mojave's Death Valley, immersing myself like a madwoman in its intense, 125 degree heat. I was rewarded with an equally intense and welcome inner clarity. 
I need the ocean, but I'm fascinated by the desert and all the life it embraces. I returned home to the beach from Tucson four days later, and I finally knew what this music was really about. ${ }^{170}$

The various trios in this set are not simply arrangements of the same work, such as is the case in other works like Intermezzo. The pieces in this set have a similar, unifying programmatic idea, but the music and stories in each piece are unique.

\section{Flea Circus}

Date of Composition: 2007

Duration: 1:00 minute

Description: Not Available; Recording Only; Adapted from the third movement of Trio for Clarinet, Violin and Piano; Composed for the 2008 VoxNovus 60 x 60 DanceProject; for Clarinet, Violin and Piano. Very slightly processed... ${ }^{171}$

Publisher: Activist Music (ASCAP)

Score Location: Not Available

Score Formats Available: Not Available

Available Recordings:

1. mp3 audio (complete, short work)

2. Youtube video

Location of Recordings:

1. alexshapiro.org $<$ Works $<$ Trios $<$ Flea Circus

2. alexshapiro.org $<$ Works $<$ Trios $<$ Flea Circus

Related Arrangements With Piano: This is the original work; no other arrangements exist.

Related Arrangements Without Piano: None

Composer's Webpage Notes on the Score:

Life is short. Fleas are short. This piece is short. Three terrific Los Angeles musicians of moderate height make these performing insects dance for you: clarinetist Berkeley Price, violinist Nancy

170 "Desert Notes," Alex Shapiro; Composer, accessed March 15, 2015, http://www.alexshapiro.org/DesertNotespg1.html.

171 "Flea Circus," Alex Shapiro; Composer, accessed March 15, 2015, http://www.alexshapiro.org/FleaCircuspg 1.html. 
Roth, and pianist Deon Nielsen Price. Step right up! A trio awaits to amuse you with their amazing antics! No fleas were harmed in the making of this music. ${ }^{172}$

This short work was composed as part of a dance project for the 2008 VoxNovus 60 x 60 Dance Project. It is short, comical, and original. No music scores of this work are available at the time.

\section{Trio for Clarinet, Violin and Piano}

Date of Composition: 1998

Duration: 12:00 minutes

Description: Three-movement work: "Allegro," "Adagio," and "Vivace." 30 pages, 8.5" $\mathrm{x} 11$ "

Instrumentation: Clarinet, Violin and Piano

Publisher: Activist Music (ASCAP)

Score Location: alexshapiro.org < Works < Trios < Trio for Clarinet, Violin and Piano Score Formats Available:

Available Recordings:

1. mp3 audio clips for all three movements

2. Price Duo's Cambria Master Recordings, 1999 CD, Clariphonia: Music of the $20^{\text {th }}$ Century on Clarinet

\section{Location of Recordings:}

1. alexshapiro.org < Works $<$ Trios $<$ Trio for Clarinet, Violin and Piano

2. alexshapiro.org $<$ Purchase $<$ Purchase CDs

Related Arrangements With Piano: This is the original work; no other arrangements exist. The third movement was slightly adapted and recorded for Shapiro's Flea Circus.

Related Arrangements Without Piano: None

Composer's Webpage Notes on the Score:

Trio for Clarinet, Violin and Piano was composed at the suggestion of my dear friend, composer and clarinetist Bronwen

172 Ibid. 
Jones, whose wonderful encouragement of my music directly led to my ongoing delight in composing chamber works. This piece was composed using classical sonata form as a point of departure for a modern tonal and rhythmic palette, and each of the three movements evokes a distinctive mood.

The Allegro introduces a strong theme, first heard in the clarinet and then developed for all three instruments throughout the movement. A quiet piano entrance begins the Adagio, an unabashedly romantic gesture that gradually builds with a lyrical, ascending line. The third movement, Vivace, is a fun, raucous sort of gypsy dance that cavorts through bitonality and shifting meters and ends the entire Trio with a big grin. ${ }^{173}$

\section{Piano Trio No. 1: Elegy and Related Arrangements}

Shapiro wrote this piano trio as a tribute to her father, who had passed away shortly before she began working on this piece. She later composed Elegy in 2004, based on the original piano trio but scored for $\mathrm{C}$ trumpet, cello, and piano. Later, in 2010, she composed one more related work, for B-flat clarinet, cello, and piano, known as Elegiac. Each of these works symbolizes the struggles her father faced with his nine-year battle against dementia.

Date of Composition: 1999

Duration: 8:00 minutes

Description: One-movement work. 8 pages, 8.5 " x 11 "

Instrumentation: Violin, Cello and Piano

Publisher: Activist Music (ASCAP)

Score Location: alexshapiro.org < Works < Trios < Piano Trio No. 1: Elegy

Score Formats Available: Print or Digital

173 "Trio for Clarinet, Violin and Piano," Alex Shapiro; Composer, accessed March 15, 2015, http://www.alexshapiro.org/TrioforClpg1s.html. 
Available Recordings:

1. mp3 audio clips for Piano Trio No. 1: Elegy, and Elegy for Trumpet, Cello and Piano

2. Trio Chromos' 2007 CD, Trumpet Colors (contains Elegy for Trumpet, Cello and Piano)

\section{Location of Recordings:}

1. alexshapiro.org < Works < Trios < Piano Trio No. 1: Elegy

2. alexshapiro.org $<$ Purchase $<$ Purchase CDs

\section{Related Arrangements With Piano:}

1. Elegy (2004) for C Trumpet, Cello and Piano

2. Elegiac (2010) for Bb Clarinet, Cello and Piano

\section{Related Arrangements Without Piano: None}

\section{Composer's Webpage Notes on the Score:}

This Elegy was written shortly after the death of my father at the early age of 69, in the wake of his nine year bout with Alzheimer's disease. It is plaintive and lyrical, and although it uses a modern tonal sensibility, there is a romantic, late nineteenth century presence that informs much of the piece. In my mind, this Trio has moments that faintly echo the Brahms trios which my father adored throughout his life. The opening theme in the violin descends in a variety of ways, and the flow of the music attempts to cry out and fight against such decline. The middle of the piece brings a moving cello melody which swells upward and ultimately plays against the violin motive in an emotional plea. The piece ends with stillness, the quiet, lone voices of the instruments, and the acceptance of loss. ${ }^{174}$

\section{At the Abyss}

Date of Composition: 2003

Duration: 14:00 minutes

Description: Three-movement work. 39 pages (score), 8.5" x 11 "

Instrumentation: Piano, Marimba, Vibraphone and Percussion

Publisher: Activist Music (ASCAP)

Score Location: alexshapiro.org < Works < Trios < At the Abyss

174 “Piano Trio No. 1: Elegy," Alex Shapiro; Composer, accessed March 15, 2015, http://www.alexshapiro.org/Elegypg1.html. 
Score Formats Available: Print or Digital

Available Recordings:

1. mp3 audio clips for all three movements

2. Innova Recordings' 2005 CD, Music for Hammers \& Sticks

\section{Location of Recordings:}

1. alexshapiro.org $<$ Works $<$ Trios $<$ At the Abyss

2. alexshapiro.org $<$ Purchase $<$ Purchase CDs

\section{Related Arrangements With Piano: None \\ Related Arrangements Without Piano: None}

\section{Composer's Webpage Notes on the Score:}

During the time I composed this piece, October 2002, too many sad, threatening and violent events throughout the world offered proof of the terminal fragility of humans and of our planet. Politically. Ecologically. Ethically. I titled this piece At the Abyss because as members of a species which remains too savage for its ultimate group survival, we're staring directly into a huge crevasse that is our future. We are poised to plummet to its depths if we do not act accordingly.

The three movements are "Observe," "Reflect," and "Act"... akin to my three-step approach to life in general. In this instance, I'm observing the world, and stepping back to reflect on it in grief while accepting that there's only so much that will change. Finally, I realize that the least one can do is... act. In one way or another. ${ }^{175}$

175 "At the Abyss," Alex Shapiro; Composer, accessed March 15, 2015, http://www.alexshapiro.org/AttheAbysspg1.html. 


\section{Quartets with Piano}

To date, Shapiro has composed three quartets with piano. Evensong Suite was composed in 1999, for flute, clarinet, bassoon and piano. The second movement in this set, Phos Hilaron, has received the most attention. This is a liturgical work that can be performed equally well as part of a religious service or in a concert setting. Additionally, each movement can be performed individually or as part of the whole set.

Music for Four Big Instruments is a 2006 adaptation of her work Music for Two Big Instruments composed in 2000 for Tuba and Piano. And, lastly, Unabashedly was composed in 2006, for flute/piccolo, violin, cello and piano.

\section{Evensong Suite}

Date of Composition: 1999

Duration: 17:00 minutes

Description: Six-movement work: "Prelude," "Phos Hilaron," "Magnificat," "Nunc Dimittis," "Ascendit Deus," and "Postlude." 40 pages, 8.5" x 11"

Instrumentation: Flute, Clarinet, Bassoon and Piano

Publisher: Activist Music (ASCAP)

Score Location: alexshapiro.org < Works < Quartets < Evensong Suite

Score Formats Available: Print or Digital

\section{Available Recordings:}

3. mp3 audio clips for all six movements

4. Innova Recordings' 2007 CD, Notes from the Kelp (features movement II, Phos Hilaron)

\section{Location of Recordings:}

3. alexshapiro.org $<$ Works $<$ Quartets $<$ Evensong Suite

4. alexshapiro.org $<$ Purchase $<$ Purchase CDs

\section{Related Arrangements With Piano: None} Related Arrangements Without Piano: None 


\section{Composer's Webpage Notes on the Score:}

The Evensong Suite was commissioned by St. Bede's Episcopal Church in Mar Vista CA., and it is a modal and very melodic set of six short pieces, each two to three minutes in length. Although it was composed specifically for an Anglican Evensong service, during which each movement precedes or follows a corresponding prayer or reading, the piece is equally effective when performed in a concert setting. Any of the six movements may be performed separately.

The Prelude opens the Suite in a pastoral mood, with a rising motive to reflect the Ascensiontide occasion for the piece. The Phos Hilaron evokes a slow and quiet glow, mirroring the beauty of the last vesper light of a setting sun. The Magnificat, traditionally the dramatic center of the Evensong service, uses strong opposing motives which refer to the mighty being cast down from their thrones and the meek being lifted up. Nunc Dimittis is a pensive lullaby which blossoms into contentment and inner light.

The Ascendit Deus was written to encourage generous donations during the Offertory for the Sunday after the Ascension (!), and in celebration of the Savior rising up, so do the lines of the music! Finally, the Postlude begins with a contemplative and noble chorale and makes references to motives and moods from the earlier Prelude and Magnificat, bringing the Suite to a triumphant conclusion. ${ }^{176}$

176 “Evensong Suite," Alex Shapiro; Composer, accessed March 15, 2015, http://www.alexshapiro.org/PhosHilaronpg1.html. 


\section{Music for Four Big Instruments}

Date of Composition: 2006

Duration: 7:00 minutes

Description: One-movement work. 21 pages, 8.5 " x 11 "

Instrumentation: Tuba, Piano, Double Bass and Drum Set

Publisher: Activist Music (ASCAP)

Score Location: alexshapiro.org < Works < Quartets < Music for Four Big Instruments Score Formats Available: Print or Digital

Available Recordings: Only available in Music for Two Big Instruments (see previous section titled "Duets with Piano")

Location of Recordings: (See Music for Two Big Instruments)

Related Arrangements With Piano:

1. Music for Two Big Instruments (2000) for Tuba and Piano

Related Arrangements Without Piano: None

Composer's Notes on the Score: (See Music for Two Big Instruments)

\section{Unabashedly}

Date of Composition: 2006

Duration: 11:00 minutes

Description: One-movement work. 25 pages, 8.5 " x 11 "

Instrumentation: Flute/Piccolo, Violin, Cello and Piano

Publisher: Activist Music (ASCAP)

Score Location: alexshapiro.org < Works < Quartets < Unabashedly

Score Formats Available: Print or Digital

Available Recordings:

1. mp3 audio clips

Location of Recordings: alexshapiro.org < Works < Quartets < Unabashedly

Related Arrangements With Piano:

1. Unabashedly More (2010) for Flute/Piccolo, Clarinet, Violin, Cello and Piano

2. Unabashedly Said (2011) for Flute/Piccolo, Clarinet, French horn, Violin, Cello and Piano

Related Arrangements Without Piano: None 


\section{Composer's Webpage Notes on the Score:}

We need beauty and emotional truth for our sanity. Uneasy melancholy, anger and despair, quirky acceptance, calm, and complete elation, each pulse through our lives and insist that we stare directly, without flinching. When we are most true to ourselves, we neither mince our words nor parse our notes. We communicate as passionately and unabashedly as we wish. ${ }^{177}$

\section{Quintets with Piano (None to Date)}

177 “Unabashedly," Alex Shapiro; Composer, accessed March 15, 2015, http://www.alexshapiro.org/Unabashedlypg1.html. 


\section{Sextets with Piano}

To date, Shapiro has composed three sextets with piano. Two of them were mentioned previously under the quartet Unabashedly and are titled Unabashedly More and Unabashedly Said. Of the two, Unabashedly More contains separate program notes by the composer, conveying a message quite different from the other two similarly-titled works. The third sextet with piano was composed in 2011, and is titled Perpetual Spark. It is an adaptation of Shapiro's 2011 work Spark, for solo piano.

\section{Unabashedly More}

Date of Composition: 2010

Duration: 11:00 minutes

Description: One-movement work. 38 pages, 8.5 " x 11 "

Instrumentation: Flute/Piccolo, Clarinet, Violin, Cello and Piano

Publisher: Activist Music (ASCAP)

Score Location: alexshapiro.org < Works < Sextets < Unabashedly More

Score Formats Available: Print or Digital

Available Recordings: $\mathrm{mp} 3$ audio clips

Location of Recordings: alexshapiro.org < Works < Sextets < Unabashedly More

\section{Related Arrangements With Piano:}

1. Unabashedly (2006) for Flute/Piccolo, Violin, Cello and Piano

2. Unabashedly Said (2011) for Flute/Piccolo, Clarinet, French horn, Violin, Cello and Piano

Related Arrangements Without Piano: None

\section{Composer's Webpage Notes on the Score:}

I loved the concept of The Sanctuary Project the moment Lunatics at Large pianist Evi Jundt described it: poets and composers collaborating on their impressions of what "sanctuary" means to them. A private thought, brought to the public forum of performance. 
There are many places in which each of us finds sanctuary, and for me the most frequent, and certainly the most reliable, has been in the act of composing. This is where I've always been safe. Safe enough to express aspects of my otherwise cheery personality that might not be considered socially acceptable, were I to blurt my inner rage, or laugh uncontrollably, or sob, in the midst of, say, a cocktail party.

The protective confines of the manuscript paper allow me an emotional freedom, as do the welcoming ears of audiences who are prepared - eager, in fact - to receive whatever the notes on those pages communicate, as is the case with a few of my thornier, funnier, or more disconsolate pieces. But "Unabashedly More" is not such a piece: it falls on the other side of the emotive spectrum. These notes find their sanctuary within beauty and lyricism, and sometimes, within great simplicity inspired by the natural world that surrounds me as I compose on San Juan Island. Melancholy floats through the piece until the final measures, which then unabashedly state my feelings of tremendous excitement and delight toward the world around me, despite its pain and challenge. Through this piece, I can share a very special sanctuary with anyone willing to listen, and reflect back to them their own joy and wonder. ${ }^{178}$

\section{Unabashedly Said}

Date of Composition: 2011

Duration: 11:00 minutes

Description: One-movement work. 38 pages, $8.5 " \mathrm{x} 11$ "

Instrumentation: Flute/Piccolo, Clarinet, French horn, Violin, Cello and Piano

Publisher: Activist Music (ASCAP)

Score Location: alexshapiro.org < Works < Sextets < Unabashedly Said

Score Formats Available: Print or Digital

Available Recordings: mp3 audio clips of Unabashedly More only

Location of Recordings: alexshapiro.org < Works < Sextets < Unabashedly More

Related Arrangements With Piano:

1. Unabashedly (2006) for Flute/Piccolo, Violin, Cello and Piano

1. Unabashedly More (2010) for Flute/Piccolo, Clarinet, Violin, Viola, Cello and Piano

Related Arrangements Without Piano: None

178 "Unabashedly More," Alex Shapiro; Composer, accessed March 15, 2015, http://www.alexshapiro.org/UnabashedlyMorepg1.html. 
Composer's Webpage Notes on the Score: (See Unabashedly under "Quartets with Piano")

\section{Perpetual Spark}

Date of Composition: 2011

Duration: 7:00 minutes

Description: One-movement work. 26 pages, 8.5" x 11 "

Instrumentation: Flute/Piccolo, Violin, Viola, Cello, Double Bass and Piano

Publisher: Activist Music (ASCAP)

Score Location: alexshapiro.org < Works $<$ Sextets $<$ Perpetual Spark

Score Formats Available: Print or Digital

Available Recordings:

1. mp3 audio clips

2. Fifth House Ensemble's Summer 2014 CD for Cedille Records titled Excelsior

Location of Recordings:

1. alexshapiro.org < Works $<$ Sextets $<$ Perpetual Spark

2. alexshapiro.org $<$ Purchase $<$ Purchase CDs

Related Arrangements With Piano:

1. Spark (2011) for solo piano

Related Arrangements Without Piano: None

Composer's Webpage Notes on the Score:

The music of the sextet, Perpetual Spark, was first composed for solo piano in a piece simply titled, Spark. Each note was inspired by the life, love, energy and heart of Dale Mara Bershad, a gifted musician who often used her talents to share the joy of expression and wonder with young children. As a mother, teacher, and performer, Mara's remarkable inner light cast an indelible glow. Her essence remains radiant and present: a perpetual spark from a life filled with passion and delight, burning brightly, intensely, and without end. ${ }^{179}$

\section{Archipelago: Single Work to Date for Large Chamber Ensemble with Piano}

Date of Composition: 2009; revised 2013

Duration: 11:00 minutes

179 "Perpetual Spark," Alex Shapiro; Composer, accessed March 15, 2015, http://www.alexshapiro.org/PerpetualSparkpg1.html. 
Description: One-movement work. 56 pages (score), 8.5" x 11 "

Instrumentation: 2 Violins, Viola, Cello, Double Bass, Flute/Piccolo, Oboe, Bb Clarinet, Bassoon, French Horn, and Piano

Publisher: Activist Music (ASCAP)

Score Location: alexshapiro.org < Works < Large Chamber Ensemble < Archipelago

Score Formats Available: Print or Digital

Available Recordings: $\mathrm{mp} 3$ audio clips

Location of Recordings: alexshapiro.org < Works < Large Chamber Ensemble < Archipelago

Related Arrangements With Piano: None

Related Arrangements Without Piano: None

\section{Composer's Webpage Notes on the Score:}

I live in a beautiful archipelago in which each island has a distinct character. Some are similar to each other, and others cause me to wonder what the geo- and meteorological forces could have been to make them so contrasting. This piece is not dissimilar, as it wends its way through a series of cohesive but varied segments, each subject to the forces of my own emotional geology.

Similarly, a musical ensemble is its own archipelago: wonderfully contrasting individuals who, when experienced together, form a compelling unified group. As with navigating the channels and straits between isles, or those of one's psyche, Archipelago offers a journey, and every listener will experience the landscape differently. ${ }^{180}$

180 “Archipelago," Alex Shapiro; Composer, accessed March 15, 2015, http://www.alexshapiro.org/Archipelagopg1.html. 


\section{Four Duets and One Trio with Harpsichord}

To date, Shapiro has composed five chamber pieces with harpsichord. These consist of four duets: Slip (2001) for violin and harpsichord; Transplanted (2012) for viola and harpsichord; Brat (2013) for viola and harpsichord; and Fleas (2013) for viola and harpsichord. Three Insanities (2013) for viola and harpsichord is a compilation in three movements consisting of the previously mentioned works: Fleas, Transplant, and Brat. Her one other chamber piece with harpsichord is an interesting combination of timbres, a trio from 2006 titled Slipping for violin, harpsichord and percussion. Humor is a unifying element of each of these works. Due to the harpsichord's historical importance and the composers and works that are often associated with it, Shapiro felt the need to contribute something lighter (or even funny) to the instrument's repertoire. ${ }^{181}$ Many of these pieces also have related arrangements for various instruments. Transplanted, for example, was adapted from Shapiro's equally humorous solo composition, and her only work to date for organ, Transplant.

181 The author would like to note that humorous compositions for harpsichord and organ do exist by composers of the Baroque period. For example, Jean-Philippe Rameau's $L a$ poule (The Chicken) was composed for harpsichord in 1728 and imitates the clucking sounds made by a chicken. 


\section{Slip and Slipping}

Date of Composition: 2001; 2006 respectively

Duration: 9:00 minutes

Description: One-movement work. 14 and 20 pages respectively, 8.5" x 11 "

Instrumentation: Slip: Violin and Harpsichord; Slipping: Violin, Harpsichord, and Percussion

Publisher: Activist Music (ASCAP)

Score Location: alexshapiro.org < Works < Harpsichord < Slip (or Slipping)

Score Formats Available: Print or Digital

\section{Available Recordings:}

1. mp3 audio clips of both

2. Antonio D'Andrea and Maria Clotilde Sieni's 2007 DC Records CD, La

Discordantia (recording of Slip)

3. Innova Recordings 2007 CD, Notes from the Kelp (recording of Slipping)

Location of Recordings:

1. alexshapiro.org $<$ Works $<$ Harpsichord $<$ Slip (or Slipping)

2. alexshapiro.org $<$ Purchase $<$ Purchase CDs

3. alexshapiro.org $<$ Purchase $<$ Purchase CDs

Related Arrangements With Harpsichord: Slip, Slipping

Related Arrangements Without Harpsichord: Slip (for flute and guitar) ${ }^{182}$

\section{Composer's Webpage Notes on the Score of Slipping:}

Slipping is an adaptation of a comedic 2001 duet titled "Slip," commissioned by Robin Lorentz as a gift for her friend and partner in musical crimes, Kathleen McIntosh. In this new incarnation, I called up my pal, gifted Los Angeles percussionist Dan Morris, and we had a great time adding live drumming from around the world to flesh out the myriad genres that breeze by in this onslaught of musical schizophrenia.

Since the violin is found in all corners of the globe, I decided to make the harpsichord a chameleon as well. I turned it into a host of different plectrum instruments, including dulcimer, koto, mandolin, rock n' roll keyboards, guitar and bouzouki, setting it in

182 Alex Shapiro, email message to author, June 15, 2015. Shapiro added that the work was commissioned by a duet called "Bas Duo" and just completed the previous week of this email. This information is not yet available on her website. 
every idiom except the expected baroque style to which it is so often tethered. Throw in some Cuban montuno rhythms for a little variety, and suddenly the piece is a world tour for anyone with attention deficit disorder.

This bit of whimsy was written with the intent of giving Robin and Kathy something that would be unexpected at the close of their otherwise respectable concerts. Quite ironically, the first few lighthearted measures were written on September $10^{\text {th }}, 2001$. After the horrors in New York City the following day, Robin called me up and made it clear that given the circumstances, it would be absolutely fine with her if I felt instead like writing a very serious piece. Thinking about it for a moment, I replied that no, I wanted to continue in this upbeat direction, perhaps as a bizarre antidote for my grief. During the rest of that stunned month, there were times when the television glared silently in the corner of my studio with its constant images of devastation, as I irreconcilably wrote these giddy passages.

I'm a New Yorker. I grew up in Manhattan and watched the construction of the World Trade Towers when I was a little girl. As those edifices tumbled from hatred 29 years later, I thought of the people of all nationalities who perished that sunny morning. But New Yorkers are resilient, and composing this internationallytinged piece may have been my way of declaring that to best honor those who have lost their lives, the rest of us should live ours to the fullest extent, for whatever time we're given. Just as these musical styles slip suddenly from one to another, life can slip from one reality to the next. As Ram Dass said, be here now. ${ }^{183}$

183 "Slipping," Alex Shapiro; Composer, accessed March 15, 2015, http://www.alexshapiro.org/Slippingpg1.html. 


\section{Transplanted}

Date of Composition: 2012

Duration: 4:00 minutes

Description: One-movement work. 17 pages, 8.5" x 11"

Instrumentation: Viola and Harpsichord

Publisher: Activist Music (ASCAP)

Score Location: alexshapiro.org < Works < Harpsichord < Transplanted

Score Formats Available: Print or Digital

Available Recordings: mp3 audio clips of Transplant for organ

Location of Recordings: alexshapiro.org < Works < Harpsichord < Transplanted

Related Arrangements: Transplant for solo organ

\section{Composer's Webpage Notes on the Score:}

Having brought my ridiculously silly piece Slip to life a few years ago in a wonderful recording with violinist Robin Lorentz, harpsichordist Kathleen McIntosh felt a need for more silliness, went through my catalog, and pointed directly to a little ditty called Transplant, for organ, which can probably best be described by the suggestion, "imagine the Three Stooges performing open heart surgery." This was the piece she wanted to do with her duet partner Marlow Fisher. And, after determining that yes, it would indeed sound great with a frantic violist trying to keep up with a possessed harpsichordist, I was off and running so that the two of them soon would be as well. ${ }^{184}$

184 “Transplanted," Alex Shapiro; Composer, accessed March 15, 2015 , http://www.alexshapiro.org/Transplantedpg1.html. 


\section{Brat}

Date of Composition: 2013

Duration: 2:00 minutes

Description: One-movement work. 8 pages, $8.5 " \mathrm{x} 11$ "

Instrumentation: Viola and Harpsichord

Publisher: Activist Music (ASCAP)

Score Location: alexshapiro.org < Works < Harpsichord < Brat

Score Formats Available: Print or Digital

Available Recordings: mp3 audio clips of version with Alto Saxophone and Piano

Location of Recordings: alexshapiro.org < Works < Harpsichord < Brat

Related Arrangements: Brat for Alto Saxophone and Piano; Clarinet and Piano; Oboe and Piano; and more pairings may be imagined by the performers

Composer's Webpage Notes on the Score: (See Brat under "Duets with Piano" and Three Insanities below)

\section{Three Insanities}

Date of Composition: 2013

Duration: 7:00 minutes

Description: Three-movement work: Fleas, Transplant, and Brat. 35 pages, 8.5" x 11 "

Instrumentation: Viola and Harpsichord

Publisher: Activist Music (ASCAP)

Score Location: alexshapiro.org < Works < Harpsichord < Three Insanities

Score Formats Available: Print or Digital

Available Recordings: (Substitute recordings suggested by Shapiro)

1. mp3s of Fleas, Transplanted, and Brat coming soon

2. Fleas: Listen to Flea Circus (Clarinet, Violin and Piano)

3. Transplanted: Listen to Transplant (Organ)

4. Brat: Listen to Scherzo (Third movement of Sonata for Piano)

Location of Recordings: alexshapiro.org < Works < Harpsichord < Three Insanities Related Arrangements: "Also available for piano, with probably a number of other pairings, too!"185

185 “Three Insanities," Alex Shapiro; Composer, accessed March 15, 2015, http://www.alexshapiro.org/ThreeInsanitiespg 1.html - watch. 


\section{Composer's Webpage Notes on the Score:}

Three Insanities offers a look into the goofier side of concert music, because the harpsichord repertoire deserves more silliness! Composed with the joyous spirit of Mara Bershad in mind, and written for the huge grin of Kathleen MacIntosh performing with McFish violist Marlow Fisher, these three little pieces could very possibly cause someone to... break out into a smile. Imagine that.

Fleas might conjure a talented (if jumpy) flea circus, a household pet problem, or any number of life's slightly nervous and ridiculous moments. Transplant can probably best be described by the suggestion, "imagine the Three Stooges performing open heart surgery." And Brat is a ham-it-up encore showpiece that owes its physical comedy to the ghost of Victor Borge. Enjoy! ${ }^{186}$

\section{Fleas (See Three Insanities)}

\section{Transplant for Solo Organ}

Date of Composition: 1999

Duration: 4:00 minutes

Description: One-movement work. 7 pages, 8.5 " x 11 "

Instrumentation: Solo Organ

Publisher: Activist Music (ASCAP)

Score Location: alexshapiro.org < Works < Organ < Transplant

Score Formats Available: Print or Digital

Available Recordings:

1. mp3 audio clip

Location of Recordings: alexshapiro.org < Works < Organ < Transplant

Related Arrangements: Transplanted (2012) for Viola and Harpsichord

${ }^{186}$ Ibid. 


\section{Composer's Webpage Notes on the Score:}

When organist Frances Nobert first commissioned this work for one of her upcoming concerts, I asked her to describe the other pieces on her program and to think about what she might like to add that would provide contrast. After some thought, she responded with "a quiet scherzo." My mischievous mind took off, and not too much later I presented her with Transplant, which can probably best be described by the suggestion, "imagine the Three Stooges performing open heart surgery." Much of the pipe organ literature is beautiful but ponderously serious; here's a slightly offbeat piece that probably won't sound like anything else on the program. $^{187}$

187 “Transplant," Alex Shapiro; Composer, accessed March 15, 2015, http://www.alexshapiro.org/Transplantpg1.html. 


\section{Conclusion}

Shapiro's collection of chamber works including piano or harpsichord, as well as her one solo work for organ, provide the listener and performer with a wide array of experiences. In addition to her fascination with combining various instrumental timbres in individual ways, much of what makes her music unique and effective is the way in which she incorporates her own personality and life experiences. From the Middle Eastern influences heard in Of Breath and Touch to the audible illustration of her home in San Juan Island, heard in Archipelago, Unabashedly More and Intermezzo, Shapiro carries listeners around the world, writing programmatic music that is free from the restraints of musical labels. There is a spiritual element prevalent in her works. This can be heard in the liturgical collection of the Evensong Suite, the powerful messages of change and peace heard in At the Abyss or even more personally in the dedication to her deceased father in Elegy. In contrast, Shapiro's humorous personality shines through, especially in her collection of chamber works for harpsichord and her solo organ piece Transplant. The variety of styles, timbres, and influences represented in Shapiro's compositional output are as diverse as the many facets of her complex and vibrant personality. With such a gifted imagination and compositional mastery, there are no foreseeable limitations to what she will come up with next. 


\section{Chapter Eight}

\section{Conclusion of Research}

This project serves as a study of the solo and chamber keyboard compositions by American composer Alex Shapiro. The author's motivation in discussing Shapiro's music stemmed from the intrinsic joy and fascination of discovering her pieces as well as a desire to share that excitement with others. The goal was to introduce her solo works in moderate detail in order to inform others about her music and to encourage further study, performance, and appreciation of her works.

The author plans to incorporate these compositions into her performance and teaching repertoire. In addition, she plans on pursuing opportunities for sharing the works in professional music settings such as conferences, lecture recitals and partial publications in music journals.

The chamber works, as well as Shapiro's one solo piece for organ, were discussed in less detail, mainly providing original comments by the composer, as well as basic information such as dates, locations of scores and recordings as well as related arrangements. The author's motivation in discussing Shapiro's music stemmed from the intrinsic joy and fascination of discovering her pieces as well as a desire to share that excitement with others.

The following summary of this project reviews some of the many facets and characteristics displayed through this composer's output, as well as elements that were of particular interest to the author. In terms of musical characteristics, Shapiro's keyboard works typically explore the entire range of the piano. She often uses extreme contrasts in 
dynamics, texture, range, and articulation to provide contrast and create drama. The entire spectrum of emotions is explored, from the melancholy acquiescence ${ }^{188}$ experienced in her Piano Suite No. 1, The Resonance of Childhood to the homage to Robert Schumann and his imaginative figures Florestan and Eusibius, present in Slowly, Searching. One can find hope in the euphoric atmosphere present in Spark, conviction in her chamber work At the Abyss, or a playful, humorous attitude in her sets on Brat, Fleas, Flea Circus, or any number of her works with harpsichord or organ. She intentionally avoids the more serious connotations usually associated with the twentieth-century revival of these early period instruments. Emotional communication is a central part in her compositional process and is one of the reasons the author felt such intense interest in these works. In fact, the author was particularly fascinated by the way Shapiro synthesizes influences from as early as the $17^{\text {th }}$ century to modern-day practices. For example, her ability to compose in classical structural forms, such as the sonata or suite, while maintaining a present-day sense of tonality, rhythm and meter, and without compromising her own musical voice, are what make these pieces original and beautiful to the author. They are not without structure; but at the same time, structure and symmetry do not hinder Shapiro's unique ability to portray emotional affects in all of her works.

Many of Shapiro's works are highly programmatic, including notes at the front of scores as well as often providing textual suggestions throughout. One example is her latest piano suite, Arcana, composed from the perspective of healing plants that face threatening opposition from the careless acts of humans. This work also uses visual aids for increased drama, for example asking the pianist to begin and end the work by

188 Alex Shapiro, Piano Suite No. 1: The Resonance of Childhood (Activist Music (ASCAP), 1996) Program Note. 
grasping the piano while playing the top and bottom notes of the instrument. In addition, Shapiro suggests placing a light inside the piano for added effect. Another example of highly programmatic writing is her solo piano piece Luvina and its later arrangement known as Vendaval de Luvina, both based on the short story Luvina, written by the late Latin-American poet Juan Rulfo. This piece also serves as an example of Shapiro's interest in electroacoustic sounds. Vendaval de Luvina carries the listener to a place of dark, impending hopelessness, characterized by a gloomy and aimless piano part as well as haunting electronic sounds. Rulfo himself is heard reciting the poem in Spanish, on a dual-layered pre-recorded tape.

Shapiro is a true polymath, extending her interests to include: environmentalism; civil rights activism; photography; essays and a blog based on life, nature and music; promotion of other musicians as well as herself; education; and innovative leadership roles in music, technology and many other capacities such as publishing and copyright education. From the Middle Eastern influences heard in Of Breath and Touch to the evocation of salty ocean water present in Intermezzo, At the Abyss, and many other works of hers, Shapiro's compositional output spans continents, as well as centuries of influences. Her music is aesthetically beautiful, meaningful, and worthy of widespread exposure. 


\section{Sources Consulted}

\section{Works Cited}

ASCAP: The American Society of Composers, Authors and Publishers. "Board of Directors: Alex Shapiro." http://www.ascap.com/about/board-intro/alexshapiro.aspx (Accessed February 5, 2015).

Barker, Elizabeth. “Q\&A with Alex Shapiro.” Vegetarian Times no. 360 (2008): 23. MasterFILE Premier, EBSCOhost (accessed February 5, 2015).

Gann, Kyle. “American Composer: Alex Shapiro,” Chamber Music 25, no. 3: 22-23.

Kosack, Alicia Joyelle. "American women composers: Selected published works for flute and piano and for unaccompanied flute composed between 1930 and 2008." DMA diss., University of Maryland, College Park, 2010. ProQuest, UMI Dissertations Publishing, 2010. 3534282.

Moore, Tom. “An Interview with Alex Shapiro," 21 $1^{\text {st }}$ Century Music 17, no. 10 (2010): $1-7$.

Rumson, Gordon. “Alex Shapiro.” Music \& Vision, May 7, 2001. Accessed March 6, 2015. http://www.mvdaily.com/articles/2001/05/cooman.htm.

Shapiro, Alex. Email messages to the author. December 22, 2014; February 1, 2015; February 17, 2015; June 15, 2015; and July 9, 2015.

Shapiro, Alex and John Steinmetz. Liner Notes. Notes from the Kelp. With Mike Aarvold, Phil Blackburn and Chris Campbell. Innova 683.

Young, Sabrina Peña. “The 2011 Athena Festival: Embracing Diversity-Expanding Horizons.” IAWM Journal 17, no. 1 (2011): 41. 


\section{Music Scores Consulted (All score excerpts were used with permission from the publishers)}

Schumann, Robert. "Sehr langsam.” Measures, 1-3 and 11-13 in Kreisleriana, Op. 16. Milwaukee: G. Schirmer, Inc., 1967.

Shapiro, Alex. Arcana. Activist Music (ASCAP), 2014.

Shapiro, Alex. Chord History. Copyright @ 2014 Alex Shapiro.

Shapiro, Alex. Intermezzo. Activist Music (ASCAP), 1998.

Shapiro, Alex. Luvina. Activist Music (ASCAP), 2007.

Shapiro, Alex. Piano Suite No. 1: The Resonance of Childhood. Activist Music (ASCAP), 1996.

Shapiro, Alex. Slowly, Searching. Activist Music (ASCAP), 2009.

Shapiro, Alex. Sonata for Piano. Activist Music (ASCAP), 1999.

Shapiro, Alex. Spark. Activist Music (ASCAP), 2011.

Shapiro, Alex. Vendaval de Luvina. Activist Music (ASCAP), 2010. 


\section{Internet Links by Alex Shapiro}

“Archipelago.” Alex Shapiro; Composer. Accessed March 15, 2015. http://www.alexshapiro.org/Archipelagopg1.html.

"At the Abyss." Alex Shapiro; Composer. Accessed March 15, 2015. http://www.alexshapiro.org/AttheAbysspg1.html.

"Biography.” Alex Shapiro; Composer. Accessed February 4, 2015. http://www.alexshapiro.org/ASBio.html - PInv.

"Brat." Alex Shapiro; Composer. Accessed March 14, 2015. http://www.alexshapiro.org/Bratpg1.html.

"Chord History." Alex Shapiro; Composer. Accessed February 1, 2015. http://www.alexshapiro.org/ChordHistorypg1.html.

"Commercial Scoring." Alex Shapiro; Composer. Accessed February 4, 2015. http://www.alexshapiro.org/ASJazzFilmTV.html.

"Desert Notes." Alex Shapiro; Composer. Accessed March 15, 2015. http://www.alexshapiro.org/DesertNotespg1.html.

"Evensong Suite." Alex Shapiro; Composer. Accessed March 15, 2015. http://www.alexshapiro.org/PhosHilaronpg 1.html.

"Flea Circus." Alex Shapiro; Composer. Accessed March 15, 2015. http://www.alexshapiro.org/FleaCircuspg1.html.

"Home.” Alex Shapiro; Composer. Accessed February 5, 2015. http://www.alexshapiro.org/index.html.

"Intermezzo.” Alex Shapiro; Composer. Accessed March 14, 2015. http://www.alexshapiro.org/IntermezzoforPianopg1.html. 
"Music for Two Big Instruments.” Alex Shapiro; Composer. Accessed March 14, 2015. http://www.alexshapiro.org/MusicforTwoBigInstpg1.html.

"New American Piano Music: Sonata for Piano.” Alex Shapiro; Composer. Accessed February 19, 2015. http://www.alexshapiro.org/ASSonataCD1.html.

"Notes from the Kelp: Nature and Music in the San Juan Islands, from composer Alex Shapiro.” Accessed March 25, 2015. http://www.alexshapiro.org/blog/.

"Of Breath and Touch." Alex Shapiro; Composer. Accessed March 14, 2015. http://www.alexshapiro.org/OfBreathandTouchpg1.html.

"Piano Trio No. 1: Elegy." Alex Shapiro; Composer. Accessed March 15, 2015. http://www.alexshapiro.org/Elegypg1.html.

"Perpetual Spark." Alex Shapiro; Composer. Accessed March 15, 2015. http://www.alexshapiro.org/PerpetualSparkpg1.html.

“Slipping.” Alex Shapiro; Composer. Accessed March 15, 2015. http://www.alexshapiro.org/Slippingpg1.html.

"Sonata for Piano." Alex Shapiro; Composer. Accessed February 19, 2015. http://www.alexshapiro.org/Sonatapg1s.html.

“Three Insanities.” Alex Shapiro; Composer. Accessed March 15, 2015. http://www.alexshapiro.org/ThreeInsanitiespg1.html - watch.

“Transplant.” Alex Shapiro; Composer. Accessed March 15, 2015. http://www.alexshapiro.org/Transplantpg1.html.

“Transplanted.” Alex Shapiro; Composer. Accessed March 15, 2015. http://www.alexshapiro.org/Transplantedpg 1.html.

"Trio for Clarinet, Violin and Piano." Alex Shapiro; Composer. Accessed March 15, 2015. http://www.alexshapiro.org/TrioforClpg1s.html. 
“Unabashedly.” Alex Shapiro; Composer. Accessed March 15, 2015. http://www.alexshapiro.org/Unabashedlypg1.html.

“Unabashedly More.” Alex Shapiro; Composer. Accessed March 15, 2015. http://www.alexshapiro.org/UnabashedlyMorepg1.html. 


\section{Discography of Solo Piano Works}

For My Father, from Piano Suite No. 1. From Californian Concert: Music of European Immigrants and Their American Contemporaries. Susanne Kessel (piano). Oehms Classics/WDR. OC 534. 2006, compact disc.

For My Father, from Piano Suite No. 1. From Notes from the Kelp. Susanne Kessel (piano). Innova Recordings. 683. 2007, compact disc.

Luvina. From Solo Rumores. Ana Cervantes (piano). Quindecim Recordings. 186. November 27, 2007, compact disc.

Scherzo, from Sonata for Piano. From William Garrison Piano Competition Winners 2005/2006. Beatrix Klein (piano). American Liszt Society Baltimore Washington Chapter. 2006, compact disc.

Slowly, Searching. From An Robert Schumann. Susanne Kessel (piano). Obst Records. P330.30. 2009, compact disc.

Sonata for Piano. From New American Piano Music. Teresa McCollough (piano). Innova Recordings. 552. 2001, compact disc. 


\section{Discography of Chamber Works with Piano or Harpsichord}

At the Abyss. From Music for Hammers \& Sticks. Teresa McCollough (piano), Tom Burritt (marimba and vibraphone), and Peggy Benkeser (percussion). Innova Recordings. 630. 2005, compact disc.

At the Abyss. From Notes from the Kelp. Teresa McCollough (piano), Tom Burritt (marimba and vibraphone), and Peggy Benkeser (percussion). Innova Recordings. 683. October 16, 2007, compact disc.

Elegy. From Trumpet Colors. Trio Chromos: Josè Luis Castillo (piano), Ismael Betancor (C trumpet), and Carlos Rivero (cello). Crystal Records. 766. 2007, compact disc.

Music for Two Big Instruments. From Notes from the Kelp. Bradley Haag (piano) and Alan Baer (tuba).

Music for Two Big Instruments. From Coast to Coast. Bradley Haag (piano) and Alan Baer (tuba). Baer Tracks Records. BTM 001. 2005, compact disc.

Of Breath and Touch. From Beck and Call. Delores Stevens (piano) and Carolyn Beck (bassoon). Crystal Records. CD 846. 2005, compact disc.

Perpetual Spark. From Excelsior. Jani Parsons (piano) and Fifth House Ensemble (chamber: flute/piccolo, violin, viola, cello and double bass). Cedille Records. CDR 90000 148. 2014, compact disc.

Phos Hilaron, from Evensong Suite. From Notes from the Kelp. Frank Basile (piano), Brice Martin (flute), Charles Boito (clarinet), and Carolyn Beck (bassoon).

Slip. From La Discordantia. Maria Clotlide Sieni (harpsichord) and Antonio D'Andrea (violin). DC Records. DCR 0024. February 8, 2007, compact disc.

Slipping. From Notes from the Kelp. Kathleen McIntosh (harpsichord), Robin Lorentz (violin), and Dan Morris (percussion).

Trio for Clarinet, Violin and Piano. From Clariphonia: Music of the $20^{\text {th }}$ Century on Clarinet. Deon Nielsen Price (piano), Berkeley Price (clarinet), and Nancy Roth (violin). Cambria Master Recordings. CD-1125. 2000, compact disc. 


\section{Discography of Related Works without Keyboard (Where none with Keyboard was Available)}

Desert Tide. From Saxtronic Soundscape. Douglas Masek (soprano saxophone) and Electronic Soundscape. Centaur Records. 2862. 2007, compact disc.

Intermezzo. From The Dreams of Birds. Jenni Olson (bass flute) and Marcia Dickstein (harp). Delos Records. DE3434. February 2012, compact disc.

*Numerous audio and video clips are available at alexshapiro.org. In addition, Shapiro accepts personal requests for audio mp3 samples of any of her works not otherwise accessible, pending availability. 